Florida International University FIU Digital Commons

\title{
The Sound of Silence: Ideology of National Identity and Racial Inequality in Contemporary Curaçao
}

Angela E. Roe

Florida International University, angelroe@gmail.com

DOI: 10.25148 /etd.FIDC000734

Follow this and additional works at: https://digitalcommons.fiu.edu/etd

Part of the Caribbean Languages and Societies Commons, Cultural History Commons, $\underline{\text { Race, }}$ Ethnicity and Post-Colonial Studies Commons, and the Social History Commons

\section{Recommended Citation}

Roe, Angela E., "The Sound of Silence: Ideology of National Identity and Racial Inequality in Contemporary Curaçao" (2016). FIU Electronic Theses and Dissertations. 2590.

https://digitalcommons.fiu.edu/etd/2590 


\section{FLORIDA INTERNATIONAL UNIVERSITY \\ Miami, Florida}

THE SOUND OF SILENCE: IDEOLOGY OF NATIONAL IDENTITY AND RACIAL INEQUALITY IN CONTEMPORARY CURAÇAO

A dissertation submitted in partial fulfillment of the requirements of the degree of DOCTOR OF PHILOSOPHY

in

GLOBAL AND SOCIOCULTURAL STUDIES

by

Angela E. Roe 
To: Dean John F. Stack, Jr.

Steven J. Green School of International and Public Affairs

This dissertation, written by Angela E. Roe, and entitled The Sound of Silence: Ideology of National Identity and Racial Inequality in Contemporary Curaçao, having been approved in respect to style and intellectual content, is referred to you for judgment.

We have read this dissertation and recommend that it be approved.

Andrea Queeley

Heather Russell

Guillermo Grenier

Jean Muteba Rahier, Major Professor

Date of Defense: July 6, 2016

The dissertation of Angela E. Roe is approved.

Dean John F. Stack, Jr.

Steven J. Green School of International and Public Affairs

Andrés G. Gil

Vice President for Research and Economic Development

and Dean of the University Graduate School

Florida International University, 2016 
@Copyright 2016 by Angela E. Roe

All rights reserved. 


\section{DEDICATION}

I dedicate this doctoral dissertation to my mother, Dorothy Spong, who always believes in me, even when I don't. Through her emotional, mental, and financial support she has made this Ph.D. possible. I also dedicate it to my father, Robert Roe, who instilled in me that unassailable passion to contest injustice and inequality, who taught me the tricks of the academic trade, and who, in spite of his recent passing, continues to whisper in my ear. 


\section{ACKNOWLEDGMENTS}

A work like this is in the end the result of the joined efforts of a community. I wish to express my deepest gratitude to those who for all sorts of reasons have become my community, starting with my Dutch anthropology professor André Droogers, who guided me through my MA degree at the Free University of Amsterdam, and who showed me the route to a Ph.D. in the USA. Following his directions I met Dr. Jean Muteba Rahier, who agreed to become my major professor and who welcomed me at Florida International University in Miami. Over the years Dr. Rahier has provided me with gems of knowledge that have proven to be invaluable and empowering assets to my work and personal life, and he has helped me tremendously in sharpening my critical gaze. I am forever thankful for his support and feedback, his chastises, his praises, his faith in me, and his good humor.

I also am most grateful to Dr. Guillermo Grenier, for his inspired teachings and the many hours we spent discussing and reflecting on my dissertation topics. His support has added great depth to the theoretical frameworks and the topics that I address.

Furthermore I am much appreciative to Dr. Heather Russell, who has always been a source of positivity and encouragement, and to Dr. Andrea Queeley, for her patience and acuity.

Also, I extend a deep thank you to Dr. Kathleen Martin. She was the first to interest me in self-ethnography and the power of being a "vulnerable observer" (Behar 1996), in my first semester at FIU. Her inspiration and encouragement has been crucial to this study. 
I also am greatly indebted to my Curaçaoan colleagues who became part of my life after I finished my coursework in Miami and went to live in Curaçao. I thank Richenel Ansano for his valuable, detailed feedback on my dissertation and his warm and empowering support in general. And I thank my friend Dr. Louis Philip Römer for his indepth, thorough, and ever present feedback, and the many spirited conversations we had through social media.

I deeply thank my beloved friend, Dr. Mamyrah Prosper, for her friendship, for encouraging and supporting me in my writing process, listening to my woes, and for offering me her place when she was traveling for the summer so I could write undisturbed for many weeks on end. And I extend a deep gratitude to the many wonderful friends and colleagues in my Caribbean Studies Association community, who have welcomed me home in our shared Caribbean space, inspired me, encouraged me, and who have showed me my worth, time and time again.

To the people who have participated in my research I say a special thank you, for their willingness to open up so eagerly and courageously about topics that were until then so unspoken despite their importance. We spent many beautiful hours together.

Then there are three very special people that I wish to thank. I also am most thankful to my partner Selwyn de Wind, for his warmth, his patience, his support, for loving everything that I do, and for his endless feedback on my work. I am deeply grateful for my dear father, who has been one of my greatest teachers, in life and in my academic pursuits. As a professor in psychology he introduced me into the world of academia and large universities when I was only a toddler. My dream becoming an academic started with him. He has always graciously extended his knowledge and skills 
to me, helping me to bring my work to a higher level and to challenge myself. He has been a great force in writing and finishing my dissertation. But the person who I am most indebted to is my precious mother, Dorothy Spong, who has supported me emotionally, spiritually and financially throughout this journey of doing the research I had always dreamed of. She encouraged me to start the Ph.D., chased away my doubts time and time again, talked me through down from whatever ledge I was on, and helped me with anything that I needed to complete this degree. She was my inspiration to start this particular research, for the story of this dissertation starts with her. Without her this work would not have been possible.

And last but not least I am very thankful to FIU for giving me the opportunity to obtain this degree and to acquire this wealth of knowledge, and for the financial support provided. 


\section{ABSTRACT OF THE DISSERTATION \\ THE SOUND OF SILENCE: IDEOLOGY OF NATIONAL IDENTITY AND RACIAL INEQUALITY IN CONTEMPORARY CURAÇAO}

\section{By}

Angela E. Roe

Florida International University, 2016

Miami, Florida

Professor Jean Muteba Rahier, Major Professor

This dissertation addresses racism in contemporary Curaçao — a former Dutch colony in the Caribbean that remains a component of the Kingdom of The Netherlands. The dissertation theorizes racism as a partially hidden constituent of the island's ideology of national identity, which throughout its history has emulated hybridity before being influenced, more recently, by multiculturalism. The research's main objective is to uncover the ways race and racism have been entangled with Curaçao's hegemonic ideology of national identity, a reality too often omitted and always under-theorized in Dutch and Dutch Caribbean scholarship.

Using historical, ethnographic, statistic, and discourse analysis data, the dissertation reveals how profound the operations of race have been on Curaçaoan society, and on all Curaçaoans on the island and in the diaspora. It discusses the historical formation of ideologies of race and national identity in Curaçao, to contribute to the explanation of the current state of race relations on the island. It exposes the silencing impacts that the hegemonic ideology of national identity has had on individual Curaçaoans' understanding of self through the reflexive presentation of an 
intergenerational family history. The dissertation ends with ethnographic analytic descriptions of five neighborhoods differently located in Curaçao's racial/spatial order, which reveal the mechanizations of multiculturalism and the prevalence of racism. 


\section{TABLE OF CONTENTS}

CHAPTER

PAGE

Introduction: Trouble in Paradise. an Introduction to the Study of Race and Nation in Curaçao

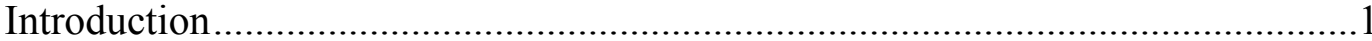

Curaçao, a Racial Paradise? ..................................................................................

Research Objective and Contribution .............................................................. 14

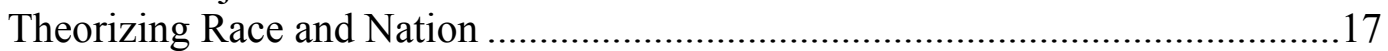

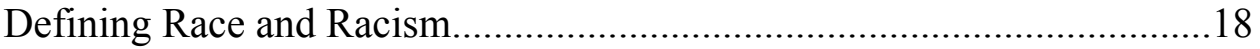

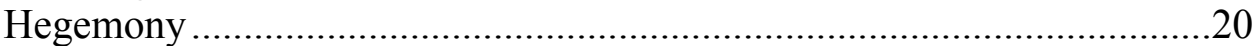

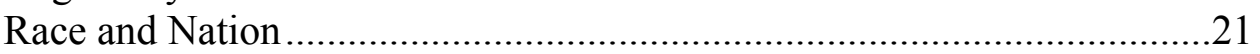

Race and the National "Imagined Community" ...................................23

Racial Homogeneity and Diversity in the Imagination of the Nation .......24

The Ideology of National Identity: from Racial Hybridity to Multiculturalism...............................................................................27

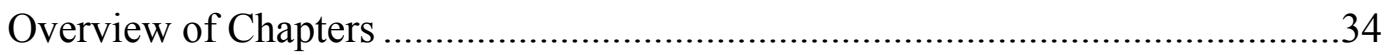

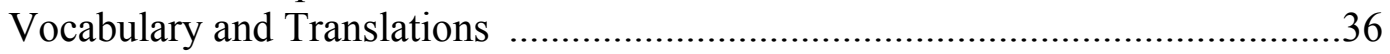

Chapter I. A Historical Exploration of the Interplay Between Racial Ideology

And National Identity Formation in Curaçao ......................................................39

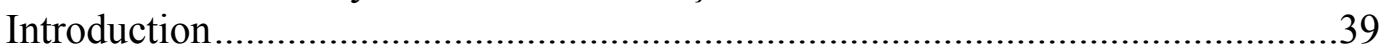

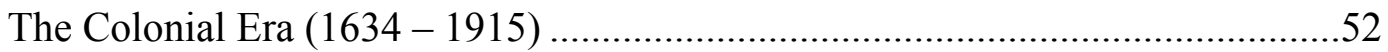

Curaçao's Segmented Population ............................................................56

Inter-Racial Intimacy and Creolization...............................................68

Race-Based Marginalization and Exclusion ...........................................78

Catholic Civilizing Mission (1824-1915) .............................................8 82

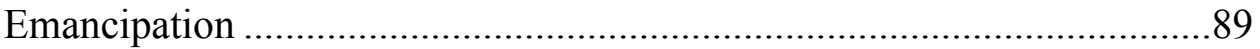

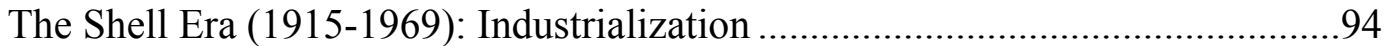

The Politicization of the Yu'i Kòrsou Identity ........................................95

Creolization, Antillianization, Folklorization and the

Invisibilization of Race .................................................................. 102

Post-Industrial Curaçao (1969 - now) ...........................................................107

Multiculturalism and Racelessness .................................................109

Political Reform and its Key Players ....................................................111

Legal Reform .............................................................................. 120

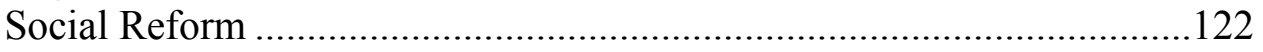

Hegemony, Whitewashed History and Racelessness ...........................130

United Nations Decade of People from African Descent .......................133

Conclusion 138

Chapter II: The Intimate Dimensions of Hegemony: A Reflexive Presentation

of an Intergenerational Family History

Introduction 
Silence, Hegemony, Censure, and Resistance ..............................................147

Case study 1: My Grandmother Sophie and our Forgotten Ancestors ................153

Rudolf - Sophie's Father ....................................................................155

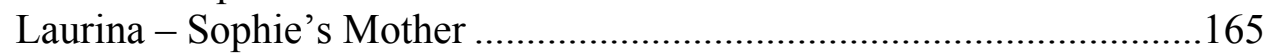

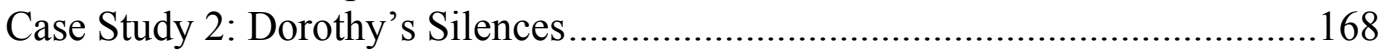

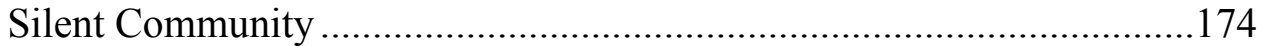

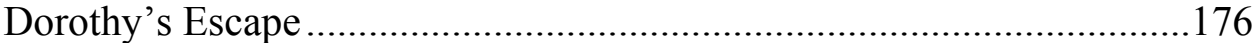

Negotiating Identity .................................................................. 180

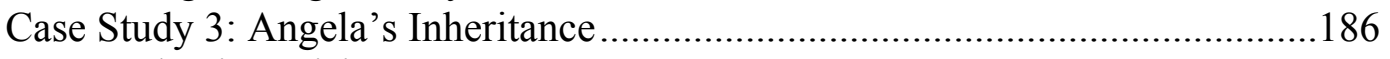

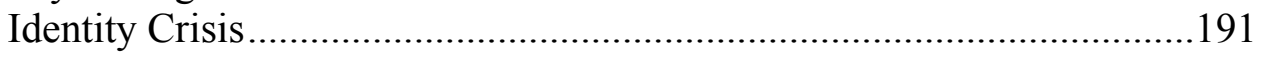

Body Politics ...................................................................................195

The Ethnicity Game .........................................................................203

Entering the Field: Curaçao 1999 .........................................................205

I Was Never White Until I Came to Curaçao ......................................212

I Was Never Black Until I Moved to the USA .....................................214

"You Are My Caribbean" ...................................................................216

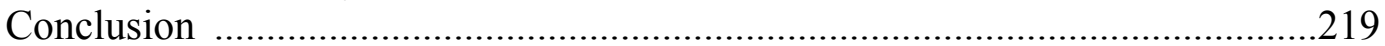

Chapter III: Race and Nation as Every-Day Lived Experience:

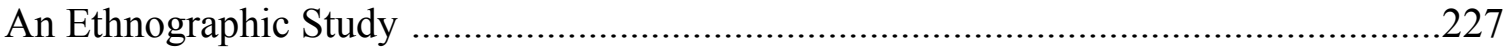

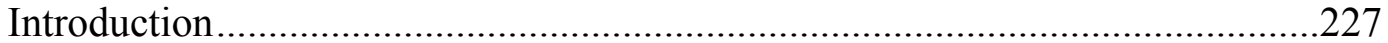

Introducing the Five Barios ….......................................................231

The Respondents ...........................................................................2237

Interview Protocol .........................................................................240

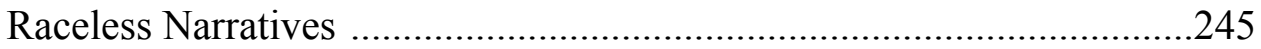

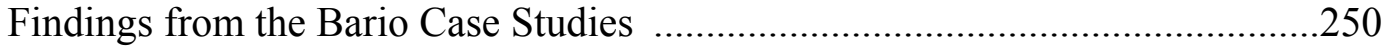

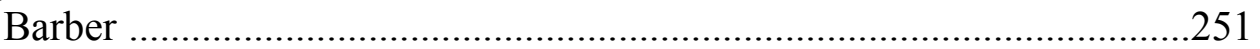

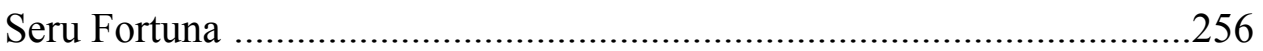

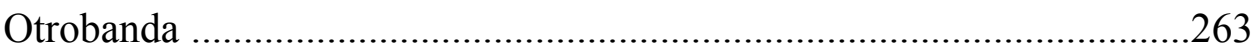

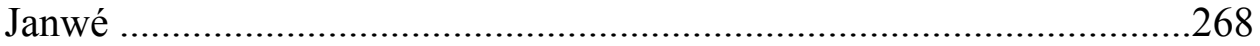

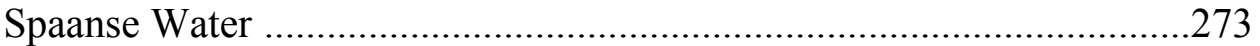

Additional Analytical Comments about the Stories Collected .........................277

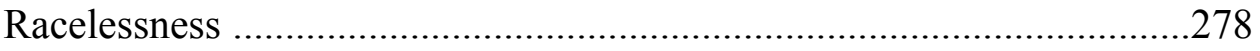

Talking about Blackness, Talking about Whiteness ...........................28

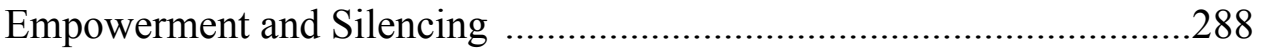

Internalized Racism .......................................................................292

Consequences of Racial Marginalization..............................................302

Resistance and Complicity ............................................................309

Conclusion

Conclusion: The Sound of Silence: The Intricacies of Race and National Ideology

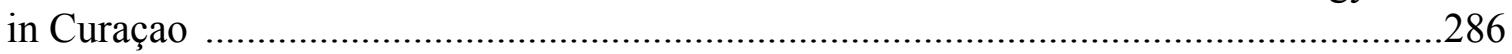

Recommendations for Research and Policy Innovation .................................331

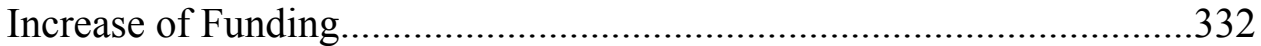

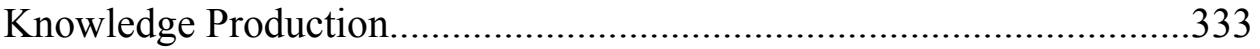


Human Rights Institute ...................................................................337

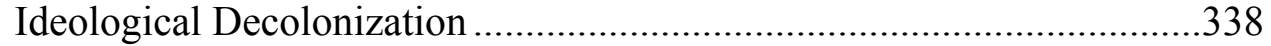

Anti-Discrimination Legislation .......................................................340

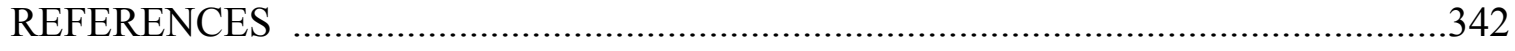

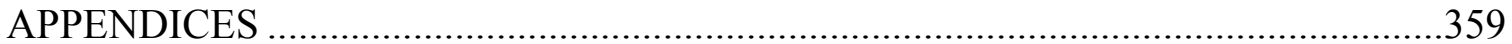

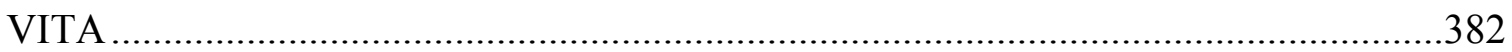




\section{LIST OF TABLES}

TABLE

PAGE

1. Socioeconomic Markers for the Five Selected Barios .........................................230

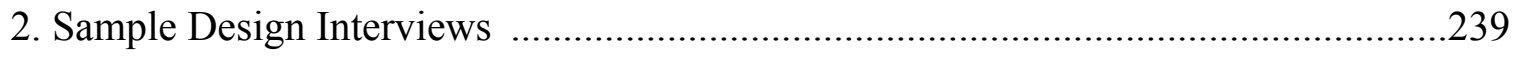

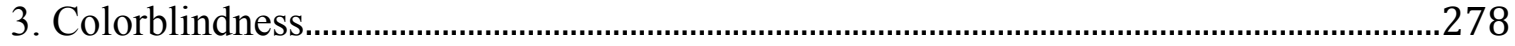

4. Attitudes Towards Whiteness and Blackness ...........................................................280

5. Important Historical Afrocuraçaoan People and/or Events ...................................288

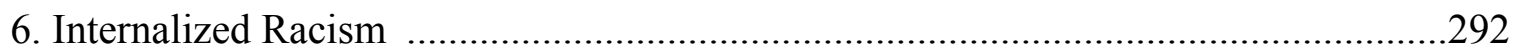

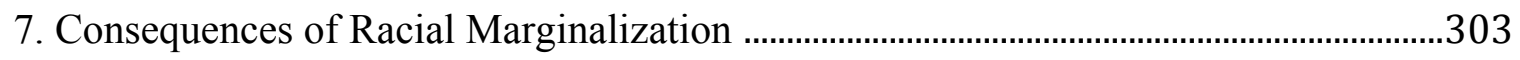

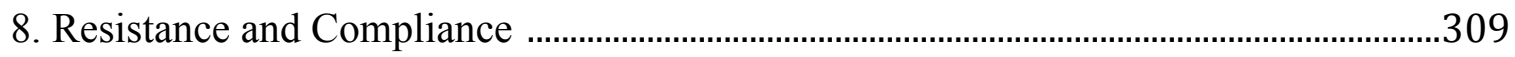




\section{Introduction}

Trouble in Paradise: An Introduction to the Study of Race and Nation in Curaçao

Your silence will not protect you.

- Audrey Lorde

\section{Introduction}

This research started in the year 2000, when I traveled from my country of birth, the Netherlands, to my mother's small Caribbean island. It was my first visit to Curaçao without my parents (see map 1).

Map 1. The island of Curaçao

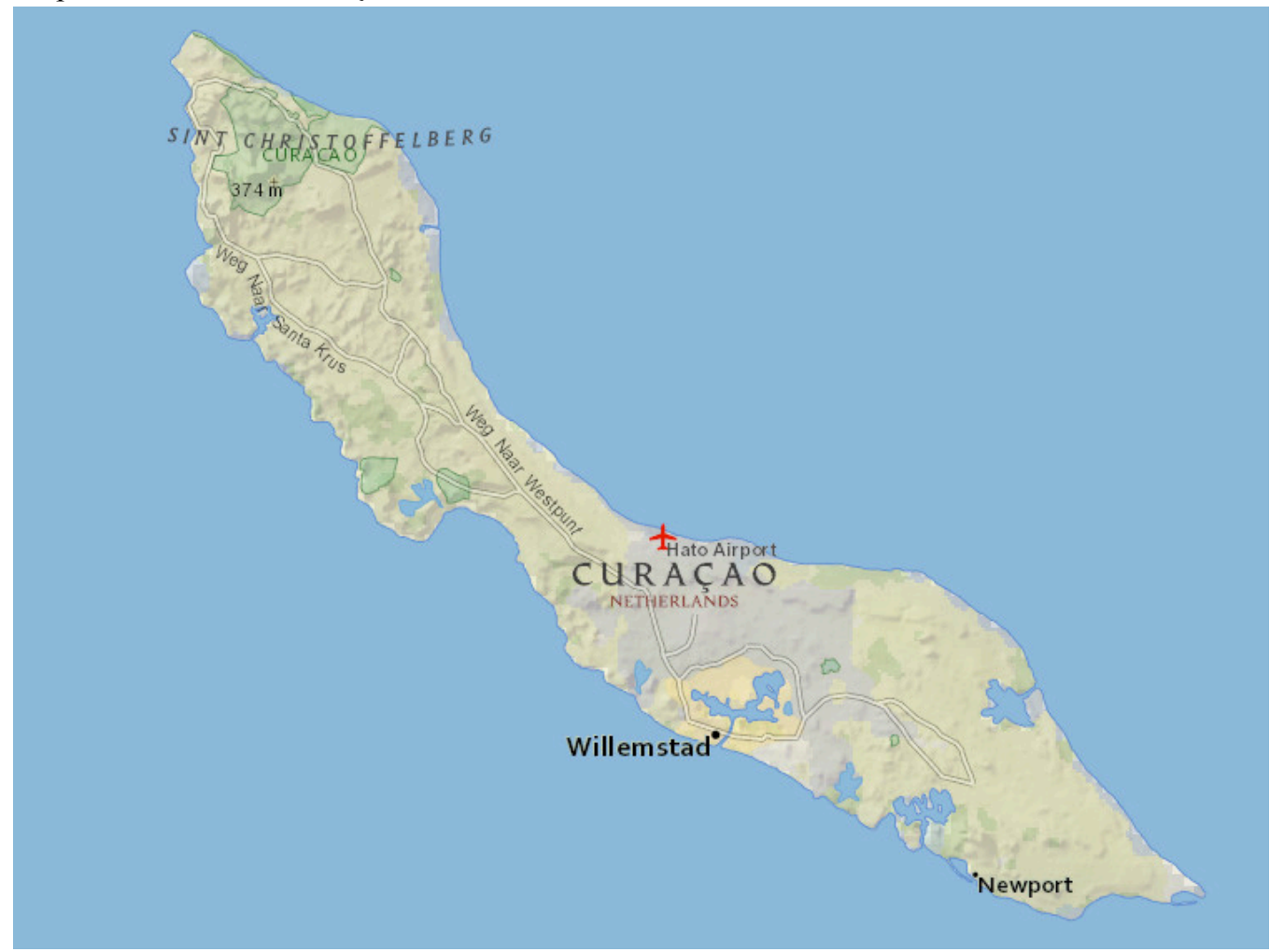

Source: Central Bureau of Statistics Curaçao

Driving with my cousin through the worn, hot streets of Willemstad, on my way to my aunt's house, I was excited. Finally I was "home again," in a world that I had always carried inside while growing up in the Netherlands, but that had never been my own. I 
was 24, in the midst of my M.A. program in cultural anthropology in Amsterdam, and Lord!, was I ready for a long summer of partying and lounging on tropical beaches trimmed with azure blue waters. Little did I know. That evening, I had just finished unpacking, my aunt told me the one rule of her household. She said: "You can do anything you like, just don't come home with a black man.”

The world stopped in its tracks. Never in my life had I expected to hear such a racist comment from one of my own relatives. But there it was. I was very confused: after all, my own mother was black. I wondered if maybe my aunt was making a joke. Unsure about how to interpret her words I had almost forgotten about it, when a few nights later I went on a date with a very dark skinned young man. I had met him in a bar with my cousin, and we had talked the evening away.

I did not yet have a driver's license, so he picked me up at home. My aunt, who had been curious — not to say suspicious — about my date, asked him in for lemonade. She invited him to sit down on one of the chairs on the porch, and positioned herself on the armrest of another chair, so she was higher up than he was. Up to that moment she had been her warm and cheerful self, so I was fully unsuspecting of what came next. While my new friend took a sip from his glass my aunt cocked her head back and started her interrogation. "What neighborhood are you from? What car do you drive? What school did you go to? What is your job?" On and on she went. Her tone was demanding, and demeaning. I watched in horror how my date sank into the porch chair, a bit deeper with every question she hurled at him. My brown skinned aunty, the sister of my brown skinned mother, asked all those questions in order to determine what kind of "black" 
person this young man was: rich or poor, proper or "disputable." She had been dead serious after all, about me not bringing home a black man.

He respectfully and honestly answered all her questions. After a few never ending minutes she released us. I could tell that she was not at all pleased with my choice: this young man was not from an upscale neighborhood, he did not have a high education, he repaired air conditioners, and his dented, old Toyota station wagon did not qualify as a respectable car. All of that had not troubled me one bit during our lively conversation, a few nights back. But what did trouble me was my aunt's interrogation. I was livid. And in shock, unsure about how to retort to my aunt, and what to say to my new friend. The date did not go very well. We went to the movies, we spoke about what happened, but still, after that date he never called me again or pick up his phone. I did not blame him. But my aunt, all summer long I contemplated what to say to her about her behavior. I was too shocked and angry to share my thoughts with her. But in that angry silence that night festered inside of me. It hurt. It festered even more when she tried to shame me through gossiping to other people about why I was so interested in black men. The word came back to me that she was telling people that I like "them" for their penises, which in Curaçaoan lore are of equal mythical proportions as elsewhere in the world.

Up to then, I had adored my aunty. But this summer ended that. Her instruction had first of all revealed racist principles that to all likelihood not only shaped her perception, but that had also affected my Caribbean family at large, which is spread out over Surinam, Curaçao, Aruba, Venezuela, Costa Rica, and the Netherlands. Furthermore, it made me realize that these racist tenets were to all likelihood common to how Curaçaoans thought, lived and breathed: they were an indication of a much larger 
problem. And thirdly, this ugly scene on the porch confronted me with my own ignorance of race and racism. Until then I had grown up in predominantly white middle-class surroundings, where I—a light skinned mixed-race woman — was perceived as an exotic “Other," just like my darker-skinned mother was. But I did not realize that this "exotification" and "otherization" were in fact manifestations of racism. I had never considered how race and racism adversely affected the lives of my mother and myself. Why did I not know about these things, and why had I never asked?

That summer became the start of this study, a plunge down the rabbit hole of Curaçao's pigmentocracy. I never challenged my aunt openly about what she had said and why, that night on the porch. I knew her well enough to know that she would deny anything that could ever be held against her. But I could not let this rest. Instead, my outrage towards her, and my annoyance at my own profound ignorance regarding race and racism developed into an academic inquiry. After obtaining my MA degree in the Netherlands it eventually led me to pursue a Ph.D. in Miami, and then brought me back to Curaçao, where I started a lengthy field study, wrote this dissertation, and wrote, directed, and co-produced the documentary film Sombra di Koló ("The Shadow of Color" 2014) on race relations, which has traveled around the world. Sixteen years lie between that dreaded evening in June and the day of completing this work. But I got my answer, to my question if this racial exclusion was my aunt's outdated belief, or if this was in fact normal to Curaçao, and why I had been so unknowing of the way race shaped our lives, including our choice of who we came home with. 


\section{Curaçao: a Racial Paradise?}

This dissertation addresses racism in contemporary Curaçao as a partially hidden constituent of the island's ideology of national ${ }^{1}$ identity, which emulates cultural, ethnic and racial diversity, and which in recent decades has adopted multiculturalism. At first glance, anti-black racism does not appear to be much of an issue in contemporary Curaçao, a small island in the Dutch Caribbean (see map 2) with a population of approximately 150.000 people who over the centuries have become ethnically and racially diverse, while remaining predominantly of African descent (Allen 2009a; Hartog 1961b; Römer 1979).

Map 2. Curaçao in the Caribbean Basin

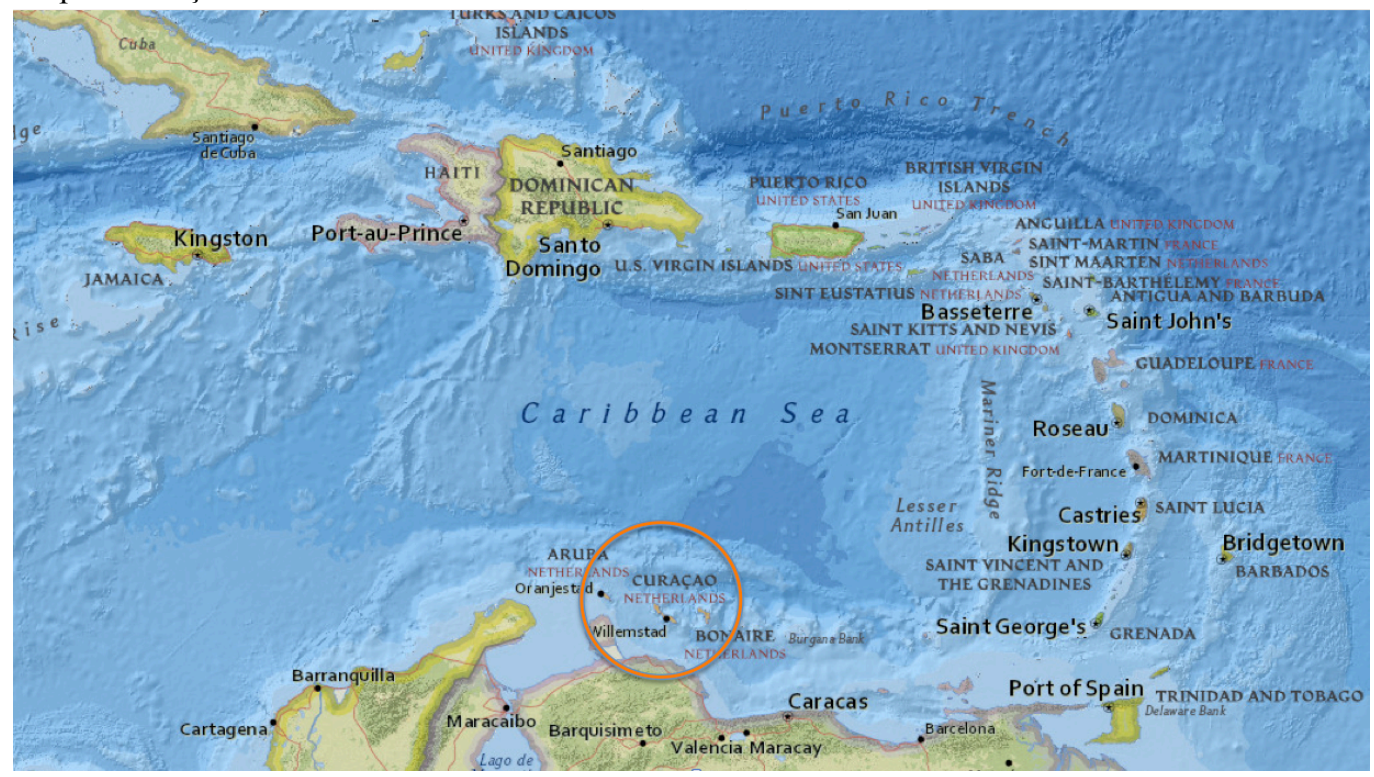

Source: Central Bureau of Statistics Curaçao, adapted by me

\footnotetext{
${ }^{1}$ Until 2010, Curaçao was governed as one of five island territories of the former Netherlands Antilles. On October $10^{\text {th }} 2010$ Curaçao and St. Martin became constituent countries within the Dutch Kingdom, together with Aruba and the Netherlands. The other islands, Saba, Statia and Bonaire are oversees municipalities of the Netherlands. Consequently, Curaçao is not a sovereign nation state, but I argue that it certainly is a nation. Though influenced by Dutch national discourse and ideology, the island has its own specific history and national culture, which has always differed significantly from the Netherlands. Its population uses an ideology of common descent, the Yu'i Kòrsou identity that connects them to the soil of this island. Curaçao has its own currency, language, flag, and anthem.
} 
Curaçaoans praise the Yu' $i$ Kòrsou or "Child of Curaçao" ideology of national identity. This ideology suggests that all Curaçaoans are perceived as equal, regardless of their ethnic or racial profile. It replaced the racial inequality and segregation of black and white that characterized the island's colonial era, and celebrates cultural, ethnic and racial diversity and promulgates unity. Today Curaçao prides itself for its diverse society, and tourism capitalizes on it. Any visitor to the island will be immersed in "diversity": in ethnic groups, in the multitude of languages, musical styles, cuisines and religions that have become part and parcel of the island culture or cultures, and in the abundant collage of phenotypes one encounters in the streets.

The culturally, ethnically and racially diverse make-up of Curaçaoan society dates back to colonial times. Curaçao is small in size, but it occupied a prominent role in the Dutch Empire (see map 3), which was not as large as the British, French and Spanish empires, but still held a significant position in the colonial world.

The Dutch started their imperial enterprise in Asia at the beginning of the $17^{\text {th }}$ century. Because of its strong naval force soon thereafter they successfully extended their pursuits to the Western hemisphere. In spite of the relatively small amounts of territories in their possession, during the $17^{\text {th }}$ century the Dutch were a key player in the global market (Wolf 1982) and the transatlantic slave trade (Oostindie 2000:18).

In 1635 the Dutch confiscated Curaçao, a small, dry island off the coast of Venezuela. It served as a slave market from which slaves were shipped to other parts of the Americas, and as a popular trading hub of the Dutch West India Company. Both legal and contraband trade brought people from all over the world to its shores (Rupert 2012). The major population segments, however, where those of the white Dutch colonials and 
Portuguese Jews, and the enslaved Africans. Ideology of racial inequality—-foundational to colonialism and slavery-determined their interaction.

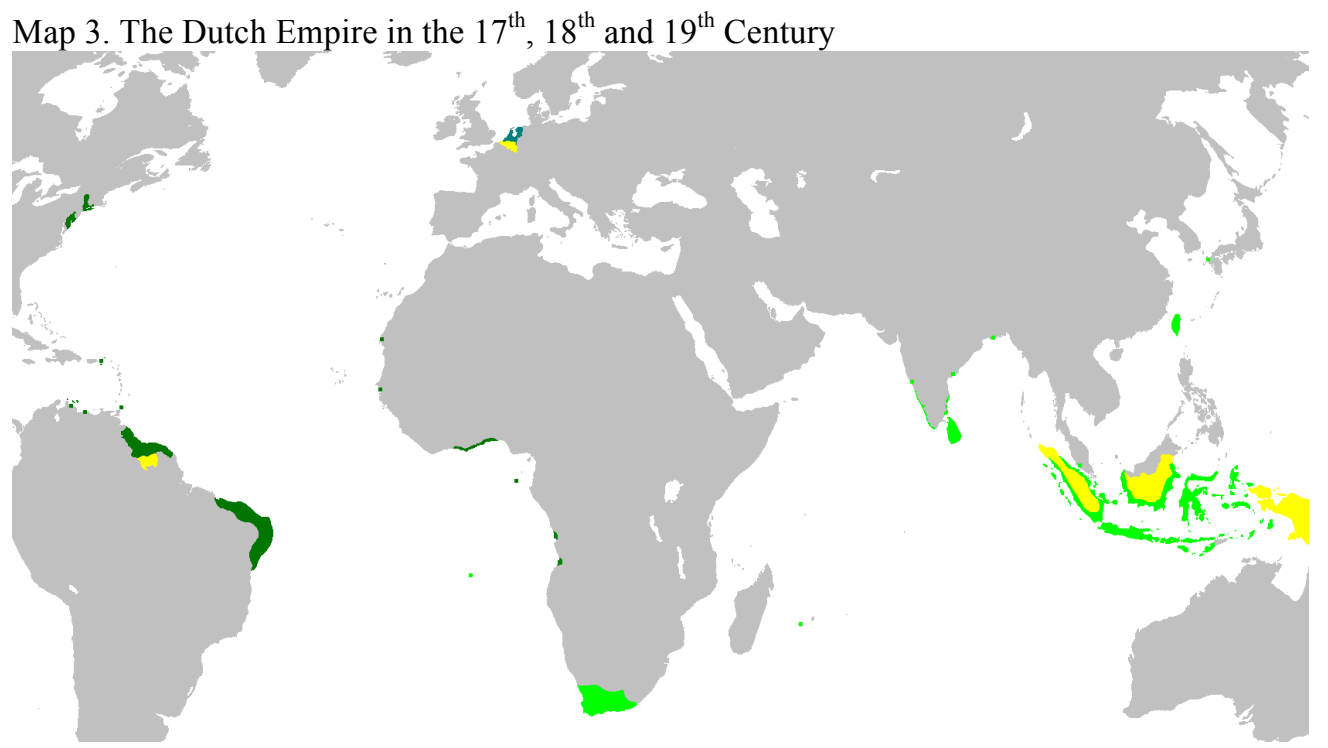

Source: Wikimaps

The dark green areas refer to the 17 and $18^{\text {th }}$ century territories of the Dutch West India Company, light green to those of the Dutch East India Company, and yellow to the territories occupied during the 19th century.

The construction of the prestigious Royal Dutch Shell oil refinery in 1915 marked the beginning of the island's industrialization. Large numbers of immigrants from the Caribbean, Europe, Asia and the Middle East moved to the island, eager to profit from the economic boost (Dalhuizen et al 1997; Oostindie 2000; Römer 1979, 1998). Between 1915 and 1965 Curaçao's population more than quadrupled, growing from 33,000 people to 136,289 (Römer 1981:45). Today, Curaçao has become home to 160 different nationalities (Ministry of Social Development, Labor \& Welfare 2014:3).

During the industrial era colonialism's racially exclusionist ideology, which had explicitly separated black and white, was replaced with one that promulgated a first sense of a national unity in racial diversity. The old colonial elites had to ensure that the black 
masses would not overthrow them, but instead formed a willing proletariat. In the face of this rapid population growth the first rendition of the "Child of Curaçao" or Yu'i Kòrsou ideology of national identity sought to evoke a sense of unity among the old black and white population segments, based on the metaphor of black and white alike being born to the island's soil (Römer 1979). This ideology served to protect white dominance, both from the black masses and from the new Dutch colonials that were sent to the island to run the increasingly complicated administration.

The refinery brought prosperity to many. Curaçao's black working class, however, remained stuck at the bottom of the economic ladder. In between 1948 and 1964 the refinery downsized drastically, firing 75\% of its employees (Verton 1977:61). Economic recess hit hard, and impacted especially the black working class. On a sunny Friday in May of 1969, a union-led strike of Wescar laborers-a company that worked for Shell—attracted thousands of laborers from various companies (Römer 1979:162). They gathered at the gates of the refinery to protest against their abominably low wages and the many lay-offs. The strikers eventually decided to head towards town. Along the way more and more people joined. Decades if not centuries of pent up anger over racial inequality, poverty and lack of social upward mobility began to boil over. People looted stores and burned cars. The police intervened. When one of the leaders of the revolt, Papa Godett, was shot, the already tumultuous protest turned into a violent uproar in which people not only looted but burned down stores in the inner city center (Römer, 1979:163). The Dutch military put an end to the chaos.

The city burned for days, and the government fell. New elections were held, after which it was replaced by an administration that allegedly was more representative of 
Curaçao's black masses. As for example Gert Oostindie's collection of stories about the revolt (Curaçao 30 Mei, 1999a) indicates, many people argued that "race did not initiate the revolt." But people from all sides, from different racial and class backgrounds, all say that the revolt started over poverty, and the continued marginalization of black people (Committee May 30 1970; Oostindie 1999a; 1999b; Römer 1974, 1979). Thus, even though the revolt had not been planned, and was never deliberately and explicitly geared at resolving racial inequality, it would become a turning point in Curaçao's black empowerment, and the start of Curaçao's multiculturalism.

In the decades after the revolt, opportunities for education, employment, and social, cultural and political engagement increased considerably for Afrocuraçaoans (Allen, 2007; Oostindie, 1999a; 2000; Römer, 1979). As a consequence Afrocuraçaoans have pervaded the middle and upper classes, which has brought many to reason away the claim that racial inequality survives in contemporary Curaçao, even though in today's colorist society blackness continues to be associated with inferiority and lower social standing.

Immediately after the revolt the interim government—still dominated by the old elites - initiated significant social reform. Three black men were appointed to the highest governing positions of the island: Curaçao got its first black governor, lieutenant governor and prime minister (Reinders 1993). From the 1970s the prohibition on racism and all other forms of discrimination, already part of the constitution, became part of the criminal code. Furthermore, several international treaties were ratified in which Curaçao 
agreed to combat discrimination in all forms ${ }^{2}$. A new version of the Yu'i Kòrsou

ideology of national identity was adopted that propagated increased intercultural equality,

the celebration of diversity and an increased visibility and appreciation of Afrocuraçaoan

culture and Curaçao's creole language. Diversity has become a key component of the

Yu'i Kòrsou ideology of national identity, and "multiculturalism" a buzzword in

Curaçaoan policies, reports, tourism and everyday vernacular. This is reflected in the

2001 governmental cultural policy plan, which provides the following definition of the

Yu'i Kòrsou, one that is still in official use today (Allen 2012b:1):

A yu-di-Kòrsou is someone who lives in Curaçao or abroad, and who fits the following criteria. He/she speaks and understands Papiamentu. He/she is willing to work to advance Curaçao. He/she can declare to the world that he is a yu-diKòrsou and accepts his/her culture and history without any shame. He/she accepts and adheres to Curaçao's multicultural situation, and accepts cultural diversity. He/she does not consider cultural elements of his/her ethnic group to be Curaçao's culture, but he/she considers them as part of Curaçao's culture. He/she accepts that Afrocuraçaoan elements dominate the majority part of Curaçaoan culture (Rosalia 2001:10) ${ }^{3}$.

\footnotetext{
${ }^{2}$ See appendix II for an overview of Curaçao's anti-discrimination legislation.

${ }^{3}$ This definition shows the two components that over time have become part of the Yu'i Kòrsou ideology, as scholars like Rose Mary Allen (2006), Aart Broek (1994) and René Römer (1974) illustrate. In the first half of the $20^{\text {th }}$ century the Yu'i Kòrsou ideology indicated that the Yu'i Kòrsou were the white, black and mixed populations of the colonial era vis-à-vis the large influx of immigrants. Eventually it became more inclusive and also included the large immigrant population. In the 1980s, when emancipation and the civil rights movements of that time instilled in people a stronger appreciation of blackness, Afrocuraçaoan culture and folklore, as well as the Papiamentu language became the core of this national identity. Hence, the real Yu'i Kòrsou was black (Allen 2006; Broek 1994; and Römer 1974). In this more recent version we see that one no longer has to be born on the island or have a parent who is to be a Yu'i Kòrsou. In my field research I have found that the most important qualifications are speaking Papiamentu, being well versed in
} 
The cultural policy plan defines "multiculturalism" as "different cultures that are co-existing in interaction" (Rosalia 2001:12) ${ }^{4}$. This definition reflects the way in which the word is commonly used in Curaçao's society, presupposing equal appreciation and respect for the island's various cultural groups. White supremacy, which is part and parcel of multiculturalism, remains largely unaddressed by academia, the government and in the mainstream media. It has been predominantly because of the work of local NGO's, artists, scholars, political activists and cultural workers that the development and appreciation of Afrocuraçaoan culture has increased, and the position of Afrocuraçaoans in society at large has strengthened.

Still, in spite of their important work and the pro-black reforms that have been taking place, the persisting racial inequality has remained a sensitive subject in everyday conversations. People do not discuss race much — if at all. It does not easily arise in intimate settings, or in public or governmental discourse. The existing legal instruments are severely underused. In conversations with both the Ombudsman and the President of the Court of Justice I learned that people rarely file official complaints when they have been discriminated against, and that such complaints virtually do not amount to court cases or prosecution ${ }^{5}$. During my data gathering process it repeatedly became apparent that many Curaçaoans are insufficiently informed about their rights and the legal

\footnotetext{
the island culture, history and folklore, and loving the island and making a valuable contribution to its advancement. I also found that all these versions of the definition remain active, and that being Afrocuraçaoan is an important element.

4 "Diferente kultura huntu den relashon" literally translates as "different cultures together in relation."

${ }^{5}$ The Ombudsman who served until 2015 informed me in a conversation that in the past decade no complaints were filed on the basis of racial discrimination, and in an email the President of the Court informed me unofficially that on very rare occasion lawyers have presented cases on the grounds of racism, but this does not easily lead to actual criminal charges being pressed, or to prosecution.
} 
instruments available to them: some are even unaware that racism is in fact illegal. The anti-discrimination legislation that has existed for over four decades has yet to be translated into nation-wide awareness of these instruments, as well as in organizations and institutions that facilitate and encourage their access and use. These findings are corroborated by those in the Report of the Working Group of Experts on People of African Descent, which visited Curaçao in between June $24^{\text {th }}$ and $28^{\text {th }} 2014$ with the aim to assess the current situation of people of African descent. The report states that:

[t]he Working Group was concerned that racial discrimination is considered a "taboo" subject and identified a lack of understanding within the society about its manifestations. As a result, cases of racial discrimination against people of African descent in Curaçao are not being reported to the authorities (UN 2015:4). This is lack of reporting is aggravated by the fact that "there is no national human rights institution or an equality body" (UN 2015:6,7). The Working Group also commented on the underrepresentation of Afrocuraçaoan judges (UN 2015:15) in Curaçao’s Court of Justice ${ }^{6}$.

What's more, when the topic of racial inequality does arise, it stands out to me that people fervently adhere to the island's "inclusive" Yu'i Kòrsou ideology of national identity, to reason away the racial part of the inequality. The common perception is that discrimination and especially anti-black racism belongs to a colonial past. In this day and

\footnotetext{
6 “The Working Group also learned that there were limited possibilities to learn the Dutch legal system and it was highly inaccessible to ordinary Curaçaoans. The University of Curaçao has a law faculty where Curaçaoan law (very similar to Dutch law) can be studied. Though after studying law, one still has to obtain additional training in the Netherlands before being able to open a law practice. As a consequence, there are very few native Curaçaoan judges in the court system in Curaçao. The Working Group's request to meet the Ombudsman for further clarity in this matter was not successful" (UN 2015:15).
} 
age all are equal, and ethnicity, race and phenotype no longer matter. One's misfortunes are therefore not caused by the systemic racial inequality that results from a long history of race-based exploitation, but by one's own abject behavior or lack of perseverance. This, as we will see in subsequent sections, is a tenet of "colorblind" or "raceless" racism (Bonilla-Silva 2010).

In arguing that "all are equal," this ideology of national identity places the intricate mechanizations of persisting white supremacy out of sight. White privilege remains normal and natural. People are acutely aware of the prevalence of racial inequality, especially with regards to people of African descent, but they often do not see or suspect that there is a broad, institutionalized dimension to racial inequality (see Goldberg 2002). This structural base, upon which I will elaborate in the following subsections and chapters, like the bottom of an iceberg, remains largely "hidden" from the masses, whether they identify as white, black or any other racial category. We may know that the iceberg has a bottom, but we do not know how big it is, and what shape it has. Consequently, people may know that racism and oppressive and marginalizing measures exist, but they do not know how extensive they are, and how- exactly - they operate.

But masses and elites_—whose precise members are not easily identified and which are thus not easily delineated - are ultimately socialized into the same norm and value system (Goldberg 1993; Koeningsberg 2009; Smith 2010 and Applebaum et al 2003). The elites thus perpetuate this system in part without having a clear awareness of the full extent of its mechanizations. Nonetheless, I use the word "hidden" to signal the deliberate intent on the part of the elites in not making the perpetuation of structural 
oppression visible, and preserving their privileges. It also signals the reluctance, of black and white people alike, to explicitly address racism. Like with an iceberg, one has to remind oneself that there is an underwater part, for to the unsuspecting eye they appear to float on the surface; the bottom is unseen. In similar fashion, the impacts of race and racism can also be reasoned away and denied to the extend that we indeed believe that it no longer exists, which is what colorblind and raceless ideologies seek to do.

With regards to scholarly works on Curaçao, numerous Curaçaoan and Dutch scholars such as Rose Mary Allen (2007), Alejandro Paula (1967), René Rosalia (1997) and Gert Oostindie (2000) — to name only a few — have explicitly addressed that this inequality has its roots in colonial times. Yet, their scholarship has not yet amounted to the development of theoretically substantiated, in-depth studies on race, racism, racial inequality and multiculturalism in Curaçao, or to policies by the Curaçaoan government directed at racism's dissolve.

As is the case across the African Diaspora, in Curaçao too, much has changed in the relations between the black and white population segments. But racism and racial inequality have far from disappeared. In their contemporary form they are largely unaddressed, to the point that to many it appears as if racism indeed no longer exists.

\section{Research Objective and Contribution}

The main objective of this dissertation is to critically analyze and theorize Curaçao's contemporary racism as a partly hidden constituent of its ideology of national identity of the Yu'i Kòrsou. Curaçao's 1969 revolt, which corresponded with the era of the civil rights movements in the U.S., challenged the existing status quo of Curaçao's race 
relations. But race and racial inequality have remained topics that are too often omitted, especially in political debate and policy making. This omission is furthermore clearly reflected in the academic literature on Curaçao, which is predominantly generated in Curaçao and in the Netherlands. Scholars address a wide range of topics that pertain to Curaçao's white and black populations. However, the explicit and comprehensive study of race, race relations, racialism, racial inequality, racism and multiculturalism is largely absent from this body of work. ${ }^{7}$ Many studies have referred to Curaçao's issues of racial inequality (see for example Allen 1996, 2006, 2007; Hoetink 1958; van Hulst 1997; Oostindie 2000; Paula 1967; Römer 1979, 1998, 2003), and various studies have explicitly focused on the national Yu'i Kòrsou narrative (Allen 2009a; Broek 1994; Römer 1979). Yet I have not come across studies that operationalize race, or explicitly theorize and analyze the ramifications of racial differences in Curaçao and their connection to hegemonic formations and structural inequalities. Also, the reinforcement of hegemonic ideologies under neo-liberalism and multiculturalism are not themes that are easily addressed in a theoretically substantiated manner, if at all. Racial inequality is commonly framed in the context of statements about cultural and ethnic differences and social change.

This research seeks to fill this injurious gap in the scholarship, by pioneering a theoretical and empirical exploration of contemporary race relations on the island, and the role that hegemonic ideology plays in these. I expect that my approach will generate ample new insights regarding the historical interrelatedness of race and nation in

\footnotetext{
${ }^{7}$ Harry Hoetink (1958), Alejandro Paula (1967) and René Römer (1979) do explicitly write in racial terms. But it is noteworthy that more recent publications tend to avoid the notion of race, and especially racism.
} 
Curaçao. With this original research on Curaçao, which wants to bring into focus current racial inequalities and how these are supported by hegemonic ideology, I want to open up a space wherein constructive solutions can be debated and adopted. In doing so, I hope to contribute to the disciplines of anthropology and sociology, and to a number of multiand inter-disciplinary fields of inquiry: race and racism studies, creolization studies, multicultural studies, and Caribbean and African Diaspora studies. My research results should be of use to a broad range of policy-makers and educators in, but not limited to, Curaçao, and to individual Curaçaoans and others seeking extended awareness regarding racism and black empowerment.

Naturally, this doctoral study is far from panoptic and conclusive. I focus predominantly on hegemonic ideology and how that persists in people's awareness, and less on how the masses react to this, or on the precise contributions and contestations that the Afrocuraçaoan population makes to dominant culture and ideology. The examination of the intricate ways in which the Afrocuraçaoan population responds to racism in overt and hidden ways certainly is the follow up project. Because I have split these two foci up the current study appears somewhat one-sided. Although black agency, resistance and empowerment surface continuously throughout this dissertation, these themes do not constitute the theoretical and analytical core of this dissertation. Nonetheless, this study is still embedded in praxis theory (Berger and Luckmann 1972; Bourdieu 1977; Foucault 1978; Giddens 1984, 1995; Gramsci 1971). I very much acknowledge the complexity of power relations: the nation's masses are never passive recipients of ruling class culture and ideology, but always active agents or actors that create the system that is also passed on to them. 
What's more, through my current focus on ideology I attempt to reveal how persistent racial inequality is, and how it is deeply woven into the fabric of society. Therefore, at times my analyses may sound as if this system is fixed, as if the elites are quintessentially far more powerful than the masses they seek to dominate, and as if the future holds naught but ever-lasting doom and damnation for the oppressed. But nothing is further from the truth. The past has shown us that dominance is never permanent, and that the subjugated never simply subject. Hegemony is dependent on its silences and its "invisibility:" on people perceiving their oppression as normal and natural to the point that they do not challenge it. Therefore, seeking to unveil at least some of hegemony's mechanizations - as I do in this thesis - is my deliberate act of counter-hegemonic activism.

\section{Theorizing Race and Nation}

Curaçao is a "pseudo-nation," since the island has never reached sovereignty. Nonetheless, as a territory that is 4,240 nautical miles ${ }^{8}$ removed from its superordinate nation-state, the Netherlands, Curaçao has its own specific history, culture, population composition, legislation, government, and even language, which all mark it as very different from the Netherlands. I argue that Curaçao functions much the same as a "regular" nation would. In fact, it shares very little national binding with the Netherlands other than remaining a territory "belonging" to the Kingdom of the Netherlands, which means that it is bound to its Charter. Since Curaçao functions much like autonomous

\footnotetext{
${ }^{8}$ http://www.timeanddate.com/worldclock/distances.html?n=722
} 
nations do, I consider it particularly relevant to use the conceptualizations of ideologies of national identity studies.

\section{Defining Race and Racism}

Even though biological and natural scientists reject the validity of "race" as a sound biological concept to categorize humans, for social scientists "race" is a social construct that functions in society (in many societies) as if it had the biological credentials it doesn't have (Armelagos and Goodman 1998; Omi and Winant 1998; Cornell and Hartmann 2007). Yet, to view race solely as a social construct obscures its mechanizations. Stuart Hall (1992) warns that in spite of its mythical foundations race still appears to stem from the domain of the natural and the biological. This naturalness makes race appear static and essential, and renders its changeability and historicity relatively invisible, which—as Cornell and Hartman argue (2007)—allows it "to play such a powerful role in legitimizing and rationalizing social hierarchies and inequalities" (Cornell and Hartman 2007:39). Bonilla-Silva (2010) argues that in spite of its constructedness, race entails a social reality that "produces real effects on the actors racialized as 'black' or 'white'” (2010:9). This, he argues, makes it appear as if it were a constant and unchanging entity.

Race is thus necessarily contextual and is always one of the axes along which national power is exercised (Goldberg 2002). Bonilla-Silva writes about "racial structure" and "racial ideology." The concept "racial structure" refers to "the totality of the social relations and practices" that protect and perpetuate the privileges of the dominant group (Bonilla-Silva 2010:9). The "racially based frameworks used by actors to explain and 
justify (dominant race) or challenge (subordinate race or races) the racial status quo," on the other hand, comprise a society's "racial ideology" (Bonilla-Silva 2010:9, see also Omi and Winant 1998). After all, ideology is one of the main instruments within the play of power because it allows the dominant group to generate a primary perspective that legitimizes, safeguards and perpetuates its superiority (Bourdieu 1977; Foucault 1978; Giddens 1984, 1995; Gramsci 1971). The racial ideology defines the different racial groups within a population, it hierarchizes them according to its norms, and it legitimizes and indoctrinates this hierarchy as well as the racial structure through which this hierarchy is institutionalized and thus operated (Memmi 2000). This brings us to the core of racism.

As is the case with race, there is a wide range of definitions of racism. I work with two definitions in particular. The first one states that: "Racism is a negative attitude towards persons in virtue of their race" (Arthur 2007:14). It emphasizes the fact that racism does not so much specify actions but rather generates attitudes that stem from the inherent negative norms defined in the racial ideology (Arthur 2007). These attitudes vary from hostility to indifference to reluctance even, and can be explicit or hidden, conscious or unconscious (Arthur 2007). The second definition I find particularly worthwhile was crafted by Albert Memmi (2000):

Racism is a generalizing definition and valuation of differences, whether real or imaginary, to the advantage of the one defining and deploying them [accusateur], and to the detriment of the one subjected to that act of definition [victim], whose purpose is to justify (social or physical) hostility and assault [aggression] (Memmi 2000:100). 
This definition highlights the power dimension of racism, which, in an indispensible functionalist sense, allows for an understanding of the motivation behind the act.

\section{Hegemony}

Inspired by the works of Antonio Gramsci (1971), W.E.B. Du Bois (1903), Sidney Mintz (1985), Eric Williams (1994/1944), Leslie Carr (1997), David Goldberg (1993; 2002), I use a perspective that builds on contemporary Marxist theories to examine the interrelation between race and nation. This study specifically focuses on ideology as a tool used by the ruling class to organize the nation and exert dominance. Nationalism, a specific kind of hegemonic ideology, has the ability to imagine and instill a sense of belonging in people, a sense of roots, of shared identity, history, culture and territory. It instills a sense of solidarity that binds individuals to the "nation" (Cornell and Hartmann 2007; Smith 1993). Hegemony thus engenders allegiance and loyalty through indoctrination of the masses.

Gramsci (1971), who coined the notion of hegemony, stated that the nation always educates the masses into who belongs to the in-group, and who does not (see also Hall, 1999; Foucault, 1977). It does so in a way that makes dominant norms and values appear as natural, self-evident, self-imposed, and self-created thoughts of individuals. This is what makes it eventually harder to contest this ideology and its naturalized hierarchies (Goldberg, 1993). And that is precisely what hegemony revolves around. Where there is hegemony, there is a significant level of consent from the subjugated masses: they espouse the perspective of the ruling and governing power to the extent that 
this perspective becomes normalized and naturalized. Even though people are aware of oppression or injustice, they do not contest it.

To Gramsci (1971) the ruling elites are always plural, and comprised of various groups and social classes with shifting alliances. Gramsci calls this the "historic bloc" (Gramsci 1971:771): sections from different class layers that seek allegiances to bring a shared ideology to the level of hegemonic dogmas. In Gramsci's understanding neither elites nor working classes are homogenous, Hall argues; they are quintessentially divided by "conflicting interests, historically segmented and fragmented in this actual course of historical formation" (Hall 1986:14). Unity within a class segment has to be forged, and must never be assumed. Dominant discourses are always in close dialogue with the masses that they speak to. Therefore, the various media used to broadcast dominant ideology are therefore not a one-way channel from elite to masses, but rather a space in which rivaling social forces battle and negotiate for power. Hegemony is powerful because it is internalized, naturalized and operates virtually unseen, but it is never static. No one is ever powerless, and the dialogue between hegemony and counter-hegemony is unending and always in flux.

\section{Race and Nation}

Goldberg $(1993,2002)$ argues that race came into existence with modernity, and with the voyages of discovery and the subsequent era of imperial expansion and colonialism that started in the fifteenth century. These led to the rise of industrialism, capitalism, and the birth of the nation-state, always premised on, and organized along the lines of race (Goldberg 1993, 2002; Said 1993; Williams 1944; Wolf 1994). Devising myths that 
proclaimed that indigenous peoples did not work the land and thus held no ownership over it, which made them "inferior peoples" if human at all, allowed Europeans to establish their rule and to begin exploitation and dominance. The soil was "readily" available, as was "capital." And for the endless labor force, Europeans resorted to slavery, first putting the indigenous populations to work, but quickly replacing them with Africans (Williams 1944; Wolf 1994). Thus, Eric William wrote:

Slavery was not born of racism: rather, racism was the consequence of slavery (1944/1994:7); Racial differences made it easier to justify and rationalize Negro slavery, to exact the mechanical obedience of a plough-ox or a cart-horse, to demand that resignation and that complete moral and intellectual submission which alone makes slave labor possible (1944/1994:19).

Following Williams' Marxist approach I view race as a most powerful ideological construct devised specifically by white colonial elites to implement and instill oppression, for the sake of economic gain, and to secure all dimensions of power related to it. Racial ideology is part of the ideology of national identity, which it defines, explains, legitimizes and perpetuates. Consequently, ideologies of racial superiority became a fundamental part of the colonial—and postcolonial—world (Walters 2003:15). Comprised of a set of ideologies, attitudes and relations, racism became a vital tool for the exercise of power in European expansionism: one that is forever changing and highly context specific, always adapting to and interacting with other dimensions of power, even though always characterized by white supremacy and black abjection (Goldberg 1993; Memmi 2000). 


\section{Race and the National "Imagined Community"}

Benedict Anderson (1983) claims that nations only exist by the grace of the imagination. Nation building revolves around story telling, and around telling the same story to all who can "hear" or read. When the printing press was invented in the $15^{\text {th }}$ century, ideas could be fixed into words on paper, and in a standardized way be distributed to populations living in large territories. These standardized messages had the power to instill into individuals an awareness of a communion with a larger group of people who they had never met and would never meet. Among the working classes they raised a loyalty to an elite that gloriously and intrepidly safeguarded this collective. Anderson's use of the word "imagined" does not refer to the meaning "invented;" he argues that the community "is imagined because the members of even the smallest nation will never know most of their fellow-members, meet them, or even hear of them, yet in the minds of each lives the image of their communion" (Anderson 1983:6).

Hobsbawm (1983) elaborates on that, connecting Anderson's imagined communities to what he refers to as "invented traditions." The deliberate construction of history and tradition, Hobsbawm argues, is a key tool in the construction of the nation. Under the pretext of being firmly rooted in a distant past such stories or national myths legitimize the claims groups make regarding inclusion in and exclusion from the nation (Hobsbawm 1983, Andermann 2009). This deliberately constructed history and tradition serves to strengthen national cohesion, but also explains why not all people living in a national territory are invited to participate and take equal part in this comradeship.

There are ample ways in which the nation is imagined. Anderson argues that in the image that is spread across the nation there are both myths and facts (See also 
Gramsci, 1971; Hobsbawm, 1983; Trouillot, 1995; and Poria and Ashworth 2009). Under the pretext of having the nation firmly rooted in a distant past, national myths naturalize the claims groups make about inclusion in and exclusion from the nation. Continuously broadcasted through symbols and standardized carriers such as flags, seals, heroes, rituals, currencies, monuments, warfare, education, folklore, canonized arts, and consumption industries, national narratives instruct multitudes of people participating in the nation, be they insiders or outsiders.

Racial Homogeneity and Diversity in the Imagination of the Nation Anderson (1983) argued that the nation is quintessentially homogeneous and that racial heterogeneity and inequality are anomalies that should be seen as separate from, and threatening to, the nation. He argued that racial heterogeneity and racism undermine nations' imagined communities, which are always premised on cohesion through homogeneity (Anderson 1983). Will Kymlicka (1995), however, considers racial heterogeneity as part of the contemporary nation-state, but as something that is resolved through what he calls "liberal multiculturalism." This he understands as the shift from assimilationist to "sincerely" inclusive politics towards minority groups. In Kymlicka's view, liberalization amounts to a decentralization of state power and to the increasing efficacy of democracy in resolving inequalities. In his perception, liberalism can dissolve racial inequality.

Goldberg disagrees. In his view, liberalism played a key role in preserving racial inequality, and making it an integral and largely unseen part of the nation. He argues that: 
Liberalism plays a foundational part in this process of normalizing naturalizing racial dynamics and racist exclusions. As modernity's defensive doctrine of self and society, of morality and politics, liberalism serves to legitimate ideologically and to rationalize politico-economically prevailing sets of racialized conditions and racist exclusions. It is thus key in establishing racialized reasoning and its racist implications as central to modernity's moral and social political sense (Goldberg 1993:1).

Liberalism was comprised of a discourse of liberty and equality, while at the same time it rationalized and legitimized racial inequality and exploitation. Goldberg argues that the ideologies that sprang from liberalism and modernity became embedded into the national myths from which the budding nation states were manufactured, and as the oppressed and exploited populations resisted their exploitation and marginalization, these ideologies became all the more sophisticated, established, indoctrinated and naturalized. For, as Goldberg argues, "[t]he modern state, it might be said, founds itself not just on exclusions, those absences that render invisible, but on the internalization of exclusions" (Goldberg 1993:9).

In contrast to Anderson, scholars such as Goldberg (1993, 2002), Koeningsberg (2009), Smith (2010), and Applebaum et al (2003) argue that nations are highly dynamic, complex, yet coherent entities that emerged from the endeavors of colonial exploitation and the advent of modernity. In a Marxist view the material base or economic make-up of society determines the superstructure, or society's ideological foundation. The superstructure in turn supports and facilitates the needs of the material base (Marx 1859). This perspective suggests that any ideology about race most and foremost supports and 
adjusts to the forever changing economic circumstances. Therefore, Carr argues, as does Goldberg, that racism has always been part of the nation.

After all, the colonial project was premised on the exploitation of non-white peoples by white peoples. This exploitation and expansion could only occur successfully when these non-white peoples were labeled as both vitally different and inferior to white people. In the early days of the colony race was not yet that common as a notion (Carr 1997), yet the difference between the colonized and the colonizer was phrased as the difference between culturally inferior and culturally superior people; as subjugated versus dominant. In the $18^{\text {th }}$ and $19^{\text {th }}$ century this distinction became phrased in racial terms. It became part and parcel of the founding myths of the young colonizing European nations. In these myths, this difference between colonizer and colonized was formulated in such a way that it communicated white superiority. Furthermore, it presented a glorified narration of the nation's history that justified exploration, expansion and exploitation. For as an ideology, racism defines, explains, legitimizes and perpetuates dominance, and informs those partaking in the nation of the "natural" order of things. Through these racebased national myths, nations thus became organized into elites, working class masses, and slaves (Goldberg 1993, 2002; Tilly 1994): an order that is challenged continuously, but that still persists. For ideology is highly malleable and easily adaptable, and can be shaped to fit the needs of the dominant and to — at least temporarily—defuse the contestations of the subjugated ${ }^{9}$. Racism, too, has always adapted to the needs of the elites, and the ways in which the subjugated masses make their claims to equality and

\footnotetext{
${ }^{9}$ This also applies when the balance of power flips and new regimes overthrow old ones, as history has proven many a time.
} 
retribution. So as history passes we witness how the explicitly racist ideologies of Curaçao's colonial days changed into the "color-blind" or "raceless" renditions that shape our contemporary societies.

\section{The Ideology of National Identity: From Racial Hybridity to Multiculturalism}

Nations are unavoidably premised on racial inequality and on a politics of race-based inclusion and exclusion. Numerous scholars such as Applebaum et al (2003), Goldberg (1993, 2003), Koeningsberg (2009), and Smith (2010) address processes that have taken place worldwide and across large spans of time, to contend that both those who constitute the elites and the racial majority in a nation, and those who are racially otherized and made invisible or otherwise marginalized, are constructed and legitimized through discourses of purity and racially based ideologies of national identity (Goldberg 1993, Koeningsberg 2009, Smith 2010 and Applebaum et al 2003). According to this line of theorizing, national myths of population homogeneity serve to create order and unity to cover over the "disorder" that heterogeneity and subsequent inequality eventually entails. These ideological narratives edify this imagined homogeneity as a lived and natural reality, obscuring the ways racial diversity and inequalities structure the nation to safeguard the privileges of the elites.

In "white" nations, such as those of $19^{\text {th }}$ and early $20^{\text {th }}$ century Europe, discourses of national homogeneity were perhaps rather easy to craft and impose. However, in the much more racially mixed nations of Latin America and the Caribbean, anthropologist Jean Muteba Rahier (2003) argues, ideologies of national identity have emulated mestizaje, mulataje, and créolité, and presented specific mixed race identities as the 
prototypical national identity. During the period Rahier called "monocultural mestizaje," which extends from the early $20^{\text {th }}$ century to the late 1980s (Rahier 2012:1-14), most countries in the region emulated such ideologies of national identity. Intellectuals of the region writing at the service of the building of these ideologies even foresaw that the mestizo race, the "fifth race," would end up being superior to the then dominant "AngloSaxon race" (see Martínez-Echazabal 1998; Rahier 2003; and the works of Mexican philosopher José Vasconcelos 1925, and Brazilian sociologist and anthropologist Gilberto Freyre 1933). Hybridity was no longer considered a biological aberration, or a polluting, degenerative influence, as colonial ideology had declared. Instead, through miscegenation the negative traits and inferiority that had been ascribed to non-white peoples waned through mixing with the "superior" white race.

Contemporary scholars have revealed these ideologies of national identity that emulate race mixing as ultimately revolving around the ideal of white supremacy since non-whites were supposed to whiten: indeed, these ideologies didn't prescribed whites to mix with non-whites, but instead they showed the way to non-whites to whiten themselves culturally and racially (Hale 1996; Hintzen 2002; Martínez-Echazabal 1998; Price and Price 1997; Rahier 2003; Sheriff 2001; Skidmore 2002; Stepan 1991). During the period of monocultural mestizaje these hegemonic ideologies provided a particular narration of the nation in which citizens were nothing but all mestizos... Those who did not phenotypically conform to the prototypical national identity were at the same time otherized, invisibilized, and marked as not fully belonging to the nation.

In Caribbean ideologies of national identity the notion of "creoleness" and "creolité" served a similar purpose of unification. The notion of "creole," in use since the 
$16^{\text {th }}$ century, has a broad range of context-specific meanings that refer to the syncretism or cultural mixing that is commonly attributed to "New World societies" (Stewart 2007:2-3, see also Palmié 2006). This mixing of cultures comprised dramatic loss, violence, degradation and inequality (Hall 2003:35), as well "resilience and creativity" (Stewart 2007:4).

In the early $20^{\text {th }}$ century new ruling elites deliberately devised ideologies of creoleness (or créolité in Francophone contexts) in order to facilitate their nation building endeavors. Creoleness became a trope that signaled hybridity as the essence of the nation. It served to erase the stark colonial boundaries between white and black, and to generate a national identity that served as an in-between space between "the civilized" and "the savage" (Hintzen 2002; Palmié 2006). Creolization — the processes of exchange, mixing, reformulation and invention - transformed the cultures and bodies of the heterogeneous populations that shared the (former) colonial space "in a regime of identific solidarity" (Hintzen 2002:92) $)^{10}$. The propagation of such unity obscured racial inequality, perpetuated exploitation and white privilege (Condé 1999; Hintzen 2002; Price and Price 1997).

Yet, creolization affected both parties, Hintzen argues: "When applied to Europeans, creolisation implies the taint of savagery. When applied to Africans it implies a brush with civilization" (Hintzen 2002:94). Thus, ideologies of creolization demarcated

\footnotetext{
10 "Creolization" has a broad and varied use. It refers to the early 20th century ideologies of national identity devised to create unification in heterogeneous societies, especially in the Caribbean and parts of the Americas (Bernabé et al. 1989/1993; Glissant 1995; Hannerz 1987). In more recent times it has been adopted by the social sciences as part of theories of cultural mixing, transculturation, and globalization, often still referring to, but no longer limited to, the Caribbean (Hall 2003; Khan 2001; Mintz 1998; Stephen 2007).
} 
clear lines between Europe and the New World. The true white European falls outside of creole space, while the white Caribbean elite falls outside of white European space and can occupy only the top ranks of nationalist creole space. This legitimized European superiority while still making white elites in the colonies part of the fraternal unity that this creole space proposes (Hintzen 2002).

From the 1970s these discourses of alleged unity and equality would come under fire (Rahier 2012). Social movements across the region led by progressive whitemestizos, indigenous people, and Afrodescendants began rejecting mestizaje and creoleness as ideologies of national identity (Hale 1996; Rahier 2012; Skidmore 2002). They were becoming aware of what Goldberg calls "the tension between racial conditions and their denial, racist states and their resistance, and about the ways homogeneity has been taken axiologically to trump the perceived threat of heterogeneous states of being" (Goldberg 2002:6). Worldwide resistance of subaltern populations emerged everywhere in the Global South, while in the U.S. the civil rights era unfolded. Goldberg argues that nations and states deflected this resistance with the creation of new ideologies and discourses of national identity that embraced multiculturalism and ethnic pluralism instead of reifying mestizaje (Goldberg 2002:5, see also Greene 2007; Hale 2002, 2005; Rahier 2012), through what Shane Greene calls “state-supported politics of recognition" (2007:329). As a novel ideology of national identity multiculturalism refers to nations and states officially recognizing the cultural, ethnic, and racial diversity of their populations through constitutional reform, geared at acknowledging and protecting the rights of these different groups — often indigenous and Afrodescendant populations (Brondo 2010; Greene 2007; Hale 2002, 2006; Htun 2004; Rahier 2012; van Cott 2000). 
Here, it is important to note that while the turn towards multiculturalism unfolded - differently in different national contexts—in the 1970s in the Global North (mostly the U.S., Canada, and Western Europe), the multicultural turn in Latin America and the Caribbean generally took place much later, as it expanded in the 1990s (see Rahier 2012). However, in the former Caribbean colonies that were not yet independent the multicultural turn was severely impacted by the trajectories chosen by their former colonizing nations (Reiter 2013). Greene urges to keep the particularities of the historical, cultural and political contexts in which multiculturalisms develop in different nations well in sight. He argues that "multiculturalism is not one phenomenon but many" (2007:336).

Multiculturalism is characterized most and foremost by an explicit shift in ideology of national identity, expressed in the adoption of new constitutions or major constitutional reforms and of laws premised on "inter-cultural equality" (Hale 2002:490). What could be called "multicultural legal instruments" (Rahier: personal communication) were devised to protect citizens of all and any backgrounds from discrimination, giving them a series of "new" rights including but not limited to the constitutional right to bilingual education and to collective ownership of ancestral lands for indigenous communities (see Brondo 2010; Hale 2002, 2005; Hooker 2005; Greene 2007; Rahier 2012).

The multicultural turn potentially provided tools for marginalized populations to better fight to improve their socio-economic and political positioning within the nation in ways previously unavailable to them. But as it has been argued by a great number of scholars, the multicultural turn didn't really alter the socioeconomic and political order of 
things in existence before its advent, it simply provided the national elites with a new narration of the nation that does not attempt to erase its diversity and that — most of allpermits the continuation of societal arrangements. A multitude of well-researched Latin American case studies show that the practice of multiculturalism has been coming along with a wide range of obstructions - sometimes disguised as celebrations of diversitywhich impede or undermine the application of the new law or constitution (see Brondo 2010; Hale 2002; Greene 2007; Rahier 2012). Hale argues that:

The great efficacy of neoliberal multiculturalism resides in powerful actors' ability to restructure the arena of political contention, driving a wedge between cultural rights and the assertion of the control over resources necessary for those rights to be realized. This is not a divide between (endorsed) individual rights and (prohibited) collective ones but rather a retooled dichotomy between base and superstructure: a Marxist vision returning to social movements as a nightmare. (Hale 2005:13)

Goldberg, who writes about the Global North (2002), presents useful insight in the racialized nature of multiculturalism. In his address of the intersection between race and nation he particularly critiques "racelessness" or "colorblindness" as components of multiculturalism that undercuts the propagated "letter of the law." Such discourse renders race and racial inequality relatively invisible. The consequence is a "relative silencing of public analysis or serious discussions of everyday racisms," (Goldberg 2002:217), which makes difficult to address in arenas of public debate, academic analysis, politics and policymaking. This relative invisibilization of race and racial inequality also places out of sight the causal relation between past oppression and exploitation and contemporary 
racial marginalization. Instead a positive, whitewashed history is formulated, which presents "the indomitable superiority of whites - in prestige, achievements, education, wealth, and power - not as a natural phenomenon but as historical outcome" (Goldberg 2002:212). In the color-blind discourse racial inequality is explained as being the fault of the victim. In larger society race no longer matters, the narrative goes: all have equal opportunities. People who are disadvantaged owe their misfortune solely to themselves and their life choices (Goldberg 2002:217). Through the alleged inclusiveness and equality propagated by multiculturalism the actual address of white supremacy is deflected (Goldberg 2002; Greene 2007; Hale 2002, 2005; Rahier 2012).

In this dissertation, I hypothesize that Curaçao's Yu'i Kòrsou or “child of Curaçao" ideology is one of these ideologies of national identity that has reified hybridity, creolization, and especially multiculturalism. Following what Goldberg has taught us about the State, I posit that instead of being obsolete, as many claim it is, racism is a partially hidden constituent of Curaçao's ideology of national identity. Though cherished by the population, this ideology, like a Trojan horse, is a silent bearer of white supremacy, and protects racial inequality at the detriment of Curaçao's Afrocuraçaoan population. This study seeks to deconstruct the multiple layers of Curaçao's national narrative(s). It intends to demonstrate the concrete existence of Curaçao's racial hierarchy, how it is protected and perpetuated by the Yu'i Kòrsou ideology, and how it has come to structurally impregnate the whole of Curaçaoan society. The ultimate objective of this study is perhaps to attempt to understand how hegemony actually works, through the examination of how Curaçao's hegemonic ideology of national identity 
inserts itself into the minds of Curaçaoans, whispering to them what to see and what not to see, while producing and requesting a great many silencing.

\section{Overview of Chapters}

To address my research objectives I have developed three large case studies, which each use various methods of triangulations. Each case study is presented in a separate chapter. The first chapter presents a historical examination of how Curaçao's ideology of national identity developed over the course of nearly four centuries. Using mostly secondary sources, I observe the racialized structure of society as it developed out of colonization, which in Curaçao was characterized by slavery, extensive international trade, and a small-scale plantation economy, and how this racist foundation persisted as $20^{\text {th }}$ century ideologies of creolization and later on multiculturalism arose. After a discussion of the colonial era, the chapter explores the rise and development of the Yu'i Kòrsou ideology of national identity, the messages regarding national belonging and citizenship that it promulgates today, and the multiple silences it entails, which are exercised in among others the whitewashing of colonial exploitation, the deflection of Afrocuraçaoan resistance, and the relative invisibilization of persisting racial inequality.

Chapter 2 explores my self-ethnographic transnational family history. It focuses on my mother, my grandmother, and myself: all women of color, who live or have lived in Surinam, Curaçao and the Netherlands. Following Gilroy's notion of the "changing same" (1995), this chapter captures how the essence of white supremacy, embedded in Dutch ideology of national identity, shaped us across these different eras and different territories in the Dutch Empire. In doing so the main focus of the chapter is to make 
visible how hegemonic internalization of racism—and colorism as a particular dimension of it-operates. Silence and its multiple dimensions of oppression and resistance is the central lens of my theoretical scaffold. In addition, Ann Stoler's conceptualization of intimacy as a micro-dimension of imperial power (2002) further frames this selfethnography. Chapter 2 thus brings into sight the way racist ideologies of national identity influence the deepest parts of our lives and psyches, and the different positions we take on the battlefield between indoctrination and resistance, as victims and agents. This chapter also reveals my positionality as a partial insider and partial outsider of the community in focus in my research project.

In the third chapter, I turn my attention back to Curaçao, and share the results of my ethnographic field study in five very different neighborhoods or barios ${ }^{11}$. Through a presentation of my research results I attempt to answer a number of questions: what is the specific work done by Curaçao's Yu'i Kòrsou multicultural ideology of national identity on Curaçao's inhabitants? How do Curaçaoans perceive and experience racial inequality? And in what ways does racism as part of multiculturalism operate in ways that people are not always aware of? I interviewed a total of twenty-nine respondents, and contrast and complement their narratives with participant observation, informal conversations, and statistical data. In this chapter I continue to use silence as a theoretical lens in order to expose hegemony, and the way in which "raceless" racism (Goldberg 2002, see also Bonilla-Silva 2010) —a key element of multiculturalism—serves to perpetuate white supremacy while at the same time keeping it largely out of sight.

\footnotetext{
${ }^{11}$ Bario, spelled with one $\mathrm{r}$, is the Papiamentu word for neighborhood or residential area. I use it throughout this thesis.
} 
This study deals with ideology. This has determined the methodologies used. David Jacobson (1991) establishes a distinction between two main levels of reality considered by anthropological research: the modes of thoughts and the modes of action (1991:9, see also Firth 1975). The modes of action address what people actually do. To support claims about modes of actions, a researcher must use exclusively data that consist in observed actions through participant observation. Ideology, on the other hand, pertains to the modes of thought, which are about what people actually think, how they perceive their world and their positions in it. The privileged data used as evidence to support claims about modes of thought are linguistic data obtained through verbal statements in interviews, conversations and written texts (Jacobson 1991:12). Jacobson is adamant in asserting that methodologically claims about modes of actions may not be supported by linguistic data (there is always a gap between what people do and what they say they do). Vice versa it is not satisfactory that claims about modes of thought be supported by observed actions. This dissertation zeroes in on hegemonic ideology; as such it addresses modes of thoughts. Consequently, linguistic or verbal data constitutes the vast majority of the data discussed in this dissertation. Only on limited occasions do I make reference to actual observed actions.

\section{Vocabulary and Translations}

Curaçao is a colorist society, where people recognize a wide range of different skin colors and phenotypes. These are listed in great detail in appendix I. I will however not refer much to these emic categories as they are very specific, and have very diffuse 
boundaries. But the vocabulary that I do use throughout this dissertation deserves some elaboration.

“Afrodescendant" refers to all people of African descent ${ }^{12}$. I use the notions of "people of color" and "black" interchangeably. They refer to lighter and darker skinned Afrodescendants alike. In Curaçao, the notions of hende di koló ("people of color" in Papiamentu) and hende pretu ("black people" in Papiamentu) do however not refer to people with a white or nearly-white phenotype that in the U.S. could pass for white even though they have black ancestry. In this dissertation, the notions "people of color" and "black" thus have a Curaçaoan meaning, for in practice the marginalizations that people of color experience in Curaçao's colorist context do not easily affect very light skinned people of color. Hende di koló is more inclusive of lighter skinned people than hende pretu, which specifically refers to Afrodescendants with a darker phenotype.

The word "Afrocuraçaoan" is used to refer to people of color with a Curaçaoan heritage. But since Curaçao's population is ethnically very diverse with significant Afrocaribbean and Afrolatino communities, the word "Afrodescendant" is more appropriate in some contexts. These notions largely correspond to the respective emic notions of Afrodesendiente ("Afrodescendant" in Papiamentu) and Afrokurasoleño (“Afrocuraçaoan" in Papiamentu).

After lengthy debate I have decided to use the problematic and outdated word "mulatto" to refer to Afrocuraçaoans of mixed race descent, because until the mid- $20^{\text {th }}$ century they formed a separate class and racial sub-segment in Curaçaoan society. This

\footnotetext{
${ }^{12}$ This does not refer to white people born on the African continent.
} 
term is much used in the literature about Curaçao. Its use has however disappeared with time when miscegenation became much more generalized and legal differences between Afrocuraçaoans and mulattos dissipated. Today it is no longer commonly used.

Throughout the paper I use it where relevant.

In this dissertation the word "white" refers to people from European but also Middle Eastern ancestry.

All translations in this dissertation are mine. 


\section{Chapter I}

A Historical Exploration of the Interplay Between Racial Ideology and National Identity Formation in Curaçao

"The ultimate mark of power may be its invisibility; the ultimate challenge, the exposition of its roots."

- Michel-Rolph Trouillot (1995)

\section{Introduction}

This dissertation's hypothesis is that racism is a partially hidden constituent of Curaçao's ideology of national identity, which today is founded on multiculturalism. In this chapter I examine both the historical development of the island's racial ideology and current status quo, and the emergence of the ideology of national identity that is in effect today, in this autonomous but not-independent Caribbean territory of the Kingdom of the Netherlands. The focus of the chapter is twofold. It seeks to identify a number of important gatekeeping mechanisms, which I see as the processes by which persons or groups control access to resources such as information, goods, services and networks (Lee 2004). These mechanisms protect the privileges of the white elites from claims of the non-white masses that also seek upward social mobility, and restrict the Afrocuraçaoan population in their access to these privileges. The chapter tracks these mechanisms over the course of time, with the objective of enlightening the contemporary realities lived by Afrocuraçaoans today, which are in focus in this dissertation. Furthermore, it analyzes the impact of multiculturalism — an ideology adopted in the second half of the $20^{\text {th }}$ century-on the perpetuation of white supremacy through the 
deflection of Afrocuraçaoan claims on a reformulation of the power balance (Hale 2002, 2005; Goldberg 2002; Greene 2007).

I divide Curaçao's history up in three main time periods: 1) the colonial era, which spans nearly three centuries, from 1634 to $1915 ; 2$ ) the industrial era, which started in 1915 with the building of the Shell oil refinery and involves rapid and large-scale demographic, economic and social changes; and 3) the post-industrial era, which starts with the famous laborer's revolt of May $30^{\text {th }} 1969$, and again ushers in an era of significant social change. When discussing these three periods I specifically focus on the racial ideology of white supremacy in tandem with the development of the Yu'i Kòrsou ideology of national identity as it developed and impregnated people and things. Whenever I can, I attempt to uncover the mechanisms through which these ideologies were infused in the social fabric through various means of indoctrination.

Today the Yu'i Kòrsou identity is a popular national identity, whose "unifying" message is consumed by the Curaçaoan population at large in a rather uncritical manner. In the sixteen years that I have visited and lived on the island, and in various field research projects that I have conducted during this time, I repeatedly found that people genuinely take pride in being a Yu'i Kòrsou. They use it to debate one's level of insiderand outsiderness, to express patriotic feelings towards nos dushi Kòrsou ${ }^{13}$, and to praise the island's "multicultural" society in which this ideology of national identity is embedded. Dominant and non-mainstream renditions of Curaçaoan history all center on the ethnic diversity of the colonial population ${ }^{14}$. Over the course of time numerous other

\footnotetext{
13 "Our sweet Curaçao." It is a notion that is often used to express one's love for the island.
} 
ethnic groups have merged into the already diverse island population (Allen 2006, 2007;

Dalhuizen et al 1997; Hoetink 1958; Römer 1978, 1998; Rupert 2012; Oostindie 2000).

In this every day vernacular use of the notion multiculturalism denotes the co-existence

of different cultures on the basis of equality. In these renditions multiculturalism as a celebration of equally valued and respected cultures appears to be perceived as a natural and logical progression in the move away from colonialism. I argue that the current definition of who is a Yu'i Kòrsou must be understood in the frame of this national ideology of diversity. As we saw in the introduction, the working definition of the Yu'i Kòrsou in use by the government today (Allen 2012b:1) is:

A yu-di-Kòrsou is someone who lives in Curaçao or abroad, and who fits the following criteria. He/she speaks and understands Papiamentu. He/she is willing to work to advance Curaçao. He/she can declare to the world that he is a yu-diKòrsou and accepts his/her culture and history without any shame. He/she accepts and adheres to Curaçao's multicultural situation, and accepts cultural diversity. $\mathrm{He} /$ she does not consider cultural elements of his/her ethnic group to be Curaçao's culture, but he/she considers them as part of Curaçao's culture. He/she accepts that Afrocuraçaoan elements dominate the majority part of Curaçaoan culture (Rosalia 2001:10) ${ }^{15}$.

\footnotetext{
${ }^{14}$ Given the omission of the notion of "race" in Dutch Caribbean and Dutch academia, "ethnicity" is the operative notion.

${ }^{15}$ This definition shows the two components that over time have become part of the Yu'i Kòrsou ideology, as scholars like Rose Mary Allen (2006), Aart Broek (1994) and René Römer (1974) illustrate. In the first half of the $20^{\text {th }}$ century the Yu'i Kòrsou ideology indicated that the Yu'i Kòrsou were the white, black and mixed populations of the colonial era vis-à-vis the large influx of immigrants. Eventually it became more inclusive and also included the large immigrant population. In the $1980 \mathrm{~s}$, when emancipation and the civil rights movements of that time instilled in people a stronger appreciation of blackness, Afrocuraçaoan culture and folklore, as well as the Papiamentu language became the core of this national identity. Hence,
} 
Citizenship or legal immigration status is not part of this contemporary definition. Instead it solely centers on ideology, which propagates quintessential heterogeneity and alleged inclusiveness. In the chapter I will examine earlier versions of this ideology, and further analyze and unpack the contemporary version, as well as its larger frame: multiculturalism.

The debate whether the Yu'i Kòrsou identity might obscure and, in doing so, facilitate the reproduction of racial inequality, is not part of colloquial dialogue or general academic concern. This chapter illustrates however, just as it has been the case for most countries in the region with their respective ideologies of national identity, that throughout history the Yu'i Kòrsou ideology has been at the service of the elites who devised or elaborated it and who directly benefit from the reproduction of the status quo it allows.

This chapter is mostly grounded on the consultation of secondary sources. At the exception of the work by Rose Mary Allen, René Rosalia and Richenel Ansano, most of the scholarly texts on Curaçao's history are based on archival documents of various kinds, as well as on the recorded voices of the participating national and colonial elites that fill the Dutch colonial archives. This has compounded a difficulty for those, like myself, who are indeed interested in Afrocuraçaoan voices. Official or hegemonic representations of the nation, always generated by the elites who also always control the

the real Yu'i Kòrsou was black (Allen 2006; Broek 1994; and Römer 1974). In this more recent version we see that one no longer has to be born on the island or have a parent who is to be a Yu'i Kòrsou. In my field research I have found that the most important qualifications are speaking Papiamentu, being well versed in the island culture, history and folklore, and loving the island and making a valuable contribution to its advancement. I also found that all these versions of the definition remain active, and that being Afrocuraçaoan is an important element. 
state, are at the service of the reproduction of a particular socio-economic and political order. These representations of the nation-state and of what is true national citizenship attempt to mask the always intrinsically heterogeneous nature of national populations.

Jens Andermann (2007), Christine Buzinde and Carla Santos (2008), and Alexandra Cummings (2004) address the politics of hegemonic representations in contexts of tourism and (national) museums, which provide some of the many stages on which imaginations of the nation are deployed and performed. They note that such enticing hegemonic representations were particularly important as colonial regimes began to wane, and the brutal regimes that ran the plantation economies changed: the elites needed new ways to ensure their positions of power (Buzinde and Santos 2008; see also Poria and Ashworth 2009).

There is an extensive scholarship on the making of ideologies of national identity and the ample silences they entail, in European and non-European settings alike. As Trouillot (1995), Hobsbawm and Ranger (1983) and Rahier (2003) argued, the celebration of official history comes with its erasing, forgetting, and invention of what actually happened (see also Aronsson and Elgenius 2011; Timothy and Boyd 2006). Whitewashing of history (Butler 2001) can be achieved via various methods such as symbolic annihilation, trivialization of events, deflection (see also Brooms 2011; Eichsted and Small 2002), eliminating descriptors and omitting controversial historical accounts (Brooms 2011; Buzinde and Santos 2008; Hall 1999; Timothy and Boyd 2006), and accentuating the socio-economic prowess of the white upper class (Buzinde and Santos 2008; 2009). These narrative techniques enable the hegemonic narrator to make the atrocities of colonialism seem less brutal - if they are referred to at all. They draw 
white social actors constructed as heroes to the forefront while demonizing black social actors as villains, if at all mentioned. When painful historical sites, such as plantations and haciendas, are rewired as what Buzinde and Santos call "mnemonic devices" (2008: 469), the past is represented as an entirely positive, unproblematic, source of pride that led to the imagination of the nation as harmonious and unified, with racial inequality and racial oppression out of narrative sight.

The consultation of the existing scholarly literature on race and nation-making in Curaçao makes evident the conspicuous absence of serious work on the importance of race in the socio-economic and political structure of the island. Like elsewhere in the African Diaspora, the former Dutch colony of Curaçao has a lengthy history of colonialism and slavery, which resulted in a contemporary society where phenotype has of old played an important role in determining social status (Allan 2006, 2009; Hoetink 1958; Oostindie 2000; Paula 1967; Römer 1979). Akin to many other former colonies in the Americas, under colonial rule light skin and other European physical features were commonly associated with beauty and higher social status. In contrast, blackness has been associated with ugliness and marred to slave status and inferiority. This old racebased value system certainly appears to have remained in effect today.

In Curaçao's contemporary society phenotype has remained a determinant of social status. The "color hierarchy" that Dutch sociologist Harry Hoetink writes about in The Pattern of the Old Curaçaoan Society: A Sociological Study ${ }^{16}(1958)$ is still in effect. It is a colorist system (Banks 2000; Burton et al. 2010; Harris 2008; Hunter 2007), or

\footnotetext{
${ }^{16}$ The original title is in Dutch: Het Patroon van de Oude Curaçaose Samenleving: Een Sociologische Studie.
} 
what Trinidadian sociologist Anthon Allahar refers to as a "pigmentocracy" (Allahar 2001), in which somatic features are ranked on a detailed hierarchical scale always characterized with dark-skinned blacks at the bottom and whites at the top. The persistence of this hierarchy is among others visible in everyday use of language. In Papiamentu, Curaçao's creole language, expressions like e ta pretu mahos, which conflates the words "black" (pretu) and "ugly" (mahos) as to say "(s)he is black and therefore ugly ${ }^{17}$," and mal kabei meaning "bad or kinky (black) hair," are common. Furthermore, Papiamentu has a broad lexicon to mark nuances in skin tones and hair types, which serves to identify one's place on the color hierarchy (see appendix I for a detailed description). The island's racial structure also arises in a broad range of jokes, expressions and proverbs. No hasi kos di bo koló is an old expression usually addressed to someone who is dark skinned. It translates as "don't do things of your color," which suggests that inappropriate behavior accentuates one's blackness, and as a consequence diminishes social standing. It thus serves to shame the person into subscribing to white norms of respectability, and into denouncing blackness. Pasombra mi ta pretu, "because I am black", has become a catchphrase for any kind of disadvantageous situation a person finds him or herself in. It is used in gest, for example when drawing straws and pulling the short one, or when a bag of chips is passed around and the last person doesn't get any because the chips have run out. And it is used in serious ways, to address possible racist behavior, or a situation in which someone might have been marginalized on the basis of their race, such as when not getting a particular job. Curaçao is a society in which race

\footnotetext{
${ }^{17}$ The expression indicates that the person's color makes him or her ugly. This pertains to dark skinned people, not lighter brown people (koló bruin), see appendix I.
} 
and color are always part and parcel of social interactions, even if people do not easily talk about how race and color affect their every day lives, and even if the systemic and institutional dimensions of racial inequality remain mostly unaddressed in government policy, pop culture, education, the mainstream media, and academics.

Curaçao's color hierarchy is also reflected in the representations of the national population in the mainstream media. Even though black people have long been represented, the vast majority of mainstream images about the island show white and lighter skinned black people. In a series of 100 billboards that I photographed along the main roads across the island in 2014 only three contained a dark skinned black person, depicted in advertisements for low skilled jobs and a pawnshop. This preference of lighter skinned black people over darker skinned ones subscribes to ideals of whitening as presented in ideologies of national identity that reify mestizaje and mulataje (Hale 1996; Hintzen 2002; Martínez-Echazabal 1998; Price and Price 1997; Rahier 2003; Sheriff 2001; Skidmore 2002; Stepan 1991).

The racial divides can also be seen in the racial/spatial order of the island, or the somatic make-up of the island's socio-economic classes: "in Curaçaoan society, class distinctions have for long coincided with racial differences (Allen 2006:19). Various scholars agree that socio-economic classes by and large conflate with races (see also Allen 2009a:3, Römer 1981:22). A drive across the small island reveals the concrete existence of a color line. The lower classes are predominantly black, the middle classes are mixed, with a lot of lighter skinned black people, but also large groups of darker skinned and white people, and the upper classes are predominantly white. This is a feature that is far from uncommon in the societies of the region. 
But as said, especially in Dutch and Dutch-Caribbean scholarship, concern over racial inequality and racism in Curaçao has yet to lead to serious inquiry. Richenel Ansano argues that "African consciousness in Curaçao has been systemically overlooked and downplayed except through the work of very few researchers, including Rose May Allen and Rene Rosalia” (2015:2), and I may add, himself. While across the Caribbean an abundance of writings on race has arisen, Curaçao falls far behind in an explicit and theoretically substantiated address of race and racial inequality. Many authors, such as Rose Mary Allen (1996, 2006, 2007, 2009), Richenel Ansano (2011, 2012, 2014, 2015), Aart Broek (1994), Leo Dalhuizen et al (1997), Charles Do Rego and Lionel Janga (2009), Frank Martinus (1997, 2003), René Römer (1979, 1998), René Rosalia (1997), Wim Rutgers (2012), Gert Oostindie (1997/2000, 1999a, 1999b), and Peter Verton (1977), to name only a few, address related topics such as colonial history, exploitation, slavery, national identity, ethnicity, and the inequality between the different population segments. Though these authors comfortably refer to Curaçao's racial nomenclature where whites, blacks and mulattos are named, their works do not provide much theoretical substantiation of the core importance of race, or on the systemic nature of racism.

The only publication that directly addresses skin color in Curaçao is Show Your Colors: Idealization and Denial of One's Own Skin Color ${ }^{18}$, by Valdemar Marcha, Paul Verweel and Jacqueline Werkman (2012). It presents a collection of interviews on how Curaçaoans of different ages and class layers experience skin color and thus race. The interviews, which are presented in their entirety and read as small stories, do give

\footnotetext{
18 The original title is in Dutch: Kleur Bekennen: Idealisering en Ontkenning van de Eigen Huidskleur.
} 
information on how Curaçaoans experience race, and on the persistence of racial marginalization and white supremacy. They however also entail unproblematized expressions of colorblindness, black-to-white discrimination, and multiculturalism. Although the study aspires to conduct ethnographic research (Marcha et al. 2012:19), it does not present an operationalization of the variable race, an explanation of the methodology used, an elaboration on the way in which the respondents were recruited, or a theoretical framework through which to analyze the gathered data. This makes the reliance of the data presented questionable. Furthermore, there is no critical discussion or analysis of the myriad of experiences that arise in the interviews. To my opinion the publication is therefore best seen as a journalistic read than as an academic contribution. An older generation of scholars addressing Curaçao, including Cornelis Goslinga (1956), Johannes Hartog (1967a, 1967b), Harry Hoetink (1958, 1961, 1967, 1973), Alejandro Paula (1967) and also René Römer $(1979,1981,1998)$ wrote about race and racial inequality mostly in a descriptive rather than in a critical or theoretical manner. An exception to this are certainly Hoetink's The Split Society in the Caribbean ${ }^{19}(1962)$ and Slavery and Race Relations in the Americas (1973), in which he addresses various theories and dimensions of race, racism, mixed race identity and nation building ${ }^{20}$.

This academic silence is not a coincidence: it fits within a nationwide tendency to avoid talking about race and racism in the Netherlands, which affects everyday life

\footnotetext{
${ }^{19}$ The original title is De Gespleten Samenleving in het Caribisch Gebied.

${ }^{20}$ These two works focus mostly on the Caribbean region at large, which makes them less relevant for my particular research. Also, Hoetink's theories on race and nation building are a product of his time, and often contrast with my theoretical positioning. Therefore in this dissertation they will not be discussed as elaborately as some of his other work.
} 
academia and national politics. In fact, in the Netherlands the national census also omits the category of "race," which undoubtedly sets the tone for the way the censuses are conducted in its overseas constituents. Currently, this prevents Dutch and Curaçaoan governments from collecting data per racial and ethnic group, which are of crucial importance in bringing to light patterns of racial inequality and race-based exclusion of Afrodescendants (UN 2015:10). Instead, the data are gathered by country of birth, which provides no information on people's racial identity.

A few scholars, such as Paul Bijl (2012), Philomena Essed (1987, 1990, 1991), Ramón Grosfoguel and Eric Mielants (2006), John Helsloot (2012), Guno Jones (2012), Melissa Weiner (2014) and Gloria Wekker (2016) have made important contributions to the study of race and racism in the Netherlands, and to the critique of contemporary academia in the Netherlands for its lack of engagement with race and racism.

Weiner in particular contends that scholars who do engage in such research have at times experienced ostracism, "forcing many to continue their work in universities outside of the country" (2014:732).

Combined with the national denial of race and racism, the lack of independent granting agencies in The Netherlands inhibiting most scholars from acquiring funding to study racism, and faculty and graduate students of color in Dutch universities has hindered critical scholarship addressing this subject for nearly two decades (Weiner 2014:731).

This has indeed been my experience. After I graduated in the Netherlands I spent four years looking for a Ph.D. admission, so I could research race in Curaçao. I found none. 
When I decided to try my luck in the United States, I immediately got accepted into a graduate program.

The result is that the interrelatedness of Dutch colonial exploitation and persisting racial inequality in the Netherlands and its former Caribbean territories is not easily addressed in Dutch and Dutch Caribbean academia (Bijl 2012; Helsloot 2012; Jones 2012; Weiner 2014).

This Dutch status quo is relevant for Curaçao for two reasons. Suman Seth argues that "Western scientific knowledge has been co-constituted with colonialism" (2009:374), which of course also was the case for Dutch social science production. In the $18^{\text {th }}$ and $19^{\text {th }}$ century it was by and large Dutch scholars who determined the sociocultural, political, geographical, and biological "truths" of the colonized territories and populations.

In the $20^{\text {th }}$ century many more people from Curaçao and other decolonizing territories in the Dutch Caribbean got the opportunity to study in the metropole. Not all Curaçaoan scholars studied in the Netherlands. Some studied in the United States, others in the Caribbean or in Latin America. But as Caribbean citizens of the Netherlands, obtaining an education there was affordable and easily accessible. More and more formerly colonized or "subaltern" people, as Gayatri Spivak calls them (2010), obtained education and degrees, and joined the ranks of Dutch scholars. These scholars have been developing their visible and critical voices that challenge mainstream Dutch knowledge production. Thus, while many Curaçaoan scholars have made abundant, most valuable, and sophisticated contributions to the knowledge produced on Curaçao, they thus do so in fields of inquiry that have always been, and continue to be dominated by white scholars, 
and that has a long tradition of turning a blind eye on he importance of race and the necessity to study local forms of racism.

In this chapter I rely heavily on secondary sources of information, many of which were written by Curaçaoan and Dutch scholars. A great deal of them-especially those researching the colonial and pre-industrial eras - also use written primary and secondary sources as their main data, such as travel accounts, mission logbooks, colonial correspondence, and scholarly books and articles, rather than on oral histories and participant observation. These written sources mainly preserved and present the white male voices of colonial administrators, missionaries, merchants and such. In more recent times, scholars — many of whom are of Afrocuraçaoan descent—-have made great efforts to collect original data among Curaçao's Afrodescendant population, and to make both male and female Afrocuraçaoan voices much more heard. The collection of poems and scholarly articles, Mundu Yama Sinta Mira ${ }^{21}$ : Womanhood in Curaçao (Ansano et al 1992), is only one of the increasing numbers of contributions that sheds light on gender and womanhood in Curaçao of past and present from an Afrocuraçaoan perspective. But especially with regards to the colonial era the majority of the available data is heavily raced and gendered: the white male narrative dominates. Since this chapter serves as a contextualization of this study, and was not intentioned to present original research on the colonial era, it unfortunately perpetuates at least some of this racial and gendered narrative.

\footnotetext{
${ }^{21}$ Mundu yama sinta mira is a proverb that translates as "the name of the world is sit and see" (Clemencia 1992:ix).
} 


\section{The Colonial Era (1634 - 1915)}

Curaçao was first annexed by Spain in 1499, and turned to Dutch hands in 1634 during the Eighty Years War: a lengthy religious war, fought predominantly on Dutch soil (Oostindie 2002:18). Even though this small, dry island did not seem like much of a loss to the Spaniards, there was much at stake. The war took its toll on the Dutch economy, which brought the Dutch to explore new lands from which to combat Spain and to put significant dents in its stronghold. By the turn of the $16^{\text {th }}$ century Spain had already initiated the colonial rat race in the Americas. Large quantities of silver and gold, extracted from its new colonies, fuelled its wars. These new riches resulted in territorial expansion oversees as well as in Europe, and until the early $18^{\text {th }}$ century the Spanish Kingdom extended well into the Netherlands. In 1621 the Dutch founded the Dutch West India Company to wage economic warfare against the Spaniards and the Portuguese, whose territorial expansion oversees was also increasing, and to thwart the Southern European attempts to dominate Europe (Oostindie 2000:18; see also Rupert 2012). Warfare, but also raiding Spanish and Portuguese colonies and trade routes in the Americas and the African West Coast, enabled not only the Dutch but also their French and British counterparts to rupture the flow of silver that financed Spain's iron grip on Europe (Oostindie 2000; Rupert 2012).

The Eighty Years War broke Spain's colonial monopoly in the West, and the British, French, and the Dutch followed suit, conquering many islands and starting their own West Indian colonies. Sidney Mintz argues (1985) that the North European colonists were less interested in the search for precious metals than the Spaniards and the Portuguese were (Mintz 1985:35-36; see also: Oostindie 2000:21). They were more 
interested in "marketable commodities" such as cacao, tobacco, cotton, coffee, and of course, sugar (Mintz 1985:36). Sugar in particular became the prize crop of the Caribbean, partly due to the efforts of Dutch entrepreneurs (Oostindie 2000:19; Mintz 1985:35). The British started the first sugar plantations in Barbados in 1627 (Mintz 1985:37). The Dutch modeled their Guyanese colony—Surinam—after this new plantation model, which quickly became highly lucrative due to opportune investments in technology and slave capital (Oostindie, 2000:19). Yet, Curaçao and the other small islands that the Dutch conquered from the Spaniards were not quite cut out for the same destiny.

Curaçao, together with Aruba and Bonaire, is one of the Leeward Islands, situated close to the Venezuelan coast. Here the climate is too dry for profitable plantations: the island's agricultural and livestock endeavors could not produce sufficient quantities needed for export. Instead, the plantations that were created on Curaçao were small and geared at providing for the food consumption of the local population, which made it somewhat less costly to maintain the colony (Hoetink 1958:16. See also: Oostindie 2000). But the Dutch saw other possibilities for these arid islands. They had pursued Curaçao in particular for its numerous large natural harbors, its saltpans, and its proximity to the Spanish colonies. Whereas to the Spaniards these small islands had initially been considered rather "useless"22 (Martinus 2003; Oostindie 2000), to the Dutch Curaçao in particular was mostly of strategic value (Hoetink 1958:11; Do Rego and Janga 2009).

\footnotetext{
${ }^{22}$ The Spaniards actually named the islands Islas inutiles: "useless islands" (Oostindie, 2000:22, see also Eckkrammer, 2003).
} 
Part of its strategic position was related to commerce. Because of its natural harbors Curaçao quickly developed into a trading post. From the late $17^{\text {th }}$ century on it became the center of general and contraband trade with the region, and the beating heart of the infamous Dutch slave trade (Hoetink 1958:7; Klooster 1994:283; Oostindie 2000:55; Rutgers 2012), which supplied the Spanish and the Dutch colonies in other parts of the Americas. Rupert writes:

Lacking the basic resources to sustain agricultural production, Curaçao's merchants sought markets throughout the Caribbean and the Americas that would provide them with agricultural commodities they would sell in the wider Atlantic system (2012:165).

They became so successful at this that, much to the dismay of the other European powers that operated in the region, the goods that the richer colonies produced were traded through the open ports of Curaçao (Rupert 2012:121).

Officially governed by the Dutch West India Company, but ran mostly by individual entrepreneurs (Rutgers 2012), the bustling harbor city of Willemstad developed around the big St Anna Bay. It attracted merchants and entrepreneurs from the far corners of the world. The big harbor facilitated abundant trade with the Venezuelan coast, New Granada, Hispaniola, Panama, Puerto Rico, and Cuba (Klooster 1994:283), while the island's numerous smaller bays made dropping off an illicit load or two most easy (Hoetink 1958:18 23 . The island also generated revenue by serving as a depot for weapons and provisions for the Seven Years War between France and England, and for

\footnotetext{
${ }^{23}$ Here Hoetink is referring to Cola Debrot: Bevolkingsgroepen op Curaçao, in: Cultureel Indie, 7e jrg p. 131-144, 1945.
} 
the American Revolutionary War (Hoetink 1958:7,8). These glory days, however, did not last. When Caribbean mercantilism ended by the end of the $18^{\text {th }}$ century, followed by the decolonization of the Spanish empire in the Americas and by the end of the slave trade in the $19^{\text {th }}$ century, Curaçao lost its merit to the Dutch (Hoetink 1958:8). The colony slowly but surely demanded newer and larger investments in order to turn it from a burden into a self-sustaining part of what had by then become the Kingdom of the Netherlands.

While Curaçao's trade networks spanned most of the Americas, the trade between the island and the Netherlands had always been modest (Rupert 2012:121). Economically speaking the economic successes of the Dutch islands and even of plantation colony Surinam were of little relevance for the Netherlands (Oostindie 2000:22; see also Hoetink 1958:26-27). In fact, the Dutch had to invest greatly to keep their colonies running. They did make such investments in Surinam, which was a plantation colony, even though it yielded insufficient revenue. However, the colonial motherland sent considerably less funds to Curaçao and the other Dutch islands (Oostindie 2000:30-31). Consequently, the Dutch Republic did not support or protect its possessions in the Antilles much (Oostindie 2000:30; Hoetink 1958), nor was it very involved with the administration of the growing population. When focusing on Curaçao in particular, we see that the consequence of this noninvolvement was that the island became rather self-sufficient early on. The Dutch elites that ruled the island became more focused on the Latin American mainland in their culture, language and trade relations than on the Netherlands (Oostindie 2000:36). 


\section{Curaçao's Segmented Population}

The racial groups that constituted Curaçao's populations in the early days of the Dutch colony were the Caiquetío, the indigenous inhabitants of the region and the island itself, the white Europeans, and the enslaved Africans: a common composition in many a part of the Americas. Over the course of the centuries people from all over the world would join, seeking out opportunities in the island, which had become an important trading hub. Curaçao became a very multi-ethnic and multi-racial island early on (Hoetink 1958; Oostindie 2000; Rupert 2012). But in spite of the spatial intimacy and miscegenation between blacks and whites, Hoetink argues that since its very days of origin as a Dutch colony Curaçao's society had been a severely segmented society (Hoetink 1958, 1961).

In spite of repeated instructions from the colonial motherland to Christianize all non-Dutch inhabitants of the colony, Curaçao's Dutch elites were reluctant to encourage the acculturation of the enslaved population and non-Dutch immigrants into their religion and cultural practices, norms and values (Hoetink 1958:109,110). In fact, the Dutch colonials would eventually use religion and even language to exclude non-Dutch people from their ranks (Hoetink 1958; Oostindie 2000). Frank Martinus wrote that in the forts on the African coast the Catholic Church demanded that enslaved people be baptized before they could be transported. Initially the Church even demanded that there was a priest on board of every slave ship (Martinus 1997:127, quotes Carreira 1983a:282$283)^{24}$. But once in Curaçao the Protestants did not bother with the Christianization of their "property." On the contrary, Oostindie quotes a compelling diary entry of early

\footnotetext{
${ }^{24}$ Cabo Verde. Formaçāo e extinçāo de uma sociedade escravocrata (1460-1878). Praia: Instituto Caboverdeano de Livro).
} 
eighteenth century Reverend Bosch, who elaborates on the motivation behind segregation:

When I had spent several years in Curaçao, I however saw the true reason, why the protestants have saved their churches here only for people of a white color, a reason that signified more than the abovementioned suitability of the Roman Catholic Church for dumb folk. This was, namely, in a colonial politics, to bring people with a black and brown color in disdain. The larger one makes the distance between whites and blacks, and the more one humiliated the latter, the more steadfast and longer, one thought, the colonial system would stand; for did fear for the whites not keep the Negroes at a respectable distance, was there among the latter not respect for the moral majority and higher worth of the former, then live and possessions, peace and safety were in danger" (My translation. Bosch 1829:226. In: Oostindie 2000:62).

When the Dutch took over the island they deported the small amount of remaining Spanish residents to Venezuela (Hartog 1961a). The majority of the Caiquetío population that had originally populated the island followed the Spaniards; only a few dozen Caiquetío remained behind. Johannes Hartog (1961a) writes that the Dutch did not intermingle with these native inhabitants the way the Spaniards had. They did not engage in the concubinary relations that the Spaniards had maintained, nor did they baptize the Caiquetío, as the Spaniards had done, or introduce them to their European ways (Hartog 1961a:207-208; Paula 1967).

The Dutch Protestant population itself separated into two classes: the elites, and the middle- and working class citizens. The "higher" Protestants, as Hoetink calls them 
(1958:44), were the well-educated officers and employees of the colonial government, sent to Curaçao to implement the administration. Through their assigned functions they became the island's elite (Hoetink 1958, 1961; Paula 1967). The "lower" Protestants were the sailors, soldiers, and laborers and such who filled the economic niches of artisans and small merchants (Hoetink 1958:44; see also Paula 1967). These two groups also remained economically, socially, and spatially separated. Through this divide the higher Protestants aimed to safeguard their newly acquired elite status (Hoetink 1958:45; Paula 1967), which they had not enjoyed in the home country. However, in religion, education and language the divide between higher and lower Protestants was far less strong: both groups attended the same churches and schools, and spoke Dutch. But intermarriage between these two economic segments did not occur much, if at all, nor could the lower Protestants obtain the jobs of the elite of administrators (Hoetink 1958:47).

In 1656 a large number of Sephardic Jews arrived on the island. They originated from Spain, where they had been expulsed by the Inquisition. After having resided in Portugal, Amsterdam and Brazil for a great many years they were eventually welcomed in the Dutch colonies, where they quickly proved to be very successful "merchants, but also insurers, ship owners and seafarers" (Hoetink 1958:37). Not only did the "Portuguese" Jews, as they became known, merge predominantly with the higher societal echelons, their financial successes in fact proved of great economic value to the colony (Hoetink 1958:37). Yet, again there would be no significant intermingling between the Jews and the Protestants. Their relations were predominantly formal and limited to business and trade (Dalhuizen et al 1997; Hoetink 1958; Paula 1967; Oostindie 2000). 
The fact that the Jews were not allowed to occupy official administrative positions reserved for the Protestants fortified the Jewish-Protestant separation (Hoetink 1958:39). Also, through their successes in trade in particular, the Jewish elites soon posed somewhat of a threat to Dutch economic, social and political dominance-yet another reason why the two groups remained separate (Hoetink 1958, 1961; Paula 1967; Oostindie 2000). Map 4 illustrates that the Dutch and the Jews developed separate residential areas, which further limited social interaction (Hoetink 1958; Paula 1967). The Protestants settled in Punda and Otrobanda, the Jews in Pietermaai and Scharloo. Also in religion and in marriage there was virtually no intermingling. Neither the Portuguese Jews nor the Dutch Protestants were interested in letting the other group enter their religion, or marry into their families (Hoetink 1958:41; see also Oostindie 2000).

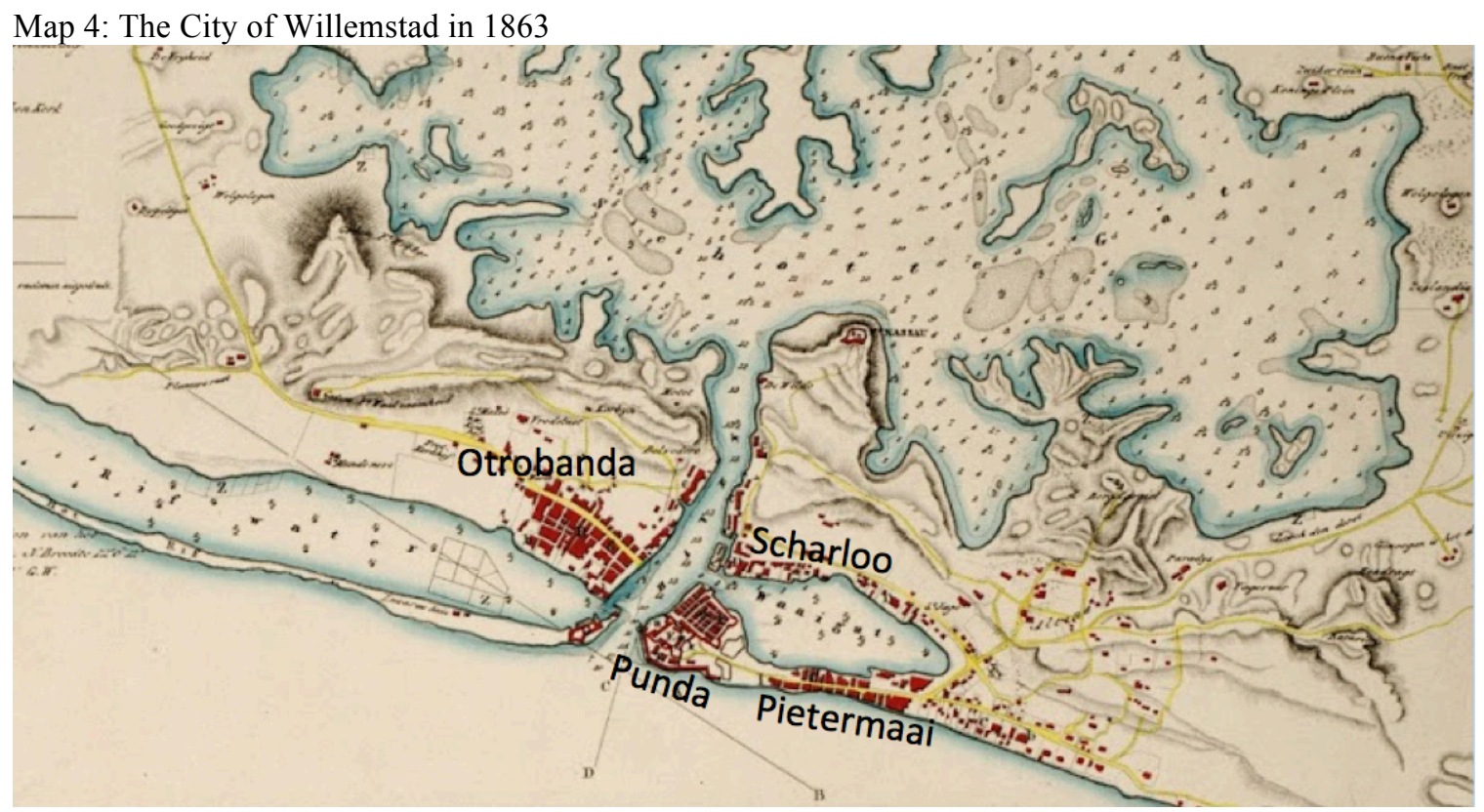

Source: Detail of Map of the Island Curaçao, Hulst van Keulen, G. (1836), adapted by me.

Even linguistically these two segments remained rather separate. As a Dutch colony the official language of the island was Dutch. Jewish men often did speak Dutch 
for trading purposes, but their maternal languages were Portuguese and Spanish (Rupert, 2012:136; see also Fouse 2002, Hoetink 1958). The Dutch were less proficient in these languages, but linguist Gary Fouse argues that the Dutch often did speak Spanish and other European languages for trading purposes (Fouse 2002:66), especially since Dutch was not a viable trade language in the region. Still, language and especially religion can be seen as means of ethnic gatekeeping between these two groups.

Because of the forced migration of Africans, which lasted over two centuries, Afrodescendants came to form Curaçao's largest population segment. Ample miscegenation between the black and white populations resulted in a growing mulatto population that, like in many other colonies in the Americas, would over time develop into a separate class segment (Hoetink 1958; Römer 1979). Initially, the Dutch West India Company set up relatively large government plantations (Rupert 2012:135), which, because of the island's dry climate, were still quite small compared to plantations in other parts of the Caribbean.

Of 376 owners in 1735 , only 38 owned more than 10 slaves. The largest slaveowner at the time had 120 slaves. And in 1863, the year of abolition, when six to seven thousand slaves were emancipated, the great majority of owners still owned fewer than five slaves. The "average" slave-owner held a few slaves as coachmen, house-servants, or gardeners. Only on the so-called plantations (especially in the western part of the island) were there slave-holdings of more than 50 slaves, and only rarely more than 100 (Hoetink 1983:3).

However, in the early $18^{\text {th }}$ century the Dutch West India Company already sold its plantations to independent merchants (Rupert 2012:135): they were not lucrative. 
Hoetink writes that most plantation owners generated their income via ample commercial activities: "If any of these owners had had to depend exclusively on their plantations for their income they would have been bankrupt in a few years" (Hoetink 1983:3). The plantations were thus more a status symbol than a genuine source of income, he argues $(1983: 3)$

Because of the small scale of Curaçao's plantations, black and white people cohabitated in far closer proximity than on the big plantations that characterized most of the Americas. This absence of a large-scale plantation economy also meant that the Afrocuraçaoan population did not predominantly do the agricultural-related work, as was so common at the large plantations in the region. Afrodescendants-both slaves and freedmen - often worked in and around the harbor as construction workers, artisans, sailors, traders, musicians, and military personnel, among others (Allen 2007; Klooster 1994). In these settings they often worked side by side with the poor white population. Or they would be dockworkers, ferrymen, fishermen, or have their own property in town from where they operated a small business (Rupert 2012:145). Due to the mercantilist nature of the colony and the small scale of the plantations, in the $18^{\text {th }}$ century the Afrocuraçaoan population became rather self-reliant (Allen 2007; Klooster 1994; Rupert 2012), and.

It deserves mention that the segment of freedmen kept expanding as manumission became common in Curaçao (Allan 2007; Hoetink 1987; Klooster 1994; Rupert 2012). Klooster, referencing Hoetink (1958/1987:75) writes that in $181732.2 \%$ of the island population was comprised of free non-whites, while in 1833 this percentage had already 
increased to $43.5 \%$, bringing the population of free people of color to outgrow the slave population as the largest segment of the island population (Klooster 1994:288).

Slaves and freedmen were in constant interaction with both lower and upper class whites (Oostindie 2000:33; Rupert 2012). On the small plantations, which sometimes only housed a handful of slaves, but also in the city, white and black people lived in close proximity (Hoetink 1958). We already saw that since the Curaçaoan plantations hardly provided enough work for the slaves they often worked as seamen, carpenters, gardeners, household servants and fishermen, and as craftsmen, construction workers and laborers in the harbor (Klooster 1994; Rupert 2012). The old colonial architecture reflects this spatial intimacy between blacks and whites. In the courtyards of the many old mansions and plantation houses that have been preserved across the island we see the former slave quarters, often no more than a few steps away from the main house. And in Otrobanda, the old inner city center, the large mansions, and the houses that once belonged to the colonial middle class, the working class, and slaves and freedmen all stand shoulder-toshoulder, lined up along an intricate maze of alleyways and hidden passages.

Inter-racial sexual arrangements were a key component of this intimacy between black and white. According to Hoetink, Protestant and Jewish boys as young as 15 or 16 were expected and encouraged to have their first sexual relations with women of color (Hoetink 1958:56). It was a norm rather than an exception for white men to have sexual relations and live in concubinage with one or more women of color (Hoetink 1958:119, 120). Hoetink even states that this kind of relationship was "institutionalized" (1958:119). In this segregated, small-scale society there was a great shortage of available marriage partners for white men. Therefore people often married within the family, as to 
preserve the family capital (Hoetink 1958:119). The often long lasting relationships these men had with women of color could be seen as a "supplement, a substitute perhaps of the official marriage" (Hoetink 1958:119). For women of color such relationships provided material gain and social privileges, among which a higher social status for their mixedrace children (Allen 2007:90). Formal marriage between a lower class Protestant man and a light-skinned Afrocuraçaoan women happened on occasion (Hoetink 1958:49). But more so, concubinage, which Hoetink also describes solely as a white man and black woman endeavor, was a given.

It deserves mention that in the literature that I consulted I have only found minimal references regarding the sexual violence that is such an important part of colonialism. Hoetink's seminal work, which heavily informs this dissertation and many other scholarly works, unfortunately presents a romanticized and one-sided narrative on interracial relations. His work is founded mainly on secondary literature and archival sources such as travel logs, correspondence and reports written by missionaries and colonial administrators, rather than oral history and ethnography. These sources convey the voices of white middle class and elite males of the colonial and pre-industrial era: the voices of women - especially of Afrocuraçaoan but also of European and South American descent—are not part of them.

Although Hoetink does address the relationships between mulatto children and their white colonial fathers, many of whom belonged to the class of slave owners, I have not been able to find any mention of sexual exploitation of Afrocuraçaoan women. Hoetink speaks in positive terms of the sexual prowess of the young white males (1958:56,57), and of the apparently consensual nature of interracial sexual relations. This 
may reflect the way his sources chose to describe such interactions: they may not have made much mention of rape or violence to begin with. But whether they did or did not address sexual violence, Hoetink's narrative is notably constructed in the absence of voices of women — and also men — of color that were forcedly part of these detrimental interactions.

Rose Mary Allen, who is another main source in this chapter, does use an abundance of oral histories of Afrocuraçaoan men and women. Especially in in $\mathrm{Di} K i$ Manera: A Social History of Afro-Curaçaoans, 1863-1917 (2007), she conducted interviews with Afrocuraçaoans of a very high age. They recounted stories and songs from their parents and grandparents, which paints an important picture of what life was like during and after slavery. In her work the voices of women of color are abundantly present, but she also does not present an in-depth discussion of intimate relations between Afrocuraçaoan women and white men, nor does the topic of sexual violence surface.

In a brief article about Curaçaoan women in slave society, Nolda Kenepa-Römer writes: "The $[\ldots]$ status distinction among the slaves, the skin color, developed because the female slave was also subjected to sexual exploitation" (1992:24). She then continues with a discussion of the distinction between house- and field slaves. While she at least mentions the forceful and violent dimension that is also very much part of interracial contact, she presents it as a given, and does not problematize it further.

Even though there must be more sources that make more mention of this dimension of sexual exploitation, the lack thereof in the sources that I used is significant. It appears to signal a silencing of this horrid but integral part of the colonial past. On the side of the white elite such a silence could indicate the whitewashing of destructive white 
actions, as well as a naturalization of white oppression. If people find it normal and selfevident that (female) Afrocuraçaoan slaves were raped, it suggests that white dominance is also normal and self-evident. On the part of Afrodescendant people that are first-, second-, or multiple generation survivors of such violence, silencing could indicate a deliberate forgetting, to help assuage internalized oppression and shame (Sheriff 2001:83). But as Sheriff (2001) and Scott (1992) argue, such silences should also be seen as powerful forms of resistance; as ways to shield the trauma that these transgressions caused until there has been sufficient healing, and to deflect a perpetuation of potentially damaging narratives and stereotypes of black female bodies as vulnerable.

With regards to the children that were begotten in intimate interracial contacts, Hoetink argues that it was socially accepted for Jewish men in particular to acknowledge their biracial offspring, and to favor them in over other Afrodescendant children. They would for example manumit them, provide them with education, a good job, or even some land (Paula 1967:30); things that were not easily available to enslaved people and, manumission aside, to freedmen. Also, it was not uncommon for these children to take on their fathers' family name. Protestant men also extended such favors to their Afrodescendant children, with the exception of their family name. The child could only allude to its white lineage through changing its fathers' name a bit (Hoetink 1958:120).

Hoetink is less explicit about the ways in which bi-racial children remained structurally disadvantaged compared to their white siblings. Interracial relations were so common that miscegenation appeared to be part of the "natural order of things," he argues. He paints a romantic picture of black and white children living in the same yard, growing up together as playmates and friends, both groups knowing their place in the 
balance of power, something that Gilberto Freyre too writes about with regards to

Brazilian society (Freyre 1933). "One met their negro relative in every street of Punda"

(Hoetink 1958:121) ${ }^{25}$. But history across the African Diaspora illustrates that these

children often also served as cheap additions to a plantation owner's slaves. In Hoetink's

work their voices also do not surface much — if at all. In this representation of

miscegenation the oppressive and violent dimensions of interracial relations remain out

of sight.

It is important to observe the gatekeeping mechanisms at play in these intimate yet unequal relations. Ann Laura Stoler specifically addresses this "realm of the intimate" as yet another mechanism through which colonial dominance was exerted (2002). The official and implicit rules, sanctions and prohibitions regarding who could bed and wed who and under what circumstances, how colonial parents were to interact with their mixed-race children and how nurse maids were to interact with white colonial children, informed both the white colonials and the enslaved and otherwise subjugated population. They were a continuous implementation and affirmation of colonial power and white supremacy (Stoler 2002). Women of color that had relationships or interactions with

\footnotetext{
${ }^{25}$ This romantization of interracial intimacy is a common theme throughout the African Diaspora, and often spotlighted in Curaçaoan national imagination, like in the popular novels My Sister the Negress by Cola Debrot (1935/1955), and Slave and Master written by Carel de Haseth (1988/2008). Both books rank highly in Curaçao's literary canon. However, in popular culture the topic of sexual violence directed at women of color also appears to be minimally present. Much more research is needed to determine if this indeed the case, see appendix X. In de Haseth's book a white man and a slave who grew up together as friends both fight over the same woman of color, with whom they are both deeply in love. In Debrot's book a white elite Curaçaoan man returns to the island after studying abroad and falls in love with the black girl that tends to his father's house. She turns out to be his sister. Both stories strongly feature romanticized, quintessentially unequal amorous relations between black women and white men, from the male perspective. Pierre Lauffer's famous poem about the slave Buchi Fil and his wife Mosa Nena (1964) describes how the overseer tries to break Buchi Fil's strength by selling Mosa Nena. This is a powerfully violent act in which rape may be implied, but in Lauffer's poem it is not explicitly mentioned. An in-depth analysis of the imagination and representation of interracial relations in the Curaçaoan arts in past and present, and how these contest or perpetuate hegemony, would be most valuable.
} 
white men — consensual or not—could reap benefits from them, but even when such relations were amorous and permanent, Afrodescendant women could never enter white European space as a white man's legitimate partner (Stoler 2002:39; see also KenepaRömer 1992). For the non-white, mixed-race children they had with these white men the same gatekeeping mechanisms applied. There was a good possibility that they received privileges from their fathers and from society at large, but never to the extent that they became part of the white elite ${ }^{26}$ (Kenepa-Römer 1992:22,23).

Therefore miscegenation must not be romanticized: during the colonial era in particular it always contained the threat of violence and the exploitation of black bodies (Stoler 2002). White males could rape women of color or demand sexual favors ${ }^{27}$. And the children that resulted from such relations were likely to have had more privileges compared to their darker skinned peers, but their white peers would by default outrank them. Racial labeling is of key importance in this gatekeeping process:

The colonial politics of exclusion was contingent on constructing categories. Colonial control was predicated on identifying who was "white," who was "native $\mathrm{e}^{28}$, , and which children could become citizens rather than subjects, on which were legitimate progeny and which were not (Stoler 2002:43).

\footnotetext{
${ }^{26}$ In chapter 2 I will use Stoler's work to present a much more in-depth analysis of how white supremacist ideology was exerted through the various intimate interactions between black and white people in Curaçao.

${ }^{27}$ White men would also sexually violate and exploit black men — a heavily silenced dimension of colonial oppression in general, and certainly in the literature on Curaçao's colonial era. But naturally this would not amount to miscegenation. Hoetink does not elaborate on this, or on intimate relations between black men and white women, but like elsewhere in the colonial realm, these were not condoned and heavily sanctioned. This too is a marginal topic in the existing literature on Curaçao.

${ }^{28}$ Stoler writes here about Indonesia, also a part of the Dutch Empire. In Curaçao's case "non-white" or "Afrodescendant" should replace "native".
} 


\section{Inter-Racial Intimacy and Creolization}

The previous section indicates that, even though the Protestants - and also the Jewswere averse to outsiders acculturating into their cultures, there was ample racial and also cultural mixing between black and white segments of Curaçao's population. Linda Rupert's Creolization and Contraband (2012) illustrates the highly complex processes of creolization that took place during the early days of the colony, when people of different ethnic backgrounds and classes interacted abundantly in cultural and economic arenas.

The notion of "creolization" has multiple uses. As discussed in the introduction, it refers to the early 20th century ideologies of national identity devised to create unification in heterogeneous societies, especially in the Caribbean and parts of the Americas (Bernabé et al. 1989/1993; Glissant 1995; Hannerz 1987). In more recent times creolization has become a favored concept by the social sciences to theorize and analyze processes of cultural mixing, transculturation, and globalization, often still referring to, but no longer limited to, the Caribbean (Hall 2003; Khan 2001; Mintz 1998; Stephen 2007). This is also how Rupert, as well as Hoetink, Römer and Martinus employ the notion in a Curaçaoan context: as "processes of sociocultural exchange and adaptation that occurred among all the diverse peoples of the early modern world who were thrust together with the rise of European overseas empires" (2012:6).

Hoetink (1958), followed by Römer $(1979,1981)$ and Martinus (1997), specified three main trends of cultural exchange that led to the mixing, reformulation, and invention of different cultural elements: processes that have been referred to with expressions such as "africanization," "dutchification," and "latinization." These can be 
seen as often converging, specific trends in the creolization processes ${ }^{29}$ that took place on the island $d^{30}$.

In this Dutch colony, the Dutch culture, norms, values, language, and modes of operandi were the norm, and associated with the superior status that the Protestant elite enjoyed (Hoetink 1958:51). This created a cultural framework in which other parts of society develop. Dutchification refers to the influence from the dominant cultural norms and practices from the Protestant Dutch colonizers on the Jewish and especially the Afrodescendant populations (Hoetink 1958:84). Especially after emancipation Dutchness would become a much sought after norm for people of color, adopting elements of Dutch culture and religion was a way to secure social mobility.

Hoetink wrote about the herengedragspatroon or "master behavioral pattern," which is an ideal typical pattern belonging to the elites and the "slave behavioral pattern" (Hoetink 1958:125). These two ideal typical ${ }^{31}$ behavioral patterns mainly instructed whites and blacks the correct display of respect, obedience, prowess and dominance. The general gist of the master behavioral pattern was that one was to be fierce, proud,

\footnotetext{
${ }^{29}$ Hoetink initially appears to have perceived creolization to be the synonym of Africanization (Hoetink 1958:49). Römer understands creolization as an almost natural and self-evident amalgamation of these three processes, which according to him resulted in a unified island identity. Allen, however, critiques Römer in particular for being oblivious to the racial and socio-economic inequality and subsequent tensions between the groups involved in this amalgamation. She claims he did not take into account the "socialpolitical dimension" that is part and parcel of creolization (Allen 2006:23).

${ }^{30}$ It deserves mention that particularly the writing of Hoetink and Römer arises during a time when ideology of national identity shifts towards a focus on creolization. Both were influential scholars in Curaçao. Hoetink's work on the different ethnic and racial groups in post-colonial Curaçao's and their interrelatedness was unprecedented and has to this day remained a seminal work. Römer was the first scholar to analyze Curaçao's post-colonial era. Their analyses and knowledge making fuelled the imagination of the intellectual elites involved in the imagination of the nation and with that the national narrative from the 1960s on. No longer were the black and white population segments depicted as castes: their profound interrelatedness became a new trope in Curaçao's national imagination.

${ }^{31}$ Hoetink understood that there were many nuances and variations in people's individual behaviors.
} 
respected, superior to blacks, dominant, and ambitious; the slave behavioral pattern required a performance of being submissive, obedient, and patient towards whites (Hoetink 1958:125). However, the lighter skinned free population also adopted the master behavioral pattern, thus intentionally pursuing dutchification. Imitating the colonial elites and their behaviors of superiority was a way to signal one's deliberate moving away from slave status (Allen 2006, Klooster 1994). It went hand in hand with a deliberate distancing from African descendent culture, mores, practices, which were seen as inferior (Hoetink 1958:89). The Catholic Church, which was gaining influence over the non-white community after emancipation and avidly denounced all African influences, added more momentum to the dutchification process (Hoetink 1958:84, see also Allen 2006, Römer 1981).

The other process Hoetink describes is latinification. The culture of Curaçao's Protestant elites, he claims, bore a closer resemblance to that of the Catholic elites of the South European nations and especially their Latin American colonies. It was characterized by an unusually strong patriarchal character, a "virginity complex," which pertained to the women of the Dutch elites, a very present "virility complex," which concerned the men, and much more celebration and festivity than was common in the Calvinistic oriented Netherlands of the $16^{\text {th }}$ and $17^{\text {th }}$ centuries. Girls and women were duly chaperoned and confined to the home while black servants run all the errands (Hoetink 1958:52-54). Men, on the contrary, were from their early teenage years on encouraged to be sexually active and promiscuous (Hoetink 1958:55,56). As previously discussed, fathering children out of wedlock was common and encouraged. Historical sources also indicate that Curaçao's culture was characterized by ample celebration and 
social interaction, always with an abundance of music and dance, which both had West European, Latin American, and African elements (Hoetink 1958:59-60). In the Netherlands these trends were far less present: the culture was characterized by frugality, piousness, abstemiousness and a much more subdued sexual morale. Paralleling his findings to the works of Gilberto Freyre (1933) and Eric Willems (1954), Hoetink attributes the differences between Dutch Protestant culture in Curaçao and Dutch Protestant culture in the Netherlands to the Latin influences. For a large part these influences arose from frequent trading contacts with the mainland (Rupert 2012), and from interactions with the Portuguese Jews on Curaçao ${ }^{32}$.

For lower class Protestants, more so than for the elites, there was another latinization influence: marriage to "mestizo" women from mainland, who brought their culture (Hoetink 1958:48). Hoetink however claims that while the lower Protestants knew that latinization was unavoidable, they did not appreciate it, as it was perceived as diluting their Dutchness and the superior social status that was associated with that: in the Dutch oriented colonial culture their Dutchness automatically gave them a superior position over non-whites (Hoetink 1958:84).

For the mulatto group on the other hand, latinization was yet another way to distance oneself from the Afrocuraçaoan cultural domain and its ascribed inferiority (Hoetink 1958:89), as well as from Curaçao's rigid colorist system. This group was financially equal or superior to the lower Protestants, but in the social hierarchy they were always perceived as inferior to whites. Often lighter skinned people, and especially

\footnotetext{
${ }^{32}$ The Protestant aristocracy, as Hoetink calls is, did not actively seek to imitate cultural norms, values and behaviors of the Jewish group. Until the end of the $19^{\text {th }}$ century the Dutch elites looked down on the Jews, and thought them "unequal" and "inferior" (Hoetink 1958:51).
} 
those that were fairly affluent, tried not to marry darker skinned black people as to prevent "social downturn," Hoetink argues. Instead they too sought mestizo or white marriage partners from South American mainland (Hoetink 1958:83). "By confessing to South American culture and morals, they as it were sought to detach from the local hierarchy, and to experience their being of color as less disgraceful" (Hoetink 1958:83).

But Curaçaoan linguist Frank Martinus argues that latinization already took place in the $16^{\text {th }}$ and $17^{\text {th }}$ century Portuguese-run slave forts on the West African coast, from where they were bought among others by Dutch slave traders (Martinus 1996:126). In collaboration with the Catholic Church the Portuguese slave laws of the time stated that African captives had to be baptized, for which the Church collected a tax (Martinus 1997:127). So before arriving in Curaçao, slaves were deliberately socialized into the Portuguese-based pidgin language used in the forts, and in the religion ${ }^{33}$. They even learned a trade such as masonry, carpentry, distillery or blacksmithing, which would increase their value (Martinus 1997:126). Latinization of the Afrocuraçaoan population also occurred through the ample missionary work of the Catholic priests who reached Curaçao from the South American mainland in the $18^{\text {th }}$ and early $19^{\text {th }}$ century, before Dutch Catholics came to the island (Klooster 1994:292).

The third trend, africanization, pertains to the cultural influences of Afrodescendants on the various white groups of the island. Because of the small size of the plantations there was ample personal and intimate contact between enslaved people and their owners (Hoetink 1958:123). This facilitated the continued and two-way

\footnotetext{
${ }^{33}$ Martinus states that captives could stay in these forts for months if not years, for lack of transportation (Martinus 1997:126-129).
} 
exchange of cultural elements between enslaved black children and the white children of the slave master growing up together on the same compound; in interracial sexual relations, which as said were often permanent, personal, and affectionate (Hoetink 1958:120); in the relations between fathers and their mixed-race children who were commonly raised by their black mothers rather than in the house of their father, and between white and non-white siblings (Hoetink 1958:121-125). Lower Protestants working as artisans, civil servants and shopkeepers in the city frequently interacted with the black population, both free and enslaved (Hoetink 1958:148): they were clients, employees, colleagues, neighbors and acquaintances.

The yayas or wet-nurses are often mentioned as a key element in the specific transmission of Afrocuraçaoan language and social practices, beliefs, and values to the Jewish and Protestant families they worked for (Hoetink 1958:124; Römer 1981:71; see also Stoler 2002:133). Interestingly, Stoler, in writing about colonial Indonesia and colonialism at large, describes the apprehension that elites had towards the servants. They were perceived as a source of "contamination" and "corruption" of a child's European mindset and identity (Stoler 2002:136). Hoetink does identify the elites' apprehension towards the yaya's "africanizing" influence, but both Hoetink and Römer depict her in a rather romanticized way as a positive symbol of creolization (Hoetink 1958:152; Römer 1995). She was the person who transferred Afrocuraçaoan culture as well as the Papiamentu language to "her" white children, through the milk in her breasts and the songs she sang them to dry their tears. Römer also depicts her as a figure of authority, as someone who was able to direct her white bosses (Römer 1995). In his descriptions, the 
yaya does not appear as a threatening influence, one that erodes the boundaries between black and white.

Also in Martinus' work both the concubine and the yaya or nursemaid were considered important vectors for the transmission of Papiamentu and Afrocuraçaoan culture to young white Curaçaoans (Martinus 1997). Elite white Curaçaoans that were raised with the Yu'i Kòrsou ideology (see below) commonly talk with great nostalgia about their yaya as "their black mother." To many she was the woman who loved them even more than their white birth mothers, and who nurtured them into adulthood.

Martinus' perception is however dangerously one-sided: the accounts of the women that worked these jobs are not included. Returning to Stoler's Carnal Knowledge and Imperial Power we see that, much like white elite Curaçaoan memories, the accounts of the Dutch colonials in Indonesia "are filled with tender anecdotes and demonstrations of affection, loyalty, and mutual recognition" (Stoler 2002:173). But as Stoler relays, the stories of the female domestic servants are structurally untold - they are silenced accounts of hegemonic tresspassings. This silence, she argues, is deeply embedded in a "gendered local script for colonial service: the tale of the sexually exploited and morally debased female domestic" (Stoler 2002:180). Dutch perception of the domestic servants could easily shift from a nurturing presence to a sexually disruptive threat to the marital bed (Stoler 2002:180). The fear over this stigma, which could end their livelihood, concealed the abuse that servants endured from their Dutch employers (Stoler 2002:180,181). As was the case with the sexual violence directed at Afrocuraçaoan women, in Stoler's memory work she too finds that this violence is stored, and navigated, in silence. This silence is oppressive: it preserves the dominant position of the white 
colonials. But, I argue, it can simultaneously be seen as a deliberate act of self-protection (see Sheriff 2000), as a way to navigate and diminish the impact of violence directed at non-white women. Speaking up would severely damage the woman's reputation, and to all likelihood result in the end of her employment. Her silence may not end the abuse, and therefore has a dimension of complicity; nonetheless it is also an expression of subaltern agency.

In Curaçaoan academic literature, sociologist Ieteke Witteveen is one of the few critical voices that questions this white colonial memory work of the yaya as a "onesided, romanticized image of an older woman who effaces herself”' (Witteveen 2006:33). She does raise the critique that there was absolutely no equality between this black woman and the white people she worked for, or between the amicable slave and his white childhood friend (Witteveen 2006). But as Stoler emphasized, colonial power penetrated all dimensions of the relationship between colonizer and colonized, and in this case between slave owner and his children's wet nurse.

Still, in these unequal and often abusive interrelations, africanization left a visible imprint on Curaçao's culture in lore, music, dance and other art forms, and in beliefs in the supernatural and healing practices (Hoetink 1958:144-147, Römer 1981, 1998). The island's lore is among others characterized by a strong presence of Ananzi or Kompa $N a n z i^{34}$, the trickster spider that has his origins in Ghana, West Africa (Römer 1981:73, see also Allen 2012). In Curaçao too Kompa Nanzi, who is loved by black and white alike, always schemes his way out of difficult situations, while ridiculing his superiors.

\footnotetext{
${ }^{34}$ Kompa is short for Kompader, the Papiamento word for "friend" or "companion."
} 
The dominant musical and dance styles on the island also have strong African influences (Hoetink 1958:140; Römer 1981, 1998; Rosalia 1997), be it in the syncopated rhythms and instrumentation of the Curaçaoan waltz, which clearly diverges from its European predecessor, or the complex polyrhythmic tambu and its West African instrumentation, and the feet stomping and hip gyrating couple's dance. Also there is an abundance of songs, rhymes and proverbs that are deeply rooted in the Afrocuraçaoan experiences of racial inequality and slavery.

Language was another a very important space of creolization. Linguists Eva Eckkrammer writes: "Given the fact that the two most prestigious social groups lack a common language, the emerging Creole language—-based on an Afro-Portuguese Pidgin (or Creole, cf.2.2) spoken by the black population and fully established around 1700-is quickly adopted" (2007:75). In the $18^{\text {th }}$ century Papiamentu developed into "the chief medium of every day communication" (Eckkrammer 2003:99-100). It was spoken by blacks and whites, and people of all other racial and ethnic backgrounds (See also Fouse 2002:66).

There are various theories about the origins of Papiamentu, which is an Iberianbased instead of Dutch-based creole language. The polygenesis theory claims that the language developed in the Caribbean, in the contact between the Caiquetío population and the Spaniards (Martinus 1997). The monogenesis theory, on the other hand, suggests that "all creole languages derive from a West African Pidgin Portuguese that was spoken in and around Portuguese forts and trading settlements along the West African coast from the $15^{\text {th }}$ to the $18^{\text {th }}$ century" (Fouse 2002:89). The latter theory suggests that an early version of Papiamentu was developed to facilitate the slave trade. Martinus argues that 
the language, mainly composed of Portuguese and West-African elements, was used to facilitate easier communication amongst the European and African slave traders, but also to indoctrinate or "ladinize" 35 the captivated Africans into European culture (Martinus 1997:126). This ladinization ${ }^{36}$, Martinus argues, was grounded on the baptizing of the captives, which was mandated by the Catholic Church. For every baptized captive the Church collected baptism tax (Martinus 1997:127). Furthermore, while awaiting transportation in the European forts on the West African coasts, something that could take months, slaves were taught all sorts of skills, such as carpentry, masonry, and blacksmithing, in order to raise their worth (Martinus 1997:126). Since the captives often had different native languages and could not communicate with one another easily, they used that early version of Papiamentu. This Afro-Portuguese Pidgin was also the language the traders used on the ships and in Curaçao (Martinus 1997). Martinus argues that in Curaçao, then, this West African Portuguese Pidgin was partially relexified; a part of the lexicon was replaced with Dutch and Spanish words, without changing the grammatical structure of the Afro-Portuguese Pidgin (Martinus 1997:8).

The Papiamentu that developed on the island was thus shared by the racially stratified population. But Papiamentu also had a gatekeeping function. The Dutch attitude

\footnotetext{
${ }^{35}$ Martinus uses the word "ladinize" and "ladinization" rather than latinization, like Hoetink. Martinus uses Portuguese sources, which use a slightly different spelling of the word.

${ }^{36}$ Martinus borrows the notion of "ladinization" from Carreira (1969:118-119, in Martinus 1997:126. As Companhias Pombalinas de Navegaçao, Comércio e Tráfico de Escravos entre a Costa Africana e o Nordeste Brasileiro. Porto: Imprensa Portuguesa). Here too it referred to cultural influence by the Southern European colonizers, and in particular to the indoctrination of African captives into the religious traditions and the language of the Portuguese slave traders and missionaries. Hoetink also speaks of "latinization," to refer to the influence of Southern European people, those speaking Latin based languages - in the case of Curaçao the Portuguese Jews - on the Dutch as well as the Afrodescendant people in Curaçao (Hoetink 1958: 45).
} 
of excluding the Portuguese Jews from Dutch language and religion also pertained to the Afrodescendant population (Fouse 2007:68). Even though Rupert argues that especially in the city Afrocuraçaoans often had a basic understanding of the European languages (2012:137), until the $20^{\text {th }}$ century only white children would be officially educated in European languages (Fouse 2007), which were considered symbols of refinement and white superiority. Since Papiamentu was spoken by the Dutch, the Portuguese and the Afrocuraçaoan population, there was no need to instruct Afrocuraçaoans in Dutch or Portuguese. Even though many Afrocuraçaoans did learn these European languages, officially they remained closed off to the black population. Papiamentu thus bridged the racial divide while also maintaining it.

\section{Race-Based Marginalization and Exclusion}

Notwithstanding hybridization, miscegenation and creolization, during the colonial era the Afrodescendant population, slave or freed, remained segregated at the bottom of social hierarchy. Racist ideology, as I argued previously, works to justify this hierarchy. Racism should be seen as a "structure of knowledge and representations" that aims to naturalize the socio-economic and political order. It is maintained, among others, through gatekeeping mechanisms (Lee 2004), which serve to shield privileges of the white elite from claims of the non-white masses.

As was the case elsewhere in the Caribbean, Curaçaoan slaves had very limited rights: they were perceived as property, not citizens. There were laws that protected them, but these were rarely reinforced (Paula 1967; see also Allen 2007; Klooster 1994). In Curaçao, slaves were perhaps somewhat freer in their comings and goings than in large- 
scale plantation settings. They were often contracted out, and some had their own houses in separate locations from their owners, or a small side business or a garden of their own where they grew food (Allen 2007:85-86; see also Rupert 2012). But in the end the enslaved population was economically dependent on the slave owners for their livelihood, housing arrangements and general spatial mobility, especially since the dry climate of the island made it difficult to obtain much revenue from agricultural activities. Phenotypically, legally, and economically enslaved Afrocuraçaoans remained a separate societal category, as was common throughout the colonial world at the time.

For the mulatto population things were somewhat different than for the darker skinned population. Mulattoes were sometimes manumitted, and their white fathers might give them educations, jobs and even property. This was common throughout the colonial realm. Curaçaoan sociologist Alejandro Paula, who writes specifically about these black and white relations during the colonial era (1967), argues that it was in part through this parental acknowledgement, but predominantly because of the lighter skin tone that mulattoes were perceived as different from blacks (Paula 1967:30-31, see also Allen 2007:73-74). Even though these privileges were by no means given to all mixed race children, their lighter phenotype entailed increased privileges in society at large. Over time the mulatto group did develop into a new socio-economic class, positioned in between the dark skinned enslaved and free population, and the white elites (Paula 1967:30-31). Allen writes about the slavery era (1635-1863):

With the increase in the number of colored people, one's skin became the deciding factor for social mobility. Legal discrimination was introduced. Hair 
texture and the degree of one's skin pigmentation became important markers of identity (Allen 2007:73).

Allen and Paula describe an elaborate ranking system that existed within the black population at large, and that was both fed by, and perpetuated through, the privileges white people attributed to those of lighter skin. These ranks, Allen argues, had started with those being born on the island being considered superior to people who had newly arrived from Africa (Allen 2007:73); something that was common in the Americas at the time. Lighter skin tone added further to this social stratification.

"It was in particular among the group of mixed racial descent, hence the group of "mulattoes" or "coloreds," that an elaborate hierarchy existed regarding the amount of the negroid part in everyone's descent" (Hoetink 1958: 81).

Eventually this separation of mulattos from blacks would become sanctioned by colonial law (Paula 1967:31; see also Stoler 2002), which reinforced the color hierarchy ${ }^{37}$. The colonial government also began to distinguish between the two groups on the basis of somatic appearance when making "administrative and military classifications" (Paula 1967:31), yet another a gatekeeping practice:

Such classification would serve as one more distinctive factor between the Whites and the Negroes. The establishment of a clear distance between the Negroes and the Mulattoes could only favor the "respect and due reverence" of the Negro for his white master (Paula 1967:31).

\footnotetext{
37 The literature used does not make explicit, however, on what precise basis this distinction between mulatto and darker skinned black was established, whether this based on phenotype - and if so, by what criteria was phenotype "measured" — or on other criteria.
} 
During the slavery era the mulatto group eagerly accepted this superiority and exerted racist behaviors towards their darker skinned counterparts: white supremacy had a deep seat in peoples' consciousness. This group posed a threat to the white elites in a way that the darker skinned Curaçaoans did not. Stoler describes a similar tension in colonial Indonesia. Miscegenation confounded the once clear and physically visible markers of Europeanness, which entailed the risk of non-white people gaining access to this carefully protected European space, and to the privilege and power that came with it. "Conceived as a source of subversion, it was seen as a threat to white prestige, and embodiment of European degeneration and moral decay" (Stoler 2002:80). Stoler uses the notion of "interior frontiers," which was coined by German philosopher Johan Gottlieb Fichte. Rather then expecting the enemy of the nation at exterior frontiers, it suggests that through miscegenation white ranks would be penetrated from the inside out (Stoler 2002:80).

In Curaçao, mulatto people certainly had more access to European culture- "the source of civilization"- then their dark skinned counterparts. On occasion, the mulatto population was able to become Protestant, something that was impossible for the darker skinned population. We already saw briefly that Afrocuraçaoans were not welcomed into European culture. European culture, language and religion were the landmark of any kind of social status (Hoetink 1958; Oostindie 2000). Dutch slave owners believed that it was dangerous to educate slaves and to allow them to congregate, which is why the Protestants not only did not instigate missionary activities, but initially also refused Spanish Missionaries to baptize and educate slaves. Consequently, slaves were not baptized until the end of the eighteenth century (Allen 2007; Hoetink 1958; Klooster 
1994; Paula 1967). Naturally, the Afrodescendant population developed their own spiritual and religious practices, which to a large extent centered on the drumming tradition of the tambú. The work of Rose Mary Allen (2007), and especially René Rosalia (1997) illustrates how Afrocuraçaoan religion and spirituality was fiercely oppressed by the plantation owners, the Catholic Church, and the State, and the many ways in which Afrocuraçaoans challenged and resisted this white dominance.

The colonial government did allow some mulattos to be baptized as Protestants, but reluctantly so. The Protestant Dutch had a great disdain for the Catholics, Hoetink writes $(1958: 109,110)$. This is why, should any religion be administered to people of African descent, the work befell to the zealous Catholic missionaries. In the early days of the colony the colonial government however greatly restricted Catholic priests, who were by and large of Spanish origin (Klooster 1994: 291-292. See also: Allen 2007:93), and therefore seen as untrustworthy. Klooster argues that the Dutch West India Company was in fact barely aware of these Catholic activities (1994:291). It would take until 1824 before the Catholic presence significantly increased in scale. In the $19^{\text {th }}$ and $20^{\text {th }}$ century large numbers of Dutch Catholic clergy came to the island, where they would play a key role in the indoctrination of Afrocuraçaoans into the norms of white supremacy.

\section{Catholic Civilizing Mission (1824-1915)}

This Catholic presence expanded at a time when the freed blacks had outnumbered enslaved people (Klooster 1994:288, see also Broek 2006), and had begun to pose a considerable threat to colonial dominance. Hoetink argues that the mulatto and freedmen population mimicked the behaviors of the white elites. Because of this "master behavioral 
pattern" (Hoetink 1958:125), as he calls it, blacks denounced the role of subjection and obedience that was expected of them, and instead acted with superiority, ambition, and pride. Through this behavior they challenged white supremacy. Consequently, Klooster writes that this large free black population caused great worry among the white elites over their struggle to govern this "proud and rowdy lot," in addition to their deep fear for slave revolts (1994:290).

Because of the various ways in which Afrocuraçaoans could earn money, which was unlikely prospect for field slaves on larger plantations in the region, it was fairly easy for Curaçaoan slaves to attain manumission, more so than in other colonies (Rupert 2012:145). Enslaved people often manumitted themselves: by the 1840s freedmen already outnumbered slaves (Allen 2007:66; see also Klooster 1994). Allen argues that especially slaves that had artisan skills were able to make money to manumit themselves or their loved ones (2007:89; see also Klooster 1994). Slave owners, the Jewish ones in particular, also manumitted slaves for various reasons. Sometimes they freed people for humanitarian reasons, especially the slaves that they favored, such as their Afrodescendant children (Allen 2007:89-90; Hoetink 1958:111). But slave owners also manumitted slaves that were sick and old and thus no longer profitable, or when they themselves faced financial struggles and could not afford to feed extra mouths. Allen writes:

The masters were not forced by law to support their manumitted slaves, as was the case in the British Caribbean. Thus manumission did not necessarily imply opportunity and benefit for everyone (Allen 2007:90). 
Goslinga (1956), Hoetink (1961, 1973), Paula (1967), Römer (1979) all claim that consequently, the freedman's status held no particular privilege or opportunity. Still, those who had special skills could do well for themselves. Many freedmen moved to Willemstad, (1994:286), where they found employment in the city and around the harbor. The small and dry plantations, unfit to yield significant profits, did not offer much work for the large Afrocuraçaoan population.

At the beginning of the $19^{\text {th }}$ century the Dutch colonial government allowed the Dutch Catholic Church to start an elaborate mission program in Curaçao, specifically directed at the Afrocuraçaoan population. Curaçao's elites were afraid of violent uprisings, and as Dutch sociologist and literary scholar Aart Broek contends, they collaborated with the Catholic Church to avert this threat for the safeguard of the colony's wellbeing (Broek 2006:12). Under the guise of humanitarian care, the Church would become one of the island's new institutions working for the reproduction of the racial status quo, and indoctrinating the island population even further into the ideology of white supremacy (Allen 1992, 2007, 2014). Dutch Catholic missionaries transformed many aspects of the island's landscape: they built churches, established villages, and set up education and health care (Allen 2007; Broek 2006; Hoetink 1958). It was not only colonial law that legitimized the racist ideology that had been firmly established over the course of the previous two centuries; now God Himself would inculcate and validate the message (see Hall 2002). 
During the preceding two hundred years a segmented society had developed, with a population that was subdivided into four main categories ${ }^{38}$ according to race/ethnicity: the white Dutch Protestants, the white Portuguese Jews, the mulattos, and the darker skinned Afrocuraçaoans. As discussed, in many ways these categories remained separate, surrounded by clear boundaries that were premised on race, and exerted through demography, religion, language and labor. Thus, by the early $19^{\text {th }}$ century Curaçao this racist structure, which centered on what Hoetink calls a "somatic norm image" (Hoetink 1958), was securely in place and supported by a legal structure that separated whites from blacks, and that gave to mulattos - freed and enslaved — certain privileges that were not available to blacks.

In the official colonial acts too, there was a clear distinction between whites and blacks: the former were citizens, whose rights and privileges were well looked after. The latter were not (Paula 1967:28). In the colonial act of 1741 slaves were not allowed to congregate, not even for weddings or funerals, at the risk of severe punishment. The colonial act of 1820 forbade slave marriage (Paula 1967:34). The mulatto population, however, was less restricted by such sanctions. As previously discussed, at the turn of the $19^{\text {th }}$ century the colonial government started to classify mulatto's and darker skinned Afrocuraçaoans differently (Paula 1967:31), and the privileges that mulattos received increased. This further reinforced the color hierarchy.

Spanish priests from the South American mainland had been operating on the island in very modest numbers since the mid $17^{\text {th }}$ century, in spite of resistance from

\footnotetext{
${ }^{38}$ During the colonial era people from other ethnic backgrounds had moved to the island and carved out a place for themselves in Curaçao's society (Hoetink 1958; Rupert 2012), but their numbers remained small compared to these main segments.
} 
Curaçao's colonial government. The enslaved and free black and mulatto people, who had not been initiated into the Protestant or Jewish faith and who were discouraged to practice their own religion, had however shown great interest in the Catholic faith that did welcome them (Klooster 1994:291). Initially the Dutch West India Company had not paid much attention to this development (Klooster 1994:291), but when by the mid $18^{\text {th }}$ century virtually the whole Afrocuraçaoan population was Catholic the colonial administration slowly began to perceive the large Catholic congregations of Afrocuraçaoans as a threat, while at the same time recognizing the religion's potential to exercise control over this group (Klooster 1994:291, 292).

The early priests from the mainland laid the groundwork for the Dutch Catholic missionaries who arrived in the island in the 1820s, led by Mgr. Niewindt. Niewindt's personal objective was to "civilize" the Afrocuraçaoan population (Allen 2007:94), and to instill in these "poor black souls" the virtues of "white culture"- the epitome of civilization - while depicting the African continent as inherently devoid of any sophistication and refinement (Allen 2007:94). The Dutch missionaries labored industriously to build schools, hospitals, churches, parishes and villages (Allen 2007; Broek 2006; Hoetink 1958). In only four decades the Catholic Church arose to great power:

Even though the colonial government dealt with issues that were related to citizenship in its attempt of eradicating what it deemed as 'improper' behavior by the former enslaved, it was less present in engineering collective identities and belonging among the former enslaved than was the Church. At the time of emancipation, the Roman Catholic Church was the primary institution exercising 
authority and control over the lives of African descendent Curaçaoans (Allen 2014:47).

Initially keeping Afrocuraçaoans outside of "European civilization" had been a major part of the gatekeeping efforts of the white Protestant and Jewish elites (see Lee 2004). Now this European civilization was used to further indoctrinate the Afrocuraçaoan population. "The civilization work of Niewindt was aimed at shaping the slave, so he would accept submissiveness to his master as his moral duty" (Allen 1992:19): it was thus a "deliberate strategy" (Allen 1992:19). White European religion was put at the service of the imposition and naturalization of the racist social order. The goal was to generate a healthy, manageable, docile and well-organized population ${ }^{39}$.

Consequently, the Church waged war on anything African (Allen 1992:22, Rosalia 1997), the tambú in particular (Rosalia 1997). To this day people see this tradition as a way through which to connect to their ancestors and even to the African motherland. Playing the drum is considered a way of praying, a way to find strength and solace (Rosalia 1997). But as of old the tambú songs have also been a way to critique society, be it a bothersome neighbor, an unruly wife, a rigid pastor, or the repressive actions of the slave owners or shons ${ }^{40}$ (Rosalia 1997). Consequently, the tambú was fiercely repressed, especially when the power of the Church expanded. Rosalia describes avidly how the shons, the police and the missionaries would dispel such gatherings

\footnotetext{
${ }^{39}$ The colonial government had initially not been convinced of the usefulness of Catholicism as a means of control. But when the State witnessed the success Niewindt had with his civilization mission it initiated a much more intense collaboration (Allen 2007:94).

40 "Shon" translates as sir or mister. It is a term of respect that signifies a person with a high social status. The notion is often used to refer to the white elites and their superior economic status, especially vis-à-vis slaves. However, shon is also used to refer to a respected black person, such as an elder or someone with a specific kind of wisdom, regardless of whether this person has a high economic status or not.
} 
whenever they could, punishing the tambú players and dancers if they could catch them, and destroying their instruments. In spite of ample resistance ${ }^{41}$, physical violence, and legal and religious sanctions became the three pillars that instilled fear in Afrocuraçaoan people for practicing their tradition (Rosalia 1997) ${ }^{42}$.

Both Allen (2007) and Rosalia (1997) illustrate that in spite of this reign of terror the Afrocuraçaoan population resisted this oppression of Afrocuraçaoan culture and beliefs. As a result tambú, seú, and many other Afrocuraçaoan beliefs, practices and cultural expressions survived colonial oppression and still exist today. In fact, for centuries they have fuelled Curaçao's black counter-hegemonic identities (Allen 2007; Rosalia 1997), which amounted to several slave revolts, among which the famous slave revolt of 1795, and the violent revolt of 1969, but also the post 1969-revolt developments of black empowerment and "antilleanization." Still, the Church was fairly successful in its oppression of Afrocuraçaoan culture: many people feared the lei di pastor or "law of the priest" (Allen 2007:170, Rosalia 1997:202), and the wrath of God that would be unleashed upon them if they got involved in 'heathen' practices. Catholicism offered a way to gain some access to "white culture," and with that to some upward social mobility

\footnotetext{
${ }^{41}$ See Rosalia's dissertation (1997) for copious descriptions.

${ }^{42}$ The sanctions on performing the tambú were harsh. The shons could punish the players physically, through beatings and whippings, or through a cut in their rations. After 1863, when slavery was abolished, many former slaves rented small bits of land from the shons through the paga-tera or share cropping system. This kept people trapped in a strong dependency on the landowners (Allen 2007). When resisting the ban on the tambú people risked loosing their right to these lands and to become homeless and jobless (Rosalia 1997). The police arrested people for playing, singing and dancing tambú, and destroyed the drums. But the punishments by the priests were equally feared. The missionaries initiated violent raids to dismiss the gatherings and destroy the instruments, and preached that the tambú was the devil's work. They threatened the practitioners with excommunication and no longer being allowed to confess and receiving the sacraments. There was even a corner outside of the cemetery's walls where the 'damned' people would be buried (Rosalia 1997:206).
} 
(Allen 2007, 2014; Hoetink 1958:84), which gave it significant appeal to many Afrocuraçaoans.

\section{Emancipation}

After abolition, oppression of Afrocuraçaoan culture and beliefs intensified. In the Dutch colonies, Curaçao included, slavery ended officially on July $1^{\text {st }} 1863$. Like elsewhere in the colonial world, Afrocuraçaoans exited slavery to enter a status of 'second-rate' citizens. In theory they now lived under the same laws as all other citizens, and were entitled to the same rights (Allen 2014; Römer 1978; Paula 1967). But similar to other colonized territories, in practice this meant that formerly enslaved people were perceived as a threat to the economic status quo of the colony and the safety of the white population (Allen 2014; Paula 1967), especially since by the second half of the $19^{\text {th }}$ century the Afrocuraçaoan population constituted approximately $80 \%$ of the population (Allen 2007:66) and thus far outnumbered the white population. The elites feared resistance. As a consequence Afrocuraçaoan rights to citizenship became specified in a series of new laws, which served to restrain their behaviors and specify their obligations to safeguard the well being of the nation (Allen 2014:3). And in order to enhance feelings of national belonging and patriotism among the Afrocuraçaoan group, the Catholic Church intensified its so-called "civilizing mission" of the black masses (Allen 2014:9-11).

Economically speaking abolition brought the Afrocuraçaoan population very little relief and socio-economic reform (Allen 2007, 2014). The already challenged plantation system crumbled due to continued droughts: the economy was worse than ever (Allen, 2007; Römer 1979). Afrocuraçaoans now received some basic education in the Catholic 
schools, but the old elites continued to protect their economic and societal positions and continued to restrict black people in their access to education, jobs, political power, and wealth (Allen 2007, 2014). These restrictions also applied to mulattos, though in somewhat lesser degrees. In the late $19^{\text {th }}$ century whites occupied the upper and middle classes; mulattos managed to move upwards, seeping into the middle classes; yet the formerly enslaved — the largest population segment—remained at the bottom of the social ladder $^{43}$ (Allen 2007, 2014; Römer 1978).

In the Catholic schools and churches, which were initially solely attended by black and mulatto children, the civilization mission perpetuated. Until 1935 the language of instruction was Papiamentu (Narain 1995:23, see also Broek 1994; Fouse 2002) ${ }^{44}$. Generally speaking, the white elite of the island, various missionaries included, was opposed to using a "slave language" for this civilizing process: they considered it too crude to impart any level of sophistication (Broek 2006:21). If "civilization" of the black masses was necessary, it had better be achieved by using a "refined" European language, people argued initially. And for the sake of the assimilation of the black masses into the Dutch Kingdom, it was thought best to use the Dutch language (Broek 2006:22). However, a group of late $19^{\text {th }}$ century local upper- and middle class writers supported the Church in its favoring of Papiamentu (Broek 2006:22,23). This was the language that Afrocuraçaoans knew best and communicate in comfortably. Instead, this group of white

\footnotetext{
${ }^{43}$ Afrocuraçaoans were not recompensed for the abuse and exploitation they and their ancestors had suffered. Their former owners, however, did receive "financial 'compensation' for the loss of their 'property' (Allen 2014:4).

${ }^{44}$ Through the publication of educational and religious materials the language stabilized considerably; in 1874 a first Papiamentu grammar was created, followed by a dictionary a year later (Fouse 2002).
} 
and mulatto writers started writing literature and poetry in Papiamentu, and in doing so they argued that Papiamentu was perfectly fit for expressing anything and everything. Also, it captured better the essence of the Curaçaoan multiracial population at large and its many experiences than did Dutch (Broek 1994, 2006:23).

The island's first newspaper in Papiamentu, Civilisado ${ }^{45}$, played an important role in this acceptance of Papiamentu. Launched in 1871, this newspaper was directed at the Afrocuraçaoans, and aimed to perpetuate the spread of "civilization" according to the norms of the Catholic Church (Broek 2006:13-15). However, the Afrocuraçaoan population, which was still largely illiterate, and the mulatto population, which according to Broek rather distanced itself from Afrocuraçaoan culture, did not display the expected interest: the newspaper did not last long (Broek:13-15). Even though it had been unsuccessful at indoctrinating the population of color in the civilization narrative of the Church, it still made an important contribution to the appreciation of Papiamentu by all layers of society. Civilisadó had established Papiamentu as a "civilizing" language, but also as a language that allowed for "civilized expression" (Broek 2006:15). In the first decades of the $20^{\text {th }}$ century Papiamentu developed into one of the major markers of Curaçao's culture, one that would soon be picked up by the elites and used in their search for a national identity separate from the colonial motherland: the Netherlands. More newspapers in Papiamentu and various kinds of Papiamentu literary expressions saw the light of day, extending both the notion of who were considered civilized and by what measures, as this sense of a budding Curaçaoan national uniqueness and awareness

\footnotetext{
45 Civilisadó translates as "he who has been civilized."
} 
(Broek 2006; Eckkrammer 2003). Here we see the power of the printing press as underscored by Benedict Anderson (1983/1991).

Around the turn of the century the notion of the Yu'i Kòrsou began to emerge on occasion in publications of the Catholic Church, such as an article published in the newspaper La Cruz in 1900 , dedicated to the " $20^{\text {th }}$ anniversary of the daughter of William III, Queen Wilhelmina" (Allen 2014:12). Allen analyzes numerous original documents for the promulgation of such sentiments, such as publications in the Papiamentu newspapers La Cruz and La Union, which were initiated by the Catholic Church in respectively 1900 and 1922, and were directed at the Afrocuraçaoan population (Broek 1992:121,122). In these texts she notices the frequent use of the word $y u$ or "child" to denote the formerly enslaved (Allen 2014:9). In some of these texts the notion of child explicitly refers to their status as lesser beings, compared to whites. This, Allen argues, concurs with the prevailing race-based ideologies of that era in Curaçao and across the region, which in spite of their newly acquired citizenship perceived blacks as inferior to the white population (Allen 2014:11, see also Paula 1989).

Allen's rather succinct article appears to be the only inquiry into the use of the Yu'i Kòrsou notion during this time period. I find it therefore difficult to conclude that the notion of the Yu'i Kòrsou or Child of Curaçao was indeed devised by the Catholic Church as a narrative or doctrine directly and exclusively aimed at the Afrocuraçaoan population. However, the evidence that Allen presents suggests that the frequent notion of the word "Yu" in Church propaganda did have a strong and specific reference to black people's inferior status. This could indeed indicate that this early use of the notion of the Yu'i Kòrsou was geared at instilling a sense of national belonging among 
Afrocuraçaoans, though be it as lesser humans and not as equal citizens. If a first rendition of a Yu'i Kòrsou narrative indeed developed during this time, and was widespread enough to be perceived as an ideology, it was one that propagated explicit racial inequality: as Allen argues, blacks were represented as inferior and childlike compared to whites.

This overview of the first 280 years of the colony illustrates the development of the island's overt hegemonic racial ideology of white supremacy, and its implementation through language, religion, law, education, work, citizenship status, and demography. During this era miscegenation had become a norm that had many implications. The white population reinforced colonial dominance and white supremacy through intimate, unequal, interracial relations (see Stoler 2002). This dominance was further reinforced through the colorist system or color hierarchy that developed along with miscegenation, and that ranked white over black. For people of color miscegenation was an important way to pursue and achieve social upward mobility. Still, miscegenation must not be romanticized: it always also contained the threat of violence and the exploitation of black bodies (Stoler 2002).

In spite of ample cultural and racial mixing, the racial segments remained separated. Protestants and Jews stuck to their own communities, and race-based gatekeeping mechanisms by and large kept Afrocuraçaoans_-mulattos included — from integrating into these white population segments, and especially from successfully claiming white privileges. 


\section{The Shell Era (1915-1969): Industrialization}

In 1915 the Royal Dutch Shell built an oil refinery on the island. In only two or three decades the refinery's presence changed Curaçao "from an agrarian-commercial into a modern, capitalist and industrialized society" (Broek 1992:120). Its economic impact was enormous. Curaçao's colonial government eagerly supported the refinery, meeting its needs through "facilities, legislation, protective measures, and a significant say in government policy-making" (Broek 1992:120). Not before long, the refinery became a key player in Curaçao's society. It instigated the building of various residential areas for the workers it attracted, and to this day it is a key sponsor of many social initiatives on the island (such as the arts, sports, education, and health care). One of the consequences of the installation of the refinery was Curaçao's government expansion, thanks to the revenues the refinery provided. This is when the government funded education and health care for Afrocuraçaoans developed. The Catholic Church, which had been until then providing health are and social services, saw its zone of influence dwindle (Broek 1992:120).

Large numbers of foreign laborers were drawn to the island to work in the oil industry and related industries (Dalhuizen et al 1997:82,83; Oostindie 2000; Römer 1979). For nearly three centuries, Afrocuraçaoans, now constituting the working class, had been agriculturalists. Römer contends that they did not feel inclined to work for the refinery; they rather migrated to Cuba to find an agricultural job (1979:102, see also Allen 2009b). Between 1915 and 1965, Curaçao's population more than quadrupled, growing from 33.000 people to 136.289 (Römer 1981:45). Fifteen years after the construction of the refinery, immigrants from the Netherlands, Asia, the Middle East and 
the Caribbean already constituted 28 percent of the island's population, hence adding to Curaçao's diverse society, causing profound socio-economic changes (Römer 1978:111). The refinery thus generated a massive influx of high- and low skilled immigrants that either came to work directly in the oil industry, in the administrative sector, or that sought to participate in the growing economy at large $\mathrm{e}^{46}$. This led to rapid population growth and demographic expansion, and the government struggled to modernize the provision of water, electricity, telephone, healthcare, infrastructure and education (Römer 1979:126, 142). The composition of the population changed drastically, which impacted the understanding of national identity. Many who had inhabited the island for the previous two-and-a-half centuries felt apprehension about this huge population influx.

\section{The Politicization of the Yu'i Kòrsou Identity}

This period of industrialization in Curaçao's history led to a growing xenophobic sentiment among the "older" Curaçaoan population. Hoetink claims that it was in these 'roaring' 1920s that the notion of the Yu'i Kòrsou arose again, and became part of every day vernacular. This time, it denoted the old Curaçaoan population, as to distinguish it from the newcomers (Hoetink 1962:195).

After the old Protestant elite had ruled the colony for almost 300 years, a large group of highly skilled Dutch immigrants took their place at the apex of Curaçao's socioeconomic hierarchy. The old Protestant elite had not been educated enough to keep up with the new demands put on Curaçao's industrializing and rapidly expanding society

\footnotetext{
${ }^{46}$ Libyans, Syrians, Arabs and Indians in particular moved to the island to merge into the trade sector, importing products from Asia. They were serious competition for the existing traders, who imported pricier products from Europe and the US (Römer 1979:129).
} 
(Römer 1979:142), and could not fulfill the refurbished positions of engineers, civil and public servants, and government officials (Römer 1979:145). Replaced by new Dutch colonials, the old Protestant elites slowly and grudgingly dissolved into the middle classes, contemplating ways to reclaim their dominion (Römer 1979:142).

The mulatto segment had continued to climb up to the middle class, and was now - together with Protestants, Jews, and new Dutch representatives of Shell— represented in the Colonial Council ${ }^{47}$ (Römer 1979:145), which constituted the government. The Protestant working classes had also upgraded, among other ways by contracting marriages with the impoverished Protestant elites. Much to their dismay, these elites now shared the middle class ranks with two groups that it had distinguished itself from so feverishly during the colonial era.

The dark skinned Afrocuraçaoan population, however, had not been able to move upward much, and was remained largely stuck in the working class (Römer 1979). They had to compete with the large group of immigrant laborers from other Caribbean and Latin American countries. These were often better educated and thus better suited for the lower ranking jobs at the refinery (Römer 1979:131), and therefore, initially profited more from the prosperity brought by Shell than the Afrocuraçaoan laborers.

The groups of immigrants differed from the Curaçaoan population in nationality, ethnicity, language and religion. The refinery housed the newcomers, organized by language, nationality, and socioeconomic class. For example, the immigrant laborers in

\footnotetext{
${ }^{47}$ The Colonial Council advised the Governor: he technically had the power to rule the islands singlehandedly (Römer 1979:154). Still, the Council, which after 1936 would be replaced by a parliament, governed in all of the Dutch Antilles: Aruba, Bonaire, Curaçao, Saba, Statia and St Martin. The government of the Dutch Antilles was located in Curaçao, which gave Curaçao a leg up over the other islands, and a stronger say in island affairs.
} 
camps, some of which later developed into neighborhoods or barios; executives and other high-ranking Dutch immigrants were accommodated in the fancy neighborhoods Julianadorp and Emmastad, named after two Dutch queens. This segregation of the newcomers followed the logic of the apartheid-like societal arrangements that developed during colonial times, when the Protestants and Jews developed their own neighborhoods. It contributed an even larger arrangement of "small enclaves," as Römer calls them, which initially remained culturally and spatially separate from the "local" Curaçaoan population (1979:113).

As said, the considerable threats that the large influx of immigrants posed on the economic positions of large parts of the Curaçaoan population fuelled a sentiment of nationalistic xenophobia. The social and spatial distance between the local population and the immigrants further enhanced this. Among the Protestant elites in particular, the feeling of being inferior to the "freshly arrived" Dutch elites instigated a new political awareness. On one hand, this sense of inferiority augmented the nationalistic feelings of Curaçaoans who wanted to distinguish themselves as the "true Curaçaoans" in opposition to the newcomers, who assumed nonetheless positions of power on the island (Hoetink 1962:195,196, see also Allen 2009a, Römer 1979). On the other hand it intensified the desire for autonomy and separation from the Dutch motherland that was brewing on the island under the leadership of Dr. Moises da Costa Gomes or "Doktoor" (Römer 1981:152, see also Allen 2009a, Broek 2006; Hoetink 1961; Oostindie 2000). WWII further compounded to this. For more than a decade contacts with the Netherlands were drastically reduced. Governmentally Curaçao fended for itself, and culturally the 
population became much more oriented towards North and South America (Römer 1979:151).

The first elections - which pertained to the six islands that comprised the Dutch Antilles as a whole, not just for Curaçao — were held in 1937, with the participation of Curaçao's first two viable parties: the Roman Catholic Party, led by the Church, and the Curaçaoan Political Union, led by members of the elite (Römer 1979:152). The Roman Catholic Party was the winner. What is important to note is that for these first elections the right to vote was restricted to men over 25 years of age with sufficient income and education (Paula 1989). It excluded women, and the vast majority of the black population, which predominantly belonged to the working classes: a new gatekeeping mechanism developed, again directed at the Afrodescendant population (Afrocuraçaoans and black immigrants). The white population perceived the black working class as too undeveloped to concern itself with and positively contribute to state matters. Giving the black masses suffrage would be dangerous to Dutch rule (Paula 1989:15). Consequently, only 2,5\% of Curaçao's population voted (Römer 1979:153, see also Paula 1989; Verton 1977).

As the war drew to and end two new political parties formed, which departed from strong anti-Dutch sentiments. In 1944 the Democratic Party or DP was established. It was mainly led by the old Protestant and Jewish elites, with a few mulattos in the higher ranks. The main focus of the DP was to reclaim the privileges of the white elites and the mulatto middle class vis-à-vis the newcomers (Allen 2009a; Broek 1994; Hoetink 
1962; Römer 1979). In 1948 “Doktoor” Da Costa Gomes, ${ }^{48}$ a well-educated, light skinned Afrocuraçaoan, founded the National People's Party (Nationale Volkspartij or NVP), which emerged out of the Catholic Party. Da Costa Gomes had played a central role in the Catholic Party, and now led the NVP.

In the DP, which until the 1969 revolt would remain the leading party, Protestants, Jews and mulattos fought side by side to achieve autonomy and diminish Dutch colonial dominance (Paula 1989), and to contest the power of the new Dutch immigrants, whom they called Makambas (Allen 2009a). They sought support from the black lower classes - the largest population segment on the island - that were deeply dismayed over the lack of improvement of their social position after emancipation (Römer 1979: 156, see also Oostindie 1999a, 1999b). It thus fought for the restoration and perpetuation of the old race and class based structure of white, mulatto and black, something that diametrically opposed the unity that the party allegedly advocated.

The NVP had similar interests, be it that they were less focused on the interests of the white Protestant elites, and more on interests of the Catholic Church. Though slightly different in orientation, the NVP also fought for autonomy, and for the preservation of the middle- and upper class interests, it too had a light skinned top, and a large black following. Nonetheless, the DP and the NVP were avid opponents, and fought each other tooth and claw (Hoetink 1962).

\footnotetext{
${ }^{48}$ Moises Da Costa Gomez was a mulatto from a well off family. Originally he was a lawyer, and a member of the Catholic Party. But dissatisfied with the party's program he initiated the National People's party (NVP). In 1951 he became the first prime minister of Curaçao, and negotiated autonomy and general suffrage.
} 
The notion of the Yu'i Kòrsou had already begun to surface in the 1920s, Hoetink argues, and as said referred to the black and white population segments of the old, colonial island society (Hoetink 1962:195). In the 1940s the DP in particular, but also the NVP, began to politicize the idea of an alleged unity as a way to gather sufficient backing from the black masses to achieve its goals: to protect the rights and the needs of the "old" Curaçaoan population—black and white alike—from the newcomers (Hoetink 1962:196; Römer 1979:155-156). Especially through propaganda, published in for example the DP's party paper "Democraat", the Yu'i Kòrsou notion became a narrative that was disseminated nation wide (Römer 1979:155).

Propelled by the political propaganda of the DP, this was the first time in the history of the island that such a unity in diversity was imagined and proclaimed (Hoetink 1962; Römer 1979). Even though, as we will see, actual protection of the interests and improvement of the livelihood of the Afrocuraçaoan population would be limited, during the industrial era there is an increased acknowledgement of this group as a legitimate part of the nation. This shows for example in the acceptance of general suffrage in 1948 (Paula 1989:27), which was predated by suffrage for women in 1944 (Paula 1989:17).

Following what happened in a great many national contexts in Latin America and the Caribbean, the notion of the Yu'i Kòrsou came to celebrate ethnic and racial diversity as the core symbol of Curaçao's national identity. Over time this developed into an ideology that enhanced national unity and strengthened patriotism towards Curaçao, as opposed to an allegiance to the colonial motherland the Netherlands. After all, the DP and NVP fought for Curaçao becoming autonomous from the Netherlands. This development was characterized by an increased appreciation of the creolized island culture as opposed 
to the Dutch culture (Hoetink 1962; Römer 1979), and by a "desire to achieve a homogenous society, with preservation of the status quo of the segments, to put it paradoxically" (Hoetink 1962:196). Curaçao's national identity formation thus turned towards an ideology of creolization, similar to other such ideologies that during that time arose across the region (Allen 2009a; Condé 1999; Hall 2003; Hintzen 2002; Palmié 2006; Price and Price 1997; Stewart 2007).

This novel nationalist perspective presupposed a social unity and a culture shared by all, and downplayed the socioeconomic and cultural inequalities that continued to characterize Curaçao’s society (Broek 1994; Römer 1979; see also Condé 1999; Hall 2003; Hintzen 2002; Palmié 2006; Price and Price 1997; Stewart 2007). Curaçao's ideology of national identity linked directly to the soil of the island. This imagery of the island's inhabitants being born from the soil, and not from flesh and blood individuals, suggests that the island births people of all color, which are all equal. A deeper interpretation of this could be that if black and white are "brethren and sistren" born from the same symbolical womb — that of Mama Korsou — then one's ancestry does not matter. Explicit references to actual racially mixed lineages, which exist in great abundance and which are key to the island's colorist system, become obsolete, and the deeply embedded, structural nature of racial inequality becomes relatively invisible — characteristics of ideologies of creolization (Condé 1999; Hintzen 2002; Price and Price 1997). This metaphor might even suggest that blacks and whites could be one without racial intermixing. I however argue that because racial inequality and white privilege are made invisibile in the metaphor, they can perpetuate freely. In the subsequent paragraphs we will see how the Yu'i Kòrsou became a trope that—at least temporarily—placed 
Curaçao's colonial racial divides out of sight, and imagined a homogeneous space to overlay a heterogeneous reality (Hintzen 2002).

\section{Creolization, Antillianization, Folklorization and the Invisibilization of Race}

In the development of a new ideology of national identity language continued to play a gatekeeping role. This time, it was deployed to single the newcomers out and mark them as foreign vis-à-vis the old island population. Since the Shell had such an impact on society, and new Dutch immigrants did not speak Papiamentu, the status of the Dutch language and culture upgraded (Broek 1994, 2006; Römer 1962; Verton 1977). The new Dutch administration deemed Papiamentu a "slave language" that should be banned, especially in education (Broek 1994, Fouse 2002). However, politicians, and also the intellectual elites, opposed the increased imposition of Dutch cultural norms and values (Broek 2006: 132,138; see also Broek 1994; Fouse 2002, Römer 1962). They argued that Curaçao had its own unique cultural style and developmental trajectory. It could not be subjected to Dutch standards and rules, nor should the new Dutch administrators be the ones to decide what is right for the island (Broek 1994). Various authors such as Verton (1977) refer to this focus on a Curaçaoan uniqueness as the first manifestations of "Antillianization."

Curaçaoan writers strove for a way to modernize that would fit the island, as opposed to simply following what had been prescribed by the Netherlands (Broek 2006:132,133). Papiamentu played a key role in the symbolic inscription of Curaçao's uniqueness. Various important poems were published in Papiamentu, such as Joseph Sickman Corsen's Atardi (1905), which means "In the afternoon" (Broek 1994). It is still 
avidly sung today as a "second" national anthem. This development of Papiamentu as a respectable national language and of a Papiamentu literature produced by the white elites and consumed by broad audiences thus supported the development of Curaçao's budding national imagination (Broek 1994, 2006; Eckkrammer 2003). This entailed an important shift in racial imagination. Even though Papiamentu had been spoken by black and white alike for centuries, it was still considered an inferior language that was associated with the negatively valued black segments of the island's population. However, in this novel "nationalizing" use of Papiamentu, Curaçao was projected a fundamentally creole nation, grounded on a national myth of as racial hybridity.

The Catholic Church added greatly to this creolization trend. The Church—which I argue must be seen as a component of the old colonial elite-feared that it would loose its influence on the black population due to rapid modernization brought about by the arrival of the Shell refinery (Broek 1992, 1994). Modernization threatened social stability and instigated "moral decay," as the Catholic Church put it: the only salvation was the pursuit of proper Catholic doctrine (Broek 1992:124, 1994, 2006; Fouse 2002). In order to safeguard both its position of power as people's sense of stability, the Church began to protect and preserve some of the Afrocuraçaoan cultural expressions and practices, in spite of the fact that these were plentiful and full of counter-hegemonic and race-aware content (Allen 2007). Papiamentu was part of this preservation process: it still was the language the Church used to reach the black masses, and to perpetuate its civilizing mission.

In particular the Priest Paul Brenneker (a white Dutchman) and various other famous clergymen recorded Curaçaoan festivities and folkloric practices, beliefs, songs, 
dances, stories and so on. It must be noted that not all priests were equally on board with the civilization mission, some, like Brenneker and also Amando Römer (a light skinned Curaçaoan), were genuinely interested in empowering the black population and preserved Afrocuraçaoan culture. Even though the Church was still very much involved in its mission to "advance" these "poor black souls" (Broek 1994:20; 2006), its actions allowed for the preservation of Afrocuraçaoan traditions such as the harvest festival Seú and Ananzi stories. Curaçaoan writers and cultural activists such as Pierre Lauffer (a light skinned Curaçaoan), and Ellis Juliana (an darker skinned Afrocuraçaoan), also worked diligently on this preservation of the old Afrocuraçaoan culture.

Because Brenneker, Juliana and Lauffer were prolific writers that published quite some of their materials, they became much more visible than the broad group of Afrocuraçaoans whose stories, poems and traditions they recorded. Consequently it appears often as if it was mainly because of the work of intellectuals like Brenneker, Juliana and Lauffer, many of whom were from the elite or middle class, that Afrocuraçaoan traditions and folklore were made into markers of Curaçaoan culture, for blacks and whites alike. This is not surprising since, as we saw, "Antillianization" was at least in part devised by the Church and the political elites in order to advance their inexplicit goals of preserving white supremacy. But Rosalia (1997) and Allen (2007) both illustrate profusely how the Afrocuraçaoan population was always actively producing, perpetuating and preserving their culture, and contesting its ongoing devaluation and oppression from the white population.

But folklorization is commonly an elite endeavor. The concept of "folklore" is commonly traced back to 1787 Germany and to the development of European 
Romanticism (Bauman 1992). In response to the many societal changes that followed industrialization and urbanization the artistic, literary and intellectual elites in $18^{\text {th }}$ century Europe began to idealize life before "modernization" (Bauman 1992), which became characterized by the idolization of the grand cultures of ancient times, of exotic peoples, and of rural life. In Curaçao too, the time when this folklorization emerged was one of great and rapid changes that combined with a longing for the old days. In $18^{\text {th }}$ century Europe, in the rather grimy living conditions of the newly developing cities people revered the assumed simplicity and purity of country life, as well as the knowledge, traditions, manners, beliefs and lore of country folk, which thus became labeled as "folklore" (Bauman 1992). National elites have ideologically exploited rural or non-modern cultural practices, which they have associated with national primordial time in narratives that circulate across society and that inform written texts, the material environment, cultural performances and so on (Bauman 1992).

Creating folklore entails a careful arrangement of practices, lore and knowledge. Some of these "cultural elements" represent the nation better than others, depending on how they portray the relations between the nation's elites and masses. Thus, the "folklorization" of such cultural elements - the extent to which they will represent the nation - is a political process in which a national ideology is constructed and represented. This ideology informs who are the nation's elites and who are the masses, how do they live, how have they always lived, and what their relations are with one another. Folklore, as an important part of nation building, freezes populations in imagined times of way back, to establish as a national hierarchy and to determine the superiority of one group over another. It thus serves to legitimize and perpetuate national hegemony. 
In the case of Curaçao, Broek argues, Afrocuraçaoan lore and practices that became labeled as folklore were stripped from "too much Africanness" (Broek 1994:23), and especially of the elements of resistance and empowerment. It took for example decades before the tambú, which to this day can be seen as the old seat of Afrocuraçaoan resistance and counter-hegemony, became a true part of this folklore (Rosalia 1997). Since the early $19^{\text {th }}$ century the Church had been tambú's nemesis, yet today a folklorized version of the tambú is part and parcel of national folkloric performances. The same goes for the seú, the harvest celebration that originally made offerings of gratitude to African gods. Nowadays renditions of these counter-hegemonic traditions are played in Church as part of the Catholic repertoire, speaking to a segment of Afrocuraçaoans that previously may not have attended mass.

Again we see the purpose behind this folklorization: keeping a grip on the populace by incorporating its cultural practices, though in an appropriated and whitewashed form. This folklorization and appropriation has been resisted against by segments of the Afrocuraçaoan population (Interview Ansano, April 6th 2016), and the tambú, seú, and other Afrocuraçaoan cultural practices continue to be practiced and performed in their original and in explicitly subversive forms, like they always have. But in my observation, the performances that take place outside of the arena of folklore, tourism, and national festivities, and those of the tambú in particular, are often still surrounded by the negative stigma of black inferiority and indecency ${ }^{49}$.

\footnotetext{
${ }^{49}$ In 2011 I conducted field research regarding the tambú in its various contemporary settings. This section is partially based on these findings.
} 


\section{Post-Industrial Curaçao (1969 - now)}

During the Shell era Curaçaoan society changed rapidly (Paula 1967; Oostindie 1999a, 1999b; Römer 1979, 1998). While the budding Yu'i Kòrsou ideology of the Shell era romanticized unity and national cohesion among the old black and white population segments, the large black working class - Curaçaoan and immigrant alike — struggled with the effects of the steep economic decline that set in as the oil price lowered on the world market. In between 1948 and 1964 Shell fired 75\% of its employees (Verton 1977:61), and unemployment rose to $20 \%$ of the island's labor force (Croese 1999:91). The government, which was mainly focused on elite and middle class interests, was not creating enough economic alternatives for the black working class (Committee 30 May 1970:82), nor did it invest in social services to support the increasing number of unemployed people (Verton 1977:63, see also (Croese 1999:91 and Schrils 2003:123). The marginalization of the black lower class, which had characterized the colonial era, still continued. There were ample tensions, laborer strikes, and conflicts between laborers and employers. On May $30^{\text {th }} 1969$ all this unrest came to a fiery upsurge. What started off as a union-led strike regarding low wages and ongoing lay-offs, became a violent revolt. Centuries of pent up emotions over colonial oppression, economic marginalization and racial inequality erupted. On that Friday, the city burned, ravaged by thousands of angry laborers. That day marked the start of a new era, in which the imagination of national identity would be redefined.

The revolt was the start of ample social reform. It is often marked as a pivotal moment in Afrocuraçaoan empowerment (Dalhuizen et al 1997). In the decades leading up to the revolt Afrocuraçaoans had become keenly aware of the discrepancy in the Yu'i 
Kòrsou ideology and accompanying discourse that promulgated unity in diversity, and their lived reality of race-based marginalization. As I will illustrate in the following section, the new rendition of the Yu'i Kòrsou ideology, which arose in the 70s, openly proclaimed Afrocuraçaoan culture as the core of the nation. In a series of national "markers" such as the flag and the new anthem the heterogeneity of Curaçao's population - this time including the expanding immigrant population—was embraced and celebrated, on the basis of the equal value of all the different cultural, ethnic and racial groups.

However, various scholars and critical voices from the civil society have questioned the depth of this reform (Broek 2006; Oostindie 1999b: Schrils 1997; Verton 1977). As of yet, a thorough analysis of how "pro-black," and more importantly, how impactful this empowerment movement really was and who were its key players, is lacking. Using primary sources such as reports, newspaper articles and advertisements, and interviews, as well as secondary sources, I try to gain some insight in how these processes developed.

In this section, I first examine why and to what extend the government shifted towards this much more explicit recognition of Afrocuraçaoan culture. In order to gauge the depth of this alleged pro-black reform I shed some light on the key players who first initiated the reform, their allegiance to the white elites and the black masses, and the reform that was indeed initiated during this time. Additionally, I discuss some of the ways in which this new rendition of Curaçao's ideology of national identity is framed and expressed, both by governmental measures and by civil society, for example through legal reform, a new anthem, the creation of a national flag, the establishment of national 
celebrations, cultural expressions, and continued folklorization ${ }^{50}$. I analyze this pro-black revolt within the theoretical frame of multiculturalism.

\section{Multiculturalism and Racelessness}

During the civil rights era the ideology of multiculturalism arose in response to emancipatory claims made by subaltern populations around the world. Even though this resistance and state responses to it developed differently in every nation, they share some important commonalities. In many nations new national identity ideologies developed, premised now on the appreciation the heterogeneity of their populations. These "statesupported politics of recognition" (Greene 2007:329) allowed governments to deflect subaltern resistance of white dominance (Hale 2002, 2005; Goldberg 2002; Rahier 2012). The explicit shift in ideology of national identity is expressed in inclusive cultural policy and constitutional reform, through adoption of laws premised on intercultural equality (Hale 2002:490), including but not limited to anti-discrimination legislation, bilingual education, and in the case of especially the indigenous populations the Americas reform in policies regarding collective property rights and land titles, and protection of indigenous heritage (see Brondo 2010; Hale 2002, 2005; Hooker 2005; Greene 2007; Rahier 2012).

The broad literature on multiculturalism in Latin America makes visible that multicultural reform creates an ideology of diversity and inclusion, but simultaneously omits and deflects actual empowerment and improvement. Alleged inclusion is

\footnotetext{
${ }^{50}$ It will be evident that in this thesis I can present only a most succinct discussion. This analysis deserves ample additional research (see appendix X).
} 
operationalized through tools that allow subaltern populations to contest their marginalization and increase their social upward mobility. But since such reform ultimately leads to a redistribution of resources and a rebalancing of power, it opposes the interests of national elites, which results in a range of —often not very visibleobstructions that impede or undermine actual reform and perpetuate marginalization (see Brondo 2010; Hale 2002, Greene 2007; Rahier 2012).

Goldberg (2002), writing about the Global North, highlights the role that the relative invisibilization of race is a necessary dimension of multiculturalism. "Racelessness" and "colorblindness," he argues, are common component of multiculturalism that further undercut reform. By denying racial inequality through arguing that it has become obsolete, it becomes harder to address it in the arenas of public debate, academic analysis, politics and policymaking. Furthermore, this relative invisibilization of race obfuscates the causal relation between past oppression and exploitation and contemporary marginalization. National historiography presents a whitewashed version of the colonial past, which features "the indomitable superiority of whites - in prestige, achievements, education, wealth, and power — not as a natural phenomenon but as historical outcome" (Goldberg 2002:212). Also, raceless or colorblind discourse explains racial inequality as being the victim's fault. Allegedly, since multicultural reform has secured equal opportunities for all, people that are disadvantaged owe their misfortune solely to themselves and their unfortunate life choices (Goldberg 2002:217). Thus, the inclusiveness and equality propagated by multicultural ideology deflects the actual address of white supremacy (Goldberg 2002; Greene 2007; Hale 2002, 2005; Rahier 2012). 


\section{Political Reform and its Key Players}

The morning of May 30, 1969, when the union leaders, Amador Nita, Anthony Godett, Stanley Brown, and Ewald Ong-A-Kwie ${ }^{51}$ started the strike, they had not envisioned that it would lead to a political upturn of the island. But a few days after the revolt the Curaçaoan government stepped down, and the governor resigned. An interim government, comprised of the old elite-focused parties that had constituted the government, took over. After the revolt that Nita, Godett and Brown established the political party Frente Obrero y Liberashon $30 \mathrm{di} \mathrm{Mei} \mathrm{(FOL)})^{52}$, Curaçao's first labor party (Oostindie 1999b, Reinders 1993). The FOL, which had not been part of the interim government, however had no clear ideology or program (Anderson and Dynes 1975:119), but in the election of December 1969 the party had earned enough votes to enter the coalition, still dominated by the parties that had ruled the island until then-the DP and the NVP in particular.

In the months between May 30th and the elections of December the interim government, pressured by the Dutch government, initiated the Committee 30 May (Oostindie 1999b:13). This was a group of young reformist intellectual professionals of different racial and class backgrounds, who had been charged to analyze the cause of the revolt, and to advice on how to proceed with remedies to the situation. It was a progressive group that sought social change, but it was not representative of the black masses, nor did it necessarily have a strong allegiance to it. The report concluded that the

\footnotetext{
${ }^{51}$ Three of the four leaders of the labor strike were of immigrant families: Anthony "Papa" Godett was of Bonerian and Statian origin, Stanley Brown's father was from the British West Indies, and Ewald Ong-AKwie came from Surinam.

${ }^{52}$ Laborer's Front and Liberation May $30^{\text {th }}$, or the Liberation Front.
} 
uprising had indeed been an unexpected outcome of a strike, rather than a premeditated and well-organized event. It furthermore acknowledged the extensive marginalization of the black masses, as well as their profound underrepresentation in the government (Committee 30 May 1970:83). The Committee also strongly advised the interim government to initiate significant socio-economic, cultural and political reform. The black population needed to be much more actively represented in the administration, among others through taking participation in the highest administrative positions, and through broad-based social reform focused on increased acceptance of Afrocuraçaoan culture. Furthermore, the report strongly advised in favor of placing Afrocuraçaoans in the highest positions in government, much like already was the case in the British Caribbean (Committee 30 May 1977:172). However, it also issued a significant warning: Nevertheless, it is precisely there that at present a radical "Black Power " movement is submerging that finds the "black faces" in high places insufficient, as long as the economic positions of power in society are still "white." Consequently the "black faces" are called the "Uncle Toms" of the "white power structure. This perception also appears to be represented in Curaçao and among youth in the Netherlands. For Curaçao we consider the objective included therein not realizable and therefore politically dangerous for the country (Committee 30 May 1970: 172, translation is mine).

The report identified the demand for a more pervasive economic reform made by civil rights movements in the British Caribbean, which contested the protection of the dominant position of the white elites, and suggests that the reform that was being made omitting in-depth, pro-black empowerment. By referring to these critical voices as 
"radical" the report dismantles such claims in the Curaçaoan context, and warns against reform of the white dominated economic base of society.

Journalist Mario Kleinmoedig explains that the immediate focus shared by the interim-government and the Committee was to restore peace on the island, through presenting a new national ideology of inclusion. The revolt had made the black population, comprised of Afrocuraçaoans and a large number of immigrants, much more aware of the power of their numbers. Fearing an intensification of subaltern claims on resources and the reformulation of the balance of power, the interim-government and the Committee advised to immediately assuage the black population. The old government and governor stepping down and calling for new elections was the first stride, which symbolized the goodwill of the white elites. The interim government appointing two black men to become governor (Ben Leito) and lieutenant governor (Otto Kibbelaar)the highest positions in the Curaçaoan administration — as the Committee had advised, was a second. The new prime minister would be selected in December. He would also be a black man.

Never before in Curaçao's history had black men occupied these prime administrative positions. At first sight, their appointment seemed like a victory for the black population, a signal that their race-based marginalization was coming to an end. However, a closer examination of the nature of their allegiance will complicate that. Critical voices argued that they were all token blacks ${ }^{53}$. These men had come from

\footnotetext{
${ }^{53} \mathrm{In}$ an interview with Oostindie regarding the revolt's aftermath Ewald Ong-A-Kwie, the Surinamese union leader of the strike that led to the revolt says: "The governor we got then, Leito, was in his heart a white man, a makamba pretu ${ }^{53}$. Everywhere token blacks were put in place, with the idea that things would be fine then." (Interview in Oostindie 1999a:92). Interviews with Mario Kleinmoedig (Interview March 17 2016) and with anthropologist Richenel Ansano (Interview April $6^{\text {th }}$ 2016) argue that many people, and
} 
working class backgrounds, so to their communities they were seen as un di nos, "one of us" (Interview Ansano April $6^{\text {th }}$ 2016). They became symbols for success and black empowerment, which indeed they were. But at the same time, they were conservative, pro-Dutch and pro-elite in their orientation, rather than in favor of pro-black emancipatory reform. This is a clear illustration of Gramsci's claim that we must never perceive elites — or any class segment—as homogenous. Allegiances always also develop across class segments, and not just within them (Gramsci 1971).

The new prime minister was Ernesto Petronia, a dark skinned, high-ranking Afrocuraçaoan businessman who lived in Aruba (Anderson and Dynes 1975:100). The Partido di Pueblo Arubano or the Aruban Patriotic Party (PPA) headed the coalition for the government of the Netherlands Antilles ${ }^{54}$. The PPA had its followers in Aruba's black working class, which like Curaçao was also made up of a lot of black immigrants. But it was not progressively pro-black or pro-reform: its focus was on Aruba's autonomy (Reinders 1993; Verton 1975). What's more, the PPA was a long-standing ally of the conservatively oriented DP. The two parties had formed the coalition of the government of the Netherlands Antilles since 1954 (Alofs 1999:164; Verton 1997:77): they had been like-minded enough to successfully govern the islands for 15 years. After the new elections these parties were again in charge of the major pro-black reform that was expected to take place in the Netherlands Antilles. The FOL had only a minority of the

particularly those that studied abroad and had immersed themselves in civil rights literature and actions, shared this perception. This is the group that the report of the Committee May 30 refers to as dangerous and radical.

${ }^{54}$ Interestingly, the light skinned 'mestizo' F. Tromp was officially listed as the head of the party (Reinders 1993), and should have become prime minister. 
seats, both in the government of the Netherlands Antilles and in the Island Council of Curaçao. In Curaçao the old elite-led parties DP and NVP remained in control (Reinders 1993).

Interestingly, in contemporary popular discourse, replicated on websites and Facebook, the FOL is often referred to as "Curaçao's first black government." In fact, in popular accounts of the post revolt era, pro-black reform or "antilleanization" is often directly attributed to or conflated with the FOL (see also Dalhuizen et al 1997). But in reality, stuck between the DP, the PPA and the NVP the FOL did not have the political space to implement such reform, nor did it have a sufficiently unified vision (Dalhuizen et al 1997; Oostindie 1999a, 1999b; Verton 1977; Reinders 1993).

The newly instated Government of the Netherlands Antilles was mostly focused on the increased autonomy for the Dutch Antilles (Reinders 1993:84; see also Verton 1975). It was mainly due to the influence of the unions that the government introduced some of the much-needed social reform for the black population, such as a new law regarding minimum wage (Interview Ansano April $6^{\text {th }}$ 2016, see also Reinders 1993:85), which protected in particular the rights of the black masses. A clear policy of pro-black reform was however not part of the new government's program.

The same held true for the administration of Curaçao's Island Council. The DP and NVP, which dominated the coalition, were not focused on strong social reform. The DP's main concern was still to restore the privileges of the old elites (Dalhuizen et al. 1997; Römer 1979). The NVP was the political machine of the Catholic Church, which had been a major instrument of hegemonizing white supremacy. Da Costa Gomez, or 'Doktoor,' organized events among black farmers and laborers at Isla to talk about "our 
black culture, our black people." Part of it was genuine, but part of it was propaganda, argues anthropologist Louis Philip Römer (Interview March $26^{\text {th }}$ 2016). The NVP played an important role in the founding of credit unions and labor unions and in improving the infrastructure between Bandabou and the city, but it also remained invested in the elites. It was a popular party, with a large Afrocuraçaoan following, but it did not pursue true social reform (Interview Louis Philip Römer March $26^{\text {th }}{ }^{2016)}$.

And the FOL's interests formed a stark contrast with the 'old guard.' Nita's ideological stance was strongly black and anti-colonial, and demanding of equal rights, equal facilities and equal pay for all citizens. He critiqued white power, privilege and opulence, especially of the new Dutch elites, and ongoing racism and the exploitation of the black masses (Nita 1952, 1954, 1958). Godett's focus was less on racial equality and more on improving the fate of the laborers and on relieving the dire poverty and exploitation they struggled with. Brown, however, wanted a social-democratic turn including a new constitution and independence, where power should be transferred from the elites to the black working classes, racism would be erased and black pride increased. The constant friction between these three men impeded actual policy making.

Then, less than a month after the government started to operate Nita-the only FOL minister in the government-suddenly died at age 47 . The official death report said he died of natural causes, but the party members claim it was poisoning (Anderson and Dynes 1975:102). Brown left the FOL soon after. In an interview he states that he pursued true reform but to his opinion the FOL was not the means to that end (Brown in Oostindie 1999a:21). Less than a year after the FOL's first flight had taken off the island council collapsed due too much conflict between the parties, and the government fell 
again (Reinders 1993:89). The political field was quickly taken over by the old parties, though with new fronts. In 1971 the DP, NVP, PPA and the $\mathrm{AVP}^{55}$ formed the coalition for the Netherlands Antilles (Reinders 1993:93). In the new elections the FOL had gotten a small amount of votes, but was explicitly kept out of the coalition by DP foreman Ronchi Isa (Reinders 1993:102).

Still, Anderson and Dynes argue that "[a]s a new political force the May Movement disrupted established political arrangements and led to the formation of new political organizations and power alignments" (1975:96). The impact of the revolt resounded throughout society, and even if the government was not actively involved with Afrocuraçaoan empowerment, pro-black reform was pursued and achieved on various levels, inspired and led by numerous groups and institutions.

In spite of the continued stronghold of the white and light skinned elites a new political party arose that would successfully implement black reform. In 1971 the Movemiento Antia Nobo (Movement New Antilles) or MAN, led by Don Martina, sprung from the ranks of the FOL. Martina was a dark skinned Curaçaoan from Bandabou, the rural part of the island. He had studied abroad and had returned a highly educated professional. It took a few years for the MAN to gain enough popularity, but in 1979 Martina became prime minister. This was the first time a black party obtained a true majority in the government. Martina actively advocated what he referred to as "antilleanization ${ }^{56}$," even though he never created a clearly outlined party ideology, or

\footnotetext{
${ }^{55}$ Arubaanse Volks Partij or Aruban People's Party.

${ }^{56}$ As of yet the notion antilleanization has not yet been operationalized, nor has the precise development of antilleanization and black emancipation, and its key players been analyzed or historiographed. It lies outside of the reach of this dissertation to fully tackle such a big task, but I do argue that this is an
} 
specified what precisely antilleanization entails. Still, Martina had a stronger ideological stance than Nita and Godett. The political agenda and ideology of national identity began to specifically center on the redefinition of the identity of the Afrocuraçaoan population (Allen 2009a:7), and on government directed pro-black socio-economic reform. MAN, often in coalition with the FOL and the NVP of the 1980s, was the most influential party behind Curaçao's black empowerment and antilleanization, argue Ansano, Kleinmoedig and Römer (Interview Ansano April 6 ${ }^{\text {th }}$ 2016; interview Kleinmoedig March 17 2016; interview Römer March 26 ${ }^{\text {th }}$ 2016).

In the beginning of the century the term "antilleanization" was used in decolonization discourse, to signify the increasing local focus in national discourse, reacting against Dutch colonialism and Dutch identity. But the notion is confusing because the root of the word, "Antillean," refers to the conglomerate of Dutch islands as contrasting to the colonial motherland. Yet, in the post-revolt setting it is not an Antillean identity that is pursued but a Curaçaoan one, and in the practice antilleanization refers specifically to the highlighting of Afrocuraçaoan identity. Richenel Ansano, an active advocate of black empowerment contends that in the 1970s and 80s antilleanization specifically entailed "mental decolonization, doing critical race work, and diminishing poverty through increased access to social upward mobility" (Interview Ansano April $6^{\text {th }}$ 2016). In popular discourse all reform that pertained to the black population was labeled antilleanization, while in fact a lot of it had no direct reference to it. 
After Martina, other politicians such as Maria Liberia-Pieters (the first femaleand black-prime minister) carried on parts of his message. In the 1990s the political climate became more conservative due to the economic and social crisis the island was struggling with. In popular discourse, such as for example presented in Dalhuizen et al. (1997:142-143) this crisis is often directly attributed to the alleged mismanagement of these black governments, without taking into account the many other factors that contributed to it. In this narrative black victory is again followed by failure. In the following decades political leaders and parties alternated between white and black, conservative and progressive again. In 2012, the new party Pueblo Soberano, which literally translates as "Sovereign People or Nation" won a majority of the votes. Its leader, Hermin Wiels, a dark skinned man from a working class background, was the most recent politician to pursue pro-black reform. However, contrary to his pro-black predecessors he actively sought in-depth reform, directed among others at relocation of resources and reformulating the economic power balance, an explicit contestation of white supremacy. His popular daily radio-show was an important platform for the dissemination of this awareness to the black masses. On May 5, 2013 he was assassinated, a day before releasing important documents that unveiled high-end corruption. The murder is still unresolved.

What becomes apparent in this discussion of the political field is that the government indeed adopted a new national ideology that proposed to recognize Afrocuraçaoan culture and population as an equal part of the nation, rather than as a figurehead that the old white elites used in order to distinguish Curaçao from the colonial motherland, as had been the case with the previous version of the Yu'i Kòrsou ideology. 
However, it appears that the majority of the key players that dominated the political field in the 47 years since the revolt were more allegiant to the white elites and their agendas, than to black empowerment. Politicians like Don Martina, Maria Liberia-Pieters, Hermin Wiels, and also René Rosalia, are the exception. Consequently, the recognition of Afrocuraçaoans seems not to be deliberately geared to pro-black reform, but more likely to deflecting further black contestation of white supremacy, while appeasing the black masses. This strongly indicates that the Yu'i Kòrsou ideology is a multiculturalism (Goldberg 2002; Greene 2007; Hale 2002, 2005; Rahier 2012).

\section{Legal Reform}

Nonetheless, as we will see in the subsequent sections the 1960s, 70s and 80s were characterized by important legal reform — another key component of multiculturalism (Brondo 2010; Hale 2002; Rahier 2012)—, which honored the new ideology that celebrated Curaçao's cultural, ethnic and racial diversity. The judicial changes was largely driven by the Netherlands, which had started to define a multicultural policy in the 1970s in response to its increasing immigrant population. By the end of the 1970s the Dutch government focused on the official recognition of cultural and ethnic diversity, intercultural equality, and equal rights for minorities (Sleegers 2007:15). As a consequence the Netherlands initiated the signing of a number of international treaties regarding human rights and anti-discrimination. International treaties, however, are signed by the Kingdom of the Netherlands, which between 1955 and 1986 was comprised 
of the Netherlands and the Netherlands Antilles. The different constituents decide when ratification will be in effect in their specific territory ${ }^{57}$.

In December of 1971 the prohibition of discrimination (including racial discrimination) became part of the Criminal Code of the Netherlands Antilles ${ }^{58}$. In 1972 The Kingdom of the Netherlands signed International Convention on the Elimination of All Forms of Racial Discrimination (CERD) ${ }^{59}$, which was ratified by the Netherlands Antilles at the same time. The Convention for the Protection of Human Rights and Fundamental Freedoms had already been ratified by the Netherlands Antilles in 1955, when the territories became autonomous. In 1979 the Kingdom of the Netherlands signed the International Covenant on Civil and Political Rights (IVBPR) and the International Covenant on Economic, Social and Cultural Rights (IVESCR), both of which were immediately ratified by the Netherlands Antilles. The Convention against Discrimination in Education had already been signed by the Kingdom in 1966, but was ratified by the Netherlands Antilles until 1986, when the islands had made the necessary reform.

However, in Curaçao these juridical tools have remained largely unused by civil society, the judicial force and the government. During my data gathering process I repeatedly noticed a deep unawareness of Curaçao's anti-discrimination legislation: some people are even unaware that racism is in fact illegal. The Ombudsman in office until

\footnotetext{
${ }^{57}$ While all constituents of the Kingdom were free to decide when they would ratify the treaties, they were all responsible for compliance with these treaties.

${ }^{58}$ Discrimination had already been prohibited by article 3 in the constitution of the Netherlands Antilles, which became operational in 1955, when the islands became autonomous. This legal reform was likely pressured by the Netherlands, as this anti-discrimination law was signed on December $25^{\text {th }} 1971$, and the Kingdom of the Netherlands signed the CERD treaty on January $9^{\text {th }} 1972$. In order to be able to sign the treaty all constituents of the Kingdom will have had to have anti-discrimination legislation in order.

${ }^{59}$ See appendix II for an overview of Curaçao's anti-discrimination legislation.
} 
2015 informed me that during the past decade they had not received cases regarding racial discrimination. In an unofficial communication the current President of the Court of Justice informed me that on rare occasions lawyers have presented cases on the grounds of racism. However, as of yet, such complaints virtually have not amounted to court cases, and thus to criminal persecution of racism. A recent report of the UN Working Group of Experts on People of African Descent corroborated these findings (UN 2015).

But also, conversations with the people working for the government and the court indicated that for decades the annual report that is demanded by the CERD on Curaçao's progress in anti-discrimination has been limited to a single paragraph in the report sent by the Kingdom. Time and time again administrators told me "The government is simply not interested in addressing racism." Even though Curaçao's anti-discrimination legislation has existed for over four decades, the population still does not have a good awareness of these legal instruments, and organizations and institutions that facilitate their use have yet to be developed (see also UN 2015). This is another unfortunate characteristic of multiculturalism: legislation designed to protect and empower subaltern population segments does not necessary translate into reform (Brondo 2010; Goldberg 2002; Greene 2007; Hale 2002, 2005; Rahier 2012).

\section{Social Reform}

In the social field, the 1970s and 1980s were also characterized by ample pro-black developments. One of the most important effects of this reform was the shattering of the centuries-long marginalization of black people on the job market. Due to the influence of 
the union's income levels and social benefits increased. After the revolt the labor unions rapidly gained power and even militancy (Anderson and Dynes 1975:111, 117). The political and commercial community had felt the threat of violence, and the unions had a very large reach. A far wider range of jobs opened up than had ever been available before (Dalhuizen et al 1997:142). Many were chosen for their qualities, and many others were chosen because it favored the image of the company as being inclusive and "multicultural." Even though the unions were more focused on socio-economic class than on racial disparity, they were a key element in the contestation of the marginalization of the predominantly Afrocuraçaoan working class, and in the increase of their social upward mobility.

Another major set of pro-black agents was the previously mentioned diverse group of Curaçaoan intellectuals that had been educated abroad, and that started to return to the island in the early 1960s. They brought back black left-wing ideas regarding social reform and decolonization. The turbulent 1960s had opened up the discussion on slavery, colonialism and racism (Allen 2009a:7; Oostindie 1999b:19), all of which added vital substance to the black empowerment movement. Many of these young intellectuals started their own initiatives to increase the recognition of Afrocuraçaoan culture and social standing.

The appreciation of Afrocuraçaoan culture and identity, and the strengthening of black people's socio-economical situation, had been a principal factor in the start of the revolt itself, and remained key to Curaçao's post-revolt reforms. Before the MAN appeared on the political stage this pro-black empowerment had already been carried by an increasing range of movements, individuals, foundations and institutions (Allen 
1996:5). Dalhuizen et al speak of a cultural "renaissance" of traditional Afrocuraçaoan artistic expressions (1997:142; see also Oostindie 1999b:28). In the arts, music, literature and theater the focus on black culture and black empowerment soared, and Papiamentu's popularity increased significantly ${ }^{60}$. People even considered making it the language of education, instead of Dutch (Dalhuizen et al 1997:123,142). Caribbean history was included in the educational curriculums, instead of just Dutch history (Oostindie 1999b:28). Also the "black is beautiful" movement that started in the US in the 1960s also took hold of Curaçao, resulting in a significant increase in the appreciation of dark skin and features (Dalhuizen et al 1997:142).

Popular culture was avidly preserved and expanded by the intellectual elites and by practitioners of these various traditions. Many believed that preserving and disseminating local culture was key to enabling the black masses to heal from the ongoing traumas of slavery (Ansano, interview April $6^{\text {th }}$ 2016). In the 1980s this was incited and facilitated by the political route of the MAN. Consequently, there was huge attention for all sorts of old and new Afrocuraçaoan traditions, such as the tumba, seú and tambú (Dalhuizen et al 1997:142). During the first part of the $20^{\text {th }}$ century, when a national ideology of creolization prevailed, there had already been a wave of folklorization, instigated by the old white and light skinned elites. This time Afrocuraçaoan and pro-black agents pursuing genuine black empowerment directed this development. Supported by the government Afrocuraçaoan culture was placed at the core of Curaçao's national culture and folklore.

\footnotetext{
60 Unfortunately there is no comprehensive overview of this important work done by pro-black agents, and the artistic products they made. This has yet to be researched and thoroughly documented. See appendix X.
} 
The appreciation of Curaçao's creole language also continued to rise. This became among others apparent in the shift towards bilingual education, another important feature of multicultural reform (van Cott 2000). In 1935, Dutch, the only official language of the island at that time, had become the exclusive language of instruction in Curaçao (Narain 1995:23). However, for the vast majority of the population, and particularly the lower class Afrocuraçaoan families, who were marginally exposed to Dutch, Dutch was a second language ${ }^{61}$. For this already marginalized group the shift towards Dutch increased their arrearage in their overall social upward mobility, starting in the early years (Narain 1995). In 1986 the Convention against Discrimination in Education was accepted in Curaçao. In 1987 Papiamentu became a course taught in all elementary schools (Narain 1995:24). Even though officially Papiamentu is taught as a second language, in the majority of both elementary and secondary schools it is used as the language of instruction, often in combination with Dutch schoolbooks.

Part of the acknowledgement of Afrocuraçaoan culture was the 1984 officialization of the Commemoration of Tula (Allen 1996), the leader of Curaçao's big slave revolt of 1795 . This was a highlight of the black empowerment movement. The colonial elites had often portrayed Tula as an insurgent and a criminal (Allen 1996:6). This negative representation had been supported and spread by the Church, and consumed by the masses (Allen 2007:75). But since the 1960s a group of people that sought to improve the oppressed state of Afrocuraçaoans decided to commemorate Tula as a hero, and to "get [him] a dignified place in the history of Curaçao" (Allen 1996:7). In

\footnotetext{
${ }^{61}$ The first language is the mother tongue, and the language used in the individual's primary social environment (such as the home). A second language is a language that is learned outside of the primary social environment, and can be the language spoken in society at large (Narain 1995:7,8).
} 
1984 the government, at that time led by the NVP, made the commemoration official.

However, the commemoration never became a big, nationwide happening, like the Dia di Bandera, or "Flag Day," which was also created by the government, and inaugurated in 1984, with the acceptance of Curaçao's first flag (Dalhuizen et al 1997:142).

Dia di Bandera is a more "inclusive" national celebration. It was deliberately geared to unite all the nation's citizens ${ }^{62}$. At the 5-year celebration of Dia di Bandera a government add in the national paper "the Amigoe" highlighted the symbolism of unification that was incorporated into the flag's design. The Curaçaoan flag has two stars, which both have five points. These five points, the article says, refer to the five continents from which Curaçao's people have come (Amigoe July 1 1989:2). Here we see an example of a national symbol through which the national ideology of cultural, ethnic and racial diversity was expressed. In the island's new anthem this emphasis on unity in diversity and the new definition of the Yu'i Kòrsou became were also made explicit.

\footnotetext{
${ }^{62}$ Dia di Bandera is a big celebration that takes place on various sites on the island, many of which are in predominantly black neighborhoods and the countryside. It takes place on July $2^{\text {nd }}$, conform the date of the first meeting of Curaçao's Island Council, and thus the first day of Curaçao's autonomy, on July 2nd 1951. Brion Square, which is the main square in the center of Otrobanda, has over the past years been one of the main locations for this celebration. Here all national festivities take place. The celebration is full of Afrocuraçaoan folkloristic performances, music, dance groups, and speeches. In stark contrast Tula's commemoration mainly takes place around his statue ${ }^{62}$, which was erected on the water's edge next to the water and electricity factory. Situated behind a strip of mangrove, the location is fully out of sight of everyday traffic. This is a "place of memory," as Ansano calls it (Interview April $6^{\text {th }}$ 2016). It is the actual site where Tula was quartered and fed to the sharks. The downside of the location is that the commemoration takes place in a very secluded area. There is no walkway or bridge that connects the location to the city center, which would be in close walking distance. No one visits it unless with a clear purpose. Until recently only people that seek a place to make out with a secret lover park their cars there. Nowadays it has been closed off to prevent such nighttime activity. Currently Tula is not commemorated in the city, but soon a new cruise ship terminal will be opened that will be called the Tula Pier. Tula's commemoration involves speeches, artistic and spiritual performances, and is organized and attended by people with a clear black emancipatory stance. There are several commemorative events around Tula, including "Ruta di Tula," or "Tula's Route." With a bus tour people can follow the route that Tula traveled during his revolt. There are performances at the different stops. The tour sells out quickly as there is only limited room.
} 
Analyzing newspaper articles of The Amigoe from after the revolt, I noticed that the notion of the Yu'i Kòrsou arose repeatedly. Mostly it referred to people of all sorts of backgrounds, including the broad range of Curaçao's numerous generations of immigrants. Even though the bulk of post revolt reform was directed at the Afrocuraçaoan population, in the reproduction of the new version of the Yu'i Kòrsou ideology the full cultural, ethnic and racial diversity of the island appears to be embraced $^{63}$. Especially in the comment section, on several occasions disagreement arose regarding who is a true Yu'i Kòrsou. This has been a debate that to this day persists in society at large. Immigrants were not true Yu'i Kòrsou, various contributors to the Amigoe's comment section argued: only black Curaçaoans were. This discussion flared up particularly in the months right before and after the creation of Curaçao's new anthem, which was officialized in 1979. The anthem should be directed at the real Yu'i Kòrsou, the Afrocuraçaoan population. The pro-black focus of the 1970s had indeed placed the Afrocuraçaoan at the center of the nation, and of the Yu'i Kòrsou identity. But the government adds in the paper, as well as the flag and the anthem, dismantle this and emphasize unity and equality instead. State-supported recognition of Afrocuraçaoans is thus flanked by their invisibilization, which dilutes and deflects too strong a subaltern claim to power. In the anthem, displayed below (Amigoe July $20^{\text {th }} 1978: 2$, underscores are mine), we see the words "unite," "united," and "union" appear three times, and cumulate into the Yu'i Kòrsou.

\footnotetext{
${ }^{63}$ Much more data is needed to fully support this claim. However, this lies outside of the scope of this study (see appendix X).
} 
Lanta nos bos ban kanta grandesa di Kòrsou; Kòrsou, isla chikitu, baranka den laman!

Kòrsou, nos ta stima bo ariba tur nashon. Bo gloria nos ta kanta di henter nos kurason.

Nos pueblo tin su lucha, ma semper nos tin fe di logra den tur tempu viktoria ku trabou!

Ban duna di nos parti p'e isla prosperá. Laga nos uni forsa p'asina triumfá.

Nos patria nos ta demonstrá onor i lealdat, meskos na e bandera union di nos nashon.

Nos bida lo ta poko pa duna nos pais, luchando uní pa libertat, amor $i$ komprenshon.

I ora nos ta leu fo'i kas nos tur ta rekordá

Kòrsou, su solo i playanan, orguyo di nos tur.

Laga nos gloria Kreador tur tempu $i$ sin fin, $k^{\prime}$ El a hasi nos digno di ta yu di Kòrsou!
Let's raise our voice and sing the grandeur of Curaçao; Curaçao, small island, a boulder in the sea!

Curaçao, we love you above all nations.

Your glory we sing with all our hearts.

Our people have their struggle but we always have our faith to accomplish always victory through labour!

Let us do our part for the island's prosperity. Let us unite forces so we can triumph.

(To) Our fatherland we demonstrate honour and loyalty, as to the flag the union of our nation.

Our lives would be little to give for our country, fighting united for liberty, love and understanding.

And when we are far from home we all recall Curaçao, its sun and beaches the pride of us all.

Let us praise our Creator always and forever, for He has made us worthy to be a child of Curaçao!

In the anthem, and in the government ads the cultural, ethnic and racial diversity of the population is assumed, but remains unspecified. This could be seen as a kind of racelessness or colorblindness - yet another characteristic of multiculturalism (Goldberg 
2002). In the definition of the Yu'i Kòrsou that is given in the 2001 governmental cultural policy plan, which is still in official use (Allen 2012b:1), the two meanings have been conflated:

A yu-di-Kòrsou is someone who lives in Curaçao or abroad, and who fits the following criteria. He/she speaks and understands Papiamentu. He/she is willing to work to advance Curaçao. He/she can declare to the world that he is a yu-diKòrsou and accepts his/her culture and history without any shame. He/she accepts and adheres to Curaçao's multicultural situation, and accepts cultural diversity. He/she does not consider cultural elements of his/her ethnic group to be Curaçao's culture, but he/she considers them as part of Curaçao's culture. He/she accepts that Afrocuraçaoan elements dominate the majority part of Curaçaoan culture (Rosalia 2001:10).

From the way the meanings of the Yu'i Kòrsou identity develop during the postrevolt era, it becomes evident that Curaçao's multicultural ideology was directed at incorporating the Afrocuraçaoan people and culture into the representation of the nation, more than the immigrants, most of whom have remained largely invisible in this national ideology. Shane Greene (2007) and Juliet Hooker (2005) argue that this is yet another part of multiculturalism: some groups are recognized by the state, made visible in the national narrative, while others are not. The immigrant presence in the ideology, though unspecified, does serve a purpose, I argue. The claim that Curaçao's population is formed by 160 different ethnic groups helps to avoid calling Curaçao a black nation, in spite of the fact that the Afrocuraçaoan population constitutes approximately $80 \%$ of the national 
population. The narrative of a highly heterogeneous nation prevents the Afrodescendant population from claiming too prominent a position on the national stage.

\section{Hegemony, Whitewashed History and Racelessness}

How has this ideology of unity in diversity been reproduced in national markers such as statues, museums, and the monumentalization of colonial European-based architecture? Examining such official and unofficial reproductions of the nation reveals the white supremacy that as Goldberg (2002) warns, underlies this allegedly inclusive ideology of multiculturalism.

In 2014, I researched all statues on the island. Drawing heavily on a study done by art historian Jennifer Smidt (1996) on these statues and when and why they were erected I was able to conclude that the vast majority of Curaçao's fifty-five statues was placed in the $60 \mathrm{~s}, 70 \mathrm{~s}$ and $80 \mathrm{~s}$. Only eleven of them (20\%) depict black people or important black events, and only four of these statues are well visible. The statue of Tula, which is Curaçao's biggest statue of a black person, is well hidden from public view. Thirty-two statues portray prominent white people or commemorative events of white society (58\%), and thirteen are of important Latin Americans such as Marcel Piar, Simon Bolivar, and Pablo Duarte ${ }^{64}$. The message that Curaçao's statues convey is that the achievements of white ${ }^{65}$ and light skinned people are far more worth commemorating and

\footnotetext{
${ }^{64}$ They were gifts from the government of Venezuela and of the Dominican Republic (Smidt 1996).

${ }^{65}$ This includes very light skinned people that are considered white by Curaçaoan standards. See appendix I for further elaboration on racial categories.
} 
celebrating than those of black Curaçaoans. There is no statue that represents Curaçao's immigrants or that reflects Curaçao’s "multicultural” society.

In 2015, I conducted a study on Curaçao's nineteen museums, with the aim to ascertain when and why they were initiated, and what messages their collections communicate with regards to race and nation building ${ }^{66}$. The vast majority of the museums opened in the $1990 \mathrm{~s}$ and the first decade of the $21^{\text {st }}$ century. Five museums focus on Curaçaoan society in general, nine museums present the heritages of the European elites, one museum centers on slavery, and four museums specifically address Afrocuraçaoan heritage. Again, immigrants are barely mentioned in these museums' permanent exhibitions, nor are they featured much, if at all, in temporary ones. The main focus of Curaçao's museums thus lies on European and African contributions and their prolific blends, with a clear emphasis on the representation of white elite achievements.

The white centered museums (Brooms 2011) make minimal mention of slavery. Their collection present a glorified white past full of cunning merchants and dapper seafarers. With regards to slavery the role of the white elites is obfuscated: they are depicted as benevolent slave traders and owners or innocent bystanders. In these museums there is no representation of black agency in Curaçao. The Afrocuraçaoan museums mostly show life of the post-emancipation and pre-industrial era: slavery is scarcely addressed. Here too there is very limited mention of the extent and intensity of slavery on Curaçao ${ }^{67}$, of Afrocuraçaoan agency and cultural contributions during

\footnotetext{
${ }^{66}$ See appendix IV for an overview of the museums.

${ }^{67}$ The Kura Hulanda Museum in Otrobanda prides itself on its extensive exhibition on slavery, yet it does not explicitly address slavery in Curaçao.
} 
colonization and the industrial and post-industrial eras. Curaçao's black past and present are severely watered down. Interviews with the curators reveal that this censure is the result of pressure from the boards of these museums, and of the Dutch funds that finance the museums. The collective message that the island's museums teaches us is that Afrocuraçaoan culture may be at the core of the ideology of national identity, but only in a watered down, non-critical, non-revolutionary manner that does not harm the integrity of the white "founders" of the island.

The same whitewashing of Curaçao's extensive history of colonial exploitation and oppression occurs in the policies regarding the island's colonial European-based architecture. Since 1997 Willemstad's inner city is part of the UNESCO list of World Heritage. Needless to say, this is the pride and joy of the island. Approximately 80 restored monumentalized edifices adorn Willemstad's old city core, to say nothing about the many other monuments such as haciendas, mansions and churches elsewhere on the island. In 1954, at the cusp of the autonomy of the Netherland's Antilles, the Monument Preservation Foundation $^{68}$, was inaugurated. It oversees the preservation and monumentalization of the Dutch- or European-based architecture of the white colonial population $^{69}$. In contrast, pre-industrial and even the pre-emancipation Afrocuraçaoan architecture is not perceived as monumental, and therefore not protected or preserved. The "Kunuku house" is the most common type of Afrocuraçaoan architecture, but there are various other building styles. There are dozens of these old Afrocuraçaoan houses

\footnotetext{
${ }^{68}$ Stichting Monumentenzorg Curaçao.

${ }^{69}$ Not all of these houses were inhabited by white people. Some of the small houses were inhabited by the free black population; others were former slave quarters, often as part of a large mansion. But the building styles of these small, monumentalized houses are European based.
} 
left, if not hundreds. Many have been restored (often without protecting the original materials and structures) by their contemporary owners, many others are dilapidated or have been demolished. The message that flows from this stark discrepancy in heritage preservation is grim: while allegedly all parts of Curaçaoan culture are equal, only colonial European-based architecture is worth preserving, monumentalizing, and showcasing in the tourist field.

Goldberg furthermore warns for the relative invisibilization of race and racial inequality that accompanies multicultural ideology. At the start of this chapter I, argued how race in absent in Curaçao's policymaking, academia, politics, and public debate. Instead, the unproblematized use of multiculturalism is widespread: it has become a buzzword in policy reports and tourism. As a consequence racial inequality persists and is because of the alleged racelessness and inclusiveness of Curaçao's national ideology uncontested. The gatekeeping mechanisms that were developed during the colonial era are still in place. This I will discuss in more detail chapter 3.

\section{United Nations Decade of People from African Descent}

A final topic that deserves mention in this chapter is a recent development in the governmental arena. In 2014 the Directorate of Foreign Relations of the Ministry of General Affairs (DFR) initiated a working group to attend to the United Nations (UN) resolution 68/237, which proclaimed the International Decade of People of African Descent (UNDPAD), from 2015 to 2024. In this resolution, the UN requests all its Member States to take action in order to diminish racism, racial discrimination, xenophobia and other forms of marginalization, exclusion and intolerance towards people 
of African descent, and to "promote respect, protection and fulfillment of all human rights and fundamental freedoms by people of African descent, as recognized in the Universal Declaration of Human Rights" (UN 2014:5). The working group, which is comprised of representatives from GO's and NGO's ${ }^{70}$, and of which I was also a part, was given the task to propose to the government a plan for the fulfillment of the UNDPAD in Curaçao.

The Kingdom of the Netherlands at large responded to the call to action by inviting a working group of UN experts to visit the Netherlands and Curaçao, in order to make an assessment of the current situation of Afrodescendant. In the Report of the Working Group of Experts on People of African Descent on its sixteenth session: Mission to the Netherlands (2015) the Working Group presents its findings and recommendations to most of which pertain to the Netherlands, and some of which are specifically directed at Curaçao. As previously mentioned, the findings of the report provide strong support for several of the findings and claims in my research.

Firstly, the Working Group expressed the concern "that racial discrimination is considered a "taboo" subject and identified a lack of understanding within the society about its manifestations" (UN 2015:4). It argued, as do I, that in spite of there being various legal instruments available to contest racial discrimination, people are largely unaware of them (UN 2015:13). Furthermore, Curaçao does not have a national human rights institution (UN 2015:6,7) that informs the population and the government, and that facilitates in the use of these instruments. Consequently, cases of racial discrimination are

\footnotetext{
70 The working group is multidisciplinary, and racially diverse with an Afrodescendant majority. It is mostly comprised of women; men are underrepresented.
} 
severely underreported (UN 2015:13). The report also draws attention to the small numbers of Afrodescendant lawyers and judges in Curaçao's court system (UN 2015:15), and encourages the government to find ways to increase their numbers.

It furthermore points to the lack of census data on race as an impeding factor in bringing to light the effects of racial discrimination (UN 2015:10), and to cut backs in funding from the Netherlands that might have been directed at combating discrimination (UN 2015:15). The Working Group expresses concern about the educational system, in which children are not able to receive "education at all levels in Papiamento" (UN 2015:21 $)^{71}$, and identifies the "historic underrepresentation of people of African descent [...] as institutional figures in Curaçao" (UN 2015:15), "few programmes and employment opportunities available specifically for youths of African descent" (UN 2015:21), and "insufficient measures to address gender-based violence" (UN 2015:21).

Partly in response to this UN report, the Curaçaoan working group drafted the Bill for the Curaçaoan Fulfillment of the United Nations Decade for People of African Descent $^{72}$ (2015). It makes a number of recommendations to the Curaçaoan government regarding the improvement of the situation of Afrodescendants in Curaçao. The full list of recommendations is presented in Appendix XI.

The recommendations regarding actual reform pertain to the increase of information on human rights and the available legal instruments, and to facilitate their

\footnotetext{
${ }^{71}$ The list of concerns and recommendation that I summarize here is not exhaustive, for the full report see the Report of the Working Group of Experts on People of African Descent on its sixteenth session. Mission to the Netherlands. 20 July 2015. A/HRC/30/56/Add.1.

72 The original title is Nota voor Curaçaose invulling van United Nations Decade for People of African Descent.
} 
use, as to increase the reporting of cases of racial discrimination. The bill proposes the initiation of a Human Rights Institute by the Ombudsman, an anti-discrimination agency, and a governmental website regarding the UNDPAD and human rights (Directorate of Foreign Affairs 2015:2). It also recommends that the mainstream rendition of Curaçao's history in educational curriculums, which presents a Eurocentric perspective, is adjusted to the experiences of Afrodescendants, and that there will be a "dissemination of information regarding discrimination, respect, equality and (self)acceptance" (Directorate of Foreign Affairs 2015:2). It also proposes to improve immigration policies to the betterment of Afrodescendant migrants, and to increase the awareness of human rights, racial discrimination, and the UNDPAD among the ministries ${ }^{73}$ (Directorate of Foreign Affairs 2015:2,3).

Early 2016, the bill was accepted by the Council of Ministers, which is a major achievement, and a clearly constructive development. So far the UNDPAD has been instrumental in a first breaking of a long institutional silence concerning race and racial discrimination in Curaçao. What is less positive is that we are well into the second year of the decade, and there has not been a public, nation wide launch of the decade, nor is there much attention for the decade in the mainstream media. The upcoming elections of October 2016 will have to give a foretaste of whether the government will indeed "dedicate itself to improve the societal, social and economic position of people of African descent" (Directorate of Foreign Relations 2015:2). Will the address of racial inequality be on the agenda's of the political parties?

73 For the full bill see appendix XI. 
This remains an important question: how much of this reform will be taken on by the government, and how much will remain the responsibility of NGO's and civil society, as has been characteristic of the past decades. And how much funding will the government make available for the numerous projects that will have to be constructed? This has been a constant theme in the meetings of the working group. NGO's proposed numerous projects, but some of the government officials in the working group indicated that—at least for now—-there is no government funding available. "We cannot simply give everyone money, it also has to be the responsibility of the NGO's and of civil society to make these changes," was an often heard reply. But there funding possibilities on the island are very limited, so unless the government ads significant resources that NGO's can draw from, the needed reform will not be easily attained. This has been a key characteristic of multiculturalism: governments advocate and initiate change but due to various obstructing mechanisms actual reform is minimal (Brondo 2010; Hale 2002, 2005; Hooker 2005; Goldberg 2002; Greene 2007; Rahier 2012).

Currently, the bill proposes that the Foundation National Archaeological Anthropological Memory Management (NAAM) - an NGO — will coordinate the International Decade for People of African Descent (UNDPAD). NAAM has for decades been a key organization in the preservation of tangible and intangible national heritage, both black and white. It plays a central role in community outreach, and hosts many celebrations of Afrocuraçaoan culture and traditions. This makes it by far one of the bestsuited Curaçaoan organizations to coordinate the UNDPAD. However, in spite of its important role to Curaçao, and of its continuous output of valuable knowledge and its ongoing community engagement, NAAM has been structurally underfunded and 
understaffed. This makes it challenging for the foundation to take on this elaborate task, and in fact threatens its current activities and objectives. Currently, governmental funding of the UNDPAD has yet to become available. This consistent lack of funding creates a deep vulnerability that we must monitor keenly, so the desired reform does not again peter out because of the mechanizations of multiculturalism.

\section{Conclusion}

In this historical chapter, I sought to make visible how the ideology of white supremacy became deeply embedded in Curaçaoan society, and perpetuated as a partially hidden constituent of the creolization and multicultural renditions of the Yu'i Kòrsou ideology of national identity. I have demonstrated that in $20^{\text {th }}$ and $21^{\text {st }}$ century Curaçao racism did not become obsolete, as many claim—-far from it.

The first part of the chapter showed how during the colonial era an ideology of explicit white supremacy developed. Through the system of slavery, race became the variable that distinguished Afrodescendants from Europeans, and that legitimized their exploitation and oppression. This was reinforced by a number of gatekeeping mechanisms, which also became embedded in race, such as religion, language, demography, and division of labor, which restricted the Afrocuraçaoan in their social upward mobility. These exclusionary measures pertained to the enslaved population, but also to freedmen and mulattos. However, over time the mulatto population gained more privileges compared to the darker skinned population, which resulted, like elsewhere in the African Diaspora, in mulattos forming a separate socioeconomic class that was positioned in between black and white. A color hierarchy developed on the island, which 
has to this day has remained a deeply internalized, continuous expression of white supremacy.

After abolition initially this explicit version of racist ideology remained. In the first part of the $20^{\text {th }}$ century, during the era of industrialization, it became hidden under the first version of the Yu'i Kòrsou ideology. In the face of rapid industrialization and large-scale immigration, the island's elites adopted an ideology of creolization, which appeared to be inclusive towards Afrocuraçaoans. However, as was the case elsewhere in the Caribbean, creolization served to unite a population that for centuries had been deliberately and violently segregated, with the aim to perpetuate the dominant position of the ruling elites and to further their goals. In Curaçao, the colonial elites lost their financial preeminence to the new Dutch immigrants, sent to run the island's rapidly modernizing and expanding society. This enhanced resentments among the old elites, who pursued political dominance and autonomy from the Netherlands. To this end, the elites needed the support of the black masses, which comprised the vast majority of the island population. The Yu'i Kòrsou ideology, though not explicitly advocating miscegenation, imagined the Curaçao as a mixed, heterogeneous nation, in which the old black and white population segments now formed a unified whole. In this imagination, Afrocuraçaoan culture became a figurehead of Curaçao's cultural uniqueness vis-à-vis the colonial motherland. But also, the attention for and appreciation of Papiamentu and folklorized forms of Afrocuraçaoan culture invited the black masses to be allegiant to the elites that had once so fiercely subjugated them.

However, this unity and equality that the Yu'i Kòrsou ideology proposed did not improve the marginalized socioeconomic position of the Afrodescendant population, 
which during the industrial era remained greatly impoverished, and had very limited possibilities for social upward mobility. White supremacy persisted. The violent labor revolt of 1969 demanded a more serious address of the dire straits that the Afrodescendant population was in. It was a wake up call for the old elites. They were still a numerical minority, and continued black dissatisfaction could result in the demise of their dominance.

After the revolt an allegedly more inclusive version of the Yu'i Kòrsou ideology of national identity developed. This new version was specifically directed at including the Afrocuraçaoan population on an equalitarian basis, but now it also included the increasing numbers of the first-, second-, and third generation immigrants, which had merged into the nation. In representations of the nation of the 1970s and ' 80 s the vast majority of the many dozens of different ethnic groups that lived on the island remained largely invisible, or better said, unspecified: the focus was on Afrocuraçaoan culture and heritage, which was again seen as the core of the nation. However, I argue that the presence of these many immigrant groups is crucial to the imagination of the nation: it avoids Curaçao being labeled a "black" nation, and deflects Afrocuraçaoan claims to increased power. In the new rendition of the Yu'i Kòrsou ideology Curaçao is imagined instead as a heterogeneous or "multicultural" ${ }^{74}$ nation, in which all inhabitants are unified and equal, regardless of their ethnic or racial origin.

But this new version of the ideology of national identity was embedded in multiculturalism. The new government that was elected after the revolt adopted a politics

\footnotetext{
${ }^{74}$ In this use multicultural refers to the island being culturally, ethnically and racially diverse, not to the oppressive dimensions of this ideological system as discussed throughout this dissertation.
} 
of strengthened recognition and inclusion of Afrocuraçaoan culture. This initiated ample pro-black reform, much of which was pursued and carried out by key agents and organizations from civil society. This greatly improved the possibilities for social upward mobility for people of African descent. Legal reform regarding labor rights, antidiscrimination legislation and bilingual education were to safeguard intercultural equality. The 1969 revolt and its aftermath caused a major break through in the severe racial oppression and marginalization that for so long had characterized the lives of the majority of the Afrodescendant population. People of color undeniable gained many more ways to move upward socially, and permeated the middle and upper classes. This was a major gain of the multicultural turn.

However, as is common in multiculturalism, from the start actual black empowerment and reform were obstructed and even omitted in various ways, especially with regards to a reformulation of the economic power balance and a relocation of eliteowned resources to the populace. The political arena became ruled by whites and blacks - although I argue that people's allegiance is more important than their phenotype or racial identity. The economic power however remained predominantly in the hands of the old — and new—white elites. Many of the race-based gatekeeping mechanisms that were previously discussed were partially, but not fully, dismantled. They are deeply institutionalized, and by many they are perceived as the natural order of things, and thus relatively invisible. As a consequence, today the impact of racial inequality remains significant, and is clearly observed in the racial/spatial ordering of the island: the working classes are predominantly black, the middle classes are mixed, and the elites have remained predominantly white. 
In this chapter I argue that ideology is an essential factor in the perpetuation of the racial status quo. Because of this alleged equality that is promulgated in the ideology's narrative, and because of the ample pro-black reform that has been instigated after the revolt, the ideology implies that racism no longer exists. This denial or invisibilization of racial inequality, especially on the part of the elites and the state, however makes the actual perpetuation of racism much harder to measure and address. Race, racism, racial marginalization and discrimination to this day remain largely outside of the focus of academia, policy making, and administration. This relative invisibility of especially institutionalized racism is another key tenet of multicultural ideology.

The chapter also illustrates how contemporary narrations of the colonial past often glorify white achievement (Goldberg 2002), while repeatedly downplaying or obscuring black achievement and narratives. The statues, museums, and the monumentalization of colonial European-based architecture by and large convey the island's persisting hegemonic racial ideology of white supremacy. In many such narrations the atrocities of colonialism are omitted, denied, trivialized and whitewashed, and the legacy of the Dutch Protestants and the Portuguese Jews is carefully preserved and admired. These hegemonic recitations are marginally contested, and often repeated: the majority of the population — white and black alike — proudly celebrates them as an important part of Curaçao's "multicultural" or ethnically heterogeneous society. While there is also a noticeable celebration of Afrocuraçaoan heritage in some of the museums and especially in Curaçao's folklore, the colonial wrongdoings often remain unchallenged, and even unmentioned. White supremacy - the bottom of the iceberg - continues to dictate the racial status quo, cloaked by an ideology of unity and equality in diversity-its top. 


\section{Chapter II}

The Intimate Dimensions of Hegemony: A Reflexive Presentation of an Intergenerational Family History

Until the lion learns to write, every story will glorify the hunter

-African Proverb

\section{Introduction}

This study seeks to deconstruct the multiple layers of Curaçao's ideology of national identity, and how they are deeply entwined with race and racism. Part of this inquiry is concerned with the ways Curaçao's hegemonic ideology of national identity pervades the minds of Curaçaoans, and how this is mechanized into national representations that produce different forms of silencing, but also evoke resistance. In this chapter, I explore how these ideologies shaped my mother's, grandmother's, and my own understandings and performances of self.

The chapter locates our personal narratives within the broader geographical context of the Dutch Empire. I give special attention to the territories of Curaçao, Surinam and the Netherlands, which have all three provided a home at one point or other to my family and me. Furthermore, following Stoler and Rahier, this second chapter zooms in on the micro-dimensions of intimacy as the everyday life mechanizations of hegemony. The trans-generational and transatlantic stories of my mother, my grandmother and myself illustrate how in our perceptions of self, and in our experiences, expectations and choices we perpetuated and thwarted ideological fragments of race and 
nation, which we brought with us across oceans, territories, and generations, impacting in that way our everyday lives.

Ann Laura Stoler argues in Carnal Knowledge and Imperial Power (2002) that intimacy is colonialism's handmaiden. When reflecting about colonial power, people often think exclusively about the economic and political dimensions of colonialism, its rules and regulations about trade and economic profit, its division of labor, and the issues of freedom, servitude, ownership, and citizenship. However, Stoler contends that the most intimate levels of the colonials' lives, and particularly their interactions with those who were colonized, were also a source of great preoccupation for colonial authorities in general. It is in the spoken and unspoken rules about who could bed and wed whom, who served who and how, and who raised who and how, that the dimensions of race and power were solidified in everyday practice. She illustrates how ideas about race and miscegenation, gender, sexuality, intimacy, power, identity and belonging are pliable, political constructs that were adaptable enough to keep both colonizers and colonized in line (Stoler 2002). In the end, colonial rules and regulations, and the sanctions and prohibitions they entailed, established the seat of imperial power and dominance (Stoler 2002).

In "The Microphysics of Colonial Power: Violence, Intimacy, and Sexuality in Belgian Colonial Literature” (2010), Jean Rahier makes a similar argument. Sex, race and power intersect, Rahier states, because "affective sentiments, emotions, joys and pains [...] marked the lives of both colonizers and colonized" (Rahier 2010:41). These constitute "the micro-dimensions of the practice of colonial power in the interactions between colonizers and colonized" (Rahier 2010:42). Following Michel Foucault's 
theorizing that power is always in circulation and in flux (Foucault 1978), Rahier argues that in order to comprehend the way power operates one must zoom in on the processes of interpersonal interactions, on the realm of the intimate, as much as on the larger social, economic, and political dimensions of the colonial order (Rahier 2010:42). He writes: Power is not only repressive, it is also productive. It takes us over and gives rise to pleasure, to particular kinds of emotions and relationships, as well as to forms of knowledge and discourses (Rahier 2010:42).

In this chapter I focus on the micro-dimensions of intimacy in the everyday life mechanizations of hegemony. I specifically explore (1) what hegemonic messages were transmitted to my grandmother, my mother and myself; (2) how these instructed us to respect the rules of the Dutch Empire, both in the Caribbean colonies we live(d) in as in the Netherlands, even as these imperial structures changed significantly over the course of our lifetimes; and (3) how we have incorporated/embraced or resisted these rules. Even though the findings that I present in this family narrative are specific to the contexts of our family and our personal lives, they do reveal larger patters that also pertain to others inhabiting the same imperial space, and present a vivid example of the complex ways in which hegemony operates.

First there is my café-au-lait or coffee and cream colored grandmother who left Surinam for Curaçao in the 1940s with her brown-skinned baby, in search of financial opportunities during Curaçao's oil boom. Then, there is the story of my black mother, who left Curaçao in an attempt to leave behind her own shame for her "African" features for the anonymity of the Netherlands. And lastly there is me, the light skinned daughter raised to pass-for-white, who moves back to the Caribbean to resolve her identity crises. 
In the process, I consequently discovered my family's silenced history of enduring internalized anti-black racism. Our stories, woven out of multiple strands of silence, connect Surinam and Curaçao to their colonizing nation: the Netherlands. They envelop multiple generations of people negotiating their colonial heritage and the politics of skincolor in a so-called "postcolonial world."

The stories I am presenting here are not fully self-ethnographic since the information about each one of the three life histories came from the person in focus, as well as from other individuals who played an important role in what I call a "reflexive presentation of an intergenerational family history." I collected these three life histories over the course of several years, during which I had many conversations with my mother, father, grandmother and my mother's siblings and cousins.

For my grandmother's story, I departed from my mother's stories, and from the few stories my grandmother shared with me in informal conversations before she passed away. Conversations with other relatives served to add depth and nuance to my grandmother's main storyline. I obtained the information about my mother's grandparents from my mother and her siblings and cousins. A family tree that my aunt had once lent me was very useful, because it helped me to find the great grandmothers and -fathers that came before, who I was able to trace back to two plantations in Surinam. This history, of our family's roots in slavery, had not been known to my generation, or to that of my mother.

The second case study tells my mother's story. I recorded in-depth conversations and interviews with her over the course of seven years. I also include the information I gathered over the course of my lifetime living and interacting with her. I have always 
been a witness of her life, the listener to her life stories, the comforter of her woes, and the receiver of her cares, her love, and her overt and silent teachings. Together with her and my father we have written her story.

Writing my own self-ethnography took me seven years, during which I have had constant conversations with both my parents, who read my numerous drafts, and provided me with ample material for reflection. I also spoke abundantly with my closest friends, my relatives, my partner, and my professors. Their feedback gave me again plentiful opportunities to reflect upon and refine my accounts and analyses of self.

\section{Silence, Hegemony, Censure, And Resistance}

One of the first things my mother said in our first interview on the importance of race in her life was: "Silence is where I hid, because I was never supposed to be born." As her painful story about her childhood unfolded, silence turned out to be its guiding motif. So before we hear her story, let us take a brief look at silence's personal and intimate dimensions within colonial and postcolonial discourses of white supremacy.

Pierre Bourdieu, writing about the sociology of power in his pivotal work Outline of A Theory of Practice (1977), describes the various ways in which ruling classes create and implement hegemony. Not only do they control the means of production, he argues, they also dominate the way the ideology of national identity is shaped. That ideology not only defines what the prototypical national identity is, it also indicates how the nation ought to function, what must be kept silent, and what should be considered normal, sensitive, unimportant or absurd (Gramsci 1971). Bourdieu argues: “The most successful ideological effects are those which have no need of words, but ask no more than a 
complicitous silence" (Bourdieu 1977:188). These "social silences," which according to Bourdieu can be both "deliberately or involuntarily complicitous" (Bourdieu 1977:188), may result from explicit strategies of the ruling class.

Silence is thus a favored tool of hegemony. In Silencing the Past: Power and the Production of History (1995) Haitian anthropologist Michel-Rolph Trouillot elaborated on discourse formation. Trouillot argued that history never revolves around the objective telling of facts but rather it entails a highly politicized play of power wherein silence is wielded like a blade. Not until we uncover the silences of the non-elites, creating a myriad of overlapping stories, can we grasp the true, complex nature of any given societal occurrence. But such "un-coveries" are discouraged by hegemony; silence serves to censor, to suppress or delete communicative material that is considered damaging to hegemonic rule by labeling it as offensive, unpleasant, harmful or sensitive (Gramsci 1971). This type of hegemonic silencing can be imposed through coercion, or on the contrary it can be voluntarily ascribed to by the masses - hegemony's "double-edged sword" (Gramsci 1971).

But as hegemony imposes and evokes censorship, there are also ways in which this hegemonic rule is resisted. Silence can be a powerful means of protection from and resistance to hegemony's effects, as James Scott illustrates in Domination and the Art of Resistance: Hidden Transcripts (1992). Scott argues that the hidden transcript is the offstage critique of and coping with the public transcript or the official discourse projected by the elites. The hidden transcript here refers to the "infrapolitics" or "lowprofile forms of resistance" (Scott 1992:19) of the oppressed, and is expressed in a multitude of ways, varying from gossip, stealing, anonymous attacks, silences and acting 
dumb to stalling, muttering, metaphors, blasphemy, and cultural expressions such as dress, songs, and folktales.

Scott argues that in the hidden transcript the limits of oppression are constantly tested, which happens to the "performances" both sides give in the public transcript. These performances are delivered for strategic reasons: the oppressor cannot openly falter, and the oppressed cannot openly resist without risking serious repercussions (Scott 1992). In the play of power both sides need to perform their correct role. For the oppressed this role involves the "credible performance of humility and deference" (Scott, 1992:10), while the oppressor is to present a "credible performance of haughtiness and mastery" (Scott 1992:10). Once the oppressed sees that the oppressor's performance falters and that his/her power is not as absolute as claimed, open resistance may follow. This can happen, among other things, through a public declaration of the hidden transcript, through some form of insubordination that passes without sufficiently restorative actions on behalf of the dominants' power. Should the oppressed be too overt in their hidden resistance, oppression and coercion may follow, making their plight worse than it initially was. Therefore, Scott claims that such more or less silent hidden transcripts need safe sites in which they can develop and live, out of earshot and sight of the oppressor. Hidden transcript cannot just be seen as a way to vent, as to take a deep breath and chug on. Hidden transcripts may or may not be acted upon, Scott argues, but they always are sites of resistance, and thus always contain a threat to the oppressors' dominance. They are the source from which open revolt flows, when it does (Scott 1992). Anthropological linguist Robin Sheriff's ethnography Dreaming Equality: Color, Race and Racism in Urban Brazil (2001) yields ample examples of both the subjugation 
and the resistance silence involves in a racialized context. Like Scott, Sheriff argues that silence should not automatically be understood as acceptance of dominant discourse (Sheriff 2001:118). Her study reveals that racism, racial prejudice and race-based discrimination are rarely discussed by the inhabitants of the shantytown or favela she studied. Her respondents explain that it makes them feel sad, angry, frustrated, hopeless, and powerless, so they rather ignore such experiences instead of having to relive painful situations. They are afraid that they will loose control if they fuel these emotions and express them openly, which would be dangerous since there is always the threat of punishment and retaliation by those who are accused of racist acts. These narratives of racism clearly reveal the imbalance of power that is inherent to racism, as well as people's continuous awareness of this imbalance and the injustice it involves. Furthermore, people may think that it was the victim's fault if they experienced racism, which makes it all the more painful. They should have known better and behaved more “appropriately" (Sheriff 2001:124). To talk openly and complain about racism would mean to acknowledge its power and thus "involve a kind of personal and collective surrender" (Sheriff 2001:75). Complicitous silence offers a way to cope with these predicaments.

And again, like Scott, Sheriff claims that through silence oppression is allowed to perpetuate freely, but that it does more than that. She argues: "The silence my informants practice is simultaneously a public form of accommodation and a private (and at the same time communal) form of resistance" (Sheriff 2001:83). Euphemism, deception, avoidance and denial are necessary means to soften the internalized oppression, the shame, and the wounds that one cannot adequately protect oneself from. But they are also ways to 
camouflage these negative impacts, making them invisible to the perpetrator, as well as to disobey. Silence is a multifaceted and multifunctional "space" that oppresses, but also protects and creates a "safe site" (Scott 1992) in which resistance grows.

Sheriff's findings fit the mold that sociologist Erving Goffman (1967) and also linguist Deborah Tannen (1985) paint about silence in its more general use. Tannen argues that "the meaning of silence in interaction, like other features of discourse, can be understood to grow out of the two overriding goals of human communication: to be connected to other people and to be separate from them" (Tannen 1985:97). Goffman (1967) respectively refers to these as presentational rituals and avoidance rituals. Presentational rituals allow individuals to be accepted by and in agreement with the social group. This kind of silence enhances the social connection that Tannen refers to. From the group's perspective this silence can both serve to comply with hegemony, as Bourdieu's "complicitous silence" does, and to collectively challenge and resist it. Avoidance rituals then refer to remaining silent out of disapproval or defiance, or as a means to attack or deflect. Here, the individual distances himself or herself from the collective. Similarly, such silence may signal that the individual disconnects from the group out of shame, hurt, or discouragement (Tannen 1985). In this case too, this interpersonal type of silence cuts across hegemonic and counter-hegemonic contexts, depending on the stance of the social group vis-à-vis hegemony. These types of silence should thus, as Tannen argues, "be measured against what is expected in that context" (1985:98).

And lastly, silence is a well-known part of individual traumatic response (Caruth 1996; Eyerman, 2001, 2013). Dissociation or avoidance behavior is a common response 
to emotional shock sustained during a very distressing physical or emotional event. In addition to numbness, a condition where the capacity to feel pain is temporarily suspended, amnesia and repression are defenses of the mind against such a violent intrusion. The victim simply forgets or denies that anything has occurred (Caruth 1996; Eyerman 2013:42). Trauma generates yet another form of silence: "involuntary forgetting," or the inability to recollect certain parts of one's memory (Caruth 1996:4).

But trauma also exists on a cultural or societal level, when a group or social segment is collectively affected by a crisis (Alexander et al. 2004; Connerton 1989; Eyerman 2001, 2013). The trauma that is experienced on the individual and collective level—a significant alteration or even loss of identity—becomes framed and expressed in a collectively shared narrative. Such a shared narrative can then constitute a new identity for its members, which as Jeffrey Alexander's theoretical model for collective trauma (2004) suggests, may either be empowering or detrimental to the collective at hand. In the case study that I address such collective trauma would refer to the injurious effects of slavery and other forms of racist exploitation and injustice, sustained by earlier generations or by contemporary exposure to racist encounters. ${ }^{75}$ For many postcolonial societies this trauma narrative is a subaltern discourse, which by default develops and exists in close dialogue with larger (national) hegemonic discourses. It can hence be expected that the tools that elites use to maintain its hegemonic discourse will impose censoring silences onto these narratives, as well as on groups at large, marginalizing them and rendering them relatively invisible (Alexander 2004; see also Stutzman 1981). But as

\footnotetext{
${ }^{75}$ Ron Eyerman $(2001 ; 2013)$ specifically writes about collective trauma and identity formation in relation to slavery and African-American identity.
} 
Sheriff's accounts on cultural censorship $(2000 ; 2001)$ highlight, we may also expect that members of subaltern groups will self-impose such silences, whether to shield themselves from violent repercussions flowing from oppression while nurturing some form of resistance, or to adhere to hegemonic discourse in search of its benefits.

Even though this theorizing is far from conclusive, it quickly becomes evident that much can be said about silence. Silence is not an empty space, and it is never quiet. It is instead full of power struggles, conflicting allegiances and meanings, opposed codes of behavior, norms, values, hopes, dreams, rituals, fears and pains. Like any bit of cultural discourse, silences are passed on from one person to another, consciously or unconsciously, as part of people's socialization into society's dominant discourses, as well as counterhegemonic discourses of resistance and protection, and society's specific traumas. This makes silence fundamental to understand social reality. As Bourdieu (1977:188-189), Sheriff (2001:127) and Trouillot (1995) argue, silence is in dire need of systematic research.

\section{Case Study 1: My Grandmother Sophie and Our Forgotten Ancestors}

My grandmother Sophie (see photo 1) was born in 1919 in Paramaribo, Surinam. She was a free-spirited girl, smart as a whip, and brimming with a creativity that only barely died when she did, at the age of 92 , smoking a cigarette and sipping her morning coffee at her sowing table. Her slender hands preferred the piano over typewriters and ledgers, her feet rather danced than carry her to run errands or hold still behind a desk. She wanted to sing, act, be on stage. But in the 1930s such things were not suitable for proper, light skinned middle class girls. Her parents wanted her to become a decent and sensible woman. Her 
father was a professional tailor. He ran a good business, sowing amongst others the uniforms of Paramaribo's police officers. With a family of six children he had the means to allow his daughters some education, but nothing extravagant. They were lucky to even receive secondary education: many young women didn't in those days. So Sophie studied bookkeeping. She learned how to count her blessings, but the fiery passion for arts and creativity she carried inside remained a burden for her all throughout her life.

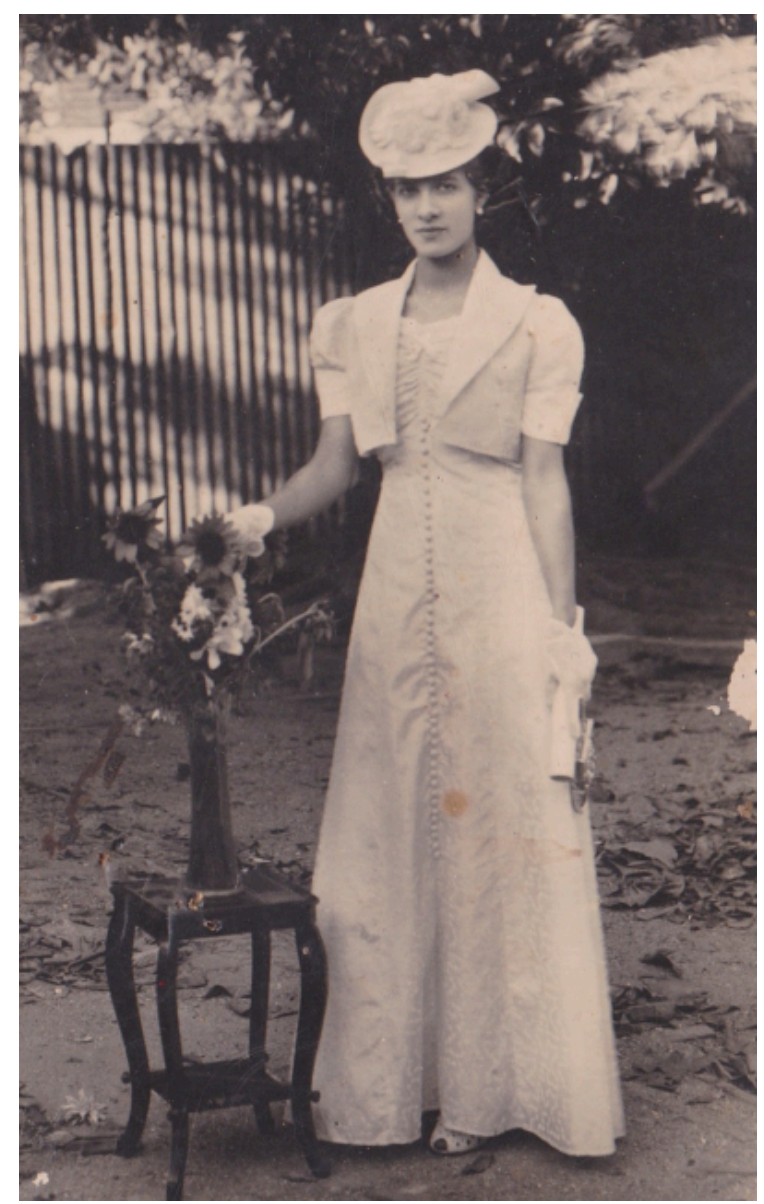

Photo 1. Sophie at age 17 in Paramaribo, in 1938

Mundane life did not fit her. Once she told me that what she had really wanted was to be part of the theater, to be on stage, be a dancer. She was so angry with her father that he would not let her. But she did sneak away once, when this big theater company came to 
town, and participated in a play. She giggled in her typical way and said to me: " $A i$ baja $^{76}$, I just did it, and I had such fun! My parents never even knew..." But they would soon become acquainted with the fruit from that experience, for my grandmother returned home, pregnant with my mother.

\section{Rudolf-Sophie's Father}

Sophie's father, Rudolf Vervuurt, was a fourth generation descendant of a Dutchman who had come to Surinam in 1795. Some of his relatives had been colonial officials, some had managed plantations, and others were tradesmen and craftsmen, like him. My mother remembers her grandfather as a tall, white man with piercing blue eyes, who dressed in the typical white colonial outfits that the Europeans wore. Other relatives also remember him like that: a white man of German descent. But he never looked German to me. On the old black and white photographs my tall, thin great grandfather's skin seemed to have a light brown hue, and the long slender face underneath his thick, sleek white hair did not look like the European faces that I knew at all.

As my mother once again told me of his whiteness, I decided to pick up the Vervuurt family genealogy printout that my aunt lent to me almost ten years ago. There I traced Rudolf's grandparents and great grandparents back to the first Vervuurt, who left the harbor of $17^{\text {th }}$ century Delfzijl, situated in the Northernmost part of the Netherlands, and set sail for Surinam with his pregnant wife.

\footnotetext{
76 “Ai baja” means "Oh God” or "Good heavens" in Sranan Tongo, the Creole language of Surinam.
} 
In contrast to Curaçao, where plantation economy was marginal, Surinam had been a settler and a plantation colony. Along the edges of the $480 \mathrm{~km}$ long Surinam River the tropical rainforest was turned into large sugar, coffee, cacao and cotton plantations. The narrow strips of land stretched inland, into the thick jungle that was the home of the indigenous population, and the refuge of maroons. Given that it was a settler colony in which the Dutch had intended to start a permanent community (Helman 1977:239), it was not surprising that a good deal of these early settlers traveled to Surinam with their families. The stencils revealed that the first Vervuurt and his wife had made it to the "New World," and over the decades their children and grandchildren married what appear to be other Dutch people, or at least people carrying Dutch names. There is however no trace of a German ancestor. So far that part of the family narrative was not holding up. But I was more interested in Rudolf's alleged whiteness, which did not look all that white to me, so I looked eagerly for the page in the genealogy with the names and places of birth of Rudolf's father and mother. If he was partly Dutch, what were the other parts of his ancestry? But the page was missing. In all of the genealogy it was the only page that was missing. Was this a coincidence, I wondered, or had someone deliberately removed it? I decided to track down Rudolf's parents via online $\operatorname{archives}^{77}$ instead, and soon enough I caught their proverbial scent. I was not prepared for what I would find. Before long the digitized Surinamese ledgers revealed to me that Rudolf's mother had been called Julia Emelina Zechiël. Further inquiry brought me to the manumission archives, listing the slaves that had been freed before slavery ended. There I found that

\footnotetext{
${ }^{77}$ I used Geneanet, the Dutch National Archive (Nationaal Archief), Ancestry.com, MyHeritage.com, and the Foundation for Surinamese Genealogy (Stiching voor Surinaamse Genealogie).
} 
Julia had been born a slave on the large sugar plantation De Drie Gebroeders (The Three Brothers) in upper Surinam. She had been a house slave there, the ledger informed me. Her mother, Bruinetta Dorothea Zechiël, had worked in the fields. At the time of manumission, in 1863, Julia was 16 years old. The fact that Julia was a house slave may have meant that she was a child of the man who owned the plantation, or that she was his "housekeeper-concubine" (Helman 1977:245). In both cases it is likely that she was of lighter skin.

Like in Curaçao, intimate relations between white men and women of color were common in Surinam. Yet, while in Curaçao such relations were encouraged (Hoetink 1958), in Surinam the colonial government strictly forbade white men to have sexual relations with their slaves. If found out about, the men would be fined small amounts of money or sugar. For white women and enslaved men maintaining intimate relations, the punishments would be far worst. But due to the large surplus of white men compared to white women these colonial rules were often bent and broken. It was common for white men to live in concubinage with slave women, who would be employed as housekeepers, something that the colonial government condoned. The mixed-race children that would result from these relations, who in Surinam became called "Creole," often held a privileged position, and might even be freed (Helman 1997). Thus, like in Curaçao in Surinam a mixed-race segment developed early on in colonial times, which became a separate population segment existing in between white Europeans and African slaves. They commonly adopted white norms, practices and culture, as argued by Surinamese writer Albert Helman (1977:245). 
In these explicit and implicit rules about interracial relations in Surinam one can observe the same contradiction that Stoler finds in $20^{\text {th }}$ century Indonesia: there is an explicit rule that established white endogamy as the ideal, meaning that whiteness is not only superior to non-white, but also that white men's allegiance should remain with the white Dutch colonial forces and the goals of dominance and economic gain they pursued. The flip side of this explicit decree is "the unspoken norm" (Stoler 2002:1), which in fact supports the message of the explicit decree as it dictates that women of color are perfectly fine to perform the household tasks and to provide sexual, physical and emotional sustenance (Stoler 2002:1) ${ }^{78}$. Women of color could never become the legitimate partner that represents European membership and access to privileges, property and prosperity (Stoler 2002:39). Thus, argues Stoler: "it was in the disarray of unwanted, sought after, and troubled intimacies of domestic space that colonial relations were refurbished and their distinctions made" (Stoler 2002:6).

Not only was Rudolph not of German but of Dutch origin, far more importantly, he was of African descent! Of all the tales I ever heard about my family this was not one of them. I remember my mother identifying as part Indonesian, Javanese, and Indigenous Surinamese, all of whom constitute large population segments in Surinam. But never did I hear anyone in my family acknowledge any Afrodescendance. Why did I not know this part of our history? Recasting Rudolph as white and European placed him and his

\footnotetext{
${ }^{78}$ Stoler writes: That prohibitions against interracial marriage were commonly late rather than early colonial inventions (in such diverse contexts as Mexico, Cuba, India, Indonesia, and the U.S. South) suggests that it was not interracial sexual contact that was seen as dangerous but its public legitimation in marriage. Similary, it was not the progeny of such unions who were problematic but the possibility that they might be recognized as heirs to European inheritance" (Stoler 2002:39).
} 
descendants in the realm of European membership and the privileges that came with it. Labeling him a man of color, on the other hand, would have denied him all that.

As soon as I had clicked open the page with their names in the online manumission register it felt as if the air in the room changed, as if my two lost ancestors stared at me from behind these letters on my computer screen. Side by side they stood, two black women against the backdrop of an open field, bordered in the distance by the tropical Surinamese forest. I clearly saw them in my mind's eye, and it made my eyes tear up, the hairs on my skin stand up. In between the black letters on the white screen I saw them, and they saw me. They didn't smile or move, my forgotten ancestors. The thick cloud of silence that had shrouded them for so long slowly filled up my room, full of their lives, their untold stories, their dreams alive and dead. I felt so honored, so delighted to meet them. And I felt a relief from their side, an exhalation. For finally being seen again after so many decades. Even though in this image they did not move, I felt them reach out to me, as if to pull me into the screen with them and look at me properly. This meeting of spirits, which defied time and space, felt to me like a homecoming. All my life the true nature my Caribbean roots had always been a mystery. But this meeting reestablished a tie that I now realize had always been there. We were of African descent. Like a kinked garden hose my, their, our belonging in this world had been choked. That one click of my return button had changed that.

I suddenly remembered having seen an old photograph of Julia. I found it in the box where I keep our old family pictures. The photo is dated 1917, shortly before Julia's death as an old woman, and two years before Sophie's birth. There she was, an old 
brown-skinned woman with an anisa ${ }^{79}$ on, sitting contently amidst three generations of her offspring. It was a poor photocopy, of an old black-and white photograph, so could not make out her face. But I guesstimate that Julia had a caramel brown skin: on the photo she was not a very dark-skinned woman, nor was her offspring. I can only guess at what point the "white blood" entered our family lineage. Maybe she indeed had a white father, or maybe her mother did. The ledger didn’t say, nor did I expect it to.

I continued to search for more information on Julia. Another archival entry showed me that Julia married the Dutch Carel Constantijn Vervuurt six years after her manumission, in 1868. I found their wedding announcement in the newspaper archive of the Surinaamse Courant, one of the big newspapers during colonial times. She must have left the plantation sometime after being freed, for she spent the rest of her life in Paramaribo, as did many Creoles after manumission (Helman 1977:247). But under what circumstances she had left, what happened to her family, and how she met Carel, the ledger does not say. What constituted their marriage - was it love? I really hope so. The ledger only says that Julia and Carel had seven children, including my "white" great grandfather Rudolf.

It is worth noting that mixed-race marriages and marriages between people of color had by then only just become allowed in post-abolition Surinam, as they had been strictly forbidden during slavery. The Church played a significant role in this state of affairs, as was the case in other Caribbean islands. Colonial government allowed missionary practices in 1825, which in Surinam were both Evangelical and Catholic

\footnotetext{
${ }^{79}$ A headscarf worn by Surinamese women of African descent.
} 
(Helman 1977:249). The missionaries tried to teach people to be 'proper' Christians. This meant abandoning their African-based practices and beliefs and ending promiscuity. This included administering “slave marriages” (Helman 1977:249; Allen 2007:95), which encouraged people to live monogamously.

The 'civilization missions' had become a powerful tool in the indoctrination of the Surinamese and Curaçaoan population during and especially after slavery. The Christian faith became a new tool through which dominance was exerted (Allen 2007:93). Not surprisingly, these Christian civilizing discourses were premised on the racist ideology that propagated black inferiority. Black people were labeled as lazy, rowdy, and hypersexual, and completely devoid of any civilization (Allen 2007; Hoetink 1958). The norm remained white purity, and the only salvation available to people of color, according to the Church doctrines, was to pursue this as best they could. During slavery people of African descent had not been allowed to marry. This had meant that children were automatically born in sin. But after 1863 the sanctity of marriage did become available to Afrodescendants (Allen 2007; Helman 1977). As a consequence the norm of white purity, which had always been the unreachable seat of European civilization, status, property and privilege, now became officially attainable (Allen 2007; Helman 1977). After slavery, hegemonic white supremacist ideology continued to be passed on through intimate relations.

From Helman's accounts on Surinam it appears that during slavery, with the approval of the slave owner, such unions among slaves were quite common, even though they were not recognized by colonial law (Helman 1977:248). But given the lack of white marriage partners, such unions had already been common between Europeans and people 
of color (Helman 1977:243). In Curaçao, during slavery the matrimonia clandestina or secret marriage of slaves and freedmen had been common and administered by the Catholic Church (Allen 2007:95). Interracial unions and marriages, however, were not common the way they were in Surinam. In Curaçao it was concubinage that was widespread during and after slavery (Allen 2007; Hoetink 1958). Even though legal marriage eventually became available to everyone in post-emancipation Surinam and Curaçao, and even though it added considerably to people's social status and respectability, it would take long for it to become the norm among the Afrodescendant population. In fact, many people preferred to live in concubinage and other forms of unions (Helman 1977; Allen 2007). But Julia had married a Dutch man. Perhaps not only the miscegenation but also the status of being wed added to the "whiteness" of their offspring.

Either way, it is evident that the racial label "white" that my family had attributed to Rudolph should be understood within the colorist context that has been ruling Surinam since colonial times, much like Curaçao's colorist system, which was previously discussed. In many Latin American and Caribbean societies "white" is in fact a far more elastic category than in the United States (Loveman 2009; Loveman and Muniz 2007; Telles and Flores 2013). But it is also important to notice that this elastic category of whiteness surfaces in our family history at a time when there was a significant change in marriage laws, which coincided with the onset of a new racial ideology of hybridity.

In the United States the "one-drop-rule" virtually requires a person to have a "pure white bloodline" to be called "white" (Carr, 1997), but as we saw in chapter 1, in Latin America and the Caribbean the ideologies of national identity emulating 
monocultural mestizaje, mulataje, and/or créolité characterized the region from the early $20^{\text {th }}$ century to the late 1980 s (Rahier 2012:1-14). And according to the ideologies of national identity that emerged in the region during monocultural mestizaje, national populations, which in these nations were largely non-white, were imagined in terms of superiority vis-à-vis the white race of European nations (Martínez-Echazabal 1998; Rahier 2003, 2012). Latin American and Caribbean intellectuals of the time such as Mexican philosopher José Vasconcelos (1925), and Brazilian sociologist and anthropologist Gilberto Freyre (1933) proposed that racial hybridity be no longer considered a polluting, degenerative influence, as it had been in the colonial past. Ultimately these references to miscegenation revolved around the process of whitening, thus again upholding colonialism's infatuation with white supremacy. This was the case in the region at large, but also for Curaçao and Surinam.

What becomes clear from my family narrative is that in the early $20^{\text {th }}$ century Surinam and Curaçao of Sophie and her parents, the racial category "white" also included light skinned people of mixed racial ancestry. But this label of whiteness became even easier to reach when one had a higher socio-economic standing, or at least adopted the behaviors, norms and values of the lighter skinned socio-economic elites. Therefore I would argue that in these Dutch Caribbean contexts, taking on a white identity is not only dependent upon showcasing light skin color. It also results from one's willingness or even eagerness to subscribe to the nation's hegemonic sociocultural and political order, and to demonstrate this through appropriate behavior and allegiance, or a performance of 'racial passing.' The rewards of passing for white are safety, protection, economic but 
also about "social and political entitlements, and psychological rewards," argues American historian Allyson Hobbs (2014:12).

I skyped my mother, and told her about her great grandmother Julia, and Julia's mother, Bruinette Dorothea, and the other Zechiëls. I told her about the plantation, and their manumission from slavery. She was as surprised as I had been, she also had not known of them. I saw her wipe her eyes, like I had done. She was excited to reconnect to our "erased" ancestors, and sad over them having been unknown for so long. She repeated how she had always seen her grandfather as white, just as she had always seen her mother as white. The deception of her own eyes surprised her - why had she not seen that they were not white, but of Afrosurinamese descent?

Later that week I met with some of my uncles and aunties in Curaçao. They too told me that they remembered Rudolf and his siblings as white. The aunt that had cared for my grandmother Sophie and lived with her when my grandmother was old, did know that Julia was a woman of color, and that she had been born a slave. She had been closest to Sophie, and heard many more of her stories than the rest of us. But clearly this was not common knowledge amongst her siblings and cousins. It certainly was not part of our family's publically performed racial identity. In fact, I have never heard my uncles or aunts identify as Creole, which in Surinam refers to Afro-descendants who live in the city and who have some white ancestry. Nor did anyone ever self-identify as Afro-descendant or black. Never did I hear anyone call my grandmother Sophie Creole, Afro-descendant or black. For all of them, Sophie was white. 


\section{Laurina - Sophie's Mother}

Having discovered Rudolph's proverbial "true colors," I began to wonder about his wife, my great grandmother Laurina van Sprang. My mom told me that her grandmother Laurina or "Madje" and her siblings were all light brown people. "All those children were very beautiful people," she said. "That whole part of the family up to today, I never thought of them as negroid. I think of my grandmother more as indigenous, native, or Javanese. She always wore her brownish hair in long thick braids..." This was another story that I had grown up with: my mother describing her grandmother as indigenous, and taking pride in an alleged non-black heritage. But I would soon discover that, like her husband, Laurina too had a silenced genealogy.

Laurina's mother, Maria Jansje Wolfina Murk, had been born in slavery in 1857, to Magdalena Adjoeba Murk (born in 1828), who had been a house slave. When their names appeared on my screen, again I felt the same thrill and honor that I had felt when finding Julia and Bruinetta, mixed with that eerie, cold feeling of never having heard of these women who made up half of my blood. But there they were, and the few words that the ledger gave me breathed a little bit of life back into them. Adjoeba was manumitted with her two young daughters in 1862, a year before slavery ended officially. They had lived on the wood plantation La Prosperité. An old newspaper announcement showed that my great great grandmother, Adjoeba Murk, married Georgius van Sprang in Paramaribo. This is where Adjoeba lived until her death.

Georgius van Sprang appears to have been born in Amsterdam, but the sources vary on that. I wondered if he was a white Dutchman, or if he was a man of color also, perhaps mixed with the indigenous Surinamese population, or with one of the many other 
ethnic groups that started to arrive in the colony at the time. His name alone did not reveal enough. The marriage announcement only showed that Adjoeba had two more children, two boys, who were born after her manumission but before her marriage. Georgius recognized all of the four children, which may all have been his own, and with the marriage they all took on his name. Laurina's mother, Wolfina Murk, thus became Wolfina van Sprang, and my family remembers her as a descendent of a well-known white family. Wolfina married Johan Jacob Willem Muntz, a man from what appears to have been a rather well-off Jewish lineage, who was born and raised in the city of Paramaribo. Wolfina and Jacob had five children together, among whom Sophie's mother Laurina.

Neither my mother, nor my aunts and uncles knew Wolfina's story. They knew that their great grandmother was not white but had a brown skin, but they did not denote her as black. But as said, in Surinam the labels of Javanese or indigenous came in handy as a way to deflect potential blackness. None of my relatives had heard of Adjoeba or her other children.

This reconnection to my forgotten great great grandmothers was a painful reminder of how much of the narratives of my family are premised on silence, perpetuated through censorship, omission, denial and avoidance. A deliberate and inherited forgetting sustained through six generations. It is also striking - though as said not uncommon - that this is becoming more and more a story about the matrilateral side of our family. The ledgers identify the mothers, who are the ones who are of African descent. However - as is in fact quite common to the colonial tale - they often present inconclusive information about the fathers, who form yet another censored part of our 
past, but in this story they also hold the key to the various processes of whitening that our family underwent, be it through rape, a fleeting passionate exchange, concubinage, marriage, or other kinds of unions.

It appears that when my grandmother and her parents were alive, passing for white was not exceedingly difficult. Their accounts suggest that clearly, society encouraged this type of silencing of one's black roots to instead subscribe to ideologies that emulate mestizaje and non-black racial identities. After all, Surinam was small, so people knew each other's lineages and genealogies very well. To this day Surinamese practice this genealogical pursuit, as a fun pass time, and perhaps to make sure that none of the youngsters accidentally pair up with an unidentified cousin. For both Rudolf and Laurina to respectively pass for white or indigenous (or at least non-black) suggests that those around them condoned it, to say the least.

Charles Hale (1996) states that "mestizaje has been a remarkably effective ideological tool in the hands of elites in many parts of Latin America, a unifying myth put to the service of state and nation building" (Hale 1996:2). The same can be said of other such ideologies of national identity that reify hybridization. National myths have had the ability to homogenize, harmonize, indoctrinate, include, exclude, and silence. Créolité, Hintzen argues, was devised by white elites in order to obscure racial inequality, colonial exploitation and white privilege. In Hintzen's perspective "the Creole," then, produces a "discursive space" characterized by the hybridization of specific ethnic, racial, cultural and national peoples and cultures within the colonial space. Through these discourses of hybridity differences were "transformed in a regime of identific solidarity" (Hintzen 2002:92). 
Racial passing doesn't subvert or reject these discourses of mestizaje, mulataje and créolité, which do nothing but confirm white supremacy. The colorist systems of Surinam and Curaçao encourage passing: phenotype in these multi-racial societies dominated by white and white-mestizo or white-mulatto elites allowed one to trump actual genetic heritage. The cases of my great great grandparents illustrate this quite well. Being white was the ideal, and hegemony rewards those who subject to it. However, Stoler argues, "[s]uch a shifting and arbitrary assignment of social membership makes clear that "European" and "colonizer" were not always synonymous categories," (2002:39). The significance of whiteness or European-ness could shift, but that did not automatically coincide with membership to white colonial ranks, and with access to the privileges of domination and access to property that this particular group had. Mixed race people could adopt a "European" lifestyle and adhere to "European" norms. As a consequence they would at certain moments enjoy certain possibilities for upward social mobility, but many other privileges were still not available to them (Stoler 2002:39, 40). The negotiating of racial identity through proposing racial mixedness or even whiteness was - and is - a manifestation of hegemony. It brought certain possibilities for upward social mobility and improved social status, while supporting rather than dissolving the racist ideologies and realities upon which these colonies were premised.

\section{Case Study 2: Dorothy's Silences}

Sophie, my mother's mother, was one of the lightest skinned of her siblings. She had grey eyes, wavy, auburn hair, and a light café-au-lait skin tone. My aunt and mom have always told me that she dyed her blondish hair black to not stand out so much. Sophie 
was young, beautiful, had a secondary education diploma, a bookkeeping job, and had mastered her father's sewing skills. She was ready to conquer the world. But then, she fell in love and got pregnant. In 1940, when Sophie was only 21, Dorothy, my mother, was born: an adorable brown skinned baby, with black features and afro-textured hair (see photo 2).

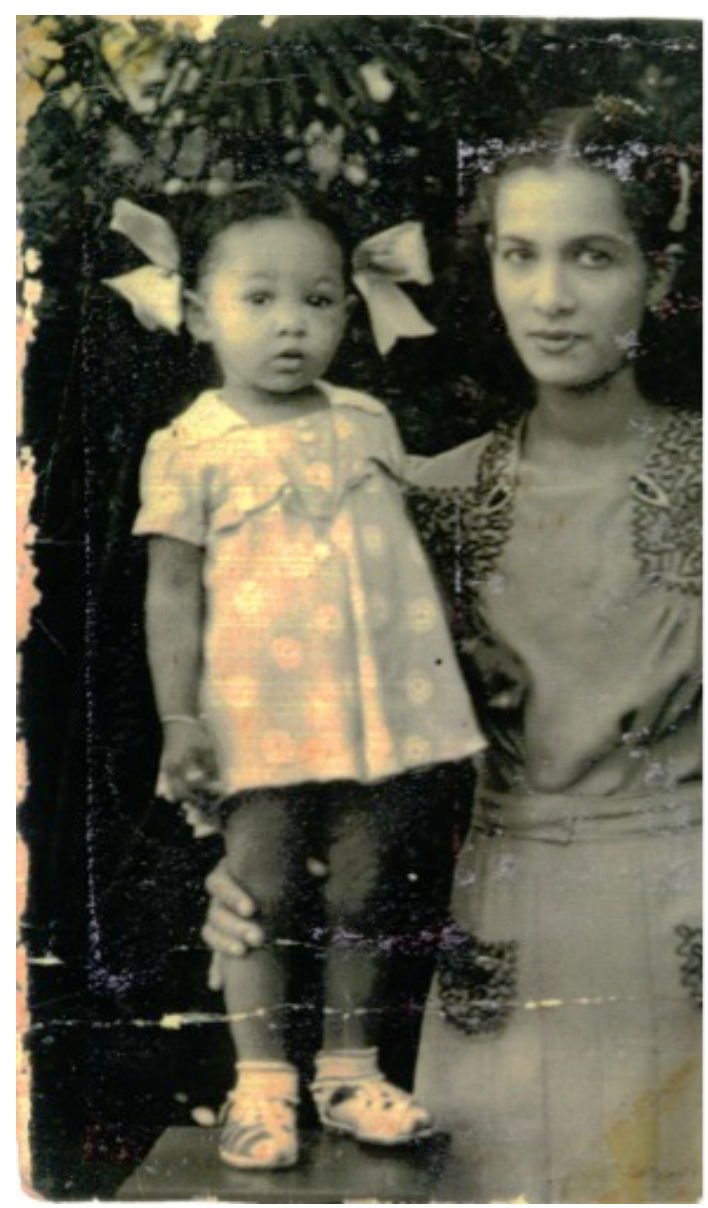

Photo 2. Sophie with my mother Dorothy (age 2), in 1942.

My mother says:

When I was born my family showed me off everywhere. I was a pretty child, so they dressed me up in the cutest outfits and paraded me around town. Everyone, 
except my mother. She was heartbroken: at age 21 she felt too young to be a mother (Dorothy, Interview 11 Nov 2013).

Sophie had dreams and aspirations for a career in the performing arts, with music, dancing, and singing. Even though Sophie knew that these dreams did not fit a girl of her social standing, she could not help it but feel her burning desire for them. She liked children, but maybe she had not necessarily wanted to be a mother, or a wife even. She wanted to be free to travel and shine, and be a star. But during her youth that was not a choice she could make easily, the way my female cousins and I can — and have- today. Sophie had to perform the scripts that society had written for her. When she got pregnant her dream world collapsed, especially when her baby turned out to be much darker than she was, and had the "wrong" kind of hair.

A marriage soon followed, and Sophie joined the ranks of "the respectable." But she was not ready for it. I can only assume that she had been marinated in the silences that surrounded her parents' black roots in slavery. Her light skin, which allowed her to pass for "white," had been Sophie's salvation. Even though her parents were not rich, because of her features Sophie was off to a good start in life. But the father of her child was not a dark-skinned man. This meant that through the phenotype of Sophie's brown baby the hushed stories of her ancestors had spoken up, and broken a carefully constructed silence. And the beautiful, innocent baby Dorothy would forever carry the brunt of her mother's anger and frustration over that.

Shortly after my mother's birth Sophie married my grandfather Stanley Spong (see photo 3), who belonged to a rather well known Surinamese family of a lineage that 
contained some Scottish blood, or so it is said, as well as some non-white descent. He was a remarkable electrical engineer and entrepreneur, and in 1941 he moved to Curaçao with his young wife, to start an electronics business. Like many Surinamese people they sought to profit from the booming Curaçaoan economy, which thrived due to the newly built Shell refinery.

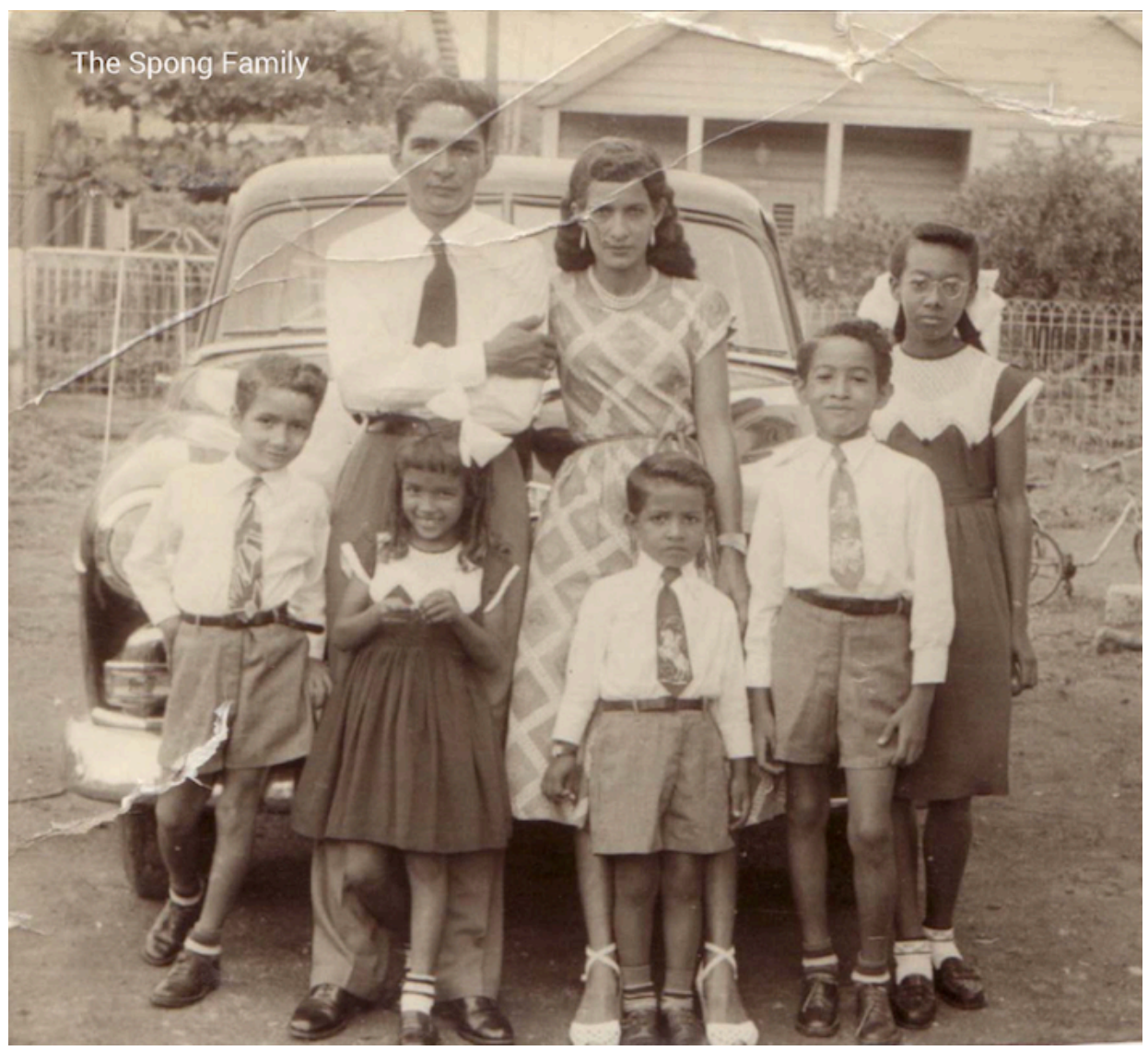

Photo 3. Family portrait taken in 1951, Dorothy stands on the far right.

Sophie's parents soon followed, and took on the care of Dorothy until she was five. So for the first years of her life my mother was cast out from her parents' world. Sophie had broken the quiet moral code of her society by birthing a baby that was darker than her. By not raising her own child she could at least temporarily cloak her failure to whiten her lineage. 
For my mother, this abandonment has always been most traumatic, and it impacted her life from its earliest days on. Involuntarily, she repressed parts of these traumatic memories that marked her existence. Dorothy remembers her grandparents always being around, but it wasn't until she was in her sixties that her older cousin reminded her that it was in fact Laurina and Rudolf who raised her, and not her mother. I clearly remember her shock and sadness over rediscovering this lost part of her memories. But she remembered plenty of other things. When she does speak about her youth, which is not often, it is often with great sadness.

Sometimes I would be so mad at life that I just froze into a kind of catatonic state. I literally could not move anymore. Tears would be running down my face, snot was dripping from my chin, but I would not, I could not move. No one could get to me but my grandfather. I would be standing frozen like that for hours, until my grandfather came home and found me. Then he would say, "Oh Pommetje, is it one of those days again? And he would hold me and I would melt, and I would be somewhat okay again. But ever since I was a little, little girl I knew that I should not have been there, and that my mother didn't want me (Dorothy, Interview 11 Nov 2013).

When my mother was five years old Sophie had another baby. Four more children would follow: my matrilateral aunts and uncles. It was now time for Sophie to take on her role as wife and mother, and to abandon her dreams of dazzling audiences and creating grand things, something that would pain her for the rest of her life. In the new and now quickly expanding family, Dorothy was labeled the "ugly" child. Being only slightly 
darker then her sisters and brothers, if in fact darker at all, her alleged ugliness was mostly attributed to her somatic features and her hair. My mother's siblings, especially when little, did have a different phenotype, with smooth, wavy hair, and thin noses and lips (see photo 3). This was considered more beautiful than my mother's thick hair, round nose and full lips. What had been true for Laurina, Rudolf and Sophie was true for Dorothy also. Racial identity was determined by phenotype rather than genotype. For Sophie and her parents it meant a social upgrade. For Dorothy the small differences with her siblings meant the reverse. She says:

I tried to not live consciously, because then there would be the pain of being unwanted and ugly. It was my way to survive. My whole life I have hidden away my real me, I just was not there. And that was the only way to live, to not be there, to be subservient to others and make them happy. So as a small child I would always wash the car, do the dishes, weed the garden, even though we had a maid. I felt as if I had to pay for myself, for ultimately I had no right to be there. I always came home from school straight away, always got straight As because imagine I would get lesser grades. I would never do anything that would make people angry with me. Had I been a blond haired blue-eyed child though, I would have added to my mother's social standing, and everything would have been different (Dorothy, Interview 11 Nov 2013).

So, for Dorothy, silence became a survival strategy. To omit the heart wrenching trauma and the shame of existing, and of being an outcast within her family, something her mother and grandmother had not had to do. Her story reveals several forms of silence and silencing. The above paragraphs show Dorothy's traumatic response - the involuntary 
forgetting, as well as her near-catatonic spells. And we see her presentational rituals (Goffman, 1967): her self-censure through behaving properly, never attracting any attention to her both interpellated and self-identified Otherness. She did that to protect herself from the violence of the racist norm and value system she had been immersed into. Her deliberate silences manifest her self-withdrawal and evoke Goffman's avoidance rituals (1967).

\section{Silent Community}

In the communities in which Dorothy lived, in both Surinam and Curaçao, race and skin color, the root of her pain, were not mentioned explicitly in everyday exchanges. Neither her parents and relatives, nor society at large ever explicitly named the differences in phenotype between my mother and her siblings. Dorothy says that in those days race and color were embedded in a discourse of shame and therefore best left unmentioned. Plus, she said, "they were there for the eye to see, so why would one talk about it?"

Of course there is that blackness. But I just never identified with it at all. I did not get the chance for that either. My relatives would say that I looked like my grandmother Madje, like an Indian. Also, no one ever told me to my face that I am black or treated me as a black person, or discriminated against me. So I don't think that I am black in the African sense. My family never did say what I am. Instead they would talk about others, who looked different than me, and say that they were pretty, like my sisters. So I filled in the blanks (Dorothy, Interview 11 Nov 2013). 
But also Rudolf, my mother's grandfather, who was so close to his granddaughter, never spoke about it with Dorothy. Perhaps he did understand that his daughter's rejection of Dorothy was at least partially due to the racist norms of early twentieth century Surinam, or perhaps he never gave it any thought. He may or may not have been aware of the crippling power of race and racialization. With what silences and ideals had his mother, who had been born in slavery, raised him? Dorothy said race was never discussed, and no one ever offered her words of strength, explanation, or solace. Whatever it was that Rudolf believed or knew or saw with regards to race, what he offered my mother in her moments of sadness was more silence. Her grandmother Laurina had been labeled as native- or indigenous-looking rather than Creole. That label was passed on to Dorothy. In labeling her as indigenous looking as well her relatives may have attempted to deflect the undesirable label of blackness, both for Dorothy and for the family at large.

As previously discussed, silence was very much a part of Surinamese and Curaçaoan culture in general. "No one really talks," my mother says. "Especially not my mother, but she sure knew how to gossip. That is all people do, gossip.” So Dorothy quickly learned never to talk about herself: "you never volunteer information that people can gossip about."

You never want to give people anything to use against you. It was pretty hard to always behave so well, especially when I was little. I could not be a child. I could never whine for anything, make trouble, throw a tantrum, run around and act crazy. All that was out of the question, especially for me. But because I never said anything I never had to worry. People knew nothing about me. Whatever I 
thought was safe. Everything about me took place inside of me, inside my head. My music, all the books and stories I read, my fascination with the Netherlands, my dreams and wishes for my future... Also, my mother's silence was an indication that I was doing okay. She never showed any interest in me and in what I did. The only times that she paid attention to me was when I had done something wrong. So her attention was not a good thing. Silence was better. (Dorothy, Interview 11 Nov 2013)

\section{Dorothy's Escape}

Dorothy used her quietude well. At age 16 she got herself a scholarship, left for the Netherlands to study and start a whole new life in a far away place. By this time the Dutch empire had begun to unravel. In 1949 the Netherlands had accepted Indonesia's independence, after a long and bloody conflict. In 1954, two years before Dorothy would leave Curaçao, the islands of the Netherlands Antilles reached an autonomous status in the Dutch Kingdom. Surinam would become independent in 1975, the year of my birth. Race relations shifted, as did the expectations empire had of my mother's intimate positioning in the worlds she participated in. Her parents expected her to take care of them in their old age. What was more, in the early 1960s it was not yet common for young middle class women to move out of their parent's home and away from their protective gaze.

Still, going to the Netherlands had always been her dream, taken from the many Dutch books she had disappeared in as a child. When her parents would not allow her to continue her secondary school in Curaçao she prepared her departure in secret, took all 
required IQ and skills tests, and arranged for her ticket through her school. She didn't tell her parents about her scholarship until two weeks before her departure, just so they could not stop her anymore. She was going to Europe. Dorothy's silence had protected her dreams and safeguarded the execution of her plans. Deep inside she had always felt European, she always tells me. The library was on her route to school. She loved to read so she secretly read every book they had. She knew all the poems and children's games and songs from the Netherlands, and she loved them: they made her feel "at home." Also she would hide in a corner of the garden and listen for hours to the songs that the Dutch neighbors played on the radio. She was always geared towards the Netherlands, and when she got that scholarship she was gone.

Her parents did not object to Dorothy's escape. They had never expected such an ambitious and emancipatory action from their quiet and docile daughter. They were proud that she obtained her scholarship, as it was a prestigious achievement. But they also did not support her in it; she had to fend for herself. Their lack of response reinforced Dorothy's beliefs that they did not care that much about her. This may or may not have been true, still their lack of either resistance or praise hurt her. This attitude had characterized her childhood, and would continue to do so throughout her studies and adulthood in the Netherlands. "My parents never so much as sent me ten guilders while I was there" she said.

Life was so hard, the Netherlands were so cold, and I was hungry so often... I would wear pants underneath my dress to get to school in the winter. I was always freezing. If my stockings tore I could not afford to buy new ones (Dorothy, interview 20 May 2008). 
Dorothy almost felt that her mother in particular saw her departure as a "good riddance." Sophie's aloofness confirmed the rejection that had so much hurt Dorothy when growing up, but the freedom and positivity Dorothy found in return was well worth it. Her parents' lack of interest did not stop her.

Since Dorothy was only 16 she had to live with an older lady who served as her guardian. In the Netherlands of the early 1960s virginity and chastity also marked a girl's social status and respectability. But my mother was not seeking sexual freedom; she just wanted to be free from the racialist judgments of her relatives that had constrained her for so long. And the Netherlands of the 1950 s and 60 s were exactly as she had expected. In spite of her hardships she felt liberated, appreciated, not so looked down upon. She could just be herself. Finally she had friends, and she loved the climate, because she doesn't like the heat. In the Netherlands my mother felt as if she could start over, distance herself from her past and reinvent her life anew. In this country, about which she had read and dreamed so much, her silence served as a clean slate. What people did not know did not count. From the ugly, unwanted child she grew into a beautiful, well educated woman, with long, straightened black hair and a stunning, slender body.

And the Netherlands welcomed her with great enthusiasm. She belonged to the first waves of Caribbean immigrants who came to the Netherlands to study. Back then, black people were still rare. The large influx of poor, uneducated immigrants from Southern Europe, Northern Africa and the Caribbean would not start until the 1980s. It is with this later Caribbean immigration wave that negative stereotypes of Dutch Caribbean people intensified. Today those prevail. But the first Caribbean immigrants were commonly well educated and successful, and those who did not return to Curaçao, or 
moved on to other destinations, often merged into the Dutch middle classes and intellectual elites, as "exotified," "rare tropical flowers" amidst the endless tulip fields.

While racism certainly was not absent in the Netherlands, I have often heard people from this first wave of Curaçaoan immigrants describe how they were looked at in a positive way. "People always adored me," my mother tells me. Her fellow students always offered to carry her bags, or escort her home, accompany her to events, make sure she was safe and content. For the first time people cared for her wellbeing. She never experienced any racism or discrimination in the Netherlands, she says. In the stories she shared throughout my lifetime she was always unusual, "exotic," beautiful, and smart. People loved the newness she brought, as did she. In Curaçao she had always made herself invisible, "but here everyone flocked around to get a whiff of my difference, the teachers included" (Dorothy Interview 11 Nov 2013).

"Exotification", "erotification" or "hyper-sexualization" of the black body is in fact a staple manifestation of racism, argues Rahier (2010, see also Said's Orientalism 1978 and Stoler's Carnal Knowledge and Imperial Power 2002) they signify once again the Otherness and alleged inferiority and subjectivity of the black subject. I well understand how this kind of attention will have been much more pleasant to my mother than the rejection she used to feel. Even though I myself also experienced the violent, debasing flip side of this kind of sexualized attention, as a teenager and young adult woman living in the Netherlands. But still, I do recognize the "positive" feelings my mother describes. She may have been objectified, but at least she was objectified as a beautiful woman, and attributed positive traits also, not just negative ones. A partially complicitous silence this is then, which illustrates how we as individuals have the power 
to negotiate the identities assigned to us (Jenkins, 1997; Nagel, 1994, 2003; Trouillot, 1995). We have the power to mute the parts of the picture that we do not like, and highlight those that we see as favoring us. In doing so we perpetuate hegemony, because we allow for the exotification, which is a manifestation of white supremacy. But in drawing strength from this label, in muting the critiquing voice inside that debases us on the basis of our race, and in redefining in a positive way what our "otherness" means to us, I argue that this adoption of such labels also contains an element of resistance and empowerment.

\section{Negotiating Identity}

The Netherlands of the 1960s were diversifying. In that multi-ethnic and -racial landscape of the 1960s people also did not always identify my mother as black. Her brown hue, straightened hair and mixed race features made people mistake her for an Indonesian woman.

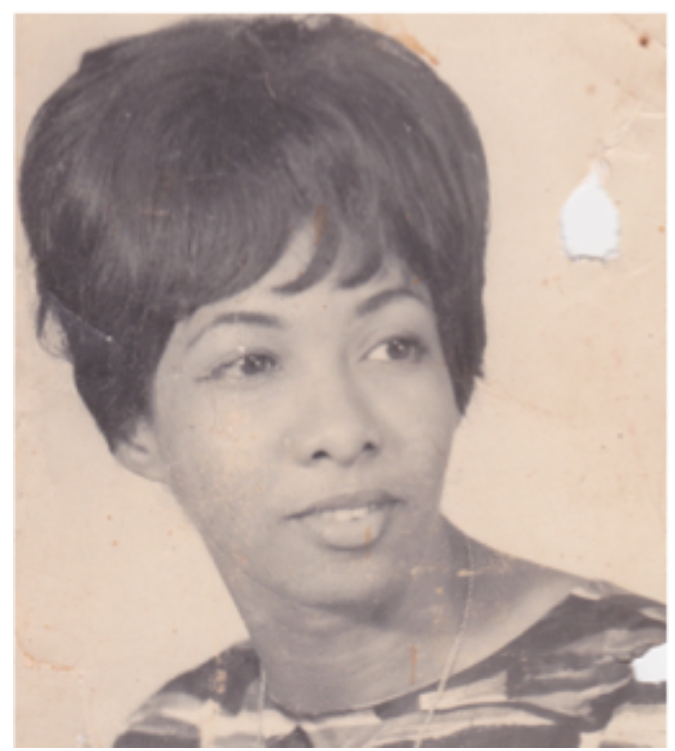

Photo 4. Dorothy in 1970 
Indonesia had been another significant part of the Dutch Empire. It had declared its independence in 1945, but it was not until 1949 that this was finally acknowledged by the Netherlands. This started a large repatriation program in which an estimated 300.000 people forcibly left the former colony. This group was comprised of the Dutch colonial population, and of Indonesian people who had been socialized into Dutch society in Indonesia and often were of mixed Dutch and Indonesian descent. By the 1960s, when my mother arrived in the Netherlands, Dutch-Indonesians constituted a significant population segment in larger Dutch cities and especially in The Hague, where she went to live. They often thought she was one of them.

When she was barely one day in The Netherlands an old Indonesian woman grabbed Dorothy's arm, and asked her to help her cross the street. She had, however, asked her question in Malaysian, assuming that my mother was Indonesian too. But Dorothy said “I'm sorry but I don't understand you madam." The old lady got mad at her and said: "You young people, the second you leave home you forget our native tongue!" Dorothy did not mind the reprimand: she preferred that newly ascribed identity to being black (Dorothy, Interview 11 Nov 2013). Over the years other people would often make the same mistake. My mother would not correct them: she did not feel any need to volunteer her true ethnic and racial roots. Her story indicates that at least in her eyes a Dutch-Indonesian identity label and the associated phenotype with straight hair was more positive than so-called "African traits." Using the imperial global racial scale, for the Dutch Dutch-Indonesians located higher up on the scale of racial respectability than their Afro-Caribbean counterparts. But still, it was within the confines of the Dutch Empire and its racial oppressive ideologies that Dorothy's new ethnic identity took shape. 
When I asked her about what the Black Power movement had meant to her, which was so present in the news when she was in her twenties and thirties, she said that it didn't really affect her because she did not feel that it pertained to her. It was too far removed from who she was, she said. She liked the black music that came out of the United States at the time. She thought that it was great that all this empowerment was happening, but never did she realize that it also concerned her. Through her studies, first in speech therapy and later in neurology, she had come to live in a "white" world in which she felt very comfortable and appreciated. She enjoyed the freedom of being able to replace the negative traits that had formed her identity as a child with positive ones. She had always known that she was black, but not until now, being in her seventies did she truly understand that the injustice and abandonment that she had suffered, to the extent of leaving her family and starting anew on the other side of the Atlantic, was in fact rooted in race.

Like her mother and grandmother, Dorothy also used the deliberate forgetting and omitting mechanisms that Sheriff mentions (2001). Dorothy did not talk about her blackness, or publicly identified as black. She did have Surinamese and Curaçaoan friends, and even a few relatives with whom she was close, and she would on occasion attend social gatherings and parties. But by and large her life developed predominantly in communities that were not associated with blackness. She did not soak herself up in Caribbean culture - friendships, music, food, literature, events, clothing - that was already so readily available in the Netherlands at the time. This was the life that I would grow up in, in which we would enter these Caribbean spaces in the Netherlands only a few times a year. She hardly ever spoke Papiamentu, the creole language of her island. 
Hers was indeed largely a complicitous silence (Bourdieu, 1977). Following the pattern Hobbs (2014) identified, Dorothy sacrificed all those cravings, interests and associations - often without truly realizing that she did so - in order to adopt a white European lifestyle.

Even if she herself could not be phenotypically white, living a "white" life was the next best thing. She married a white man, and raised her children to pass for white. She bowed to hegemony as to not get hurt more. And as time passed she distanced herself more and more from what she had left behind. She had to, for her departure had also hurt. She always kept a hunger for the Caribbean home she had sacrificed and left behind. She had wanted to escape the racial oppressiveness of the family and the society in which she grew up. But even though from an early age on my mother felt a strong familiarity and comfortability with Dutch culture, she has always been a Caribbean woman also. You can wake her in the middle of the night for rice and beans, peanut soup, salsa music, and the sight of the aquamarine ocean. She found a new pace, a space in which people genuinely appreciated her, but she paid a high prize.

My father was perhaps more aware of the way race and phenotype dictated my mother's life than she herself was. He was born in Amsterdam in 1944, the last year of the Second World War, to a Protestant mother and a Jewish father. Most of his father's family never returned from the concentration camps. In part because of his own family history he has always been a fiery opponent of any kind of injustice and inequality, something that he wove into his academic work as a work and organization psychologist. He quickly realized that in one way or another race was the root of my mother's life. The difficult relationship between Sophie and Dorothy had continued, even now Dorothy had 
moved far away. He provided my mother with some tools of resistance to Sophie's "reign of terror," as he describes it. The letters Dorothy received from her mother were not kind, warm, proud, but full of critique and sneering comments instead. "Sophie was a constant disruption," he said.

She did not show much appreciation for your mother until she married me, a white man, and until she finished her academic degree. It was as if with these two achievements Dorothy finally deserved some acknowledgement, as if that girl had finally amounted to something. Me, I always tried to neutralize Sophie's subtle yet impactful attacks, to show your mother how irrelevant skin color really is (Robert, Interview April 2015).

And indeed, color should be irrelevant. Perhaps this was why from my father's side it never was a topic that he discussed explicitly with me. But it was a topic that I now discovered was part of the conversations between him and my mother. He says that even though she herself may not have been aware of it, color was always part of her gaze, part of her interpretation of people's words and actions. From his accounts it turns out that she continued to feel discriminated against, inferior even, because she was a brown woman. Even though he often tried to debunk such thoughts, it was only fair, he said, that she thought them, for the Netherlands responded ambivalently to a brown woman. "Many people in our surroundings - educated, intellectual people especially - were very positive and appreciative of her, and others were not," he said. "Negative response could certainly be threatening, so she always had to be aware of it to some extent, and anticipate and deflect." But at the same time he describes how in her career as a speech therapist 
Dorothy found a somewhat ironic way to stand up against the white supremacist discourse of the Netherlands, whether she did so consciously or not. He said:

First, she, a brown immigrant woman from the Dutch Caribbean, was the one who taught white Dutch people how to speak their own language properly. She worked at every elementary school in our town, which led her to be a widely known and appreciated person in the village. And secondly, she showed her intellectual superiority to her colleagues, all of whom were white, as she continued to expand her knowledge and developed a series of workshops in which she instructed and certified her peers to exert new techniques, first locally and soon nationwide (Robert, Interview April 2015).

In spite of the burden of internalized and external oppression that she carried every day, my mother had always resisted it, and had in many ways been successful at it. While in her silences her oppression continued on, her silences had also given her a place to find shelter, regroup, strategize and reinvent herself anew. A few years ago my mother even received an impressive Dutch royal decoration for her groundbreaking work as a speech therapist. But still, in spite of her achievements, which in many ways challenged the racial status quo that she partook in, Dorothy continued her behavior of hiding herself away and never really being 'there,' even though it was no longer necessary. She explained to me that it had become such a habit that she did not know how else to be. I was so used to accommodating others, it had become part of my nature. And always I pushed away the past - Curaçao, Surinam, my family. But it did not bother me, as a matter of fact I was very content with this lifestyle. I lived in the 
life of my husband and my children, but never did I live my own life. It never occurred to me that I could (Dorothy, Interview 11 Nov 2013).

You win some, you loose some. My mother had made a good life for herself in the Netherlands. But her inherited as well as self-made silences and censorships mixed with unintentional and "deliberate" forgetting as ways to cope with an ongoing painful reality had become a behavioral pattern.

\section{Case Study 3: Angela's Inheritance}

My grandmother's life had been marked by her silenced black grandmothers, who signified a shameful past, and by her own racial passing. My mother's life developed in the shadow of her struggle with her sense of inferiority, and her search for upward social mobility. I was born in Amsterdam, the Netherlands, into my father's very present white Dutch world, and my mothers' quieted Caribbean world. I am a light skinned woman, born with a head full of dark curly hair, dark brown eyes that have some slant to them, and an off-white colored skin that tans fast in the summer (see photos 4 and 5).

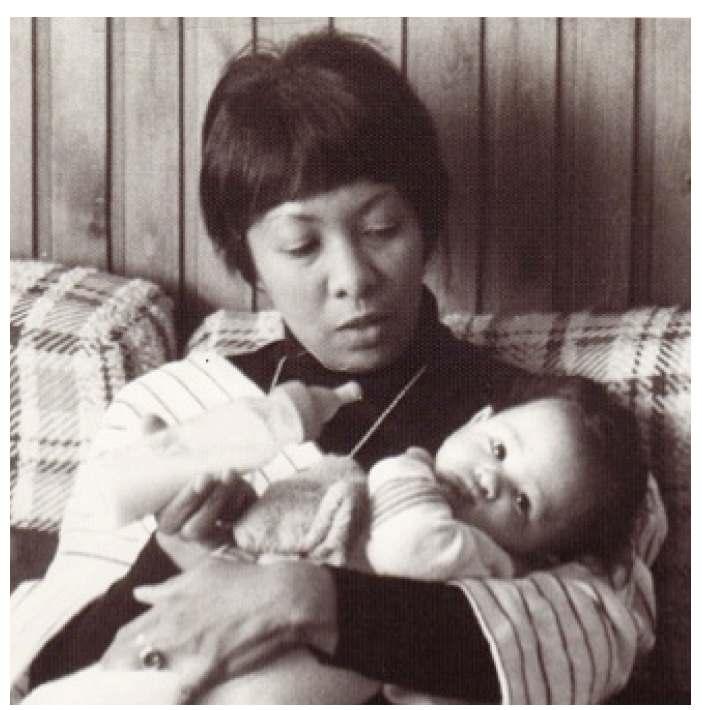

Photo 5. My mother and I, 1975

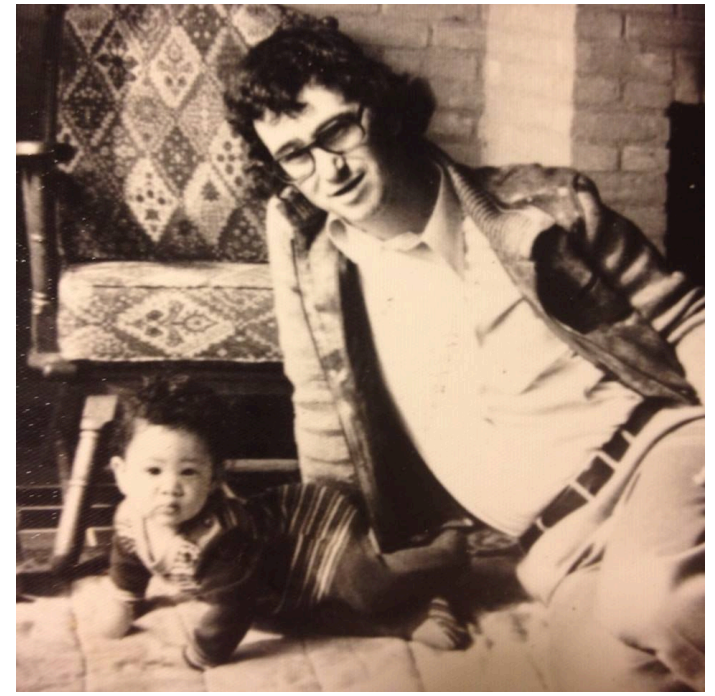

Photo 6. My father and I, 1976 
My features have always revealed that I was of some kind of mixed descent, but I didn't know that, not until I became a teenager. Consciously I only really knew the white Dutch mainstream world I was born into. Every now and then we talked about our holocaust heritage, a few Curaçaoan and Surinamese nursery rhymes, the occasional roti my father brought home from Amsterdam, still warm and almost too spicy to eat, and the Caribbean records my parents would once in a blue moon dance to in the living room. Nonetheless, ever since I was a toddler I picked up on that hidden Caribbean world that my mother carried with her. I wanted it. It stirred inside of me too. I felt it, I connected to it, and I wanted to live in it. What my mother kept hidden in silence was what I needed to make sense of my self.

I grew up in Castricum, a small commuter village in the Northwest of the Netherlands. In the 1970s and 1980s its immigrant population was tiny in size, barely noticeable. My mother was one of the few brown-skinned or black women there. But me, I never consciously attributed any meaning to her brown skin, just like I never attributed much meaning to my father's white skin, nor to my own skin or that of anyone else. My parents, one brown, one white, were the most solid and unquestioned part of my existence. I do remember my mother always saying that she had to dress properly, even for a quick grocery store run. Because, as she would always say "I'm the only black woman in the village."

My father took me to the library on Saturdays. I have loved books ever since I could hold them, and with two academically trained parents I was amply encouraged to do this. I was as little as two years old when he started this habit, but I clearly remember always looking for picture books on far away countries, preferably tropical ones. I clung 
to the tropes that my naïve mind was being socialized into, so I initially looked for books with palm trees, jungle and wild animals. Somehow they did yield small but significant clues about who I really was and where I might belong. One of the most memorable events of my early childhood was my first visit to the Museum of the Tropics, in Amsterdam. A large ethnographic museum developed in 1864, that museum houses a vast multitude of artifacts acquired during the colonial endeavors of the Dutch. I was five, my baby brother dozed in his stroller, my parents were fussing over the floor map, and there I was, walking into the endless colonial hall with the marble stairways. The Polynesian statues with their huge ornamented penises looking down on me. All these "exotic" worlds rolled over me, and whispered in my ears some strange kind of "welcome home." The spirit canoe of the Trobriand peoples, the old Indonesian gamelan, the masks, the African hut and Arabian tea house with the small television set showing a colorful program, even the imitation frescos of the Borobudur... Right there and then I knew that I would grow up to be an anthropologist, even though back then I didn't know the word yet. Ironically, this strange colonial space, this harvest of artifacts from the world over, from the Dutch empire, became my route back to my Caribbean roots, unfolding through colonial tropes and lore and representations steeped in white supremacy.

I remember always feeling different from the people around me: they were virtually all white. But in addition to my own feelings about this Otherness, every now and then people in fact confirmed that I indeed was different. Like when one of the neighborhood girls asked me: "Why do you have a perm?" "I don't have a perm," I said. "Yes you do, how come your hair is so curly then?" Never before had I thought about my 
hair. Another clue I got when my $6^{\text {th }}$ grade teacher was talking about the Third World, and African people in particular, living primitive nomadic or semi-sedentary life styles in huts built from clay and cow dung. My thoughts immediately drifted off to the Museum of The Tropics; they had a real hut like that. It was actually made of manure; I loved the sweet smell and the soft dry feel of those walls. "African people," the teacher said, "like Angela.” I snapped out of my daydream: “African people like me?” How was this stencil in front of me with these two black half-naked men in grass skirts suddenly about me? I was raised here, and my skin was white, what did I have to do with Africa? When I told my father he got very mad, but I did not understand his reaction either. No one bothered to explain to me the Afro-descendant link that indeed was there, or give me some more nuanced information about people living in Africa and its diasporas. I was "them," my teacher had said. But what did that mean? I just know that I didn't like the feeling it gave me. And when my teacher said "Why don't you read Uncle Tom's Cabin, that will be a great book for you," I didn't want to, because he didn't offer it to any of my classmates.

At home "skin color," "race" and "racism" were never discussed, partly because it had such a raw connection to the holocaust that had decimated my father's side of the family. In fact, in the Netherlands in general "race" is a taboo topic (Essed 1991; Weiner 2014). To this day race is not part of the Dutch census, in part because such an identifiable trait comes with the danger to single out a group and eradicate it, which is what had happened in the holocaust. But as scholars like Bonilla-Silva (2010), Carr (1997) and Goldberg $(1993,2002)$ argue, this "invisibilization" of race in fact gives white supremacy free play. 
So growing up I didn't know the first thing about race; what it was, why it mattered, and how it affected people. I grew up in the 1980s, the time of Live Aid, the Cold War, recycling, starvation in Ethiopia, and Green Peace spraying baby seal furs. At my protestant school we zealously held the starving children in Africa and the baby seals in our morning prayers. We learned about the Third World, where the brown people lived, and we knew of discrimination and that it was bad to treat people in such a way. But rarely did I hear a racial slur, and I never felt the threat of a true racist attack. The things that happened to me personally were concealed kinds of infringements, which I would not recognize as having been racist until many years later. Like the time when my blond, white girlfriend and I went to buy beads in a little toy store. The lady told me that surely I did not have the money to buy such beads, and wanted to shoo me out of the store. My friend, however, could stay. I had the money, and bought my beads, but I left with a strange, blazing fireball in my stomach over the woman's disgust towards me. I knew something bad had happened, but I didn't understand what for.

After my trip to the Museum of the Tropics I had a second "homecoming." In the summer I turned six we went to Curaçao on vacation. On that small rock that is my mother's island I felt like a fish in the water. My brown skinned family, the smells of the streets and of my grandmother's kitchen, the iridescent ocean with its pebble beaches, the orange colored house, my grandmother Sophie grinding green plantain into tomtom ${ }^{80}$ in a large wooden pestle while my cousin cut up a mango for me, it all felt like pure homecoming. My mother said that I walked around the island as if it had always been

\footnotetext{
${ }^{80}$ Tomtom are small balls of boiled green plantain that are eaten in Surinamese peanut soup.
} 
mine, and that I felt more at home there than she ever had. I knew that I belonged with these people, for here I did not feel different. But because my mother never extended her brownness to me, or named me her Caribbean child, somehow, when the holidays were over and I got on the plane my Caribbean world didn't travel with me. I returned to being that same wandering white girl, always looking for where she belonged.

\section{Identity Crisis}

This tug of war between my complete ignorance of my Caribbean roots and my zealous search for the "exotic" would characterize my young life until my early thirties. My mother had carried her silences initially to protect herself, and later on also my younger brother and me, from the negative racist ideology she had been raised into. However, these multilayered, intricate silences still harbored racism's negative messages. They fell into step with the white supremacist norm system of the society I grew up in.

Unbeknownst to us all, I distilled the sense of inferiority my mother had tried to escape from and made it my own. After all, I had been born into the same empire my silenced great great grandmothers had occupied, even though officially it was no longer called "empire" anymore. My brother was less affected by it. Phenotypically he looks fully white, and by and large identifies as such. He never felt the pull of the realm of the Other, as I did. My mother's compiled silences catapulted me into a full-fledged identity crisis.

In the 1990s we moved to Tilburg, an industrial city in the South of the country.

My parents were doing well in their careers so we moved to a rather fancy part of town. Both my neighborhood as the schools I attended were almost fully white, as my elementary school had been. However, this time class also featured into it. My school 
was a middle to upper class school, whereas in Castricum we had been part of a working to middle class community. My ignorance continued. I was, for example, only marginally aware of the large immigrant communities residing in other parts of the city. During summer, at the local swimming pool I got to know the Moroccan and Turkish boys that lived in the adjacent neighborhood. They would harass me for wearing a bathing suit, assuming I was like them—a Muslim from Morocco or Turkey—because of my skin color and dark curly hair. Yet I knew nothing of the large Curaçaoan community, nor of the many African immigrants that lived in Tilburg. I never saw them in the shops, cafes, clubs and other social settings in the city center that my friends and I frequented. So my world remained very white.

As a child in elementary school I had already begun to feel lesser than my peers. I looked different than them, than my Barbie dolls, than the people on TV and in magazines. In high school this feeling became more pronounced, as if I had to work harder to be equally respectable as my new white classmates, who insisted on donning brand clothes and who were all playing field hockey, two things that did not evoke the slightest interest in me. This was in part because my father did not care to splurge on material things, and rejected ostentatious labels of social status. He would always sneer at this "conspicuous consumption." Inspired by his individualistic stance I too derived my sense of self from seeking to be original and true to my real interests rather than following the herd. And also I was dreadful at any sports that involved a ball. I could see no point in running after a ball with a stick. But what was more was that I did not feel welcome in the upscale white world of my classmates and their parents. Somehow I felt as if I was tainted, not pure enough for their children to befriend or date me. 
This was a powerful feeling that quietly assaulted me daily, and that resulted in my conscious steering far away from this social segment and their professions, fancy neighborhoods, thick bank accounts and high society clubs. This was one of my silences, which I in part inherited, and fuelled with the feedback from my every day surroundings. It was a silence that was both made up of resistance as compliance. There was shame in how I felt about myself, and limiting my interactions with this group shielded me from negative feelings. But it was also self-censure. For years I would unknowingly sabotage myself by keeping myself from pursuing a well-paying career-path. But at the same time I sincerely valued my activist inclinations over becoming rich. I had been like that since my early childhood, when I dreamed about working for Greenpeace or Doctors Without Borders. My mother, on the other hand, did everything she could to belong to this group. She has successfully been living in its heartland for decades now, pulling me along on occasion.

It didn't help that Curaçao and Surinam were conspicuously absent from every course in my high school curriculum. The history book we used did have chapters on the Dutch colonies, both in the Caribbean as in the East Indies, but my teacher always told us to skip them. And in spite of our occasional trips to the Museum of the Tropics my mother rarely spoke of Curaçao. Surinam, where she had only spent the first four years of her life, was even less present. The national heroes that she had been taught about in school were Peter Stuyvesant, Piet Hein and Michiel de Ruyter ${ }^{81}$, all of whom played an

\footnotetext{
${ }^{81}$ Peter Stuyvesant was a commander in the Dutch West India Company. As director-general for the Dutch West India Company he governed several Dutch colonies, including Curaçao from 1642 to 1644, and New Netherland (now New York) from 1647 to 1664. Piet Hein is also an important commander for the Dutch West India Company. He conquered the Spanish silver fleet in 1628, which greatly impacted the 80 year
} 
important role in $17^{\text {th }}$ century colonial history. Peter Stuyvesant had even been the director of Curaçao on behalf of the Dutch West India Company, leading the colonial government in the colony's early years. She had been taught to be proud to know their names. Not once had she doubted or critiqued their colonial contributions. They were the same national heroes I grew up with, and it would not be until graduate school that I would see them as oppressors instead of heroes. Two small Curaçaoan children's books aside, I knew no Curaçaoan or Surinamese literature. It was never part of our literature classes in school, nor of hers. She knew some stories about Anansi - the spider that always tricked everyone - which she would sometimes tell my brother and me. And she taught us one of the few Papiamentu songs she had learned when she was little:

Nos ta bai Hulanda, den bapor Franses

Su master ta di oro, bandera Ulandes

Bònchi riba bònchi, hende riba hende

Sombré ku sinta pretu, Hulanda nos ta bai ${ }^{82}$

We are going to the Netherlands, in a French ship

Its mast is made of gold, the flag is Dutch

Bundles stacked on top of bundles, people stacked on top of people

Hat with a black ribbon, we are going to the Netherlands

war between the Dutch and the Spanish. Michiel de Ruyter was a Dutch admiral who played a crucial part in the $17^{\text {th }}$ century Anglo-Dutch wars.

${ }^{82}$ The song dates back to 1908, when the Netherlands and Curaçao were at war with Venezuela. During those times the South American continent struggled with ample revolutionary wars, seeking freedom from colonial rule. Due to its proximity to the Venezuelan mainland Curaçao became a refuge for revolutionary leaders in exile, who disseminated their ideas among the island population. This song was a parody on the national anthem of Venezuela, and composed to its melody. It was meant as an expression of allegiance to the Dutch Kingdom rather than to the Venezuelan Republic (Moen 2010:43). 
We always giggled about the bònchi, which sounds almost identical to bonchi, which means (little) beans instead of bundles. The thought of piles of little dried beans stacked in the boat's hull seemed funny to us then. Little did we know that the song sang praise of the glorious Netherlands; when she was little the (white) hats with the black ribbons would only be worn by white Dutch colonials, my mother said. The song tells of their happy return to the European motherland. And she followed.

\section{Body Politics}

In elementary school I had always been a bit thicker than the other girls, with weird unruly curls that contrasted starkly with the straight-haired flowerpot cuts of my peers. And I had glasses and buckteeth. However, in my teenage years I got contact lenses, braces, and I grew into an athletically built teenager, lean but with more than average curves. This was long before women like Beyoncé, Jennifer Lopez, Nicki Minaj and Kim Kardashian challenged mainstream ideals of beauty, which at the time centered on slender, straight white bodies. So I struggled tremendously with my body image, always thinking that I was fat. My mother, on the contrary, had - and has - a forever-slim physique that did fit the norms of the mainstream body image.

Still, she always sang praise of my beauty, whenever she could (and can). She is to this day my biggest fan. But I mirrored myself in her beauty, which she herself could not see. And there lay another crux. I silently inherited her tendency for self-debasement, because as a slender brown skinned woman she still did not conform to society's white supremacist norms, including to those of her mother. My father reassured me that my thick thighs were actually much nicer than what he called "camel legs," by which he 
referred to the "thigh gap," something that he absolutely abhorred. It would be many years before I could embrace my curvaceous figure, because the thigh gap certainly was a standard feature amongst the girls in my world. My friends' jeans would tear at their knees and buttocks, after which they continued to wear them, looking 'cool.' Mine however, tore on the inside of my thighs. There was no way to fix that. My jeans lasted about a year, then it was game over for me.

My hair was another "seat" of my "otherness." My mom preferred that I wear it up in a neat, tight bun or in a thick braid down my back. She always encouraged me to brush it a hundred strokes a day so it would become sleek and lose its frizz. But of course this had the complete reverse effect. Combing my long curls resulted in a huge head of frizz. Again, today that look is cool again, but in the 1980s and 1990s it really was not. One day my hairband snapped in my gym class, so I had to wear my hair down for the rest of the day. Initially I was quite excited about it, for now I had an excuse to do so whereas normally my mother would discourage me to even think about it. But when I entered the classroom all the boys howled at me: "Look, our own little negress!" "Negress..." At age 13 I was aware that words like "negro" or "nigger" or "negress" were more than derogatory. That was what shocked me first, because my classmates and I were usually on good standing, why would they seek to insult me. But also, again I really didn't get the connection between black people and my - at least to my idea - white looking self.

For a long, long time I hated my hair because no one, not on TV, not in my every day life, no one had hair like me. I always wished that it were straight. It was not until I was seventeen that I discovered that I actually had beautiful curls, as long as I did not 
comb them out when they were dry. This discovery took place at a hard rock concert. My friends and I had gotten soaked by the rain on our way over: Dutch teenagers ride a bike everywhere in any kind of weather. I was wearing my hair in a high, braided ponytail, which had gotten very heavy due to the rain. Once inside I decided to let my hair down. Mind you, I never had never done this. Ever. I looked around the concert hall to see if I saw anyone familiar, other than my girls. I might as well have taken my top of... That was how awkward I felt about untying my hair in public. But it was dark, everyone watched the concert, and I was with my two girlfriends who had seen me in more compromising ways than that. We 'headbanged' along, as was the favorable hard rock dance style, and I loved it, shaking my hair so free and loose. But then, when I went to the bathroom I was dumbstruck. Was that me in the mirror? Was that my hair? That cascade of perfect, gorgeous ringlets that poured from my scalp? I was beyond myself. Never mind that no one had hair like that, I absolutely loved these curls. And I kept them. The rain and the headbanging had unlocked the secret of curly hair, something my mother also had not known about: air dry curly hair, and never ever brush it unless it is wet, so the curls are not unraveled again into frizz.

The next day was a school day. I had not washed my hair when I came home, not yet sure if I would ever get my curls back. So that morning I walked into the kitchen smelling like a bar, but with my glorious curls intact. My mother turned around and looked at me with alarm on her face. "Are you not going to fix your hair?" she asked. "No," I said. And that was the end of it. Since that day my curls have been my pride, my joy, my expression of self, and the seat of my Otherness. It would take another ten years before I realized that they were also a proud connection to my Caribbean ancestry. I was 
overjoyed, and have received mostly praise for them ever since, in addition to the occasional worried question how I managed so much hair, is it not a huge amount of work? I proudly answered that it is not. All I need is a bit of water to touch up my curls, and I'm out the door in five minutes. Some girls in class would tease me by hanging paper clips or other things in my hair, being thrilled and disgusted at the same time that those objects didn't fall out, and that I didn't even notice them. But no one ever said "our own little Negress" again.

In my white world my thick unruly hair, my curves, and my different facial features quickly positioned me within "the slot of the exotic" (Wasserman 1994). At my high school there was only a meager handful of non-white students: three or four people for a total of 1200 white students. Like my mother, people often said I had a kind of unusual, "exotic" beauty that my peers did not have. I was also one of the good students, and I was headstrong, inquisitive and critical to the point of being annoying. But while my mother had always been a bit more timid, I used my intellect, my outspoken nature and beauty purposefully to compensate for the ways in which I felt less than my peers. These positive characteristics became my shield and my negotiating currency to achieve the same thing my mother had always sought to achieve: to belong, and to be the same as everyone else. I felt society's censorship pressing on me, even though I didn't quite understood why, but I tried to push back whenever I could.

Yet my exotic appearance had a flip side, which I did not like at all: the way in which I became over-sensualized by both my peers and my teachers. One day when we were discussing the Romance period my history teacher used me as an example of what 'romance' and 'sensuality' looked like. "Look," he said, "Angela is romantic, you can tell 
that by just looking at her. Look at how she braided her shawl into her hair, and she has

that natural sensuality..." It was such an awkward moment, why did a grown man comment on my fourteen-year old sensuality? But my classmates also thought that I was more sensual and therefore more sexual than they were. They always wrongfully assumed that I had already done "everything" and knew everything about sex. Those assumptions if not accusations were echoed by my Dutch aunties and crushed my youthful innocence in a violent ${ }^{83}$ and racist interpellation. I didn't know that I could rebut it, so I quietly stored it inside of me, and didn't speak of it with anyone. On one hand I was abhorred that I was perceived as less decent, more whorish than everyone else, while I tried so hard to be the same. And on the other hand I felt these assumptions presented me an outline of the role that I was to play as an adult. "A girl like me" should be a sublime mistress. How was I going to fit that expectation?

From the day I was born the old racist and sexist remnants of empire had surrounded and instructed me. Rahier contends that

Black and brown women's bodies and sexuality have been construed as directly opposed to the way European women's bodies and sexuality have been imagined or reported, idealized and standardized as norms for proper female bodily characteristics and behavior (2010:49).

\footnotetext{
${ }^{83}$ In an earlier version of his article The microphysics of colonial power Rahier $(2005,2010)$ differentiates between two opposing types of power. On the one hand he identifies the "legitimist view," in which violence is perceived as "illegitimate use of force," (2005:http://cas1.elis.ugent.be/avrug/violence/rahier.htm); a trespassing that is the opposite of legitimized force and coercion used by the nation-state. On the other hand he uses the concept of "structural violence" (Rahier 2010:47). Following Norwegian sociologist Johan Galtung (1969), who coined the term, Rahier adopts a notion of violence that includes "a whole range of forms of social injustice and reproduction of inequalities imposed by individuals, institutions, or the working of the society at large, which sometimes but not always, and this is the point here - involve the planned infliction of bodily injury, following subjection to physical or psychological force." (Rahier 2010: 47). This is how I, too, use violence throughout this study, and particularly in this case.
} 
This interpellation was a key part of "the grammar of empire," as Sandra Ponzanesi calls it (Ponzanesi 2005:165), to construct the black body, and specifically the female black body, as hot blooded, sexually promiscuous and immoral, inferior (Kempadoo 1999:5-6), and available (Ponzanesi 2005:165), as well as unclean (Kempadoo 1999:10) and "menacing-and-dangerous" (Ponzanesi 2005:165). This ideological construction of the black body justified its inferiority and thus its domination. "The black body became an icon for sexuality in general and $[\ldots]$ sexuality became a metaphor for domination" (Ponzanesi 2005:165). And as I experienced from an early age on, these hegemonic constructions of the non-white body are still in effect today (Ponzanesi 2005:165).

Growing up I clearly felt the contrast with my peers. It felt as if the shape and function of my body were never my own private matter, nor inconsequential. The ferocious sexual appetite and extreme sexual vigor and sensuality people projected onto me from a young age on were so intimidating. I felt as if there never was room to be who I really was inside.

Added to that was the fact that times had changed enormously since my mother's days. In the 1980s and 90s a proper girl was still chaste, virginity still had a value. In spite of the fact that the outside world expected great sexual skill and hunger from me, my mother had instilled a different norm system in me. With regards to sex and my own changing body she had frightened and shamed me enough that I would stay a virgin until a week before my $21^{\text {st }}$ birthday. These had been the rules she had grown up with in Curaçao. As a woman of color she too had had to balance the discourse of the oversexualized black female body with the virginity complex that had for centuries determined the worth of white women of elite standing. 
In the Curaçao of my mother's youth white women were the 'guardians' of European culture, morals and beliefs (Römer-Kenepa 1992:35). In order to protect their respectability they were confined to the domestic realm (Allen 2007:167). For men, on the other hand, it was fully acceptable to be sociable, openly promiscuous even. In postslavery Curaçao the State and the Roman Catholic Church sought to further instill such norms of 'civility, seeking to "influence relationships between the sexes and family life of Afro-Curaçaoans" (Allen 2007:215). The social norms of conduct that once had been reserved for white women now increasingly applied to women of color. Based on the racist ideology of the hypersexual black body these norms of virginity, chastity, monogamy and the sanctity of marriage continued to instruct people in the rules of white supremacy. Respectable young women of color always had to be accompanied by a proper person, and could never be seen alone (Allen 2007:166). In my mother's youth, these rules still applied. As a girl from a light skinned family that aspired to live by white middle class norms she had to uphold those chastity rules. However, in her experience the darker skinned girls with whom she went to school were far more free in their interactions with boys and men.

Someone had once spotted my grandfather when he took my mother to the movies. She had been a teenager then. He had put his arm around her shoulder as they watched, but the acquaintance had recognized only my mother and not her father. Sophie, my grandmother, was notified that Dorothy had been to the movies with a strange man. Even though she had been in proper company my mother was still punished severely for the possibility of such a trespassing. 
My life was significantly different. I could become anything I wanted, be anything I wanted, go anywhere I wanted. I had a freedom that she had never had. But the rules that had applied to her still existed. Thus, in an era and a country in which anticonception was readily available, emancipation of women and sexual freedom were the norm, peer pressure sky rocketed and chaperones had long gone out of style, instilling fear and shame in me was more than a perpetuation of a racist value system. It was the best - and only - way my mother knew to protect me.

I was, however, not aware of her motivations and beliefs. I was dealing with my own struggle: how to be that hypersexual woman society expected and feared me to be. As always literature was my refuge. In the library I found plenty material, so I vigorously and virtuously studied the erotic writings of Anais Nin and the Kama Sutra. I never allowed myself to discover my sexuality through the actual interactions with boys. Instead, I studied for the role I thought I had to play, and prepared a performance in which there was little room for finding out what I might like myself. As the years unfolded, this prescribed role caused me much damage, for I bowed to those specific oppressive repertoires in the national discourse I was raised in, instead of sailing my own course. So unknowingly I embraced my share of "lesserness," lacking the knowledge to recognize and oppose it.

It would take me many years to discover my true sexuality. It would also take me many years to learn that "exotification," "over-sensualization" and "-sexualization" were all discourses that aimed to subdue and appropriate me as a woman of color (see Rahier 2010; Said 1978; Stoler 2002). At first I bowed to it. But when, during my studies in Anthropology and Caribbean Studies I discovered Caribbean literature, I gained access to 
counter discourses in which women were strong, resourceful powerhouses as well as sensual beings who owned their sexuality and reveled in it unabashedly. If I had been assigned this slot as an "exotic" woman, over time I would come to flip the script and truly own and explore my sexuality. But clearly I was not quite there yet.

\section{The Ethnicity Game}

As an adolescent, ethnicity began to penetrate my self-understanding in terms of “otherness.” At age 19, I moved to Amsterdam to study Cultural Anthropology. While my world in Castricum and Tilburg had been so white, in this old metropole that Amsterdam is I met multitudes of immigrants and travelers passing through. I was happy to live in a space with people from all kinds of cultures and backgrounds. But people always seemed to wonder where I belonged, what slot I fit in. Time and time again I was asked where I really came from, to which I would answer either "from here, the Netherlands." If I was in a good mood I would add: "but my mom is from Curaçao." Many did not believe me, so I would make up fantastic stories about me being from Timbuktu, Uzbekistan, or Lake Titicaca, just to throw people off. To my surprise people from all over the Levantine region, Asia, Africa, the Caribbean, South America and virtually every corner of Europe thought that I was from their country. When in Canada Native Canadian people even thought I too was Native, or Maori. In a way I found it entertaining 'collecting' ethnicities. I also felt it unsettling to be so interpellated by complete strangers when I myself did not yet know what to call myself. Sometimes this ethnic labeling by others turned hostile, for example when the older generations of veiled Muslim women in my neighborhood in Amsterdam scoffed at me for wearing the bare 
belly tops that were so popular in the 1990s, or when a Turkish or Moroccan boy would stop on the street to yell in my face for eating during Ramadan, or shoulder block me off the curb for walking with a black friend.

I could not name myself. Until my move to Amsterdam my experiences had predominantly been shaped by the meanings and values of the white people around me. My black mother subscribed to those meanings so unequivocally that I never even realized that she was, or better said is, black. And that I - by extension - am too. She never passed that identity on to me, because she herself was so eager to shed it off. She did not see reasons to be proud of that part of our heritage. She just knew its limitations, and sought to shield me from it. Following the logic of the system in which she had been raised she taught me how to be white. Yet I was so longing to define myself as Caribbean, as part black, but I could not for the life of me see how I would fit, how I would ever be allowed in.

So in Amsterdam, amidst all of these people from everywhere I remained ambiguous, confused and ignorant about my identity. I remained that white girl with her mixed heritage bobbing behind her like a little balloon on a string. I attended black poetry circles, hip hop, reggae, salsa and zouk parties, I had had both white and black boyfriends, got initiated into the Regla de Ocha, visited the Ethnographic Museum of the Tropics almost every month, and I had friends from everywhere. I became an "Other." Though still racially and ethnically undefined, I felt better than the white label I had grown up in. In my academic work I also found solace and a sense of belonging. From my first class in cultural anthropology on I focused on the Caribbean, on Curaçao and Surinam. But back then, in the mid 1990s, much to my surprise there was not one 
department at any of the universities in the country that specialized in the Caribbean. I enrolled in three different universities in three different cities, so I could follow every class taught on the Caribbean. I studied Caribbean literature, history, politics, economics, jumping on one train after the next to make it on time to my next class. My work began to zoom in on colonial oppression and its many heritages, including racism. So it was also through picking up the sword of knowledge and fighting this "good fight" that I finally dared to declare myself a partial insider.

\section{Entering the Field: Curaçao 1999}

Near the end of my Masters' degree I traveled to Curaçao to visit my family and to "go home." It was the first time I went by myself, without my parents and my brother. By now I was already an anthropologist, preparing for a future field study on the island. That summer, when I first entered my field as a scholar, I did so as a "white-ish" woman, but certainly not as black, or mixed-race even, which is distinctively an American category. I was barely even aware that I had been socialized as a white woman. My aim was to explore colonial heritage in a post-colonial society, but my personal experience with race was mostly characterized by being oblivious to it. In fact, I knew virtually nothing about race and its role in this heritage. My knowledge was by and large shaped by my academic inquiry, which I had done at white Dutch universities, studying with white Dutch professors. Even though their contributions to my training had been rich and invaluable, as stated previously, race is a taboo notion and thus left unmentioned in classes. There were many such silences in my Dutch education. So I was fully unprepared for what I was about to encounter on my first Curaçaoan solo trip. 
My cousin picked me up from the airport. As we drove towards their house I remember thinking "I thought the island was prettier." In spite of - or perhaps because of - having studied Cultural Anthropology for over four years, the Caribbean Paradise Paradigm had lodged itself in my mind. Compared to the obsessive neatness of the Netherlands Curaçao indeed looks rather run down, with streets full of tears and holes big enough to drown a small donkey. The houses of every shape, color and level of dilapidation imaginable, faded billboards, and street dogs exploring the trash stuck in shrubs and cacti. This was exactly the kind of spontaneity I had always missed "back home" in the Netherlands. In spite of the strict moral undertone left behind by 250 years of Catholic Missionary work I quickly noticed ample space for people to invent and reinvent themselves. I wasn't used to that. It seemed as if there were less rules, or more opportunity to break them. Compared to the monotone and monochrome architecture and landscaping of the Netherlands, Curaçao felt like an explosion of some sorts, an abundance of things that seemed decrepit but that were in fact not quite broken at all. It wouldn't take long for me to appreciate the perfect imperfection of this place, and to reinvent myself anew, in ways that I had never imagined.

It started that very night, after I had unpacked my bags and settled in at my aunt's house. I was sitting on the porch, putting on my shoes, getting ready to go dance with my cousin, when my aunty shared with me the only rule of her household. She said: "You can do anything you like, just as long as you do not come home with a black man."

"Wait, what?" I did a double take. I honestly wasn't sure if she meant what she said, or if it was a horribly misplaced attempt at a joke. Never in my life had I heard someone so dear to me make a comment so racist and blunt. 
I thought: "But she is my family, and we are not like that!"

I thought: "But my mom—her sister—is black too, so she cannot be serious..."

I thought: "Wait, her own skin is brown, can black people say this about each other?"

My aunt did not elaborate; she had already walked away. But I would soon find out that she was not joking. And that condemning racism was not a genetic trait that I shared in equal measure with my relatives. I would soon learn that Curaçao's colorist ideology, or color hierarchy (Hoetink 1958) was a living and breathing construct that effects everyone, whether they agreed with it or not. I had read about it in Hoetink's old historical description of the island. Now I was engulfed by it. That summer became an involuntary crash course in the rules of Curaçao's pigmentocracy ${ }^{84}$. "Don't come home with a black man..." These words became my guiding light. Never as a rule to live by, but as a moral code to crack, pulverize, reroute. I was now adamant to excavate the roots of this horrifying system into which I had just awoken. I thought that it will make for a rocky ride.

I soon discovered that in Curaçao my light skin and curly, but not kinky, hair corresponded to an upper-tier position. The sudden privilege I got, startled me. I resisted it, finding it incredibly unjust. But no matter how I wanted to self-identify as an "average" girl, or even as the slightly "less equal" woman I had always been, I could not shake off the labels society placed on me. I scrambled to learn, for I was not at all

\footnotetext{
${ }^{84}$ Here it is of great importance to remember that in Curaçao a colorist system or pigmentocracy prevails (see appendix I), which means that skin color is ranked on a scale of white (top) to black at the bottom. This corresponds with the social class system. This correspondence of course is not watertight; over the decades and centuries many black people have moved upwards on the socio-economic scale, and there has always been a small percentage of white folks that are not part of the middle and upper classes. However, the general rule of thumb remains that the upper classes are primarily white, the middle classes are mixed, and the lower classes are predominantly black.
} 
familiar with any of these rules that connected color to status and socioeconomic class. I found it difficult to distinguish between different skin tones, features, hair types, to even notice somebody's skin color, let alone attach a value to it on a scale of good to bad, socially acceptable to pariah. And I had yet to learn the different markers of socio economic class and how people negotiated them on the island. I had to decipher which neighborhood or bario is associated with what social status and stereotypes, what brands of clothes, cars and drinks were ranked high on the status ladder and which ones were not. What beach you go to, what types of music you listen to, what clubs and supermarkets you frequent, where you eat, what kind of dog do you have, whether you wear your hair natural or not, all of that took me years to learn, with trials and errors. I learned, but most and foremost I tried to defy this pigmentocracy. I wanted no part in it. Until one night I nearly got raped by a young man I thought I had befriended. This tragic event gave me a rude awakening, and made me realize that - especially as an anthropologist - I should know better than to impose my Dutch worldview in which racial equality seemed so real, while disregarding Curaçao's social and racial/spatial ordering of people and things because they were too "uncivil" and too uncomfortable for me.

At the salsa dance night class that my cousin and I always went to on Wednesdays I once met a handsome dark skinned guy. I had been talking to him for a while. I liked his rawness, the way he was taking the world in with some kind of bewilderment. Sure, I had noticed that he often wore the same outfit, which none of the other people in the group ever did. I knew that he came by bus, while none of the others did. He lived in one of the poorer, more dangerous neighborhoods of the island. For me, someone from a lower socioeconomic level than mine would make a person less interesting. I had also noticed 
the dynamics between him and the rest of the group. People would be kind to him but they didn't interact much with him. I asked my cousin about it. She said:

"He is a good person to know when you're in trouble. He will always stand up for you, people are afraid of him. He is fierce, you don't want to mess with him."

- "But is he your friend?"

"No, you gotta be careful with him, don't get to close to him."

But based on what she had told me I didn't see why I had to steer clear from him. So I didn't. I enjoyed the chemistry, the dancing, his fiery eyes. I wanted to know him better.

On the last night of my stay, my cousin and I went to a dance night at a beach club. I had told the young man, who I will call Rayquon here, about our plans. I was happy to see him there. However, the night didn't turn out the way we planned. My cousin had been feeling under the weather all day and only came out because it was my last night. She went home early though, and arranged for me to get a ride from a friend of hers, a light skinned young man of Asian descent. Now I finally had a chance to chat freely with Rayquon. I didn't speak much Papiamentu yet, and he didn't speak Dutch very well, but we managed. He seemed a bit shy, a bit uncomfortable even, but eager to spend time with me. We sat on a table at the edge of the dance floor and exchanged stories, enjoying the music, the breeze, and the setting sun.

Then a friend of my other cousin approached me. That summer I had spent quite some time with him and my cousin, so we spoke for a few minutes. It is worth noticing that this young man was light skinned, with a big head of blondish curls. When I turned back to Rayquon he was agitated and grabbed my hand, saying that the guy who was supposed to give me a ride back had left, and that we had to catch up with him. He 
dragged me away from the party to the boardwalk that led to the next club, and I followed, never giving it a second thought. The boardwalk was quiet, surrounded by bushes and palm trees. Suddenly he tripped me, I never saw it coming. I landed on my back, and in a reflex I put my foot against his chest, blocking him, so he could not fully lay down upon me. But he was trying, and he pinned me to the ground with his arms. I knew I was in trouble. I did the only thing that popped into my mind. I looked him deep in his eyes and said:

"If you do this I can never like you again."

I do not know where the words came from and what gave them their power, but somehow that line snapped him out of his craze and he pulled me back up. He dusted off my skirt, grabbed my hand and pulled me back to the party. But I wasn't ready to be dragged along again. My head was reeling, what had just happened! Why on Earth had he attempted to rape me, after we had had such a fun night? Just before we got back to the club I stopped him. I had to know what had come over him, so I asked him:

"Why did you do that..."

He turned around, a bit taken aback by my question, and answered:

"Because a girl like you would never just be with a guy like me."

It took me a few moments to take in his words. I understood him, but the sadness of the reality behind his actions hit me like a wrecking ball. He had no reference for an "uppity" white girl—a Dutch girl— that acted like me. It didn't matter that I had been genuinely interested in him; he perceived me as too different, too far removed from what he could "have." I also felt his sadness, over what he had attempted to do, while all he wanted to do was genuinely get close to me. His belief that such a thing was impossible for him had 
come between us. That night left me breathless. The earth had moved, but not in a good way.

My sad exchange with Rayquon blasted away another layer of my ignorance. I realized that I could seek to break the moral codes of the pigmentocracy to my heart's content, but I still had to be mindful of them, acknowledge their existence, and treat them with respect, whether I agreed with them or not. I could self-identify as underprivileged, which in the Netherlands made sense maybe. However, in Curaçao I was not on the bottom of the social ladder, I was at the top. It outraged me, the disgusting absurdness of racial preferences. And I felt as if I suddenly betrayed my mother, my relatives and friends who were of color. I raged, yet, I had to come to terms with it. If I wanted to acknowledge and comprehend Rayquon's experiences, his worldview, his understanding of me, I had to see him through his eyes as best I could, through the eyes of the Curaçaoan society. Even if I really did not want to. But in the end I had to accept that not until I understood his way of seeing me, could I find a way to comprehend this society. And not until I comprehended this society, could I find a way to comprehend my mother, my ancestors, myself, and all of the colonial tug-of-war that still rages on.

That night took me straight back to the first amendment of contemporary Cultural Anthropology; "thou shalt not be Eurocentric." Because I was so personally connected to my research setting I had forgotten this. In my urge to challenge and defy this racist system I had in a way been arrogant and ignorant, thinking my knowledge system was superior. Even though I meant well, and the premise of equality upon which I had sought to overrule Curaçao's color hierarchy was a legit one, as a social scientist I had to do better. If I wanted to indeed challenge this color hierarchy I would first have to 
understand it, fully accept its existence, and acknowledge it as a powerful system of meaning that shapes the lives of hundreds of thousands of people every day. My disagreement with its premises was inconsequential here. Thus this night urged me to adopt a more professional anthropological stance, the one that allows us to study abhorrent things without letting our personal judgment get in the way. I have since come to respect Curaçao's pigmentocracy as an emic system of knowledge, and to use its emic notions and rationales to fuel my research and to continue my anti-racist agenda. And I realized that from then on I would have to be explicit and transparent about my intentions rather than simply acting and expecting people to understand me, and simply embrace my value system as if it were the only one in the world. I had to really understand that in order to give everyone the respect they deserve.

\section{Was Never White Until I Came to Curaçao}

This first summer as an adult, visiting Curaçao without my parents, taught me that in Curaçao I am white, which is denoted by the words koló blanku ("white" color) or koló klá ("clear" color) ${ }^{85}$. I do not classify as light-skinned (koló habri or "open” color), as I would be in the Netherlands. In Curaçao I am considered white. Then I am also a Makamba, a somewhat derogatory word for "Dutch person," which as we already saw harbors sentiments of resentment over colonial and postcolonial subjugation. But my Dutch-ness also contributed to my high ranking. Curaçaoan resentment goes hand in hand with a certain kind of reverence to Dutch people. An old colonial stereotype, this

\footnotetext{
${ }^{85}$ See appendix I.
} 
reverence suggests that Dutch people are more skilled, knowledgeable and trustworthy than Curaçaoans are. To my shock this summer revealed to me that I enjoyed copious privileges based on my whiteness and my high level of education, and that I could participate in the realms of the elites in ways that I could never do so in the Netherlands. I desperately did not want to be confined to that Dutch slot. I wanted to participate in Curaçao's society, and become an insider. I frantically learned my first words of Papiamentu, the social codes, I familiarized myself with the food and the music. And I had my relatives, who were proof of my at least partial belonging, and my non-Dutch curves, which people often commented on, and I was a good salsa dancer. Little by little I was claiming my own bit of Curaçaoan-ness, in spite of also being a Makamba. I was a partial insider and outsider. And lucky for me, people much appreciated my zest, which they thought was uncommon for a Dutch person, and were happy to teach me how to become a Yu'i Kòrsou.

When after that summer I returned to Amsterdam I had become more comfortable in owning my bit of Caribbean-ness. I was half Caribbean, and slowly but surely I began to behave accordingly. Society responded. I remember watching a music video of Aaliyah with a Curaçaoan friend of mine. In that video, Aaliyah wore her hair braided into thick cornrows. I said that I loved her hair, to which my friend commented that I too was "allowed" to wear my hair like that. He continued saying that it was okay for me to learn Papiamentu, and that my mom's culture also belonged to me, even if she didn't teach it to me. Never before had anyone said such things to me, given me such an outspoken "ok" to become an insider. That was my cue, I plunged right in, and the very next day I had my hair braided into my very own cornrows. And I bought a book on 
Papiamentu and began studying the language, no longer caring about what anyone said. I was plotting my return.

In 2003 I went back. I spent a year on the island, working for the local theater, developing a grassroots "open mic" show for local youth. My language skills were greatly improving. I danced salsa. I became much more socially and culturally able, and people appreciated my desire to belong and my enthusiasm to make positive contributions to Curaçao's overall wellbeing. I stayed for a year, returned to the Netherlands, and came back for another year in 2006. By then I claimed my Caribbeanness, calling myself half Dutch, half Curaçaoan and Surinamese. But still I was seen as a white girl, and dared not define myself otherwise.

\section{Was Never Black Until I Moved to the USA}

This changed when I moved to Miami in 2007. I had been accepted to FIU's Ph.D. program in Cultural Anthropology. I began to study race while partaking in a society that uses a very different understanding of race than what I had been used to. People would often mistake me for a Latina, which I rejected. But also, people began to call me black. Suddenly I was confronted with the colloquial remnants of the "One Drop Rule," which labeled me black or mixed-race, as a sub-category of blackness. In every day life I noticed that the privileged position that I held in Curaçao did not apply. Here I belonged to the slot of the "Other," yet in a different way than in the Netherlands. In the Netherlands I had been exotified, and I had often felt lesser than my white peers, which resulted in a certain level of discomfort and even underachievement. But I would compensate with being smart above and beyond my exotified beauty. I became apt at 
using the flip side of my exotification to my advantage. That often worked, as both markers give access to different sets of privileges. However, in Miami and the other big American cities I visited I was just an "Other," like so many others. Again I had to negotiate my identity differently. In a way it was easier to blend in in the US, as "Others" can be a citizen and no one will question their eventual citizenship, as people do in Europe when asking "Where do you really come from...?"

People thought of me as Latina or as black. I rejected the first label because my ethnic and cultural roots are too far removed from Latin American culture ${ }^{86}$. But I did embrace the second. What a strange experience it was for me, to have people see me as a light skinned black woman. For the first time in my life I could self-identify as mixedrace or even black without people so much as batting an eye. I felt liberated and empowered, and a bit sneaky for I was indulging in the realms my mother and our Caribbean relatives had kept locked away from me in their intricate silences. But in this new world no one cared about my divergence and convergence. For the first time in my academic career I had black professors and black fellow students. I had access to a whole new realm of thinking and experiencing. I began to connect to many black scholars. I studied their books, studied with them, and befriended them, until I realized that "them" had become "us."

\footnotetext{
${ }^{86}$ Many Curaçaoans do accept the "Latino" label when abroad, as they have been immersed in Latin American culture, language, music and history throughout their lives in Curaçao. The island receives numerous television and radio stations from the South American main land, so whole generations have grown up with the music, telenovelas (soap operas), films, game shows and news from that region. This tie with the mainland has been strong since colonial times. There has been a strong Latin American cultural presence on the island through the ongoing flows of trade, people and popular culture between the island and the mainland (Hoetink 1958). Many Curaçaoans are fluent Spanish speakers, to the point of being well versed in recognizing and even speaking different Spanish vernaculars. However, I spent 30 years in the Netherlands so I do not have any of this familiarity with "Latin" culture, and therefore did not feel comfortable claiming it.
} 
In my course work I learned about the intricacies of race, of exclusion and inclusion, of privilege and marginalization. In the Netherlands and the Dutch Caribbean race had always been a rather taboo topic in academia and everyday conversations, so this new degree I was pursuing filled in so many blanks. It started to fulfill a hunger that had haunted me for thirty years. My research had always been a very personal journey, but now it seriously shifted gears. In my classes I began to discover how these taboos I had been educated into, and the silences I had been raised in truly pertained to me, and I began to recognize more and more ways in which I had been objectified, marginalized, "Otherized" in the Netherlands. My new awareness enabled me to explore and uproot important silenced parts of my personal experiences, but also those of my mother and grandmother. Finally, I was able to formulate the question that would break these silences that we had all lived in.

\section{"You Are My Caribbean"}

My studies in the US profoundly changed the relationship between my mother and myself. For the longest time neither my mother nor I knew that any confusion I might have had about me revolved around my ethnic and racial identity. Since my mother had reinvented hers, leaving behind the negative parts as best she could while fully identifying with the Dutch culture, she naturally remained silent about her Caribbeanness. The Caribbean was a painful legacy for her, plus her white Dutch world was physically far away, which was quite convenient. Her family lived there, and in our little white town Castricum there was no such thing as a Caribbean community. So like her mother, who had never spoken about Surinam after she moved to Curaçao, my mother did not speak of 
Curaçao. Yet it was there. Her silence was what first taught me about the island, for like I said silence is not empty space.

I picked up on certain norms of behavior, which over time I came to recognize as norms that fit a light skinned woman who can "marry upwards" in the color line, like both my mother and grandmother did. Somehow I knew very well that there was a preferred way of being and a preferred type of prospective husband. Perhaps the clearest direction I received from my mother was to not wear my hair loose and wild. The hints were very subtle, but directive. They showed me that I could be something proper, decent and successful, but also that there was something else that I had to be watchful of to avoid any downfall.

It was not until I began my studies in Miami that I was able to have a civil conversation about it, without getting mad at her for never sharing her culture with me. My newly acquired knowledge and insights gave both my mother and I a vocabulary that we had never had, and my questions unlocked understandings that had always laid dormant in her, but that she had never been able to access. In one of our talks she explained that to her I had never been a white child, nor was I fully Dutch to her. I was her child, perpetuating and representing her blood, showing that she never capitulated. She might have left the Caribbean, she might have adapted and found refuge and life within the Dutch culture, but through my existence she showed the world that she was still a Caribbean woman. She said:

You are the bridge between me and being the European woman that I can never be, because of the features that I have. But also with your mixed features, you represented the goodness, the beauty of my Caribbean, without the pain of a 
wounding past, and I have always been proud that I perpetuated my

Caribbeanness in you (Dorothy, Interview 11 Nov 2013).

This was the very first time that my mother named me; after thirty years I discovered that I was her, by extension. And deep inside she had always been proud of who she was, even though her world had not encouraged that. I realized that indeed, I had always been a silent and rather helpless witness to my mother's longing, for Caribbean music, food, that familiar space she could no longer inhabit. But it was not until she spoke those words that I understood how much she had sacrificed, just to find a place where she would be appreciated. Exchanging the joy and the at-homeness of her Caribbean space for the Netherlands, and never being able to enjoy her blackness inconsequentially in the locale of her birth and youth must have been traumatizing. Silencing her memories and her cravings was easier than letting them cry for things she could no longer have. Sometimes she travels back though. On her visits to Curaçao my mother will ask me to take her dancing, and she will dance all night, every night, for as long as she is on the island. She will ask me to take her to local restaurants, to places where they sell roti and $\mathrm{pom}^{87}$, and stews, rice, beans, fried plantains. She will stock up, so she can survive, she says, when she is back in her white Dutch world.

My mother's words revealed that—just like me—-she lives betwixt and between locales; that she lives by conflicting repertoires that both scold and celebrate whiteness and blackness. And so I am my mother's daughter, just as she is her mother's daughter, her mother who also had to build a bridge between two conflicting worlds inside of her,

\footnotetext{
${ }^{87}$ Surinamese chicken pie made from mashed tayer roots.
} 
and who had to bury her great grandparents in the silence of racial inferiority, and set sail as a "white" woman with a brown child in tow. Although our lives are very different, we ultimately all share the same pain, the same craving to belong and to be home, and be accepted as we are. My mother and grandmother lived in times and spaces that were less forgiving with regards to race, phenotype and gender than I do. But—each in our own way —we all found harsh oppressors as well as nurturing sanctuaries in our silences, and each in our own way we complied, but also always resisted, rebelled, and proved the world that we could outdo the expectations it had of us.

\section{Conclusion}

The intention of this chapter was to make visible how hegemony works, how ideologies of white supremacy are internalized, and how they shape us, and the most intimate dimensions of lives, often without us being consciously aware of it (Gramsci 1971). These three stories of our lives highlight the deliberate and unconscious choices we made, seeking to improve our lives, satisfy our curiosities, and keep ourselves safe, in the face of —often implicit—race-based challenges and restrictions.

Our transnational and intergenerational stories also illustrate how the colonial ideology of white supremacy over the course of centuries shifted from an explicit to a more covert form: here we see that, as Gramsci argued (1971), hegemony is never static, but always adapts to new contestations by the masses. Each territory has its own particular historical trajectory within the Dutch empire, and developed its own culture and ideology of national identity. But what surfaces in these accounts is that the tenets of white supremacy that perpetuate in these territories have remained fairly stable across 
time and space (Gilroy 1995). Our stories are testimonies of the racism that is part of the national ideologies in Surinam, Curaçao and the Netherlands. They illustrate that white supremacy remains the norm, even in more contemporary times, and while it strongly shaped and shapes our lives, it is not always easy to identify it. At times we were acutely aware of the pain and discomfort that racial exclusion and oppression caused, without being able to identify its cause, and at other times we were aware of the discomfort and thought it was normal—just the way things are (Bourdieu 1977; Gramsci 1971).

Furthermore, the chapter shows that hegemony is executed and protected, but also challenged by a complex tangle of silences, which entail multiple dimensions of oppression and resistance: our stories are full of silences, generated by censorship, omission, denial, avoidance and resistance. And it is perpetuated - among othersthrough the realm of intimacy, which Stoler (2002) identifies as a micro-dimension of imperial power (2002). The nature of intimate relationships, which in colonial and postcolonial space is deeply racialized, informs both the elites and the masses of their respective place in society, and racial hierarchy.

But intimacy is one dimension of the gatekeeping mechanisms that were discussed in chapter 1; our stories reveal many more. We complied with these gatekeeping mechanisms, but we also sought to omit them, and found ways to circumvent the marginalizations and exclusions that they composed. Hegemonic silences muted us, and shielded the oppression into which we were indoctrinated, but at the same time silence was also our space of safety, noncompliance, and active resistance.

The first main silence is that of our family's black roots, and thus of the existence of Ajoeba, Wolfina, Bruinetta and Julia, and the many others who still remain unnamed. 
Our enslaved ancestors, Bruinetta and Adjoeba, had lived under the yoke of explicit racebased dominance and exploitation, which was wrought with violence and danger. The possibilities of moving away from this detrimental situation were restricted by various gatekeeping mechanisms.

Intimate relations are one social realm in which gatekeeping mechanisms were exerted. Even though I have no details on their lives, the enslaved status of my great great grandmothers will have had a significant impact on the nature of the intimate and procreative relations they will have had with men—white and non-white. And these intimate relations in turn reinforced the social status that was associated with their racial identity. The ban on mixed race marriages during slavery, and the unspoken norm of white men raping, bedding, or living in concubinage or other kinds of unions with nonwhite women had communicated and reinforced the norm of white supremacy. As Stoler indicates (2002), these restricted arrangements of intimacy and procreation between blacks and whites sent out a powerful message of white superiority ${ }^{88}$ (Stoler 2002), and prevented people of color from joining the ranks of the white colonials, even in the case of interracial marriages, or being a child of a white father.

Mixed race marriages were legalized in Surinam and Curaçao at the end of the $19^{\text {th }}$ century. It is interesting, to say the least, to note that once people of color were officially allowed to wed, Bruinetta and Adjoeba's daughters Julia and Wolfina both married men that were to all likelihood white. This may signal both the power of

\footnotetext{
88 This power balance between black and white was and is always profoundly gendered. Unfortunately it falls outside the scope of this study to duly elaborate much on gender. This is, however, an important topic for future research, see appendix X.
} 
hegemony (complying with the Eurocentric norms of respectability) as a resistance to it. These young women had both been born into slavery and had known intimately the ramifications of the system. To all likelihood they had been well aware of the fact that marriage to a white man would enhance the upward social mobility of their children and themselves. It will have been a way to distance themselves from a traumatic past, rife with wrongdoings that had been legally justified.

The ideal of whitening through miscegenation became a theme that to this day lives quite strongly in our family. Both my great-grandfather Rudolph and greatgrandmother Laurina were born from a marriage between a black (though possibly partly white) and formerly enslaved mother and a white father. Compared to their darker skinned mothers, the lighter phenotypes of my great-grandparents and of my grandmother, allowed them a higher social status in Surinam and later Curaçao. Whether they did so consciously and purposefully or not, over the course of their lifetimes they shed their blackness, and their connection to slavery. Or family's past became silenced, whitewashed. This was again a silence that was both hegemonic in its adherence to the white-is-better ideal, and a form of resistance: it was a deliberate moving away from detrimental influences, and seeking a stronger social position (Sheriff 2000).

When my grandmother Sophie had a darker skinned child — my mother—she was displeased: in spite of her light phenotype her genes had revealed our family's African roots. Sophie temporary abandonment of her darker skinned daughter was also a censuring silence, one that temporarily hid her "tainted" progeny, and her failure to comply with the rules of the performance of passing that was expected of her. This silence was complicitous, but it was also a coping mechanism that temporarily protected 
Sophie from losing her social standing. Soon after she married a light skinned man of European and East Indian descent (or at least so his family narrative goes). Marriage complied with the norms of white respectability, but again we must also see this as a protective measure and act of agency, as it helped hush the negative impact that having a baby out of wedlock, and especially a darker skinned one, could have had on her reputation.

My mother too chose a white husband - my father. Like my grandmother, she also closely observed the politics of respectability. Dorothy was always very properly dressed and well behaved: she married her first real sweetheart. In doing so she sought to limit and avert the white supremacist hegemonic hypersexualization and exotification that she was well aware of. The adoption of norms of white respectability gave her a way to strengthen her social standing. This did mean that she had to denounce her Caribbeanness: another silence that was both hegemonic and empowering. Although it hurt her to give up her true identity, it did enable her to create a satisfying life.

My decision to date a dark skinned man met with significant resistance by at least part of my relatives: my aunt's warning to not come home with a black man was the most explicit. And to date, very few of my uncles, aunts and cousins have came home with a partner darker than themselves. Also, I have never heard my predominantly brown skinned relatives refer to themselves as "black" or "Afrodescendant." The persistence of this silencing, which has become a family tradition, so it seems, suggests that protection from racial marginalization is still needed, and that accommodation to ideals of whitening still yields rewards, and thus that white supremacy endures. 
But silence also played a role in the ways we perceived ourselves. The temporary concealment of Dorothy's existence, when Sophie left her with her grandparents, would forever echo in the self-censoring silences my mother crafted: as a young child Dorothy literally tried to erase herself. She made herself invisible, remained quiet: a coping mechanism to shield her from the shame her mother had instilled in her. Her taking on a different ethnic and racial identity was a way to mute and escape her blackness. It was therefore a hegemonic silence that acknowledged white superiority. It was also a complicitous silence: no one had ordered Dorothy to censor herself in these ways, or to take on the subservient roles in the household. She was aware of there "being something wrong with her," but she did not comprehend exactly what it was about, and acted upon it rather than to question or challenge it. But still, the element of coping and keeping herself safe is also part of this silence. It helped her camouflage her pain. Without ever being explicitly aware of the gatekeeping mechanisms that instructed her, she navigated them, and in doing she replicated and confirmed white supremacy, but later in life she would also challenge it.

Unbeknownst to herself Dorothy extended her muted blackness and Caribbeanness to me, raising me away from her part of my cultural heritage and identity. Until I was well in my thirties I didn't know that I was Afrodescendant, or how to speak my mother's language, or cook the Caribbean dishes my grandmother excelled in. But I knew, without anyone ever telling me so, that I was different from my white peerslesser. In the Netherlands of the 1980s and 1990s, where I grew up, sexuality and propriety were defined much more freely than in the Curaçao of her days. The emancipation of women and the normalization of birth control, which had been far less 
avid when my mother was young, allowed me to partially redefine my mother's Caribbean code of respectability. But only to a limited extent. For I still participate in the same society as my mother, and live by hegemonic codes that I too am only barely aware of. That quiet internal voice of oppression and racism still dictates me, in spite of my extensive education on the topic. It took me a decade of thorough education to see how I had internalized white supremacist hegemonic ideology, how I too was continuously hypersexualized and exotified, and how that had shaped my choices, and still continues to do so. Even though I now sometimes catch myself, I still police and censor myself. I probably always will.

The fact that I am a very light skinned and highly educated, middle class woman growing up in largely white surroundings for a long time added to the prevalence of these hegemonic silence. I rarely had to deal with explicit racist exclusions, and when they did occur I didn't recognize them. I never endured police violence. Because of my light phenotype and my white surroundings my ignorance of racism persisted, as does my light privilege.

But my silences also shield the shame that I feel over feeling inferior. I never wanted to bring that up and tell people about it. Instead I compensated for it, tried to be the smartest, pretty, to define myself in my own way. This was my secret way of empowering myself, my coping mechanism. And silence for a long time has had an incubating function: I needed to finish my research before I came forward and started breaking hegemonic silences. Until now I have not spoken, written, or published much about racism. I have not retorted to my aunt. I have been waiting until the time is right, 
which was first with the release of my documentary Sombra di Koló ("The Shadow of Color") in 2014, and now upon the completion of this dissertation.

This chapter provided ample illustration of the intimate and intricate mechanizations of hegemony and white supremacy across the Dutch imperial spaces of Surinam, Curaçao and the Netherlands, and the intricate tangle of silences that protect, implement and contest them. In chapter 3, I turn back to Curaçao, and present an ethnographic examination of how Curaçaoans experience race and nation today. 


\section{Chapter III}

Race and Nation as Every-Day Lived Experience: An Ethnographic Study

Bos di buriku no ta yega shelu.

The donkey's voice doesn't reach heaven ${ }^{89}$.

- Curaçaoan proverb

\section{Introduction}

The objective of this third chapter is to assess what is the specific work done by Curaçao's Yu'i Kòrsou multicultural ideology of national identity on Curaçao’s inhabitants. The chapter examines the discrepancy between the unity and equality that is so avidly proclaimed by the Yu'i Kòrsou ideology of national identity, and the persisting racial inequality that was so little addressed and yet so easily observed. How do Curaçaoans perceive and experience racial inequality? And how does racism as part of multiculturalism operate in ways that people are not always aware of? Do people claim that there is equality and unity, as the Yu'i Kòrsou ideology of national identity suggests? Is racism in their perception indeed obsolete? In what ways do people experience racial inequality, and do they contest it?

In this study I conducted largely unstructured interviews with 29 Curaçaoans ${ }^{90}$ of all walks of life. In order to observe how national ideology is experienced in this society

\footnotetext{
${ }^{89}$ The donkey and the horse star in many Caribbean proverbs, including Curaçaoan ones; the horse (kabai) represents the white master, and the donkey (buriku) the black common folk. These horse and donkey proverbs provide a rich and critiquing body of folk wisdom on Curaçao's race relations. This proverb means that the voice of people of color is not heard - what they have to say doesn't matter. Another very telling proverb is "Si mi a nase buriku, mi no por muri kabai: if I was born as a donkey, I cannot die as a horse," which suggests that if you are black you will always remain black. Even if you manage to move upwards in society, you will never escape the label of inferiority that you were born with.
} 
that is highly differentiated by race and class I have conducted five case studies, each one in a different socioeconomic neighborhood. These neighborhoods approximate Curaçao's social stratification of race and class. In the pages that follow I describe how I entered these five communities, built rapport, selected respondents, participated in everyday life, and collected my materials. There are so many stories to tell that this chapter alone could have filled my entire dissertation. It presents a content analysis of the stories I collected in these communities, to which I've added my findings from participant observations.

Since this is a pioneering study, I had to develop a way to operationalize race, which is not one of the criteria used in the census. From my aunt's inquiry about the dark skinned young man I had brought home against her rules it dawned on me that there was something about neighborhoods, barios in Papiamentu, that I'd better elucidate. When she questioned him as to see what his social status was, she asked him what bario he was from. When he answered "Buena Vista," she had given a disapproving and all-knowing look: it was one of the poorest and most troublesome neighborhoods of the island. As time went by and I got to know the island better, I too acquired the skill of placing people on a social map by the neighborhood they live in. In Curaçao these neighborhoods are often quite homogeneous as far as the race and class of its residents, as I would soon discover. But more importantly, race and class conflate, Oostindie (2000) argues. Given Curaçao's segmented nature, residentially speaking barios could thus be seen as emic units of analysis that each time provide a seat for the multidimensional intersection of

\footnotetext{
${ }^{90}$ The sample was designed for 30 people. I will explain later on in the chapter that I had one non-response.
} 
race and class. With the lack of census materials or any other statistical material on race, I decided to use the bario or neighborhood as a proxy for race.

My first task was to choose a number of barios that seemed to provide a good cross-cut of Curaçao's society. To this end they had to differ significantly in their class and racial make up, and include rural and urban barios. Further requirements were that the neighborhoods would be very well known on the island, so respondents would immediately recognize them and association them with racial and class categories. Also these neighborhoods should be more or less homogenous in class. If my assumption that race and class conflate to a large degree were true, then homogeneity would be necessary for the neighborhood to serve as a proxy for race. With the aid of Curaçao's Central Bureau of Statistics I sifted through demographic and statistical data on these different barios in order to define the different class levels that coalesced with the racial segments of white, lighter brown and dark brown. I looked at numerous possible indicators of socioeconomic class such as income levels, education, teenage pregnancies, population density, size of the residence, unemployment rates, and modes of transportation. Since the census does not use fixed labels of socio-economic class I took the lowest and the highest average incomes of all neighborhoods, and divided them up in four brackets. These I named "below subsistence level," "working class," "middle class" and "upper class." It had been my consistent observation that the below subsistence level and working class barios have predominantly dark skinned inhabitants, the inhabitants in the middle class are of various phenotypes but mostly lighter skinned, and the upper class barios are predominantly white. Next, I made lists of neighborhoods that would both fit the class brackets as my requirements. In order to determine whether these 
neighborhoods would indeed fit the requirement of homogeneity I spent many afternoons driving and walking around a large selection of neighborhoods to see who lived there, and to ask the neighborhood population to describe who lived there. When I had a shortlist of barios I tested it on a general audience, asking them to describe these neighborhoods for their socioeconomic ranking, racial composition, and their "character." Table 1 shows the five barios that I selected for this study, in relation to some of the indicators that I used to determine their socioeconomic class.

Table 1 Socioeconomic Markers for the 5 Selected Barios

\begin{tabular}{|c|c|c|c|c|c|}
\hline & $\begin{array}{l}\text { Barber } \\
\text { (rural) }\end{array}$ & $\begin{array}{l}\text { Seru } \\
\text { Fortuna } \\
\text { (Seru } \\
\text { Papaya) }\end{array}$ & Otrobanda & Janwé & $\begin{array}{l}\text { Spaanse } \\
\text { Water }\end{array}$ \\
\hline $\begin{array}{l}\text { Median }^{91} \text { gross monthly } \\
\text { income } \\
\text { per household in } \\
\text { Dutch Antillean Florins and } \\
\text { US Dollars }\end{array}$ & $\begin{array}{l}3350 \\
1872\end{array}$ & $\begin{array}{l}1200 \\
670\end{array}$ & $\begin{array}{l}1800 \\
1006\end{array}$ & $\begin{array}{l}4500 \\
2514\end{array}$ & $\begin{array}{l}10.000 \\
5587\end{array}$ \\
\hline Teenage mothers $\%$ & 13.1 & 14.1 & 8.0 & 3.0 & $*$ \\
\hline $\begin{array}{l}\text { School participation } \\
15-19 \%\end{array}$ & 81.4 & 74.7 & 76.8 & 90 & 92.6 \\
\hline $\begin{array}{l}\text { Highly educated per } \\
100 \text { low educated }\end{array}$ & 17.9 & 12.0 & 22.3 & 73.3 & 204.4 \\
\hline Unemployment \% & 10.6 & 32.9 & 18 & 6.7 & 2.5 \\
\hline
\end{tabular}

Source: census 2011, Central Bureau of Statistics Curaçao.

* means that the value is too small

Map 5 shows where these neighborhoods are. The western part of the island is a rural area, with lots of uninhabited land and a few small villages. Willemstad, the only urban area, is positioned slightly East of the center. The uninhabited area on the Far East is private terrain, belonging to an old family of the former colonial elite. The spatial

\footnotetext{
${ }^{91}$ For income levels I chose to use the median rather than the average, because it avoids distortions caused by outliers.
} 
sequence in the class distribution of my selected barios is not representative for the class distribution on the island.

Map 5. The Five Barios

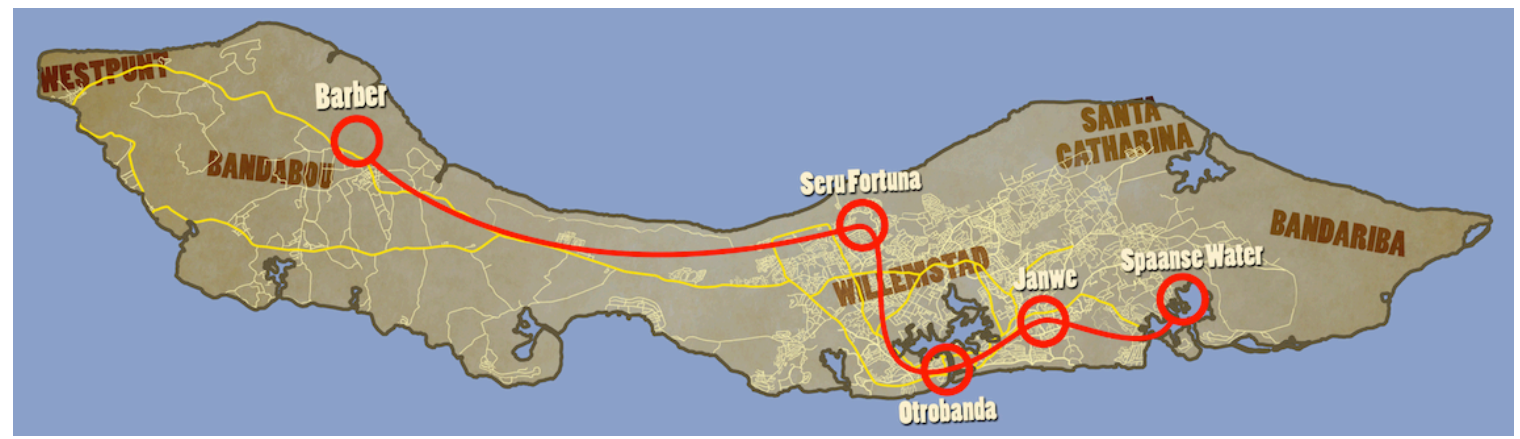

Source: Sombra di Koló Documentary 2014

\section{Introducing The Five Barios}

Barber is a village in Bandabou, the rural area of the island and the part of Curaçao where many of the old plantations were situated. It developed as a church village that emerged around a plantation. After slavery ended many of the freedmen continued to work on these plantations through the share-cropping system called paga tera, which translates as "pay for land" (Allen 2007). Since people here are often times descendants from former slaves, and since there were far less white or mixed people here than in the city, the population is commonly very dark skinned. Barber is considered to be quiet and peaceful, the beating heart of the rural area, where traditions are preserved and where people are though to be much more polite and less spoiled by urban life. However, the urban population also tends to consider Barber - and Bandabou at large - to be intellectually 
and economically 'backwards,' even though many of its inhabitants go to school and work in the city. Its income level lies between working and middle class ${ }^{92}$.

Barber has two elementary schools, a police office and a fire station, a doctor's office, a small Chinese-owned store, a snèk (a small cafeteria that also sells alcohol), a garage and gas pump, and a small branch of a bank. Two small open air parks - Parke Nashonal Tio Selcio and Hòfi Royer - host various festivals, such as the Siman di Kultura (Cultural Week), tambú drumming performances, Carnival, and political events - all of which draw people from the city. Every Sunday there is a market with local products, which attracts many city dwellers, tourists and local inhabitants alike, as does a third open-air park, Hòfi Pastor, which is home to the island's biggest tree.

Seru Fortuna, which ironically means "Hill of Fortune," is one of the most notorious neighborhoods of the island, where many people live around or below the poverty line. Seru Fortuna is a rather secluded bario, built on a hill on the north side of Willemstad, right underneath the main approach and departure routes of the airport and next to Campo Alegre, a large-scale open-air brothel. One must really be headed to Seru Fortuna to end up in it; there are no main road leading through it, nor is it at all visible from the main road leading to the airport. All you see is a green hill. As a consequence many people don't know exactly where Seru Fortuna is. Still, due the avid news reports on its high crime rate and raging poverty everybody knows of it. I have been chastised often by upper- and middle-class people for spending ample time there.

\footnotetext{
${ }^{92}$ There is quite a range of income levels in the countryside as there are three gated communities, some of which are very elite, and there are also a few very poor neighborhoods, as well as some other middle class areas. For my sample I selected one of the oldest and most well known villages of the island, one that has always been centrally positioned vis-à-vis the other communities in Bandabou, and one that represents an average of the experiences in Bandabou.
} 
Seru Fortuna started off as Dutch West India Company plantation Steenen Koraal, founded in the early 18th century (Huijgers and Ezechiels 1992:139). It however never yielded much. In the early $20^{\text {th }}$ century Shell laborers took up residency here, as did immigrants from the Eastern Caribbean. In the mid 1970s the government began developing the hill and its surroundings. Government agents leased out parts of the land so that people could build their own small houses. They also developed another part of the neighborhood into a governmental housing project. On the section of the hill officially called Seru Papaya (Papaya Hill) but commonly known as Seru Fortuna, the government built a total of 560 houses modeled after European row houses. However, when finished the houses did not comply with national building codes and were considered too small and poorly built. The houses were then allotted to social housing services. Before long, segments of the poorest population of the island were moved here. During its first decades the neighborhood quickly made a name as one of the worst neighborhoods on the island, characterized by crime, substance addiction, violence ${ }^{93}$, gang activity, ill health, school drop outs, unemployment, and teenage pregnancies. Seru Fortuna's population consists of Afrocuraçaoans of predominantly darker phenotypes. Few immigrants live here. The neighborhood has a few tiny stores that are run from people's houses. There is an elementary school, a church, a doctor's office, a neighborhood center, and a large soccer field. Other than that there are no resources.

Otrobanda, the third bario, is an old working class neighborhood in the heart of Willemstad. This is where my grandparents lived, back in the day. Otrobanda was built at

\footnotetext{
${ }^{93}$ Families brought their old feuds with them when they were relocated. The housing services paid little attention to these social dynamics. Sometimes warring families became neighbors, which often led to life threatening situations.
} 
the end of the $18^{\text {th }}$ century. Until the middle of the $20^{\text {th }}$ century the neighborhood had housed affluent white people, the mulatto middle class, the white working class, and freedmen and enslaved people (Rupert 2012), who all lived next to one another. I selected one clearly heterogeneous residential area to see if the discourse on race and nation would be different. Also, being the old city center, Otrobanda is one of the most famous neighborhoods on the island. The local architecture bears testimony to this diversity. The streets and the intricate networks of alleys show a scattering of mansions, alternated with small slave and laborer's houses and middle class houses. However, since the 1969 laborers revolt the elites left: many of the businesses in Otrobanda had been burned down during the uprising. After that the neighborhood quickly deteriorated. Poor immigrants from countries such as Jamaica, Haiti, the Dominican Republic, Columbia and Venezuela moved into the empty houses, as the rents were low. What was more, during the 1970s, 1980s and 1990s the presence of drugs flared up (Interviews respondents \#15 and \#16, see appendix IX). Since the 1990s however, Otrobanda started to gentrify. The prevalence of drugs and violence diminished. The Monument Preservation Foundation restored many houses, and slowly the neighborhood improved, attracting more affluent people and tourists. Today Otrobanda is a working and lower middle class neighborhood with some gentrified bubbles mixed in. It is still home to a racially and ethnically diverse population.

Otrobanda forms half of the city center of Willemstad. As of the $19^{\text {th }}$ century it has housed numerous schools, churches, convents, retirement homes, the hospital, the population register, restaurants, bars, hotels, theaters, and streets full of stores. It has a large police and fireman station. Also the Carnival and Seú processions pass through 
Otrobanda to end on its main square, Brion Plein, the locale for large national celebration. It is a waterfront neighborhood, so the cruise ships dock here. Thus since its earliest days the bario has important residential, commercial, educational, health oriented, religious, recreational and official functions, and nowadays it draws large streams of people from all over the island and abroad on a daily basis.

Janwé on the contrary, is a very quiet neighborhood, which like Barber, developed around a Catholic Church. It is a relatively new neighborhood, developed in the 1950s. Janwé is inhabited by a well-educated and well-earning middle class. People from Janwé are described in general as considerably lighter than in the lower class neighborhoods like Seru Fortuna and Barber. Comfortable houses, lush gardens with the occasional pool, and SUVs dominate the street view. It is flanked by the Caracasbaaiweg, a main road with lots of shops, but the bario itself has very few amenities. Janwé has no stores, recreational facilities, or a police or fire station. It does have several elementary schools, which attract a lot of traffic from parents dropping of and picking up children, and it has a large Catholic Church.

The last bario is Spaanse Water, which translates as Spanish Water. Here we find a cluster of the richest neighborhoods of the island, populated by the old white and light skinned Curaçaoan elite, a small but growing darker skinned Curaçaoan elite, and a group of wealthy (mostly light skinned or white) immigrants, commonly referred to as "expats." Spaanse Water is built around a large inland water. In colonial times various plantations were situated here, as was an asiento, a disembarking site for the slave ships. Nearby were the slave camp and slave market Sorsaka, where captives would be fostered back to 
health after the horrifying Middle Passage. However, over the course of time this history has been thoroughly whitewashed, nowadays one cannot easily find overt mention of it. In the 1970s Spaanse Water began to develop as a recreational area, mainly for the elites who lived in and around the city center. They built weekend getaways and vacation homes, but before long people took up permanent residence there. The plantations were parceled up and filled up with luxurious villas and resorts, and the asiento became one of the neighborhood's many marinas, still called "Asiento." The vast majority of the inhabitants of Spaanse Water are wealthy, with the exception of a handful of people who bought a parcel in the 1970s or 1980s, when land was still cheap. In general Spanish Water residents are stereotyped as white elites: business owners, CEOs, lawyers, doctors and politicians. They are also stereotyped negatively as former colonizers, people who acquired their wealth exploiting others, and who continue to do so today. They are admired, feared even, as well as looked upon with envy and disdain, and perceived as a group that "sticks to its own," with little interest in interacting much with the masses. Some inhabitants are indeed descendants from planter families, so their riches may indeed correspond to colonial exploits. Others are "expats" from the Netherlands or elsewhere, who moved to Curaçao during the heydays of the Shell refinery, or who came in more recent times to occupy high ranking positions or as entrepreneurs. A small segment of the population is made up of non-white Curaçaoans who climbed up the social ladder, or who were born into privilege. Yet the area remains overwhelmingly white and light-skinned. Spaanse Water is a residential and recreational area. There are no schools, churches, stores, or official institutions, but it has all the more restaurants, resorts, marinas and water sports facilities. 


\section{The Respondents}

The people that I interviewed constitute a good sample of the two main racial groups of the island since the colonial era: white Europeans, consisting of Dutch Protestants and Portuguese Jews; and Afrocuraçaoans. I argue that Curaçao’s color hierarchy developed between these main population segments, which during the more than three centuries of slavery became so heavily infused with racial significance. Since Curaçao is a trading hub, it has always attracted immigrants, both during the colonial era and especially after the Shell refinery opened in 1919. Yet these populations, I argue, found a spot in the already existing color hierarchy, adding nuances but not determining its substance. In the categories of the color hierarchy they are not represented (see appendix I).

Focused on this particular population segment, I developed a stratified probability sample. My aim was to reflect the characteristics of the Curaçaoan population for the variables gender, phenotype, and class. Per bario I selected six respondents, equally distributed over gender (M/F) and age (18-29 / 30-55 / 56+), thus amounting to a total of thirty respondents for the whole sample (see appendix VI for an overview of the anonymized respondents). In every single bario I interviewed three men and three women, divided equally over the three above-mentioned different generations. Since this study addresses the racial dynamics and the color hierarchy of the "old" Afrocuraçaoan and white European descendant population segments, these 30 respondents had to have at least one parent that was either of Afrocuraçaoan or white Curaçaoan or white Dutch descent; people of an ethnically mixed background were acceptable. Also, the respondents had to be immersed in the island culture. Recent Dutch immigrants or Curaçaoans that had never lived on the island were not part of the sample. These six 
respondents also had to reflect the composition of the population in the bario for phenotype and class. If a bario of 700 people only contains a handful of light skinned inhabitants on a significant dark skinned majority the respondents in the sample would be dark skinned. Since there are no statistical data on race or skin color I had to make an estimate of the racial composition of the neighborhood, hence my extensive driving and walking around and extensively asking the respective barios' inhabitants to describe the racial composition of their bario to me.

To get the variation in class I used the sample of the five barios. To ensure variety within these class levels I selected people of a variety of occupations and educational levels. Ideally respondents also belonged to differing social networks. But as they are from the same neighborhood it was unavoidable that some of the participants knew one another and had some relation of some sort. The matrix below, presented in table 2 , reflects the sample design. Age and gender are less important in this study, since there is already a fair body of academic and policy related literature available on both variables, specifically with regards to Afrocuraçaoans. It is the relation between class and race that remains obscure, reason why it is at the core of this study. The variables of age and gender were taken into consideration mainly to generate a sample that reflects Curaçao's population $^{94}$.

\footnotetext{
${ }^{94}$ A thorough analysis of the relation between race, gender and age is not an explicit focus in this study. However, I do acknowledge that the nation is highly diverse and complex, and inherently gendered and sexualized (Goldberg 2002, Applebaum et al 2003). Research regarding these dimensions of race and nation is much needed (see appendix $\mathrm{X}$ ).
} 
Table 2 Sample Design Interviews

\begin{tabular}{|c|c|c|c|c|c|c|c|c|c|}
\hline Age & \multicolumn{3}{|c|}{$18-29$} & \multicolumn{3}{|c|}{$30-55$} & \multicolumn{3}{|l|}{$56+$} \\
\hline Gender & \multicolumn{2}{|l|}{ M } & $\mathrm{F}$ & $\mathrm{M}$ & \multicolumn{2}{|c|}{$\mathrm{F}$} & \multicolumn{2}{|l|}{$\mathrm{M}$} & $\mathrm{F}$ \\
\hline $\begin{array}{l}\text { Phenotype } \\
(\text { scale) }\end{array}$ & \multicolumn{3}{|c|}{ Black - - - white } & \multicolumn{3}{|c|}{ Black - - - White } & \multicolumn{3}{|c|}{ Black - - - White } \\
\hline Education & High & Med & Low & High & Med & Low & High & Med & Low \\
\hline Income level & High & Med & Low & High & Med & Low & High & Med & Low \\
\hline Occupation & \multicolumn{3}{|c|}{ Various } & \multicolumn{3}{|c|}{ Various } & \multicolumn{3}{|c|}{ Various } \\
\hline Social network & \multicolumn{3}{|c|}{ Various } & \multicolumn{3}{|c|}{ Various } & \multicolumn{3}{|c|}{ Various } \\
\hline
\end{tabular}

For the selection of the respondents, I started with finding various key players for each bario (such as community workers and residents) who knew the neighborhood well and who had many social ties in the bario. These I found through the sentro di bario or "neighborhood centers" that most barios have, and through asking people in my own network for such key players. After explaining my project I asked these key players to help me find people according to the matrix I provided, I also asked them to introduce the research and myself to the potential respondents. Since the focus of my research is a rather delicate topic these intermediaries were most helpful in creating a first bit of rapport. I met some of my respondents as I was simply walking down the street. However, I found the vast majority of my respondents through the networks of others. Initially, people were surprised by the research topic: as mentioned, race is not at all a common topic of conversation. Also people were surprised that I, a light skinned woman who was not raised on the island, was conducting the research. Especially in Barber and Seru Fortuna I encountered this response: people indicated that they were not used to see a light-skinned person care about racial inequality. In Seru Fortuna, Barber

\footnotetext{
${ }^{95}$ The variable for phenotype is a fluid range, not a binary.
} 
and Otrobanda people were very enthusiastic about the research project, and immediately began sharing stories. It was much harder to find respondents in the middle class neighborhood Janwé and upper class neighborhood Spaanse Water. Especially in Spaanse Water it happened continuously that potential male respondent in the $30-55$ age category, who had initially agreed to participate, dropped out at the last minute. Those who explained why they withdrew said that they were afraid that they would be recognizable somehow, and that they would be portrayed as racists. This shared fear of being depicted as racist is remarkable, to put it mildly. It at least suggests that people are afraid of their own answers. Due to this consistent non-response, the sample of Spaanse Water consists of five instead of six respondents. But the white, upper class, male, 30 to 55-aged segment aside, people from all barios were eager to share their stories.

\section{Interview Protocol}

Initially I had been worried about how to break the silence around the topics of race and racism, and get people to talk. As I explained in chapter II, growing up in a society where race was practically a taboo topic I had been apprehensive to address it myself. During my earlier fieldwork I had expected my respondents to feel the same gene. However, during field research conducted in 2006, 2008 and 2010, I had noticed that people very comfortably mentioned racial features in describing one another. One of my female cousins, born and raised in Curaçao, would always describe her love interests first in terms of the color of his skin and the kind of hair he had before she would tell me anything else. "He is tall, white, with straight hair and green eyes...", she would say. I 
already knew that people speak in racial terms on a daily basis. They just did not voluntarily speak about the things that happened to them as a consequence of race.

Still, initially I was hesitant to ask directly about people's experiences with their skin color and with race in general. Would they get angry, sad, come apart at the seams? In my first research design I planned to ask people about the tambú, the deeply rooted yet rather controversial Afrocuraçaoan drumming tradition that I discussed previously. In December of 2010 I had already conducted preliminary field research on the tambú, and the oral testimonials I had collected then and the participant observation I had engaged in had shown that tambú's past and present were deeply embedded in Curaçao's racial divide. But one day, shortly after I had returned to the island in 2011 I ran into an elderly lady who I had known for some years in the supermarket. I was in a hurry, but she greeted me enthusiastically and asked me what I was working on. I looked for the shortest answer and said "I am studying race in Curaçao." Much to my surprise this catapulted her into a lengthy exposé on her experiences with race in elementary school. The nuns had been unkind to her as she was one of the black girls in the school. She had to sit at the back of the classroom, while the white girls sat in the front. She often got punished, slapped on the fingers with a ruler, and was not allowed to ask questions... I barely knew this lady, and yet she shared a most intimate story with me.

I continued to experiment with my one phrase, "I study race in Curaçao," and discovered quickly that in supermarket alleys, on Sunday afternoon beaches, in professional meetings, bars, on birthday parties, complete strangers and friends alike spontaneously combusted, pouring out their experiences, not to say grievances with race in Curaçao. The censure on race and racism is thus specific rather than all encompassing. 
People did talk with me about race, but not out of the blue. Yet when prompted slightly they spoke easily and in depth. I began to notice that when I did not ask a specific set of questions but only provided a bare minimum of information on my research-“I study race"-people would volunteer all sorts of stories that actively mattered to them, about current situations that bothered them, or about things that had happened long ago but that had always continued to hurt. Because these deeply personal and emotional stories came out so easily and so fast they had a very genuine quality to them. People were not giving me politically correct answers, they were really sharing, some were even unburdening themselves. Often stories were shared with such zest that it appeared to me that they had been kept in too long, as if my small prompt pushed the lid off an old pressure cooker, releasing quite a billow of steam.

During these informal conversations I also noticed that people responded very well emotionally. No one collapsed into a heap of psychological distress, and no one got stuck in their rage, which is what I feared would happen after reading Robin Sheriff's account of race and racism in a Brazilian slum (2001). There she argues that one of the reasons why her respondents generally avoided talking about racism in order to not fuel their frustrations, and relive these painful experiences (Sheriff 2001). In my research, however, I consistently found that people expressed relief and excitement, about being able to unburden themselves without feeling judged, dismissed or reprimanded. Over the years I had observed that a common response to talk of slavery and racism is "You should let the past be, not keep pulling open old wounds. Slavery ended 150 years ago, are you still going on about that?" Or "Racism is in your own mind, if you experience it it's because you were looking for it." Those answers are very consistent with Bonilla- 
Silva's findings about "color-blind racism" (2010). Time and time again I saw that exhalation, the release, when people spontaneously shared stories they had not been invited to share before. Some people even hugged me afterwards, or told me "I have never even told this story to my children." That's when I decided to reshape my research, to abandon the topic of the tambú and instead focus exclusively and frontally on race, race relations, and racism in Curaçao, and to use as few questions as I possibly could.

Given that this is a pioneer study I wanted to take inventory of people's experiences with and narratives about race and nation. What stories are most at the surface in people's lives? Was their discord and contradiction in their stories? What place do race and nation occupy in their lives? But also, what topics never arose? I decided to create as open an interview model as possible. I expected that this would invite people to share whatever topic came to mind, rather than depart from a list of topics that I would have formulated, which would be based on my specific set of experiences and observations, and on scholarly literature on the working of race and racism in other national contexts. It would be unavoidable that such a list would be biased and limited. I used my prompt "I study race in Curaçao" as the basis of my interview model and added only one open question: "Tell me something about race and color." This was the start of every interview. Rather than leading the directing of the interviews through using a premeditated protocol, I followed the respondents into their stories, and asked for clarifications along the way. My follow up questions were completely unstructured and spontaneous. The only questions that were part of a protocol of sort were about the respondent's demographic profile and the way they described their own skin color (see 
appendix VII for the interview protocol). The result was a range of very in-depth stories that were far broader than the topics I could have selected myself.

But I had more reasons to choose this unstructured open model. Firstly, it put people at ease. Curaçaoans are often afraid to answer questions because they are afraid to say the wrong thing and look stupid (Antonius 1996). I have encountered this many times when teaching at the Curaçaoan university: ask a question, no one replies. An interview about a sensitive, censured topic could have severely aggravated this reluctance to reply. But in this interview model I asked people to tell me something that they wanted to share rather than what I wanted to hear. I asked them about them, not simply about a social phenomenon. Plus my questions had no possible wrong answers: anything people wanted to share was perfectly acceptable. I intended to show a genuine interest and respect for the person and their story. I was not directing their stories or imposing my thoughts. This is an especially important element in the tension between (Afro-)Curaçaoan and Dutch people. Ultimately, even though I am partially Dutch and partially Curaçaoan tend to label me as Dutch. But I am very light skinned and highly educated. This combination of phenotype and class makes that people label me as "blanku" or white ${ }^{96}$, which in nonwhite neighborhoods gives me an outsider status. Because I was not raised on the island, and as a consequence my Papiamentu has a Dutch accent, people also label me as Dutch. Dutch people are usually seen as very directive, bossy, overly assertive, and seeking to be in charge. I actively wanted to avoid or at least diminish this association. Therefore in this interview I made sure that my respondents had the lead, and I followed.

\footnotetext{
${ }^{96}$ See appendix I.
} 
Another advantage of this "storytelling" method is that it diminished the socially desirable response. Some respondents started out with socially desirable or politically correct responses or with a specific narrative, but because they talked extensively on the topic their conflicting thoughts, schemas and emotions would also surface. This interview format provided ample room to follow the narrator in the meanders of his or her memory and motions. Some respondents realized, as they heard themselves talk, that they had stuck to some idea that was in fact racially oppressive, without them even realizing it $^{97}$. Those were also very interesting moments, for both the respondent and I. Naturally not all respondents descended deeply into their emotional memories, mostly because not everyone is equally talkative: some people are long winded; others only shared a brief story. But I had also built less rapport with some than with the others: not everyone was equally comfortable around me.

This chapter builds on moderate participant observation and informal conversations, in order to thicken the interpretations of my findings.

\section{Raceless Narratives}

Theoretically I needed a framework that would guide me in identifying the presence of the Yu'i Kòrsou ideology in people's stories, as well as the covert racist system that operates within it. To achieve this I firstly draw on the theories on hegemony and the

\footnotetext{
${ }^{97}$ Those "aha moments" were an unexpected added value. I also noticed that the interviews made people think. Not so much about things I said, but because they heard themselves speak. Quite a few people started talking with parents, friends, siblings, or children about the topics we discussed. To many it simply had not occurred to do that. And many had not thought that they had so much to say about the topic. People were often very excited about this. To my joy, many let me know afterwards what the ripple effect of the interviews had been.
} 
creation of national ideology (Gramsci 1971; Goldberg 1993; Hobsbawm and Ranger 1983; Trouillot 1993) and on multiculturalism (Brondo 2010; Hale 2002, 2005; Hooker 2005; Goldberg 2002; Greene 2007; Rahier 2012), which were discussed in chapter 1. I combine these with the theory on silence and its various hegemonic and counterhegemonic dimensions, presented in chapter 2 (Bourdieu 1977; Goffman 1967; Scott 1995; Sheriff 2001; Tannen 1985; Trouillot 1995). In this chapter I add an emphasis on racelessness and colorblindness, which I mentioned briefly in chapter 1 is a key mechanism in multiculturalism.

I have argued that Curaçao's multicultural rendition of the Yu'i Kòrsou ideology appears to promote diversity and intercultural equality, specifically with regards to the Afrocuraçaoan population and culture. However, pro-black empowerment is deflected at the same time. "Racelessness" or "colorblindness" is a common way in which multicultural ideology promulgates, but as David Goldberg argues, this so-called "racelessness" is in fact a mirage. Through formally rendering race and racial categories "unnamable" and "unspeakable" (Goldberg 2002:222), racelessness in its various forms facilitates rather than eliminates racial inequality, because it remains embedded in the very structure of the state and its bureaucracies. It takes away the vocabulary through which racial inequality can be discussed and addressed, it prevents addressing the historical and structural roots of racial inequalities, and it explains contemporary racial inequality as the outcome of nonracial dynamics, which places them outside of the realm of government intervention. This why I place ample emphasis on identifying it in the stories presented by my respondents. 
Goldberg takes mostly into consideration South African, U.S. and U.K. contexts, but scholars such as Charles Hale (2002, 2005), Shane Greene (2007) and Jean Rahier (2012) writing about Latin American contexts, identify these same mechanisms of oppression. The effect of racelessness, Goldberg argues, is threefold. Firstly, it erases reference to European colonialism, exploitation, and current racial marginalization from the public debate, "thus reshaping the narrative of European history and memory" (Goldberg 2002:217). Second, it censors direct critique or analysis of racism. And thirdly, because of these omissions and censors, the "causal connections between colonial legacies and contemporary racial conditions in Europe and settler societies" is placed out of sight (Goldberg 2002:218). Goldberg therefore views discourses of racelessness as "neoliberal attempts" (Goldberg 2002:221) at moving away from racial equality.

Eduardo Bonilla-Silva, who researches race in an American context, elaborates on this. He illustrates how in color-blind discourse the role of race is erased (Bonilla-Silva 2010). Instead, a number of explanatory frames and storylines describes racial inequality as the fault of the victim instead of a larger race-based structure. Society is seen as a space of equal opportunities that people may or may not choose to use to their advantage. Racial inequality is seen as the outcome of individuals and their choices. Affirmative action is therefore not needed. The government should not force social change upon people; when people are ready for those changes in well-being and life style, they will make them. In this explanatory frame racial phenomena are seen as "natural occurrences" (Bonilla-Silva 2010:28). Segregation, for example, is seen as the outcome of racial groups preferring to live with people who they like and can relate to. They therefore "segregate themselves." 
These explanations of racelessness or colorblindness, Bonilla-Silva argues, require "ignoring the multiple institutional and state-sponsored practices behind segregation and being unconcerned about these practices' negative consequences for minorities" (Bonilla-Silva 2010:28). They perpetuate the status quo of white supremacy and the perpetuated minority status of blacks and other non-whites, countering affirmative actions and reparations, and providing legitimate outlets to express hostility and resentment toward non-whites.

For an understanding of racial marginalization in Curaçao we must also take into account the impact of colorism as a specific form of racial discrimination that is interwoven with and operates simultaneous to "traditional" racism. Again I borrow from American literature on race. Legal scholar and critical race theorist Angela Harris explains the difference and interaction between these two types as follows:

Racism involves discrimination against persons based on their racial identity, which in turn is traditionally designated through a complex mix of selfidentification and other-identification through appearance (including color) and ancestry. Colorism involves discrimination against persons based on their physiognomy, regardless of their perceived racial identity. The hierarchy employed in colorism, however, is usually the same one that governs racism: light skin is prized over dark skin, and European facial features and body shapes are prized over African features and body shapes (Harris 2008:54, see also Banks 2000; Burton et al. 2010; Hunter 2007).

Colorism entails (but is not limited to) black-to-black racism (Hunter 2007:238). Racism, though quintessentially premised on white supremacy, also takes place between 
people of color who have internalized white supremacist values. As we saw in previous chapters, these values attribute greater privileges to light-skinned people of color compared to dark-skinned ones. Even though racism is first premised on the overall racial or ethnic category, in a colorist system the actual skin tone is an additional, and often determining, factor (Harris 2008; Hunter 2007). As Hunter explains, processes of racial discrimination thus take place on what she calls "at least two levels: race and color" (Hunter 2007:238). The first level is the systemic racism referred to by Bonilla-Silva (2010) and Feagin (2006), which is exercised through ideology and pertains to a specific racial group as a whole, regardless of skin tone nuance. On the second level the nuance of the actual skin tone exerts an important influence. "Although all blacks experience discrimination as blacks, the intensity of that discrimination, the frequency, and the outcomes of that discrimination will differ dramatically by skin tone" (Hunter 2007:238; see also Banks 2000; Burton et al. 2010; Harris 2008). "Traditional" racism and colorism may manifest as "raceless" or "colorblind" racism.

While the discussion above refers mainly to racial dynamics in white majority nations such as the USA and the Netherlands, the contents of the previous two chapters show that raceless ideologies are also at work in Curaçao, which has a majority nonwhite population ${ }^{98}$. In this chapter I continue to identify the different manifestations and mechanizations of Curaçao's multicultural ideology of national identity. I specifically focus on racelessness as a means to forge an ideology that propagates racial inequality

\footnotetext{
${ }^{98}$ There are various other types of racism that can be defined, such as cordial racism (Owensby 2005), and silent racism (Trepagnier 2010), as well as many other kinds of discourses that are operational.

Consequently this study does not seek to be conclusive, but must rather be seen as a first exploration of this field, and an invitation to others to extend this line of analysis (see appendix X).
} 
and inclusiveness; forge a whitewashed and glorified historiography of the ruling class; and deflect subaltern resistance and omit pro-black reform.

\section{Findings from the Bario Case Studies}

The main question I asked was: "Tell me something about race and color." This yielded all sorts of stories, about family ties; romance; having the "right" color children; hair styles and getting jobs; the schools of the friars back in the day, and the school system today; riding bicycles; not being seen as a full member of the sports team because you don't have the "right" color. There were stories about white privilege and being discriminated against on the work floor, and about a Dutch nurse in the 1960s who tried to wash off the brown color of her patient's skin. Not one story was alike, not one story addressed the same topic. Also, in each bario certain narratives surfaced that spoke to the particular class- and race-based challenges or privileges of its inhabitants. I will first present the findings per bario. This makes visible how people perceive and experience racial unity as well as inequality in these separate racial and class segments, and how they reproduce and critique these hegemonic ideologies.

In the second part of the chapter I provide a deeper analysis of the reproduction and critique of hegemonic ideology. I specifically seek to identify the influence of Curaçao's multiculturalism. Even though each story had been so different from the next, the interviews and observations also yielded a large body of analogous data that revealed how people perceived and experienced race, and also how they perceived and experienced the role of the national ideology of unity through diversity. For example, while someone may not state directly that "black is negative," their story might illustrate 
that this is in fact their experience. In similar fashion, my respondents did not say "I am trivializing racism" but their stories illustrated that they did. Therefore, in order to subtract this data I composed a series of short statements regarding people's experiences with, perceptions of and attitudes towards race and national identity (see appendix IX), and analyzed each interview to see if peoples' stories corroborated these statements or not. This is yet another way in which these non-structured interviews allowed me to obtain a broad range of data without having to directly ask respondents for it and risking getting socially desired answers.

Given my explicit interest in identifying the racist objectives of Curaçao's multiculturalism, in the data I specifically looked for the ways in which people reproduced the hegemonic national ideology of unity and equality; referred to racial inequality; used narrative strategies of racelessness, deflection, trivialization or whitewashing of racism and racial inequality; and their address (or lack thereof) of black agency, empowerment and resistance.

\section{Barber}

In the six stories from the rural village Barber the first narrative that surfaced was one about Curaçao's overt racism. The respondents attribute some of the discrimination they have suffered to being from a rural area, which the urban population considers backwards and inferior. But mostly the respondents, who are all dark skinned, attributed this

discrimination to racism. In response to my one question, “Tell me something about race and skin color" their stories mostly relayed negative experiences. The topics of unity and equality hardly arose. 
The two older men (\#1 and \#6), both above 40, elaborated on the Catholic education they received as children. Through the white-oriented school materials and the teachings of the friars they learned early on that black was lesser than white. The books they read in the friars' elementary school, such as the "Puk en Muk en Moortje" series by Franciscus van Ostaden, a friar from the order of Tilburg, were full of "coonish" black characters casted in dumb, lazy and delinquent roles. The white characters, on the other hand, were always smart, proper, and depicted as actual humans. This ridiculing and shaming of blackness affected them and his peers greatly, the older respondent said. They would demean one another for being black, but the white kids were never teased. "We learned that blackness was bad, and being white was good, so everyone tried to be a bit lighter," he said. His story reveals the power of Curaçao's color hierarchy. But also, as a smart and well-behaved child he identified with the white characters: he simply did not recognize himself in the black characters. He didn't think much of the racial inequality reproduced in these books until he attended secondary school and started working, which was in the 1950s..Initially those books had taught him that only white people could be smart, proper and successful. But as a young adult he began to realize that he was just as smart-or even smarter- as his white student colleagues and co-workers. This awareness led him to counter at least part of the racist ideas that he had internalized.

Even though he doesn't think that the books were purposefully made to oppress black people, he does say that the Dutch friars favored white and light skinned kids over the darker skinned ones. This was a societal trend, he said, which generated envy and resulted in a community that has remained divided by color. As an adult he observed the same attitude among his bosses, who pitted their employees against one another. 
“Therefore people of color are never united," he said. "There is always jealousy, envy and competition. This way we never make progress as a group." His story challenges the unifying tenet of the ideology of national identity: Curaçaoans are too divided to ever unify. At the same time it also exemplifies the power of racist indoctrination-it took him a while to figure out that these representations of blacks in school materials were incorrect and hurtful to him. Also, he partially trivialization of the active role of the friars in racist knowledge production. Still, his story also demonstrates his awareness of racial inequality, as well as his critique on it.

The two younger women (\#1 and \#3) both shared stories about how colorism plaid out in their contemporary school settings. The younger respondent (\#1) experienced discrimination and segmentation in the racially diverse high school she attends, the other respondent (\#3) described how in the all-black elementary school where she teaches children tease and bully each other with racist imagery and insults. This black-to-black discrimination illustrates how these young children have already internalized the tenets of white supremacy, and use them to strike at their peers, and criticize and curtail themselves.

Except for the young male respondent (\#2) everyone said they witnessed and experienced racism personally. The two older male and the middle female respondent (\#3, \#4 and \#6), however, told me that they were successful at not letting such things hurt them, to the extent that for \#3 and \#4 especially it is hard to even name incidents. This indicates a narrative of deflection and trivialization of their experiences with racism. The youngest female respondent (\#1) was considerably more weighed down by the racism she experienced, but respondents \#3 and \#6 elaborated on their coping mechanisms. The 
female respondent $\# 3$ described to me that she puts negative behaviors or comments in the wind and lets them blow away; the senior male respondent (\#6) said that he has a special drawer in his mind where he stores such occurrences, so they don't affect him, he says. He has always known exactly who he is and where he is headed: racist comments and actions have not held him back. But it takes effort. It takes years to dominate these coping mechanisms.

These six respondents talked about these events with emotional distance, as observers of these unpleasant moments rather than as emotionally reliving them. Sheriff (2001) states that it hurts to remember and talk about such personal experiences, and people direct their efforts daily at not feeling this hurt. But when I was at the school to conduct the interview with the female respondent in her thirties, some of her pupils wanted to talk with me: three young boys of 11 and 12 years old, all dark skinned. She had told her students about my study, and they had been waiting for me for weeks, she tells me. So we sat down with them on the school's patio. They told me about the names they are called by their peers: "tar," "dirty motor oil," "Zulu," "slave," etc. When they come home from school they often feel sad, listless from these verbal attacks. Sometimes it makes them cry. At night they pray to God to give them a lighter skin the next day, they say. The spontaneously shared stories of these young boys do reveal how racism wounds. The contrast between their emotional rawness and the many stories that would follow, which were all told by adults, is an indication of people learning to hide their emotions, as Sheriff argues, in order to protect themselves from the pain, and from possible repercussions (Sheriff 2001). 
I had expected the respondents from Barber to be more connected to the past of their families. Several of them live on land they inherited from their ancestors, who had been born in slavery and bought parts of the land they had been forced to work on. But my respondents didn't seem to have much interest in their family histories, or they preferred to not speak of them. No one mentioned slavery, plantation life, the white plantation owners, not even when I asked about it. Other pivotal moments in the emancipatory history of the island and its black population, such as the revolt of May $30^{\text {th }}$ 1969 and the positive effects it engendered, only surfaced briefly in the interview with the teacher (\#3) classes. She draws from this history of black empowerment, and also hints at the unifying and egalitarian message that the national ideology promulgates, to teach her pupils to stop bullying. She told me: "Black people are not bad, we are charismatic people, hard workers; we also have leading positions in society today." But a little while later she says: "Nothing that is black is good," when indicating how the color black has so many negative connotations. She urges her students to not tease each other with being black, "because when someone says that to me I will think I'm the blackest." Her tone implies that being the blackest is the worst thing one can be. In her educational strategy both the ideology of equality as that of racial inferiority surfaced, which exist and operate side by side.

No one mentioned the notion of the "Yu'i Kòrsou." The young male respondent (\#2) did express his appreciation of Curaçao's diversity, which is central in the Yu'i Kòrsou ideology: he stated that we are all the same, and that he likes everyone in equal measure. He thus did replicate the tenets of the Yu'i Kòrsou ideology. But like the senior male respondent he too added that unfortunately there is no unity in Curaçao: people are 
too focused on nuances in skin tones, and on being envious of each other's possessions and social status.

\section{Seru Fortuna}

In Seru Fortuna people did not talk about unity and equality when I asked them to talk about race and color: they did not reproduce the Yu'i Kòrsou ideology. Some of the respondents started off saying that they never experienced discrimination, but as their stories unfolded everyone addressed the impact of overt racial inequality on their lives, and the many challenges they face on a daily basis as dark skinned people living in a poor, black neighborhood.

The dominant narrative in Seru's stories attests to the extreme marginalization its population faces. Two younger female respondents (\#7 and \#9), respectively dark skinned and a bit lighter brown, talked about how difficult it is to get into a good school or to get a job. People enroll their children but will be informed that the school is full, while lighter skinned children or children with a higher social status are accepted: the school was never full to begin with. Respondents brought up this racist, exclusive measure in regards to both primary and secondary education. Children from Seru Fortuna often have to attend schools outside of their bario. There is an elementary school, but there is no secondary education. In those schools Seru Fortuna's youth is often perceived as not performing well, and as being troublemakers by default. The female respondent in her forties (\#9) has three children in high school. She spoke of the impact of poverty, and how the many disadvantages that are related to it may interfere with their school performance. Children from barios like Seru Fortuna struggle at home with the 
challenges that poverty brings, such as malnutrition, parents that have addictions or who are never home because they work two or three jobs, having to watch siblings and take care of the household's chores. They may be traumatized by the violent incidences they observe at home or elsewhere in the bario, or by being assaulted or abused themselves. A social worker working at an elite school once breathed a sigh of relief to me that she did not have to work with "those kids." "They are too much for me," she said, "the sadness, the problems they experience." She works at one of the white schools, where, as she explained, children have less dramatic problems. With regards to opportunities on the job market, the two younger women (\#7 and \#9) and the male respondent in his thirties (\#10), say that as soon as people hear that you are from Seru Fortuna your chances to get a job diminish considerably.

In interactions with people from outside the bario I often experienced how strong Seru's stigma is. The first time I heard the story about children from Seru Fortuna not easily getting into the better ranking schools, I remember having some doubts about whether this was an incident, or indeed a structural problem, as the women who told me the story indicated. I had just met with my first respondent in Seru Fortuna. It had been a nice day, and she had told me some of her stories off the record. They were delicate stories, about her trying to make a life in the face of poverty's challenges and continuous societal rejections. A young man I knew had walked with me around the bario. He showed me areas that had been particularly bad, with bullet holes in the walls. But also the soccer field, the small patches of land at the edge of the bario where people kept goats and grew vegetables, and the small square next to the neighborhood center, where after school teenagers played domino under a large tree. Evening came and I had another 
appointment, so I left. I recorded my field notes in the car and drove down the hill, headed towards the city, where I would meet up with a friend to dance salsa. As I watched the many small, colorful houses of the hill change into big streets with stores I was painfully aware of Curaçao's spatial order. I regretted to have made plans to go dancing. I needed more time to digest my experiences.

I met with my friend and we sat down on the terrace of the fancy club. Two welldressed dark skinned men approached us and began to make small talk. "What have you lovely ladies been up to tonight?" one asked. I answered him that I had spent my day on Seru Fortuna, and I mentioned my research project. Immediately his face cringed, and his friend looked horrified. I continued, recounting the story that had touched me most:

"People there tell me that it is hard to get into a good school, for as soon as the school hears they are from Seru they will say they are full." "But of course!" the man replied. He explained that he himself was a high school teacher at one of the white, elite schools. He said: ${ }^{99}$

They cannot pay the tuition so they cancel themselves out. Which is good, you don't want children like that in your school! We are an A grade school, we want to keep that status, not have it ruined by children like that, who cannot perform. I looked at him, speechless. I discovered later that he and his friend came from higher middle class backgrounds, as I had suspected. My hesitation to fully believe the extent of

\footnotetext{
${ }^{99}$ There are 35 elementary schools in Curaçao. Only five of them have Dutch as the main language of instruction, and one of them is an international school taught in English. The remaining 25 schools are mainly taught in Papiamentu. But the five Dutch schools are highly popular because early instruction into the Dutch language means that children are better prepared for studying in the Netherlands after high school. And since Dutch is a language that has a high professional value a good mastery of Dutch increases children's chances for better jobs and overall upward social mobility. Also, education in these Dutch schools is of a higher quality compared to most of the Papiamentu speaking schools. These schools cost more, so they can afford better materials and they attract teachers.
} 
the discrimination in local school my respondent had talked about that afternoon in Seru Fortuna waned. These two men confirmed my respondent's story of marginalization and racism. In the following months I got many confirmation of that kind.

There are 35 elementary schools in Curaçao. Only five of them have Dutch as the main language of instruction, and one of them is an international school taught in English. The remaining 25 schools are mainly taught in Papiamentu. Between 1935 and 1987 the language of instruction in all schools was Dutch (Narain 1997:24), and was thus taught as a first language, even though the vast majority of the pupils did not speak Dutch when starting elementary school. In 1987 this changed. The advantage of Papiamentu schools for children who have been raised speaking Papiamentu is that they have an easier start in education than if they would get education in Dutch, which at that age often is a foreign language to them. However, early instruction into the Dutch language means that children — and especially those who already master Dutch when starting school—do better at their "state" exams, which are in Dutch ${ }^{100}$ (see also Farkas 2008), and are better prepared for studying in the Netherlands after high school. Also, since Dutch is a language that has a high professional value, a good mastery of Dutch increases children's chances for better jobs and overall upward social mobility, both on the island and in the Netherlands. But what's more, education in these Dutch schools is of a higher quality compared to most of the Papiamentu speaking schools. Enrollment into Dutch schools cost more, so they can afford better materials and attract better teachers. They look for parents who are affluent enough to pay these costs. Speaking Dutch is, as discussed in

\footnotetext{
${ }^{100}$ State exams taken in secondary level education are the same exams as the ones taken in The Netherlands. They are taken on the same day.
} 
chapter 1, a gatekeeping mechanism in and of itself. But the selection procedures at these schools, which appear to be mostly race- and class-based, are additional gatekeeping mechanisms that keep the poor black population out of these schools, and favor the Dutch speaking elites and middle classes.

The stories that my respondents shared about not easily finding a job were also corroborated continuously. Time and time again people from outside of the bario would make disapproving faces or cringe when the topic of hiring someone from Seru Fortuna came up. A CEO of a bank confided in me that one of her employees is from Seru Fortuna. She however confessed that she didn't find out until many years later: the employee had listed an address outside of the bario when applying. He had always been exemplary, she said, and she felt sad that he had not dared to be honest about where he came from. But she also acknowledged that, had she known that he lived in Seru Fortuna, he probably would not have gotten a shot at the job. A dark skinned high school student told me a similar story. She did not live in Seru Fortuna itself. Instead, she lived with her mother at the Seru Fortunaweg, which is the road that circles around the bario. When she applied for a job at the McDonalds the manager concluded that she was from Seru Fortuna, based on the name of her street. He would not hire her, because in his experience the people from that bario could not be trusted. She applied for the job again, but listed her father's home address, which was in the middle class neighborhood Jongbloed. She got hired right away.

The systematic race-based discrimination that inhabitants from Seru experience in both education and employment severely limits them in their social upward mobility. And it creates a narrative inside the neighborhood that engenders a sense of hopelessness 
and unworthiness among the inhabitants. Speaking with the teenagers who so often play and sit under the huge tree on the square I heard how much they want to work, to be taken seriously, to get an education, have a positive prospect for the future, and to help provide for their families. But over the months that I conducted research in the bario I noticed that they don't get much of a chance. Instead these teenagers constantly stomached rejection. Out of frustration and necessity people look for other-often criminal—options, for which they become stigmatized as delinquent and social predators. The dark skinned male respondent in his thirties (\#10) says:

No one wants to sell or carry drugs. It is a dangerous, raw lifestyle. It is hurtful, not fun. But when your fridge is empty and your family is hungry you have to find a solution.

As previously mentioned, in 2014 I joined a government-led working group that was originated to attend to the UN Decade of People of African Descent. The objective was to create a policy plan for the government in which it would again — or finallyaddress racial inequality. This allowed me to repeatedly bring up these issues in formal governmental meetings and in informal conversations outside of Seru Fortuna. But I noticed that in this setting some people were eager to refute the correlation between race and class. This pervasive trivialization fits into the mold of the raceless and colorblind racism that is part of Curaçao's multiculturalism. "People from Seru Fortuna are lazy, they rather get involved in crime than working an honest job," I heard so very often, or “they don't want to study, they have no ambition, so it's no wonder that they never get anywhere.” In current policy making in Curaçao race and racial inequality are not 
addressed, which allows race based inequality and discrimination to persist relatively unchallenged.

Instead of considering the linkage between poverty and racial marginalization, social policy in Curaçao tends to focus more on dysfunctional families and specific cultural patterns and mentalities, often even as a heritage from slavery. However, the explanation of racial inequality through an alleged cultural inferiority is part of colorblind racism, Essed (1991) and Bonilla-Silva (2010) argue. Minority status is rationalized as "a product of their lack of effort, loose family organization, and inappropriate values" (Bonilla-Silva 2010:40, see also Essed 1991). A cultural approach to marginalization silently rests on the assumption of racial inferiority. The stories from and about Seru Fortuna bring these mechanizations of colorblind racism into clear focus.

The second dominant narrative I heard in Seru Fortuna is a rebuttal of the deep, negative stigma directed at the bario. "The neighborhood used to be really bad, but it has improved greatly," respondents said repeatedly. The bad guys died, are in jail, or they moved away, so now Seru Fortuna is a very lovely bario." While the intense crime and violence has absolutely lessened over time, and while to me Seru Fortuna also was a young, lively and friendly bario, this positive narrative deflects and trivializes the fact that Seru Fortuna is still a very poor, secluded neighborhood, with small, run down houses, car wrecks, heaps of garbage, and a plague of stray cats. Crime and violence has lessened, but not dissolved. Barber is perhaps considered "backwards" due to its rural character, but it is considered a "proper" bario, full of hardworking, God-fearing Christians. In comparison, Seru's income level is much lower, its unemployment rate considerably higher, its high school participation and level of education is lower, and 
there still is a considerable amount of crime and violence. There is little to be called "lovely" about that.

\section{Otrobanda}

To outsiders Otrobanda is a working class neighborhood, with an ethnically and racially very diverse population. This is bario is heterogeneous in ethnicity, as it has a significant immigrant population. It is also somewhat mixed in socioeconomic class, with some people that have a lower middle-class income, but the vast majority of the bario belongs to the working class. From the start the leading narrative amongst my Otrobanda respondents was that there was little to no racism in Otrobanda because the bario has always been a happy mix of races and ethnic groups that live in harmony and equality. This narrative closely resembles the Yu'i Kòrsou ideology, even though none of the respondents actually used that term. Some of the six respondents-especially the older ones - claim that Otrobanda's diversity is what Curaçao is truly like: unified and mixed.

The female respondent in her forties (\#15), a brown skinned woman, is a fervent advocate of Otrobanda's unified-in-diversity identity. She took me on walks through Rif, one of the old residential sections of this inner city bario. Built in the $18^{\text {th }}$ century, Rif is a maze of little streets and alleys. I was amazed. I thought I knew Rif. My grandparents used to live here, and I used to work in this part of the city. Yet, I had never really noticed the story that this old architecture told. Even though I had walked these streets

and alleys so many times, I still did not notice that the dilapidated $18^{\text {th }}$ century mansions stand shoulder to shoulder with the smaller houses of the middle classes and the tiny quarters of freedmen and slaves. I had never realized that the streets were only two or 
three meters wide, so everyone really lived on top of one another. My respondent argued that Otrobanda's architecture is the brick and mortar proof that this bario had always been diverse yet unified with regards to class and race. She emphasized the inclusive atmosphere of the bario, and the cordiality and intimacy between the different population segments. But when I asked if people of different colors and classes were truly intimate, if they were friends who sat on the stoops and shared beers, or married each other, or attended each other's weddings, she responded: "No, things were not exactly like that." Interactions were neighborly, friendly but superficial. Neighbors might borrow a cup of salt or sugar, or visit when someone is ill. "It was more of an exchange of things in times of need. Today it is still like that," she said.

Otrobanda's respondents vary in phenotype. The senior male respondent (\#18), a very light skinned man, told with pride that his grandparents were an inter-racial couple, and that his white grandfather was very much in favor of marrying a dark skinned woman. He went to school with children of all colors and class backgrounds, without noticing these differences. Sometimes his mother would send him out to bring food to some needy family in another street. He never realized that she sent them food because they were poor, and that poverty often correlated with skin tone. He particularly remembers the brown boys in his neighborhood for being really good at sports, which he also loved. He mentioned that when he grew up these racial divides were not that important. The revolt of 1969 was the turning point. Afterwards, he argued, the politicians heavily fuelled the racial divide with ideas about Antillianization and creolization. He clearly was not enthusiastic about the revolt and the reform it brought. It 
changed Otrobanda forever, he said. The white elites left, and the bario dilapidated. The revolt did not bring much good.

What stands out most in his account is his appreciation of the Church, and his challenge of the anti-colonial narrative that depicts Europeans as harmful individuals. $\mathrm{He}$ says:

What you hear a lot in Curaçao is that the Dutch have come with their slaves, and there are people who keep stressing that to this very day, how that influence continues to this day. It hurts, it bothers, it oppresses. The assumption is that it has a negative influence on a group of people. So people bring this to the front, people believe this, still. What I wish to say is that it is true, historically, that Europeans brought slaves here. But what I would also like to say is that the same Europeans, and in this case the Dutch, brought a lot of clergy $[\ldots]$ who have done great great work in Curaçao. Especially with regards to education and providing care for people.

Contrary to the respondents in Barber, he is most appreciative of the efforts of the Catholic Church. He described some racist practices of the clergy, who clearly favor white over black. This he condemned. However, to him the good work they did with regards to providing the black population with education and health care was paramount. He perceived the Church as instrumental in black empowerment, not as an instrument of colonial oppression.

Over the years I have often encountered this depiction of European people as benevolent and praise worthy, especially with regards to the Dutch missionaries and the Church, and as I discussed in Chapter I, with regards to the monumentalized architecture. 
Indeed, the majority of the schools on the island have been set up by the Catholic Church, as are all the big hospitals. They have been incredibly instrumental in developing Curaçao's education and healthcare, and in stimulating cultural life and the use of the Papiamentu language. Both black and white people feel strongly about this. So the pluralization of Europeans that this senior male respondent introduces certainly is justified. However, in his particular wording he trivializes and deflects the scale and impact of Curaçao's slavery, and the systemized race-based inequality that results from this. The wrongs done by colonialism were balanced out by the good done by the Church, he reasoned. His story is thus a hegemonic one, and fits in with what I call the discourse of "gratitude" that I have often encountered in both the white and the black community. The tenet of this discourse is that:

Black people should be grateful that they were colonized and shipped here, otherwise they would still walk around like the savages they were, naked or in grass skirts, living in huts made of straw and clay. Now they are civilized, now they can read and write!

But I argue that this narrative of gratitude again places the complexity of the role that the Catholic Church played and continues to play in Curaçaoan society out of sight. It deflects past and present Church-led indoctrination of the masses in white supremacist ideology (Allen 2007), and instead presents the white elites as benevolent, and as successful heroes that built a phenomenal nation (Goldberg 2002).

Still, in Otrobanda, the signs of racial inequality were also abundant. The lighter skinned participants (\#15,\#17 and \#18) claim to not have had any personal experience with racism, even though they all mention witnessing it at work, in school, in the street, 
even in Church (in the past the pews in the front were reserved for white people, and black nuns ranked lower to white nuns). Their stories also described racism among people of color, like the story about a black mother who instructed her black daughter to only sit next to white children in class. When the girl had to sit next to a black classmate she cried and cried, afraid of her mother's reprimands. The two younger men (\#14 and \#16) both of a darker phenotype, shared various personal experiences with racism, especially with regards to work. The youngest male respondent was particularly irritated, time and time again seeing the jobs he applied for go to white people, while he never got a call back. The male respondent in his thirties, a dark skinned Rastafarian, talked about his dread locks, which in Curaçao are stigmatized as the hairdo of rebels, delinquents and criminals. "If you have locks you can only get a job in construction," he said. There they don't care what you look like, as long as you do the work. Everywhere else people will tell you to cut and shave your hair and beard." For many years he covered his locks because they were so negatively stigmatized, until he realized that he was in fact bowing to the system of white supremacy that he sought to defy with his hairstyle. The youngest man also mentions this respectability politics regarding to hair (Allen 2009, see also Besson 1993; Stoler 2002; Thomas 2004; White 2010; Wilson 1969). The norms regarding to what is "proper" are based on the somatic norms image of the white elites (Hoetink 1958). When he wanted to grow out his afro-textured hair the school management told him to cut it. "One has to look proper when wearing the school uniform," the school explained to him, and dreadlocks or too long an afro simply are not proper. Over the years I noticed time and time again that this code regarding hair is indeed very strong in Curaçao. As I illustrated in chapter 2, I grew up not even knowing I 
had such big curls. The recent change in fashion on the global stage eases the shame on naturally worn afro-textured or big, curly hair. Particularly girls are increasingly wearing their hair natural, but locks continue to be perceived as distasteful.

\section{Janwé}

Janwé is a well-off bario, with a mainly well-educated and lighter skinned population: this perspective is shared by outsiders and insiders alike. Their houses, lifestyles and occupations demonstrated their higher socio-economic status and social upward mobility. However, the respondents of Janwé did not share a clear narrative about their bario, like the people of Seru Fortuna and Otrobanda did. The respondents also did not refer to the larger ideology of national identity of unity and equality, but the younger female respondents (\#19) and (\#21), who are respectively very light skinned and "red ${ }^{101}$," did refer to the racial mixedness of their own families, and stated that this mixedness is normal for Curaçao. Their stories suggest that hybridity is a national symbol of Curaçao, and in spite of an explicit reference to it, obviously adhere to the national narrative or Yu'i Kòrsou and its praise of diversity and hybridity, including its proclamation of the insignificance of race and skin color.

The respondents of Janwé varied in skin color. Both the youngest (\#19) and the senior female respondents (\#23) are very light skinned. Especially the senior female respondent's story attests to the power of light privilege as part of Curaçao's colorist system. In the 1940s she was one of the first young light skinned black woman to work as

\footnotetext{
${ }^{101}$ See Appendix I.
} 
a shop employee at a prestigious white store. Beforehand those positions were only open to white girls: people of color worked in the back of the store. In the 1940s the government however made it mandatory to employ non-white local people, so these jobs opened up mainly to light skinned people. She got the job and worked there until her retirement. In her story the gratitude discourse also surfaces, both to her kind and caring employers and to her Church. But her story also indicates that as a young, unmarried, light skinned black woman she was economically vulnerable. The virginity complex (Stoler 2002), which I elaborated on in chapter 2, had in pre-emancipation Curaçao applied to white women. But after emancipation it became part of the Catholic Church's civilization mission (Allen 2007:215). These Eurocentric social standards of conduct demanded that "proper" women of color lived by the norms of virginity, chastity, monogamy and the sanctity of marriage, and ideally did not venture out of the house and work (Allen 2007:166, see also Stoler 2002; Thomas 2004). For many women of color this bida drechi (proper life) was not an option, given the fact that with or without a male partner, they lived in poverty and had to sustain their families. Furthermore, a marriage ceremony was costly. Women who did not live by these norms were much more free in their comings and goings, but they paid a price for it (Allen 2007). My respondent described how children born out of wedlock, called yu di piká or "child born in sin" would not be accepted into the good schools, could not get the better jobs, and did not easily receive the sacraments in Church $^{102}$ (see also Allen 2007:161). Her parents had

\footnotetext{
${ }^{102}$ Allen writes that children born out of wedlock would be shamed with names such as: "yu di skuridat' (child of the dark), "yu di puta" (child of a whore), "yu di porko" (child of a pig), or "yu di diabel" (child of the devil) (2007: 158, 161). To this day people that are sexually active but that are not married are not allowed to receive the Eucharist sacrament (take the wine and bread), nor can they play any role in organizing Church's activities.
} 
been married, which was crucial in her getting this particular job. But she had to work since her family needed the extra income after her father passed away. Women of color that aspired to live a bida drechi could not work just anywhere, but this job at a fancy white store was appropriate. She was very lucky, she said, to have gotten the position. Her story not only illustrates the advantages light people received in Curaçao's colorist system, but also of the way in which the white supremacist norms instilled by the Church could both enhance and limit the social upward mobility of people of color, especially in the time period she refers to- - the first half of the $20^{\text {th }}$ century.

All Janwé's respondents brought up overt racism, whether they witnessed it, or experienced it. Their stories illustrate that racism does not disappear as one gets higher up the social ladder. Like in Otrobanda, in Janwé the most troubling stories about racism were told by men. The older male respondent (\#24), a dark skinned bank manager with an international career, initially stated that nowadays people of color have moved upward considerably. After May $30^{\text {th }} 1969$ the boundaries between the racial tiers became more permeable for blacks, with the result that many Afrocuraçaoans today head large multinational companies and work jobs their parents never could have dreamed of. These are indeed imperative and long standing victories. But he also spoke about constantly being undervalued and underestimated as a person of color, whether it was in a casual setting, like people not serving him at a bar or a restaurant, or on the work floor. In this account we clearly identify Essed's everyday racism (1991). She uses this notion to refer to (white) people's surprise about the accomplishments of black people, whom they still assumed to be inferior. "As a person of color you must learn to suppress your emotions," he said. It is dangerous to challenge racist actions: you may loose your job, customers, 
business partners or investors. Because of this fear people of color not only acknowledge white supremacy but are often forced to bow to it, making this self censure a complicitous silence (Bourdieu 1977), which perpetuates the racial status quo.

The male respondent in his thirties (\#22), who has a brown skin color, emphasized that it is difficult for a person of color to start your own business. White people, whether Dutch or island elites, have their networks that give them easy access to real estate, investors, loans even, he argued. A "good” family name can already make all the difference. But what is more is that Curaçaoans themselves prefer to do business with white people instead of with their own people. White people are considered to be more reliable, professional, better educated, and more capable, he said. He observes a clear color line in the commercial world: black Curaçaoans usually run small businesses, whereas large and higher end establishments are white-owned. There are however no qualitative or quantitative data on loans, property ownership, and commercial activity, which points out a gaping hiatus in the knowledge available on racial status quo of Curaçao's economic sector. Nonetheless it is common knowledge that the majority of Curaçao's hotels, restaurants, resorts, clubs, large stores, banks, law firms, and all sorts of larger retail businesses are white owned ${ }^{103}$. Chinese and East Indian people also own a lot of businesses and properties, especially in retail, but they fall outside of the color hierarchy ${ }^{104}$.

\footnotetext{
${ }^{103}$ Especially the hospitality sector is known to be largely foreign -and white- owned, to cater to whites, and to have lots of white, foreign interns and employees. In 2015 the management of Mambo Beach, one of the large hospitality areas of Curaçao, informed the owners of the recently opened bars and clubs on their strip that they want less black people there. It expressed a strong preference to substitute nights with local bands with house and lounge music; music that appeals to white people.

104 See appendix I.
} 
The youngest male respondent (\#20) is a light skinned man in his twenties. He talked about the laziness of the Curaçaoan, something that he himself suffers from also, he complained. It is so hard to get motivated sometimes, to get off the couch and do the work that we know helps us advance in life. He wondered, could it be self-sabotage? Yet he did not consider the possible racial dimension of this self-sabotage, as part of internalized racism. But when he spoke about racism he said: "I have never felt discriminated against, because I don't go looking for it.” This expression clearly belongs to color blind or raceless discourse, and suggests that racism is self-induced and results from "inappropriate" behavior, and that it can be easily ignored (Essed 1991; BonillaSilva 2003).

What Janwé's stories illustrate is the greater opportunities for upward social mobility that the respondents experience. Some came from a poor background and worked their way up, others were born into this social-economic class. Their economic and educational position, reinforced by the good reputation of their bario, is stronger compared to that of the respondents in the previous barios. Especially the darker respondents still experience racist exclusions, but their higher social standing helps them to continue to move upwards, which for their lower class counterparts is more difficult. Also, some of the respondents in this sample are considerably lighter than those in the other neighborhoods, so in Janwé's stories the impact of Curaçao's colorist system also show. Some of the respondents, especially the lighter skinned ones, make reference of these advantages. 


\section{Spaanse Water}

To outsiders the neighborhood Spaanse Water is both fancy and uppity: the inhabitants are perceived as mostly white people who stick to their own, who do not easily socialize with those who are less affluent and less white. In fact, Spaanse Water's residents are thought of as having gained their wealth through the exploitation of non-whites. From the stories of the respondents themselves there does not arise one clear narrative. The two senior respondents (\#28 and 29), are both born to affluent white Dutch parents who worked and lived on the island at the beginning of the Shell era. Growing up during the 1930s, 40s and 50s they both experienced Curaçao as a very segregated island. They were not allowed to interact with people of color, nor did they easily get into contact with them. Often even the servants were white, the older lady says: they were recently immigrated, poor Portuguese workers. Both describe that it felt as if they lived in a bubble of whiteness. Especially the senior male respondent experienced that as a lack; nowadays he deliberately looks for more interaction with black people. The three younger respondents (\#25, \#26 and \#27) grew up in different times. The two younger female respondents both have black partners, and the young male respondent talks about having many friends of color and from different classes, and playing in a mixed base-ball team. Their stories allude to Curaçao's ideology of diversity and unity.

Inequality, segregation and racism are themes that all respondents from Spaanse Water address, and the three younger respondents argue that they continue to exist. The female respondent in her forties spoke about her white, Jewish family owning slaves in the past. She showed me an authentic bill of purchase that she had recently discovered in the family archives, and points out that on it six slaves are listed together with livestock 
and furniture, as if they were not humans but property. It had shocked her to see this because it had been a silenced part of her heritage. She argued that enslaved people do not get credit for building the island; it was their forced labor that made Curaçao into such a rich and important colony. But even though she rejects slavery and all the horror it entailed, she also views it as an unfortunate but necessary condition in Curaçao's development into the prominent "nation" it is today.

The stories convey that the respondents speak of inequality, segregation and racism from an "outsider's" point of view; their stories indicate that they themselves are not adversely affected by racism. Spaanse Water's residents benefit from the privileges brought about by their whiteness, whether they actively pursue or protect these privileges, or critique them, like the young female respondent does (\#25). She herself is light skinned from a mixed race background, and has experienced how this privilege operates in her personal context.

Interestingly, in this bario respondents finally actively refer to the Yu'i Kòrsou ideology and identity. The two older respondents, both born to Dutch parents, referred to the unifying and egalitarian Yu'i Kòrsou ideology, and made reference to the "multiculturalism" of contemporary unified Curaçaoan society to explain why there is no more racism today. They both celebrate Curaçao’s diversity and feel that racism belongs to the past. Afrocuraçaoans focus too much on their history of slavery, the senior female respondent explained, which traps them in a negative mentality of inferiority. Only they can set themselves free. She perceived racism as personal and self-induced, which is an expression of raceless racism (Bonilla-Silva 2010). 
However, the female respondent in her forties (\#27) and the young male respondent (\#26), both white Curaçaoans, refer to their Yu'i Kòrsou identity with regards to being discriminated against by Afrocuraçaoans. These two respondents, who selfidentify as Yu'i Kòrsou because they were born and raised on the island, indicate that as rich white or light skinned individuals they often feel discriminated against by people of color, and have to defend the fact that they too are Yu'i Kòrsou. Among the non-white population there is a noticeable disdain for the white and light skinned elites, which is comprised of resentments about past and present white privilege and black marginalization. This resentment is not commonly expressed in strong counterhegemonic discourse. Some of the previous respondents explained that non-white people often choose to remain silent instead out of fear for repercussions. But silence does not automatically signal complicity and hegemony, Robin Sheriff argues (2001). In her Brazilian case study she has often found it to be a form of resistance to white supremacy, as well as protection from repercussions following from overt critique on it. Furthermore, Scott argues that discontentment and resistance can take on a multitude of non-overt forms (1992). Seeking to exclude whites from the in-group labeling the in-group nonwhite, I argue, is one of them.

The respondents from Spaanse Water indicate that they experience such exclusions, exerted through disdain, distrust, or disinterest, as painful and unpleasant. They feel that they do qualify as a Yu'i Kòrsou ${ }^{105}$. What's more, they take the brunt for

\footnotetext{
${ }^{105}$ As her defense the middle female respondent refers explicitly to the unifying discourse, which states that everyone born on the island and who seeks to contribute positively to it is a real Yu'i Kòrsou. Her family has lived on the island for multiple generations, she loves the island and contributes duly, she speaks Papiamentu fluently, and therefore more than qualifies as a Yu'i Kòrsou.
} 
an injustice they did not cause personally and that they condemn, they argue. Their exclusion is unfair, they argue. But while negative attitudes from the rest of the population are unpleasant, these do not limit whites in their access to networks, jobs, education, material assets, and other privileges the way they do with people of color and with immigrants.

Furthermore, the white population, which given Curaçao's color hierarchy automatically has an elite status, does not have to merge with the masses and adopt the same national identity in order to be part of the nation. The Yu'i Kòrsou ideology dictates white supremacy, which means that whites are a quintessential part of the nation, regardless of if others consider them "real" Yu'i Kòrsou or not. Furthermore, in chapter 1 we saw how after the revolt ruling elites and those allegiant to them deliberately placed Afrocuraçaoan people and culture at the core of multicultural ideology of national identity, with the aim to deflect black resistance. Therefore, a rendition of the Yu'i Kòrsou as being solely black, which these white respondents refer to, cannot simply be seen as counter-hegemonic.

Also, the Yu'i Kòrsou-being-black discourse is not a the full version of the national ideology, as some of these white elite respondents claim, for it does not in any way inform the nation of structurally embedded black superiority. If one layer advances blackness as central to the nation, another layer harbors the old sentiments colonial and post-emancipation era, in which Afrodescendants were referred to as childlike and culturally inferior compared to whites (see Allen 2014). In this version, which is still very active today, black people are imagined as lower class, crude, and even coonish. I argue 
that this alleged exclusion of whites in fact confirms their separate — and superior — status within the nation.

\section{Additional Analytical Comments about the Stories Collected}

This journey through these five barios reveals some important patterns. While people may start off by reproducing fragments of the colorblind discourse, and with the ideology of national identity that is supposed to incorporate everyone, the respondents all in one way or another indicated that race-based discrimination is prevalent. In their stories the positive values attributed to whiteness and the negative values attributed to blackness surface. The majority of the respondents is deeply aware of the harmful consequences this has for people of color with regards to their upward social mobility and overall wellbeing. The effects of colorism in Curaçao also become clear. In the stories collected colorism most acutely affects dark skinned people of all class layers. The highly educated and well-earning dark skinned respondent of the middle class bario addresses similar exclusion processes as the dark skinned respondents from the poorer neighborhood do. Even though the light(er) skinned respondents in the different barios are well aware of Curaçao's racial inequality, their stories indicate that they themselves suffer considerably less from racist marginalization. In order to tease out these patterns, I developed a series of tables ${ }^{106}$ that show the distribution of these narratives, attitudes, beliefs and experiences in the stories in my sample. I discuss them in the remainder of this chapter.

\footnotetext{
106 See appendix IX for the overview of these tables per bario.
} 


\section{Racelessness}

All twenty-nine respondents observed and/or experienced racism. However, twenty-two people ( $76 \%$ of the total respondents from all barios) started off their stories by revealing an attachment to raceless ideology (Goldberg 2002).

Table 3. Raceless Ideology

\begin{tabular}{|c|c|c|c|c|c|c|c|c|}
\hline & Bario & $\begin{array}{l}\text { Barber } \\
(n=6)\end{array}$ & $\begin{array}{l}\text { SeruF } \\
(n=6)\end{array}$ & $\begin{array}{l}\text { OtroB } \\
(n=6)\end{array}$ & $\begin{array}{l}\text { Janwé } \\
(n=6)\end{array}$ & $\begin{array}{l}\text { SpW } \\
(\mathrm{n}=5)\end{array}$ & Tot & $\%$ \\
\hline & Phenotype respondents & dark & dark & varies & varies & white & & \\
\hline 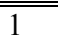 & I don't see color & 2 & 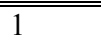 & 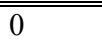 & 3 & 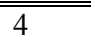 & 10 & $\overline{366}$ \\
\hline 2 & $\begin{array}{l}\text { I'm not discriminated against / } \\
\text { Discrimination is passé }\end{array}$ & 1 & 2 & 3 & 3 & 2 & 11 & 38 \\
\hline 3 & There is unity & 1 & 1 & 3 & 2 & 4 & 11 & 38 \\
\hline Tot & & 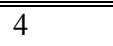 & 4 & 26 & 8 & 10 & & \\
\hline
\end{tabular}

Ten of the twenty-nine respondents $(36 \%)$ said that color does not matter anymore, eleven said in one way or another that they themselves have never been discriminated against or that discrimination is a thing from the past (38\%), and eleven talked of unity within the diverse Curaçaoan population (38\%). Table 3 shows that this raceless stance is somewhat stronger among the respondents of the white upper class neighborhood Spaanse Water, and in the middle class neighborhood Janwé, where respondents of all colors make these statements. Working class neighborhood Otrobanda stands out with its elaborate narrative that this bario is a happy mix of races and ethnic groups that live in harmony and equality. This narrative closely resembles the Yu'i Kòrsou ideology of unity and equality, although none of Otrobanda's respondents actually used the notion of the Yu'i Kòrsou.

Across the island, racelessness is a popular discourse. In December of 2015 I had the privilege to show my documentary on race and racism in Curaçao to the Parliament of 
Curaçao and the Court of Justice. The viewing was followed by an informal conversation with the President of Parliament, a man of color from a well-off background. He had watched with great interest, but argued that racism is something that people bring onto themselves through what they believe, racism is not a structural problem. Over the years of doing this research I have dozens and dozens of conversations with ministers, educators, people from all ranks of society, all phenotypes, and all walks of life. Time and time again they made the same claim: "racism doesn't exist anymore in Curaçao, racism is in people's minds!" Yet when I say "I study race" people combust into sharing personal stories about racial inequality. In these stories the topic of national unity may surface briefly at first, before quickly shifting to acknowledging and illustrating the impact of racism. Hegemonic ideology constructs a diversity-embracing national unity that attempts to cover over overt racial inequality.

I already mentioned that among my respondents, I found that reference to narratives that adhere to racelessness is something that is much more prevalent among people who themselves suffer less from the consequences of racism, whether they are white, light skinned black, or of a higher socioeconomic class. But in poor neighborhoods the discourse of racelessness also exists. As we saw in the section on the barios, quite a few of the respondents initially started of saying that they did not experience racism or that color no longer mattered, before a few seconds later sharing stories about how racism has affected them intimately. However, here racelessness appears to be considerably less profound: none of the respondents interviewed suggested that they brought the discrimination they suffered onto themselves through not being proper enough (see Bonilla-Silva 2010 and Essed 1991). 


\section{Talking about Blackness, Talking about Whiteness}

In the way the twenty-nine respondents talk about whiteness and blackness, the prevalence of white supremacy quickly becomes evident. In table 4 I listed seven attitudes towards whiteness and blackness.

Table 4. Attitudes Towards Whiteness and Blackness

\begin{tabular}{|c|c|c|c|c|c|c|c|c|}
\hline . & Bario & $\begin{array}{l}\text { Barber } \\
(n=6)\end{array}$ & $\begin{array}{l}\text { SeruF } \\
(n=6)\end{array}$ & $\begin{array}{l}\text { OtroB } \\
(n=6)\end{array}$ & $\begin{array}{l}\text { Janwé } \\
(n=6)\end{array}$ & $\begin{array}{l}\text { SpW } \\
(n=5)\end{array}$ & Tot & $\%$ \\
\hline & Phenotype respondents & dark & dark & varies & varies & white & & \\
\hline 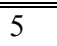 & Black is negative & 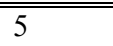 & 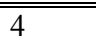 & 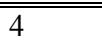 & $\bar{~} 6$ & 3 & 22 & 76 \\
\hline 6 & Black is positive & 1 & 1 & 2 & 2 & 3 & 9 & 31 \\
\hline 7 & White is negative & 2 & 2 & 3 & 2 & 1 & 10 & 36 \\
\hline 8 & White is positive & 3 & 1 & 2 & 1 & 1 & 9 & 31 \\
\hline 9 & White is better than black & 5 & 5 & 3 & 4 & 4 & 21 & 72 \\
\hline 10 & White and black are equal & 5 & 4 & 4 & 4 & 5 & 22 & 76 \\
\hline 11 & Black is better than white & 0 & 0 & 0 & 0 & 0 & 0 & $\overline{0}$ \\
\hline
\end{tabular}

In twenty-two of the stories (76\%) "black" is presented as negative or of lesser value. People tell about personal experiences with discrimination or racial inequality, or they share stories of how black is generally perceived as inferior to white. This does not necessarily mean that they agree with this assessment, rather it might simply mean that they are aware of this dominant societal hierarchy, which is the source of a great deal of hurt and frustrations in their lives. People describe how they experience the devaluation of blackness at work, in family, education, socioeconomic position, privilege, access to opportunities, and social standing in general. No one mentioned negative traits of black people on the record. Off the record, however, I have heard such stories in great abundance, specifically—but not certainly only—in white circles, about blacks being criminals, dangerous, violent, lazy, incompetent, ugly, vulgar, and so on. These are 
virtually identical to the stereotypical negative traits ascribed to blacks during colonial times.

Yet, only nine people describe black in a positive sense. In this table this "positive sense" refers to people talking about blackness as: "we can also achieve lots of things," or "I made it in spite of the adversity," or "I am also a good person." Remarkably, there were no stories that addressed situations in which black people might excel compared to white people. Nor were there many stories that relayed opinions such as "black is beautiful," "I love my black skin," "I love my black hair," or "I love our Afrodescendant culture, beliefs, traditions or art." Only one respondent specifically spoke about going natural, because she wanted her natural Afrotextured hair back, and about people's positive responses to that.

In the stories I collected there was however no sign of a unique cultural or racial pride. In the first chapter I mentioned that this pride does exist within the Afrocuraçaoan population, mostly among the small, specifically pro-black NGO's and community initiatives on the island. But none of my respondents addressed this, nor did these groups and their perspectives or achievements arise in the stories. The interviews aside I often observed people becoming quite uncomfortable in the face of this black pride. "Curaçao is not a black nation, it is a multicultural nation" is a rebuttal I hear very often. Too strong a focus on Curaçao's Afrodescendant heritage quickly evokes a reverse response, arguing that non-black traditions and lore are also part of the canon, and deserve a lot more visibility and acknowledgement.

One of the respondents that spoke positively about blackness is an older white Dutch respondent (\#29), who was raised on the island, and spent most of his life here. He 
describes that in the pre-revolt era blacks and whites did not easily socialize. The system of race relations forced him to remain an outsider to the Afrocuraçaoan community, which is something he regrets. Nowadays he makes some deliberate efforts to expand his interaction with black people and black culture.

The [Freemasons] loge that I am part of, most of the people there are dark skinned. That is also one of the reasons that I picked that loge out of the four [on the island] to become part of. I found it interesting because in my personal life I didn't have dark skinned people as friends because in the past that was not really possible. So now I have chance to interact with them and that is extraordinary in this period of time. So that is the reason why I am part of that loge.

Yet his efforts have not amounted to an expansion of his actual social circle. When I asked him if he now he does have black friends, it turns out that he does not. He remains an outsider, by choice.

His story is not uncommon, though it's not a usual one either. On one side of the scale we find a very small number of Dutch people who participate very actively in Afrocuraçaoan circles, have Afrocuraçaoan partners, live in middle- or lower class neighborhoods that are predominantly non-white, dominate the Papiamentu language and become fluent in Afrocuraçaoan tradition, history and every day culture. If they are truly proficient, Curaçaoans may perceive these Dutch people as white Curaçaoans ${ }^{1}$ rather than as Dutch or Makamba. On the other side are the people that live in predominantly white (often gated) middle- and upper class neighborhoods, have a primarily white social circle, and work in white or foreign owned companies. They commonly do not dominate Papiamentu and never or only very occasionally participate in Afrocuraçaoan culture and 
tradition $^{107}$. In my observation this is clearly the most common pattern among the white Dutch population. It appears that, in spite of his efforts to change this, the abovementioned respondent still belongs to this section.

In nine of the stories (31\%) a positive attitude towards whites surface. Three lower class black respondents and one brown skinned middle class respondent mention positive personal relationships that they have or had with white superiors at work and school. Two lower class dark skinned respondents mention their friendship with whites. The other two people, which are very light skinned (koló klá), express their appreciation for the nation building and the acculturating work that white colonizers and friars instigated during the colonial era. While these two light skinned respondents are both critical of white oppression and exploitation, they also value whites as the directing force behind Curaçao's success as a colony and as a nation today. One lower class dark skinned respondent described wanting a white baby because she thought that was beautiful, and successfully seeking out a white partner to make this happen. Even though in these stories people are not necessarily elated about whites, it becomes evident that whiteness is perceived as a marker of social higher ranking, more privileged, more aesthetically pleasing, and socially more desirable than black.

Ten respondents (36\%) shared negative stories about white people. In Barber, Seru Fortuna, Otrobanda and Spanish Water people spoke about colonial oppression and exploitation in the past, by colonials and by the Catholic orders. In Barber, Seru Fortuna, Janwé and Spaanse Water respondents addressed contemporary discrimination by whites,

\footnotetext{
107 Because of their segregation, and because of the perpetuated privilege that this group enjoys the Curaçaoan population — black and white alike_commonly looks at this group with considerable disdain.
} 
racial profiling of blacks by whites, white financial elites and their exclusive white networks, and the import of expensive, foreign white personnel instead of giving the position to a local person. The young respondents of Seru Fortuna and Otrobanda complained about white privilege in work and education, which diminished their opportunities. Only one respondent, in Barber, spoke of racist name-calling by white peers.

These stories do not mention contemporary race-based physical violence from whites to blacks. These are indeed stories that I have never heard in Curaçao. In fact, physical white violence in contemporary Curaçao is almost inconceivable. In contemporary society black people, especially those of the lower classes, are perceived as potentially violent and dangerous. The threat of the unruly, violent, angry, physically strong and hypersexual black man is the stuff of ordinary racist representations. This is the reason why so many people expressed concern for me going to Seru Fortuna.

White people on the other hand are a numeric minority. They may even be perceived as physically more vulnerable than blacks. I have not heard of the existence of white hate or extremist groups in contemporary Curaçao. This comes in stark contrast with settler colonial societies with a majority white population such as the United States, where white physical violence towards blacks is more present and is one of the major characteristics of anti-black racism. In Curaçao it is an unwritten and unspoken code that white people must act non-violently towards black folks. White people may have financial power, but the black population far outnumbers the white population, demographically. There is a silenced anger and resentment among the black population 
towards whites for past and present racial oppression, which could potentially erupt again as it did for the revolt of 1969. Curaçao's elites still fear that.

A conversation I had in 2015 with a white civil servant from Curaçao's Department of External Affairs about race and racism on the island illustrates this fear. I asked him what holds the government back to actually implement anti-discrimination measures in Curaçao. He gave a response that I have heard many times:

The government is just not interested. We don't want to re-open those old wounds. If we start talking about discrimination, and people begin to realize they are being discriminated against, then they will become angry. There is so much pain still, if you open those wounds before you know it we will have flaming, violent conflicts erupting all over the island. It will become a disaster that we cannot maintain. Our people are not yet mature enough to talk about race. It is too dangerous. We best leave this topic alone. (Conversation on July $13^{\text {th }} 2015$ ) Curaçao's elites are well aware of the many generations of pent up anger, pain, and frustration among the non-white masses. They fear both for their personal livelihood as for the destruction of white hegemony.

What also stands out in the stories that I collected is that there is very little mention of Dutch people or of white elites in particular. Yet in informal conversations Curaçaoans of all walks of life complain that Dutch people are arrogant, have a misplaced sense of superiority, and do not integrate into Curaçaoan society. The old white Protestant and Jewish elites shield their exclusive networks through which they continue to dominate the island, and they too often prefer to live separated away in their fancy neighborhoods. But people are careful who they share their complaints with. As the 
senior male respondent in Janwé said, openly accusing someone in a superior status from racism may cost you dearly (see also Sheriff 2001). Thus both elites and Afrocuraçaoans silence critique on racism. Silencing is, as we saw repeatedly, an important part of multiculturalism, which deflects subaltern critique and demands to a reformulation of the power balance (Hale 2002, 2005; Greene 2007; Rahier 2012). Since there are as of yet no organizations sanctioned by the state to address racism and other forms of discrimination, this silencing perpetuates, in spite of the ample legal reform regarding antidiscrimination.

Twenty-one people (72\%), from all class segments, age groups and phenotypes, describe that white people are better off, have more privileges and opportunities, and are considered to be more beautiful. The respondents do not necessarily agree with thisvarious respondents avidly criticize this representation-but they mention and illustrate that this is a dominant value in society.

Twenty-two respondents (76\%) talk about the ideology of whites and blacks being equal. Here again the potent raceless, national narrative of unity and equality surfaces. Respondents do not necessarily state that white and black people are indeed currently valued equally, although many do, but in their stories people argue that black and white should be equal.

Yet, none of the respondents shared a story about black being better than white. I already pointed at this absence when discussing how people talk positively about blackness. No one says that blacks surpass whites, or have superior qualities, as happens to whites when compared to blacks. Only three respondents mention Tula in passing, the leader of the 1795 slave revolt. None of the respondents describes any story of black 
pride, or refers to a rich black Curaçaoan heritage, or to the international successes of contemporary Afrocuraçaoan artists such as sculptor Yubi Kirindongo, grammy winning percussionist Pernell Saturnino, performance artists Doble RR and Izaline Calister, and writer Frank Martinus Arion, to only name a few. Nor does anyone mention the numerous international achievements of famous Afrocuraçaoan athletes such as sprinters Churendy Martina and Liemarvin Bonivacia, both Olympic participants, world champion Muaythai boxing Jemyma Betrian ${ }^{108}$, or even the long standing, above-average representation of Afrocuraçaoans in major league baseball, by men like Hensely Meulens, Andrew Jones, Wladimir “Coco” Balentien, Kenly Jansen, Jurickson Profar, and the list goes on and on. This demonstrates that underneath the ideology of unity and equality there is limited, if any, appreciation of blackness. This is again consistent with how multiculturalism operates: the ideology of diversity and inclusion is only a superficial varnish that enhances the foundation of white supremacy (Hale 2002, 2005; Greene 2007; Rahier 2012).

Thus, the way people talk positively and negatively about blackness forms a great contrast with how people talk positively and negatively about whiteness. When the respondents share negative accounts about whites the superior position and privilege of whites surfaces immediately. The negative things people share about blacks, on the other hand, illustrate the inferior ranking of blackness.

${ }^{108}$ She is multiple times world champion in the bantamweight class. 


\section{Empowerment and Silencing}

Trouillot (1997) argues that harmful but also empowering parts of the subaltern past and present are omitted or trivialized in order to convenience hegemonic historiography (see also Andermann 2007; Aronson \& Elgenius 2011; Brooms 2011; Butler 2001; Buzinde and Santos 2008; Cummings 2004; Eichsted and Small 2002; Goldberg 2002; Hall 1999; Hobsbawm and Ranger 1983; Poria and Ashworth 2009; Rahier 2003; Timothy and Boyd 2006). In table 5, I examine if and how people talk about important historic people and events that significantly impacted the Afrocuraçaoan population in a positive or negative sense.

Table 5. Talk of Important Historic Afrocuraçaoan People and/or Events

\begin{tabular}{|l|l|l|l|l|l|l|r|r|}
\hline & Bario & $\begin{array}{l}\text { Barber } \\
(\mathbf{n = 6})\end{array}$ & $\begin{array}{l}\text { SeruF } \\
(\mathbf{n = 6})\end{array}$ & $\begin{array}{l}\text { OtroB } \\
(\mathbf{n}=\mathbf{6})\end{array}$ & $\begin{array}{l}\text { Janwé } \\
(\mathbf{n}=\mathbf{6})\end{array}$ & $\begin{array}{l}\text { SpW } \\
(\mathbf{n}=\mathbf{5})\end{array}$ & $\begin{array}{l}\text { Tot } \\
\text { (1) }\end{array}$ \\
\hline \hline 12 & Phenotype respondents & dark & dark & varies & varies & white & & \\
\hline 13 & $\begin{array}{l}\text { Emancipation and Afrocuraçaoan } \\
\text { empowerment (including revolt of 1969) }\end{array}$ & 0 & 1 & 1 & 0 & 1 & 3 & $\mathbf{1 0}$ \\
\hline 14 & Slavery & 3 & 1 & 4 & 1 & 3 & 12 & $\mathbf{4 1}$ \\
\hline
\end{tabular}

In Otrobanda and Spaanse Water the senior respondents speak of the 1969 revolt because they lived it (\#17,\#18,\#29,\#30). They do not so much speak of the revolt as a celebratory event for blacks, rather they talk about the destruction, the fear and the chaos at the hands of "an angry black mob." They blame the revolt for intensifying racial tensions for many years afterward. They do however acknowledge that the empowerment that resulted from it was much needed for the black population. The male respondent from Otrobanda in his thirties (\#16), a dark skinned man, explicitly describes the revolt as a turning point in pro-black empowerment. In contrast, the female respondent in her 
forties (\#15), who is lighter brown, mainly speaks of Otrobanda's demise, due to the elites leaving the bario soon after the revolt.

In the other three barios, Barber, Seru Fortuna and Janwé, it is also the respondents in the $30-55$ or the $55+$ age brackets that bring up the revolt and its aftermath (\#3, \#9 and \#24). In these three barios the respondents that mention this are darker skinned. They explain that pro-black empowerment considerably changed life for Afrocuraçaoans, and opened up job possibilities that had not been there before. But in their stories, and in the narrative that I have found to be prevalent in every day conversation and narrative, because of the empowerment and Antillianization that resulted from the revolt racial discrimination has waned. This line of reasoning reveals several tenets of multicultural ideology (see Hale 2002, 2005; Goldberg 2002; Greene 2007; Rahier 2012).

The topic of slavery surfaces slightly more often in the stories than does the 1969 revolt, but not much. Conform the findings in chapter 1, both in the interviews and in larger society slavery is a sensitive and omitted topic. This silencing, I argue, is hegemonic, in order to whitewash inconvenient parts of the past (Trouillot 1997, see also Brooms 2011; Butler 2001; Eichsted and Small 2002; Goldberg 1993; Gramsci 1971; Hall 1999; Rahier 2003; Timothy and Boyd 2006). Again the rationale is that the anger of the black masses regarding oppression should not be kindled. Slavery is trivialized in museum collections, erased by the monumentalization and repurposing of colonial European-based architecture, and in the positioning of statues on the island: Tula's sizeable statue is hidden from plain view. In the tourism-hospitality sector colonialism is thoroughly romanticized, and slavery placed out of focus. "Slavery belongs to a past long 
gone," the mainstream colorblind narrative dictates. "We have got to move on." This silence is reflected in the respondents' stories. Those who spoke of slavery only mentioned it briefly. Two white respondents (\#18 and \#27) spoke apologetically about slavery. One argued that the wrongs of slavery were balanced out by the work of the missionaries, while the other said slavery was a horrid but necessary evil. In the account if the female respondent from Otrobanda in her forties (\#15) the trivialization of slavery becomes apparent. She stressed the cordial interactions in the bario between slaves, freedmen, mulattos and whites in colonial times. Three dark skinned respondents ( $\# 5$, \#14 and \#24) mentioned to be relieved that slavery is over and belongs to a past long gone.

But the female respondent in her thirties from Seru Fortuna (\#9) brings up a more emotional connection to slavery. She says that she still feels like a slave, always working for a white person, and never being able to move up in life. The young female respondent from Barber (\#1) mentions that "slave" is one of the words used to tease and bully blacks, which indicates that it is still a shameful notion. And the young female respondent from Otrobanda (\#13), a dark skinned eighteen-year-old girl, didn’t know what slavery was, even though she described in great detail the racial inequality she observed in Otrobanda. When I asked her why she thought this racial inequality existed, she answered: “I don't know. I don't think anyone knows.” When I asked her what she knew about slavery she was not exactly sure what slavery was, again. "Is that where black people have to work very hard and get very little money?" she asked. The colonial past and slavery are topics 
that are taught in elementary and high school, but not in great detail ${ }^{109}$. Her lack of knowledge signals the strength of this silenced discourse. Three male respondents from respectively Barber, Otrobanda and Spaanse Water, two dark skinned and one white (\#6, $\# 16$, and \#26), briefly refer to slavery as the root of racism today. People's knowledge of slavery thus varies greatly. It stands out that in my research especially the respondents from Spaanse Water people bring up this topic in considerable detail, and are quite knowledgeable about slavery, colonialism and their aftermath.

The representations of slavery brought up in the interviews however lacked any positive representations of enslaved people as being resourceful, strong, creative, and as having agency: a slave is a pitiful being. Scholars and cultural workers such as Rose Mary Allen, Rene Rosalia, Linda Rupert, Richenel Ansano, Jeanne Henriquez, Gilbert Bacilio and Ieteke Witteveen have for years been generating knowledge on Afrocuraçaoan agency, resilience, and resistance during slavery. They complain about the fact that the larger population, both black and white, knows so very little about the rich material and immaterial culture enslaved people produced. This knowledge is not a standardized component of school curriculum, of museum collections, nor of radio and television programs.

The limited availability and circulation of empowering knowledge on slavery and pro-black reform contrasts starkly with the abundant literature on white achievement. As discussed in chapter 1, white heroes and their successes are featured extensively in

\footnotetext{
${ }^{109}$ I have attempted to examine narratives of slavery in past and present educational materials and curriculum. However, this study proved to be too elaborate for this research project. Current school materials are not standardized and may vary per school and even per teacher. Schoolbooks and other educational materials used in the past have been poorly documented. Collecting these past and present materials is an arduous task. The systematic analysis of school materials is yet another important topic for future research (see appendix X).
} 
museums, statues, and especially in the monumentalized colonial architecture, Curaçao's pride and joy. This again is a characteristic of multiculturalism, which as Goldberg argues features "the indomitable superiority of whites -in prestige, achievements, education, wealth and power-not as a natural phenomenon but as historical outcome" (2002:212).

\section{Internalized Racism}

Hegemony entails that oppression is internalized and naturalized: the state does not have to use violence or other explicit forms of authority to exert its dominance (Gramsci 1971). Therefore, the internalization of racism, facilitated by the ideology-based denial that racism exists and by the omission and trivialization of black achievement and empowerment, is crucial to the functioning of multiculturalism (Goldberg 2002). This relative invisibilization of race and the internalization of a racial hierarchy translate into the ways my respondents see and appreciate themselves, and how they perceive and treat others. In table 6, I looked for ways in which these attitudes manifested in people's stories.

Table 6. Internalized Racism

\begin{tabular}{|l|l|l|l|l|l|l|r|r|}
\hline & Bario & $\begin{array}{l}\text { Barber } \\
(\mathbf{n = 6})\end{array}$ & $\begin{array}{l}\text { SeruF } \\
(\mathbf{n}=\mathbf{6})\end{array}$ & $\begin{array}{l}\text { OtroB } \\
(\mathbf{n}=\mathbf{6})\end{array}$ & $\begin{array}{l}\text { Janwé } \\
(\mathbf{n}=\mathbf{6})\end{array}$ & $\begin{array}{l}\text { SpW } \\
(\mathbf{n}=\mathbf{5})\end{array}$ & $\begin{array}{l}\text { Tot } \\
\text { \%o }\end{array}$ \\
\hline & Phenotype respondents & dark & dark & varies & varies & white & & \\
\hline 15 & Black on black discrimination & 5 & 2 & 2 & 3 & 3 & 15 & $\mathbf{5 2}$ \\
\hline 16 & Teasing / bullying with black features & 3 & 2 & 1 & 1 & 0 & 7 & $\mathbf{2 4}$ \\
\hline 17 & Color hierarchy & 2 & 0 & 0 & 0 & 0 & 1 & $\mathbf{7}$ \\
\hline 18 & "Drecha rasa" or "fixing the race" & 0 & 1 & 1 & 1 & 0 & 3 & $\mathbf{1 0}$ \\
\hline
\end{tabular}


Fifteen of the respondents $(52 \%)$ describe how people of color discriminate each other. Many of these stories describe how Afrocuraçaoans criticize each other by making fun of one another's black features (skin tone, hair texture, nose shape, etc.), or for behavioral traits that are stereotypically associated with blacks, such as laziness, not being reliable business partners, or being disreputable. This parallels the "respectability politics" that exist in other parts of the African Diaspora (Besson 1993; Stoler 2002; Thomas 2004; White 2010; Wilson 1969), and which I already referred to briefly, earlier in this chapter. Shaming by applying, rather brutally, the racist scale of physical beauty and desirable features is key here.

Teasing and bullying are a dimension of this shaming. The two younger female respondents from Barber (\#1 and \#3) and the young male respondent from Otrobanda (\#14), all dark skinned, talk about hard and hurtful bullying. As we saw in Barber's stories, people really use derogatory names for each other. Some (\#6, \#9, and \#21) mention more "playful" racist teasing, which they describe as behaviors that —in partserve to correct "improper," or "too black" behavior without chastising the beholder. In these stories there is also some mention of shame or shaming with regards to blackness or being discriminated against.

The older male respondent in Barber (\#6) describes how people are assigned racial nicknames, which initially may be intended to be hurtful, but which "stick," sometimes for life, and become neutralized. This is the case of Moortje, an old Dutch word that refers to the Moors, the inhabitants of Northern Africa who occupied Medieval Europe between 711 and 1492 (Lemm 2007). In the Netherlands, Moortje is used to call the stereotypical blackface characters that still perform at specific occasions. In Curaçao 
the nickname Moortje indicates a dark-skinned person. I already discussed how white supremacy surfaced in the old school materials used by the friars to evangelize.

The social instruction about the racial/spatial order and the preoccupation or anxiety to always perform the proper behavior in the right environment is a very important part of Curaçoan society. It also denotes internalized racism. Yet I have only heard it mentioned in colloquial conversations on occasion. Of course I myself was amply instructed into Curaçao's moral codes and into the behavior befitting my racial positioning as a light skinned woman. In chapter 2 I elaborated amply on that. There is a very intricate racist system of propriety that is upheld among Curaçaoans. It becomes particularly evident in the rules regarding hair and attire, and in the shaming and abasing that take place between Curaçaoans, and particularly between people of color.

Dutch people commonly find black hair interesting, exotic, or pretty. They send their mixed race children to school with dread locks, big afros or wide cascades of curls, possibly without even being aware of there being such a code of aesthetics, or deliberately ignoring it. In Curaçao's color hierarchy being white Dutch means one is racially and thus aesthetically intrinsically superior: "proper" attire and hair is not as necessary for them as it is for people of color ${ }^{110}$. But as I have mentioned time and time

\footnotetext{
${ }^{110}$ On the other hand, I find that Curaçaoans commonly agree that Dutch people have little style. They do not pay much attention to nails, hair, outfits, but they don't have to. When I first moved to Curaçao people immediately instructed me into the Curaçaoan dress code. "One has three wardrobes," a friend told me: "One is for formal and business attire. This means that your sleeves are not too short, your skirt reaches your knees, and for God's sake no 'open toes.' No sandals, slippers or flip-flops! The second is informal but decent attire, which you wear when going out, when you visit family and friends, or when you run errands. The third wardrobe is for the clothes worn in the home or perhaps on the beach. Those three wardrobes do not mix!" The instructions were not lost on me. I had walked into a first meeting with a potential employer, who has become a good friend, on slippers and in a casual $\mathrm{t}$-shirt. To this day, 15 years later, this friend ridicules me for it. It did mean that I had to build up my three wardrobes. It also means that one can always easily spot the newly arrived Dutch interns, who have not yet been instructed into these codes of propriety.
} 
again, among Curaçaoans hairdo, dress style, interests, or modes of behavior that are considered too "black" are quickly submitted to teasing and shaming. A strong, reprimanding and condescending expression used by Curaçaoans of all colors and backgrounds is No hasi kos di bo kolo, which literally translates as “Don't do things of your color." It means “don't act too black." This warning replicates a white norm of "propriety," much like the civilization discourse of the Catholic Church proposes. Such improper, "black" behaviors are: talking and laughing loudly; over-acting; bragging about money or new purchases; brawling, fighting or yelling in public; cat calling or "hollering;" or even getting involved in criminal or corrupt activities. Although these behaviors are not at all the exclusivity of black people, I noticed that in society at large they are perceived as crude, "ghetto-ish" behaviors that are associated with lower class Afrocuraçaoans. Such "too black" behaviors "lower" a person in the eyes of others, and might make someone more vulnerable to discrimination. This expression fits colorblind discourse, which suggests that discrimination is something one brings onto oneself through improper behavior. If one acts appropriately, one should be able to steer clear from discrimination. As one lighter skinned middle class respondent says: "I never experienced discrimination because I didn't go look for it."

The notions of bida drechi, hende nechi, hende drechi, and hende drechá are directly related to this code of ethics, which can be stood as "respectability politics" (Wilson 1969). Respectability politics entail a set of rules for the subjugated masses through which they can achieve social upward mobility, through adhering to white, Eurocentric cultural standards (Besson 1993; Stoler 2002; Thomas 2004; White 2010; Wilson 1969). Thomas, writing about $20^{\text {th }}$ century Jamaica, describes respectability as 
$[\ldots]$ a value complex emphasizing the cultivation of education, thrift, industry, self-sufficiency via land-ownership, moderate Christian living, community uplift, the constitution of family through legal marriage and gender related experiences, and leadership by the educated middle classes. (Thomas 2004:5,6).

Speech, appearance (dress, hairstyle and make up), and control over one's emotions are also part of these politics of respectability.

Because respectability politics subscribes to white norms, and shames those who do not adhere to them, it has a strong hegemonic component. However, Deborah Thomas (2004), Jean Besson (1993) and Francis White (2010) also identify the emancipatory elements of this politics, in which it becomes a seat of resistance and counter-hegemony. Adopting these standards does not automatically equate hegemony: it can be a strategy in order to achieve greater social upward mobility and strengthen pro-black reform.

With regard to Curaçao's context, we already encountered the notion of bida drechi or "respectable life," which was one of the pillars of the Church's postemancipation civilizing mission (Allen 2007). This is what surfaced in the story of the senior female respondent in Janwé, but also throughout the stories of my mother and my grandmother, in the previous chapter. Hende nechi, then, translates as "virtuous or righteous people," and even as "beautiful people." These are commonly perceived as lighter skinned people of a higher socioeconomic class who were born into the bida drechi, and who are respectful of the social norms and thus preserve their good social standing. As the senior female respondent from Janwé illustrated, here the emphasis lies on appearance, such as one's skin color, dress and hair style, and adhering to Christian the sanctimony of marriage, and on entering religious life and abiding to the moral codes 
of the Church, which include matrimonial life. Having a nice and tidy house in a neighborhood of good standing, a respectable job that makes a good living, and having or obtaining secondary education further increase ones respectability.

As of yet there is no literature on how these codes of respectability play out in society today. Also it was not the key focus of my research. Therefore, I used on Allen's work (2007) on respectability politics in the pre-industrial era (1863-1917) as a point of departure, and corroborated my observations and experiences on this topic with Curaçaoan anthropologist Louis Philip Römer, who is currently finishing his dissertation on this topic. I reached the following preliminary insights ${ }^{111}$.

Since bida drechi is commonly perceived as part of middle class lifestyle, respectability politics are mostly directed at the darker skinned people from the lower class (Allen 2007). They can "convert" to a respectable lifestyle, and become hende drechi, "correct or suitable people ${ }^{112}$." In order to achieve this status they have to distance themselves sufficiently from a lower class or "ghettoish" or "vulgar" lifestyle, and/or from practices that are associated with subversive "African" culture, such as the tambú, Afrocaribbean religion and wearing black hair styles such as afros and dreadlocks. In

\footnotetext{
111 Due to time constraints this inquiry on respectability politics needs further theoretical and empirical substantiation, as well as more elaboration on my positionality as a light skinned middle class woman who was educated in Europa and the US.

${ }^{112}$ Allen writes elaborately on bida drechi during the late $19^{\text {th }}$ and early $20^{\text {th }}$ century, and how this was shaped by the ways in which whites perceived Afrocuraçaons as inferior and second rate citizens. Suffrage for Afrocuraçaoans was initially denied because they were considered to not be "suitable" for it, she argues In 1895 J. Hamelberg, a civil servant, argued that the Papiamentu language and the many children born out of wedlock was proof of this black inferiority, and argued that suffrage should continue to be denied (Allen 2014:5). In 1948 general suffrage was introduced in Curaçao. "Before that time, voting remained restricted on the basis of literacy, income level and property ownership." (Allen 2014:5). Over a century later, these qualifications of marital life, having children within wedlock, good education, and a fairly high social standing remain in effect in the notion of the "hende drechi," and continue to marginalize lower class blacks.
} 
addition to the abovementioned requirements regarding education, work, religion, and matrimonial life, driving an above average car and paying ample attention to one's appearance aid, as do moving to a more upscale neighborhood, and marrying a person of a higher class, and preferably of a lighter skin tone. Drecha rasa or "improving the race" through generating lighter skinned offspring remains a goal that many Afrocuraçaons desire. It must, however, be noted that nowadays religion plays a far lesser role than it did in the past: one does not necessarily have to be an avid Churchgoer or have a relationship under the sanctimony of marriage to be hende nechi or drechi. And since only $6 \%$ of the population is agnostic or atheist ${ }^{113}$, it is commonly assumed that one is religious. Also, membership in white elite religions such as Judaism and Protestantism add to one's status.

Römer argues that in Curaçao the hende drechi is restricted by class (personal conversation Römer May 13, 2016; see also Thomas 2004). People of low income levels may live very proper lives (bida drechi) and adhere to the morals dictated by the Church, but that does not mean that they will be recognized as hende drechi. Poverty tends to be associated with hende bruá and hende shouru: disparaging notions that translate as “disreputable people." This links to a third notion, which conflates with hende drechi: "hende drechá," which translates literally as "improved or repaired people." Hende drechá is another rather derogatory term used by the white elites (hende nechi) or by the darker skinned middle and upper classes (hende drechi). It signals someone who is attempting to climb up on the social ladder, but whose low socioeconomic class remains

\footnotetext{
113 See appendix V for the statistical distribution of religion in Curaçao.
} 
evident in spite of his or her best efforts to live a bida drechi (personal conversation Römer May 13, 2016). When people talk about hende drechá it is usually accompanied by lots of giggles and laughter, joking and ridiculing at the expense of the people they debase. Time and time again I noticed that people from the white middle class have a lot of contempt for the lower classes, for anything too black, and ridicule what is referred to as "ghetto-ish behavior." In fact, Curaçaoan stand up comedians and actors in folk theater heavily capitalize on these stereotypes.

Römer contends that it is important that these appropriate behavioral norms and codes are maintained continuously. "Only the highest elites are safe from social degradation" (personal conversation Römer May 13, 2016), but everyone else is expected to upkeep social standing through ongoing proper moral behavior. Especially middle class people of color (hende drechi) have to strive continuously to obtain recognition of the elites (personal conversation Römer May 13, 2016). This allows people better opportunities in jobs, commerce, children's admission in better schools, and so on .

These categories of bida drechi and hende nechi, drechi and drechá are heavily racially charged, and carry deep-seated message of white supremacy, which has been, and continues to be, protected by the Catholic Church. Allen illustrates this specifically for the bida drechi $(2007,2014)$. These categories indicate the conversion from bad to good, from black to white, from savage to evolved, ugly to beautiful, disreputable to proper and suitable. The lower class is excluded from social upward mobility, from access to social networks, access to better (white) schools, and access to good jobs. It reflects that the unifying and egalitarian message of the ideology of national identity doesn't mirror everyday reality. 
However, Curaçao's respectability politics also has a counter-hegemonic side (see also Besson 1993, White 2010; Thomas 2004). As previously mentioned, there is the population segment that consciously resists white supremacy by explicitly upholding their black consciousness, allegiance and interests. The work of Curaçaoan scholars such as Rosalia (1997), Allen (2007, 2014), and Rupert (2012) avidly shows black agency and resistance to white supremacy. I was able to observe that this population segment forms a small but strong black-oriented social network that in substantial parts overlaps with the mainstream networks (people attend the same schools, frequent the same stores, and may work in mainstream organizations and companies etcetera), but that also forms its own social segment. Its members are strongly represented in the arts, culture and heritage sector, and in education. The institutions in focus here are the Kas di Kultura (House of Culture), a government organization that focuses on Curaçaoan culture and heritage; folk museum Kas di Pal'i Maishi (House of Cornstalks), where Afrocuraçaoan history is presented; and the National Archeological Anthropological Memory Management, an institute that also focuses on Curaçao's heritage. There are many more such organizations, including musical and dance groups, NGOs, and community initiatives where "black culture" is preserved and celebrated. Some of these institutions engage in a critique of white supremacy. But many participants still adhere to a bida drechi. In my discussion of Afrocuraçaoan folklore it already became clear that black cultural expressions do not automatically evoke resistance and counter-hegemony: the tambú and seú are also played in Church.

The color hierarchy, the third prompt in table 6 , is only mentioned by the junior and the senior male respondents in Barber (\#2 and \#6), both of whom are dark skinned. 
Since race is related to socioeconomic class this color hierarchy has a significant influence on people's potential for social upward mobility. I had expected that in their stories people would address this particular systemic racial inequality, and possibly even challenge it. Yet, the fact that only two of the twenty-nine respondents brought it up indicates that this might not be at the forefront of people's thoughts the way I had expected. In larger society too I found that color hierarchy goes mostly unmentioned, when talking about race. It appears to be a given, a normal part of society, rather than an issue that needs addressing. This strongly signals hegemonic ideology: Gramsci (1971) argued that hegemonic norms and values are so natural and self-evident that they are unquestioned. People use the different labels that indicate the color hierarchy's various phenotypes on a daily basis, but I have yet to hear critique on this labeling system. I also have never heard people address the way the color hierarchy operates unless they are explicitly asked about it, for instance when explaining it to a foreigner, or to me.

The already mentioned ideal of whitening through miscegenation, or drecha rasa ("fixing" or "correcting race"), is a manifestation of the color hierarchy and its underlying premise of white supremacy. The story of the senior female respondent in Seru Fortuna (\#11) demonstrated her very deliberate actions to have a light skinned child, in which she succeeded. She herself is the darkest child in her family, with lighter skinned siblings. It had always been her desire to have a white child with a handsome (nechi) white man. Her siblings loved and spoiled her son, but after he died, seven years ago, they no longer came up to Seru Fortuna to visit her, as if she had lost her social status when she lost her light skinned child. She herself does not recognize her actions as drecha rasa, a deliberate act to upgrade the social standing of her child, herself, and her 
family. Yet the story she told when I asked her to tell me something about color indicates that she is acutely aware of the unequal values attributed to white and black, which only corroborates the power of hegemonic white supremacy and its invisibilized socialization: people act on it whether they know it or not.

Many respondents chose lighter skinned partners, and many others chose partners who were darker skinned than them. The hende nechi and hende drechi norms suggest that lighter skinned people are overall considered to be more attractive with regards to esthetics, social standing, "refinement" and "overall development." This is a norm that is unambiguously mirrored in the representations of people on billboards and other commercial announcements that adorn public space and the media. When it becomes obvious that someone shows an attraction for a darker skinned person, it is often mocked by comments that hyper-sexualize people of color. As if a "penis the size of a cathedral" (Hall 1997) would be the only reason one would be interested in a dark skinned man. The color hierarchy remains in effect through shaming blackness and praising whiteness.

\section{Consequences of Racial Marginalization}

Many studies show how race is closely connected to vulnerability to poverty and other manifestations of marginalization and exclusion (Lin and Harris 2008; see also

Alexander, Entwisle and Horsey 1997; Farkas 2008; Massey 1990). Throughout this chapter, I have shown how these vulnerabilities pertain to ideology, social norms of respectability, somatic norm image, culture, historiography, education, jobs, socio economic class, religion, access to social networks, and to residential location ${ }^{114}$. As table

\footnotetext{
${ }^{114}$ A topic that is not at all mentioned is the race-based disparity in health and health care.
} 
7 indicates, the racist disparities people complained about the most are those that affect employment (69\%) and education (55\%).

Table 7. Consequences of Racial Marginalization

\begin{tabular}{|l|l|l|l|l|l|l|r|r|}
\hline & Bario & $\begin{array}{l}\text { Barber } \\
(\mathbf{n = 6})\end{array}$ & $\begin{array}{l}\text { SeruF } \\
(\mathbf{n = 6})\end{array}$ & $\begin{array}{l}\text { OtroB } \\
(\mathbf{n = 6})\end{array}$ & $\begin{array}{l}\text { Janwé } \\
(\mathbf{n}=\mathbf{6})\end{array}$ & $\begin{array}{l}\text { SpW } \\
(\mathbf{n}=\mathbf{5})\end{array}$ & Tot & $\mathbf{\%}$ \\
\hline & Phenotype respondents & dark & dark & varies & varies & white & & \\
\hline \hline 19 & Work & 4 & 4 & 4 & 4 & 4 & 20 & $\mathbf{6 9}$ \\
\hline 20 & School & 4 & 4 & 4 & 2 & 2 & 16 & $\mathbf{5 5}$ \\
\hline 21 & Poverty & 1 & 3 & 1 & 1 & 3 & 9 & $\mathbf{3 1}$ \\
\hline 22 & Crime & 0 & 5 & 2 & 0 & 1 & 8 & $\mathbf{3 0}$ \\
\hline
\end{tabular}

I explained earlier that the darker skinned respondents from all the neighborhoods indicate that they have fewer opportunities to get good jobs because of the negative stereotypes about blacks that circulate on the island. Over the years I have often spoken with highly educated, successful people of color in the middle and upper classes at business meetings, happy hours and all sorts of other events. When hearing about my research many people shared the same reaction: it is very possible to get ahead, but you have to put up a considerable fight. A dark skinned man who is now the owner of a multimillion guilder company told me how difficult it was to get a loan with a bank, or to be taken seriously by investors. To this day people still don't easily believe that a darker skinned black person is the owner or CEO of a business. I also hear many stories told by affluent people of color about not being served properly in bars, restaurants, and stores, being mistaken for the gardener or the cleaning lady when working in one's yard or when opening one's front door, or being sabotaged and counteracted by co-workers and supervisors. These stories from the middle-and upper classes indicate that abiding by the 
codes of respectability politics do not erase racial discrimination and the impact of colorism: skin color continues to matter.

Furthermore, various respondents addressed the racist exclusions in the school system, which surfaced so clearly in Seru Fortuna's stories. In informal conversations this was one of the top complaints I heard, from people from the lowest to the highest classes. People of color encounter numerous difficulties to register their child in the higherranking and better-funded Dutch speaking schools, while allegedly white parents register their children effortlessly. The most striking story I was told by a young girl described how her dark skinned mother went to enroll her daughter, addressing the administrators in Papiamentu. She was rejected, "classes are full," the school said. But when her mother called the school afterwards and sought to enroll the child via telephone, speaking fluent and accent-less Dutch, the child was accepted on the spot and the enrollment was finalized right there and then over the phone. When the mother walked back into the school to sign the enrollment form the administrators got a tremendous freight: clearly their racist practice had been exposed. One story indicated that a black parent went to enroll his child but was refused. The white parent of the same child went to enroll the child, and the enrollment took place immediately. Dark skinned people from the upper classes have told me that they had to show a salary slip as to prove that they were suitable. And always the same schools are mentioned. These stories are common knowledge, and date back multiple generations.

Informal conversations that I have had with teachers from various schools as well as a testimony given by an official of with the Education Inspectorate, who insisted on remaining anonymous, indicate that they too are well aware of these racist practices. Yet 
no one objects, files a complaint, or initiates an investigation. People do complain about this, but just not formally to the "state" (see also UN 2015). Following Scott (1992), such informal complains could be seen as a way to resist without taking overt action. At least it is a way to unburden oneself and share with others.

There are many other ways in which Afrocuraçaoans contest racism in more hidden and less overt ways ${ }^{115}$. Still, the lack of is official complaints and reports of cases of racial discrimination is significant and problematic, as the report of the UN Working Group also indicates (UN 2015). When I ask people why they don't protest many of them profess that they don't know how to. Again, many people are not aware of the actual criminalization of racism. Many others express apprehension. They don't want to critique or accuse anyone, out of fear of losing social standing, and out of fear for repercussions. One mother, a brown skinned middle class woman, told me in an informal conversation: Curaçao is a small island, everyone knows everyone. When I complain about my child not getting into that school I could end up losing my job, because some person on the school board happens to be friends with my boss, or something like that.

Respectability politics surface again: "respectable people do not make a fuss in public." People fear that becoming known as a "troublemaker" might only further complicate the enrollment of their child in a "good" school, if not impossible, and cut them off from other networks and opportunities.

\footnotetext{
115 This dimension of resistance falls outside of the scope of this study but deserves much more research and documentation, see appendix X.
} 
Even though the stories I heard indicate that these discriminatory practices have been part and parcel of Curaçaoan society for many generations - they are common knowledge, a public secret - the government does little to address this. The Educational Inspectorate appears to be aware of these practices, but does not investigate or properly address them. The fact that it has not yet happened again signals the impact of multiculturalism, where such subaltern contestation is omitted and deflected.

Poverty and crime were mentioned considerably less often in peoples' stories. In Seru Fortuna the two younger female respondents (\#7 and \#9) and the middle male respondent (\#11) spoke of the difficulties of poverty, of living in dilapidated houses, of having a hard time finding a job, not having enough food. Nearly all respondents in Seru Fortuna spoke about the high crime rate in their neighborhood. In other barios poverty was not a topic people discussed in depth. In Otrobanda the two middle respondents (\#15 and \#16) mentioned the rise of crime in the bario after the departure of the elites, following the 1969 revolt.

Crime is certainly a serious problem in Curaçao. The census' Victim Survey indicates that in $201421.7 \%$ of the population had been the victim of some sort of crime (www.cbs.cw, visited April 19th 2016, see appendix VIII). There are, however, no census data about who the victims or the perpetrators are, nor does the website of Curaçao's Central Buro of Statistics present information on crime rates, arrests or incarcerations per bario $^{116}$. Yet a detective of the Police Corps informed me that the most common types of crime in Curaçao are burglary into houses and companies, small theft, and violent theft,

\footnotetext{
${ }^{116}$ Conversations with two detectives reveal that data on perpetrators are not collected per bario. Only data on victims are listed.
} 
including armed robberies (see appendix VIII). These offenses are mainly committed by dark skinned Curaçaoan youth from poor barios, who often have had very little education, and tend to come from families with a number of "problems" ${ }^{117}$. As the table in appendix VIII indicates, the type of crime most common in Curaçao suggest a link to poverty alleviation, and to people marginalized to the extent that they have insufficient chances to advance in life by any other mean.

One respondent from Spaanse Water indirectly expressed her fear of criminals, and indicated that her bario — a gated community — was safe. I often see and hear this fear for burglary, robbery and assault expressed among people of all class layers. Most houses have iron bars on windows and doors. Most people, of all class layers, have watchdogs in the yard, and high fences. This is a trend common to all neighborhoods, regardless of race. Restaurants, movie theaters, shopping areas and other venues and beaches frequented by tourists and middle and upper class people have guards to secure parking lots and entrances. Many offices have guards at night.

The fear, I argue, is particularly directed at poor black men. People do not easily verbalize this, but both the middle male respondents from Otrobanda (\#16) and Janwé (\#22), both black, mentioned it. People clutch their purse tighter, cross the street, or lock the doors of their car when they see them. As previously discussed, the fear of the dangerous black male is part of racist stereotyping that has existed from colonial times

\footnotetext{
${ }^{117}$ What is remarkable about these Curaçaoan criminals, this detective says, is that they tend to be very violent, which results in a high incidence of robberies with extreme violence, murders and liquidations. Even though the CBS does not specify the incidence of drug related crime, these same youth often engage in it, including local drug trade and drug runs to Europe. Import and large scale trade is mainly dominated by South Americans and an occasional Curaçaoan. Higher end crime, such as whitewashing, which is not listed in the victims' table of the CBS, is mainly executed by highly educated white criminals from the middle and especially the upper class.
} 
until today. But the constant representation of poor black people as criminals in the media further feeds this fear. Curaçao doesn't have poor white barios. There is no significant white poor population: poor whites are outliers. Even though public policy and scholarly research do not link race to poverty, people certainly do.

The media, and newspapers in particular, also unambiguously establish that link. Every day the newspapers, and especially those directed at working class audiences ${ }^{118}$, display large photographs of poor black men as criminal aggressors who have been arrested for all sorts of misconduct. Black men in handcuffs, black men bent over the hoods of police cars, black men on the ground, black men killed by other black men, black men in accidents. It is mostly men, on those newspaper pages; women are not nearly as often presented as criminal. And in these representations of delinquency we see mostly black bodies, often half naked, in surrendered or even mangled positions, which had engaged in crimes because of desperation and poverty, as explained by the press. Sometimes there is no description, and the photographs tell their own stories, always casting poor black people in situations of misery, "disgrace" and "savagery."

This criminalizing representation casts poor black people in the role of criminal offenders, but leaves out of focus the multiple dimensions of how crime affects poor black people. A broad body of literature on the United States addresses how inhabitants of poor barios are also victims of robberies and assaults, and of people getting caught in a cross fire between quarreling groups, and getting hit by a stray bullet. But what is specifically important with regards to the structural side of poverty and crime is that

\footnotetext{
${ }^{118}$ These are the newspapers Nobo, Ekstra, Vigilante, and Bala.
} 
young black males with low levels of education are much more at risk at being incarcerated. A criminal record further diminishes chances at social upward mobility, as does the victimization they experience while incarcerated (Wheelock and Uggen 2008:263). Furthermore, they run a great risk at becoming the victim of robbery and homicide (Wheelock and Uggen 2008:262). The fact that the link between poverty and race is at once so explicit in the media, and so unrecognized and unaddressed in research and policy points to the mechanization and normalization or naturalization of white supremacy through multicultural, raceless ideology.

\section{Resistance and Complicity}

This chapter has revealed that Curaçao's system of white supremacy is largely normalized and unchallenged (see UN 2015; Gramsci 1971). A myriad of gatekeeping mechanisms reproduces racial discrimination in work, education, poverty and crime. But does that mean that people indeed do not challenge racist behavior? And we observed that people reproduce the principles of racelessness, equality and unity through diversity as suggested by the Yu'i Kòrsou ideology of national identity, but do people actually bring up the label of "Yu'i Kòrsou" when talking about race? In table 8, I explored these remaining questions.

Table 8. Resistance and Compliance

\begin{tabular}{|l|l|l|l|l|l|l|l|l|}
\hline & Bario & $\begin{array}{l}\text { Barber } \\
(\mathbf{n = 6})\end{array}$ & $\begin{array}{l}\text { SeruF } \\
(\mathbf{n}=\mathbf{6})\end{array}$ & $\begin{array}{l}\text { OtroB } \\
(\mathbf{n}=\mathbf{6})\end{array}$ & $\begin{array}{l}\text { Janwé } \\
(\mathbf{n}=\mathbf{6})\end{array}$ & $\begin{array}{l}\text { SpW } \\
(\mathbf{n}=\mathbf{5})\end{array}$ & $\begin{array}{l}\text { Tot } \\
\mathbf{\%}\end{array}$ \\
\hline & Phenotype respondents & dark & dark & varies & varies & white & & \\
\hline \hline 23 & Response to racist behavior & 3 & 2 & 3 & 2 & 2 & 12 & $\mathbf{4 1}$ \\
\hline 24 & Respondent mentions Yu'i Kòrsou & 0 & 0 & 0 & 0 & 4 & 4 & $\mathbf{1 4}$ \\
\hline
\end{tabular}


Allen indicates that in the past in Curaçao, rebellion and defiance were labeled as uncivilized behaviors inherent to disreputable black people, hende bruá, which had to be improved (Allen 2007). In some cases, Allen illustrates, these oppressive ideas were worked into tambú songs. We saw previously that the tradition of the tambú was-and still is - perceived as the seat of Afrocuraçaoan resistance. But still, such hegemonic tambú songs were not uncommon. In 1986 Allen collected such a tambú song from the post-emancipation era, from a respondent who himself was born in 1898, and who had learned the song from his mother. The song used to be sung by house slaves, and illustrate indoctrination of hegemonic values (Allen 2007:74,75).

$\begin{array}{ll}\begin{array}{l}\text { Papa Sewe, } \\ \text { Ata Negru tribi }\end{array} & \begin{array}{l}\text { Papa Sewe, } \\ \text { k'a lanta ku Blanku }\end{array} \\ \text { Papa Sewe, } & \text { Pho stood up against the Whites } \\ \text { Ata Negru tribi } & \text { Look at that insolent Negro } \\ \text { k'a lanta ku Blanku } & \text { who stood up against the Whites } \\ \text { Hork'é } & \text { Hang him } \\ \text { Mat'é } & \text { Kill him }\end{array}$

This song refers to Tula and the slave revolt of 1795. In it, Tula-a powerful symbol of black resistance - is purposefully presented as an enemy of the nation, not a national hero. Allen and others such as Ellis Juliana and Paul Brenneker have recorded more songs like this, which reflect the old value of resistance was linked to insolence and improper behavior, a value that persists. Shaming and silencing of resistance was done by whites and blacks alike. 
We saw in Barber's stories that when confronted with racism most people remain silent and shrug it off. In Janwé the older, dark skinned male respondent (\#24), who is highly educated and has a vey prominent job, said that it was difficult, but absolutely necessary, to keep your emotions under control when facing racism. It is hazardous to display anger publically, because you could damage your career, which you worked so hard for, and risk your job, the opportunities for your children, and so on. He described situations in which people assumed he was the gardener, or where he was not served in a bar while around him white people were served. It is profoundly denigrating, painful, and frustrating, to be discriminated against; to be "constantly devaluated because you are a person of color." But, he argues, the repercussions of your speaking up or acting out might be even more painful. He too mentions the role that Curaçao's small-scale plays in this: a complaint or accusation regarding something that takes place in the social sphere, such as in sports or among friends, may create a ramification on the work floor. The silence engendered by this fear clearly has an oppressive dimension: it preserves the principles of white supremacy. However, it is also a deliberate act of self-protection (see Sheriff 2000), and thus attests to Afrocuraçaoan agency. Even though people do not speak up, navigating and restricting the damage caused by racial discrimination is an important action.

In other barios I witnessed the same attitudes. At home, among friends and loved ones, I witnessed the same thing. I have seen grown men and woman cry hot tears about racist humiliations, but they never said a word in public, mostly out of fear for repercussions. But also, time and time again I heard people say: "What can you do?" In a conversation a brown skinned male in his thirties said: 
Curaçaoans often don't know how to calmly, verbally put people in their place. There are some people who do have that razor sharp tongue, but if you don't know how to do that then it's safer to remain silent. You don't want drama, but in that instant all the pain surfaces, so you might start yelling or hitting people. That would hurt your reputation. Discrimination often happens at work, when an employer or some other higher placed person says something ignorant. Then it is really difficult to respond: you don't want to lose your job. They will complain to others about what happened, but the boss will never know, and the abuse can go on forever. But also, Makambas often don't know better. They always want to continue making racist jokes, so at some point you say "let them be." You gotta pick your battles, otherwise you are fighting all day, and then you are seen as that negative person. Also, some black people don't really get that all people are equal. If they think Makambas are better than they are they will stay quiet and take the abuse. As if it is the Makamba's right to abuse them. But people that are more conscious will set you straight.

One young Afrocuraçaoan man of about fifteen years of age said "it's not as if racism is illegal." But as we saw in chapter 1 , it is ${ }^{119}$.

The two young dark skinned men in Otrobanda (\#14 and \#16) and the younger male respondent in Barber (\#4), all dark skinned men, are the only ones in the sample who I have seen resist explicitly, not through direct retort but through their hair- and lifestyles. After many years the man with dreadlocks (\#16) finally uncovered his hair

\footnotetext{
${ }^{119}$ See appendix II for an overview of Curaçao's anti-discrimination legislation.
} 
instead of hiding it under hats. The youngest male respondent (\#14) refused to cut his hair: he was raised in the Netherlands and grew up without Curaçao's strong censure on African hairstyles. But most others remain quiet. The teacher from Barber (\#3) teaches her pupils not to bully and to stand up against discrimination, even though her own way of dealing with discrimination was to turn a blind eye on it. What seems to add further to this silence is - again - people's unawareness of the various legal instruments against racism.

Throughout this chapter we saw repeatedly that critique on racial inequality is referred to only marginally in the interviews, and not part of mainstream society's culture and knowledge production. But the discussion of the port-revolt era in chapter 1 revealed that it certainly has a significant presence in Curaçao's past and present. As Scott indicates, there are numerous avenues for overt and hidden forms of critique. Scholars such as Allen (2007) and Rosalia (1997) have highlighted Afrocuraçaoan resistance through music, and tambú in particular. But as it is, this counter-hegemonic discourse is severely under-documented. It deserves far more elaboration, exploration, and documentation. As of yet there is no comprehensive body of work that has recorded and analyzed these different movements, the key-players, and their achievements. This invisibilization of the achievements of black empowerment is part of multiculturalism: it deflects and trivializes the importance of counter-hegemonic progress (Hale 2002, 2005; Goldberg 2002; Greene 2007; Rahier 2012).

But in spite of its relative invisibility, and there is ample critique on and resistance to against white supremacy. There is critique and resistance in music, such as in the recent rap songs "Koi Makambanan" (Dutch Things) by Mosta Man (2009), on persisting 
white Dutch dominance, and in "Nelson Mandela" by Dongo (2015), which addresses police violence directed at poor black youth ${ }^{120}$. There is critique and resistance in art, literature, story telling, film, poetry, folk theater, the multitude of proverbs that address inequality, the natural black hairstyles that are becoming increasingly popular, and through a revival of locally developed fashion using African prints and clothing styles. There is critique and resistance in delinquency and school drop out: why partake in a system that does not have your interests at heart, and why attend a school that praises white Dutch achievements over Afrocuraçaoan ones? There is resistance in engaging in Afrodescendant medicinal and religious practices such as the old herbal remedies preserved by people such as herbal specialist Dinah Veeris, and in the worship of the Santos and engaging in Afrocuraçaoan spirituality, which is often done secretly, or at least away from the public eye. There is critique and resistance in the unfriendly behavior of (darker skinned) working class shop clerks towards white tourists and other clients, and in the attitudes of aloofness and disinterest towards job supervisors (Antonius 1996).

There is critique and resistance in the broad range of institutions that have developed since the 1970s, and that focus on the preservation and stimulation of Afrocuraçaoan culture and heritage. And as discussed in chapter 1, in the political arena politicians such as Amador Nita, Stanley Brown, Don Martina, Maria Liberia-Pieters and the late Hermin Wiels openly critiqued and resisted white supremacy. They were not many, but they made important changes. However, Wiels was assassinated shortly into

\footnotetext{
120 These rappers reside respectively in the Netherlands and Colombia, but their songs pertain to both the Netherlands and Curaçao, and are consumed by the Curaçaoan community that inhabits a transnational space. There are 250.000 people living on the island, but another 140.000 people from Curaçao and the other Dutch Caribbean islands live in the Netherlands (http://www.zorgatlas.nl/beinvloedendefactoren/demografie/etniciteit/nederlandse-antillianen-en-arubanen/). See appendix XII for their lyrics.
} 
his first term, one day before he had announced to reveal data regarding the corrupted practices by wealthy white families. He was shot on a Sunday afternoon, when he went to drink a beer on the beach. He had sent his bodyguards home. To this day his murder has been unresolved. Nita, one of the leaders of the 1969 revolt, died only a few months into his first term as minister in the government. The people close to him claimed that he was poisoned, but this has never been proven (Anderson and Dynes 1975:102). The possibility of there being a correlation between their political orientation and their untimely deaths is whispered, not spoken. But it certainly does not diminish the sensitivity surrounding the critique on white supremacy, which is fuelled by fear of repercussions (see also Sheriff 2001).

But in spite of all this critique and resistance, overt and systematic contestation of white supremacy and the racial status quo in Curaçao is minimal. And the critique and resistance is directed to certain parts of white supremacist oppression, while other dimensions people are far less aware of. I argue that, while there is critique and resistance, it is silenced to such an extent that white supremacy is hegemonic. Again, hegemony does not mean that people are unaware of their subjugation, or that they agree with it. Hegemony means that, in spite of their discontentment, the masses consent to their subjugation, and perceive the status quo as natural and self-evident (Gramsci 1971). In the iceberg metaphor, which I presented in the introduction, I argued that this silencing — and with that, hegemony—results from a large part of the mechanizations of hegemony not being clearly understood. The top of the iceberg, we see. In the metaphor this refers to the ideology that propagates unity and equality. We are likely to be aware that the iceberg has a bottom, but do not know its shape or size. Consequently, people are 
aware that racism, racial discrimination exist, but they do not know how extensive these oppressive and excluding measures are, and how—exactly—they operate. But it is difficult to dismantle that which we cannot see or hear or comprehend. But as I also explained in the introduction, hegemony is never absolute, nor static, but always in flux as it is forever adapting to new contestations by the masses.

The Yu'i Kòrsou was very rarely mentioned in the stories collected. None of the respondents from the non-white neighborhoods ever mentioned the Yu'i Kòrsou ideology by name, unlike the white respondents in Spaanse Water, who brought it up to reason away racism, and to claim their place in Curaçao's "multicultural" society. Their defense of national unity in diversity is most certainly in accordance with their interests of not being ostracized as an ethnic and racial demographic minority that genuinely dominates all domains of Curaçaoan societal structure. Their attachment to the Yu'i Kòrsou identity gives them ideological means and tools to attenuate - if not completely erased from view - their obvious positioning at the apex of the Curaçao's racial/spatial order.

I have also found that people refer to the Yu'i Kòrsou at the "borders" of the nation, when interacting with foreigners. And it arises when people want to explain the nation's core "nature," and when talking about political reform, national culture and heritage. Curaçao is a relatively young nation. It has only reached its current status as a "constituent country" within the Kingdom of the Netherlands in 2010. Therefore topics of nation building are often on the table in political and governmental meetings and speeches. But in my case study, the respondents, with the exception perhaps of the white Curaçaoan respondents, have not felt the need to refer to the Yu'i Kòrsou ideology to 
explain or understand their circumstances, to organize their lives, or to formulate their hopes and worldviews.

However, in reverse, when I ask people to define both the Yu'i Kòrsou ideology and the Yu'i Kòrsou identity (which I did not do in the interview but which I often did in informal conversations), respondents connect it to race and racism quite immediately. People say: "all are equal," but the elaboration on racial disparity immediately follows. The structurally defining influence of race on the shape of the nation is an influence that is largely invisible. Instead the nation is perceived as defining race.

$\begin{array}{lll}\text { Race } & \rightarrow \text { Nation } & \text { invisible relation } \\ \text { Nation } \rightarrow \text { Race } & \text { visible relation }\end{array}$

\section{Conclusion}

The objective of this third chapter was to assess how Curaçaoans today perceive and experience race in their every day lives, and to examine the discrepancy between the unity and equality that is so avidly proclaimed by the Yu'i Kòrsou ideology of national identity, and the persisting racial inequality that is so little addressed and yet so easily observed. The chapter also examines the impact of multiculturalism on the imagination and representation of race. The bario is a crude measure that cannot replace census or other statistic data on race. Nonetheless, using the bario as a proxy for race proved to be a worthwhile approach to gain some valuable insights.

Firstly, the twenty-nine stories showed a significant discrepancy between the unity and equality that is propagated by the Yu'i Kòrsou ideology of national identity, and people's everyday experiences with racism. The ideology of inclusion and equality, 
the top of the proverbial iceberg, was the very first thing that surfaced when I asked people to "tell me something about race and color," like a knee-jerk response. Many respondents initially argued that there no longer is racial inequality. Even when racism was part of their every day life experiences, this national ideology was very much at the forefront, and surfaces throughout in their stories as a base-line for racelessness (Goldberg 2002; see also Bonilla-Silva 2010; Hale 2002, 2005; Greene 2007).

But as people continued to talk their stories dismissed this unity and equality. The respondents mostly spoke about racial inequality: their overt critique on racial discrimination in for example education and on the job market fills most of the stories. The vast majority of the stories did not celebrate unity through diversity but were largely testaments of racism's obvious persistence. In informal conversations I observed the same trend: people talk much more about racism than about unity and equality.

In these twenty-nine stories the previously mentioned gatekeeping mechanisms again became apparent. People spoke of how racial discrimination in for example the field of education and on the job market restrict social upward mobility of Afrocuraçaoans. These marginalizations especially affected the lower classes. Everyone acknowledged the impact of the color hierarchy, and the current racial/spatial order of the island. The upper classes have remained predominantly white, the middle classes are mixed, and the lower classes are primarily dark skinned. The different religions are still largely racially segregated. The Catholic Church still plays a strong, directive role in the lives of the Afrocuraçaoan population, and still upholds numerous tenets of its civilization mission. Education has become one of the main routes to social upward mobility for people of color, but it is a double-edged sword. Education in Papiamentu 
gives mainly Afrocuraçaoan children—many of whom speak Papiamentu at home—a better start and more positive appreciation of self. Nevertheless, mastery of the Dutch language remains a key asset on the job market, especially with regards to higher skilled jobs, and to pursuing higher education in the Netherlands. The neighborhoods are still largely segmented by race and class. Poor—black—neighborhoods, where the large social housing projects are located, are stigmatized, which adds to inhabitants' marginalization when applying for a jobs or when seeking to enroll in certain schools. The black-is-beautiful ideals from the 70 s and 80 s have waned, and colorism is again in full effect. It was clear that race was not a topic that people commonly spoke about, but it surely is a topic about which people spoke eagerly, and had plenty to say, and most of it was far from positive.

But the full extent of racism, especially its structural, institutionalized dimension, did not appear to be very clear to people. People mostly described incidences, not larger patterns. This corroborates with the iceberg metaphor: we know that the bottom is there, but we have no real idea of its size or shape. I repeatedly observed that people trivialized the horrors of the colonial past, and how these are related to persisting racial inequality today. The obfuscation of this correlation signals the impact of multiculturalism, which as we saw places especially the structural and institutionalized dimensions of racial inequality out of sight and promotes racelessness.

The second part of the chapter zooms in on this. It offers a deeper analysis of the twenty-nine stories, through which I specifically looked at multiculturalism and how this is implemented through the principles of racelessness (Goldberg 2002). This section makes visible the hegemonic narratives of white supremacy that people reproduce 
without being fully aware of this: the bottom of the iceberg. After all, hegemony demands that one has internalized the subjugating norms and values to the extent that they appear normal and natural, and often difficult to even define. But because these norms are so normal and natural people do replicate them continuously.

This deep reading of the stories indicates that many respondents argued that there should be equality, but that in Curaçao's society white is generally still seen as superior to black, and that black continues to have strong negative connotations. Many of the stories contained narratives that normalize and naturalize black inferiority and racial inequality compared to white superiority. At the same time, the glorification of white achievement and history—another principle of multiculturalism—was obvious. Whiteness continues to be associated with superiority and respectability, even though the respondents overtly expressed their dissatisfaction with this. Dark skinned, but also many of the white and light skinned respondents, critiqued white privilege and called it unfair. But some of them also reproduced mainstream renditions of national history, such as the salvation that the Catholic Church brought Afrocuraçaoans through education, health care, and religion, and the importance of slavery in making Curaçao a prominent Caribbean nation.

This glorification goes hand in hand with a consistent trivialization of the horrors of slavery and colonial oppression, which were absent from the majority of stories. When respondents did refer to slavery, they portrayed enslaved people as victims, not as potent agents. Their mention of Tula as leader of the 1795 slave revolt was an exception to this. But Tula also turned out to be one of the antagonizing names used by kids, when they tease and bully one another. In this use, children referred to Tula's slave status and not 
his powerful agency, and shamed their playmates or rivals for their alleged inferiority due to their dark skin. Nonetheless, this narration of slavery echoed the white mainstream rendition of Curaçao's colonial past, and reinforced black submission rather than empowerment.

The stories did not indicate that people were irritated about this whitewashing of the colonial past, and of the glorification of elite achievements. This signals hegemony: many perceive this particular narration of past and present as normal, and reproduce it without much contestation, and often even with great pride. Over the years of living and working on the island I have repeatedly noticed that Curaçaoans are very proud of their beautiful old city, and particularly on the colonial mansions and haciendas ("landhuizen"). When the Curaçao Tourism Board posts yet another video on Facebook that celebrates this colonial European-based architectural heritage, thousands of peopleblack and white alike-like it and post enthusiastic comments. Generally, I have found signs of critique to be few and far between.

In these narrations colonial exploitation as the root case for contemporary racial inequality also became trivialized, or even obfuscated. The respondents, and especially those in Seru Fortuna, did perceive race to be a key factor in their restricted access to employment and education, and in the high poverty and crime rate they experience. However, as previously mentioned, in larger society this correlation between race and poverty and other kinds of detrimental effects of racism is denied and made invisible. Consequently race has not been a variable that has been incorporated in governmental policies or academic research. The stories that did refer to this correlation do not mention 
the lack of this address on behalf of government and academia. People appear to perceive the lack of attention for race as normal, which makes this particular silence hegemonic.

What's more, these hegemonic narratives in these stories revealed a constant trivialization of Afrocuraçaoan reform, resistance, and achievement, which deflects possible black contestation of white supremacy. In the stories there was a minimal presence of black heroes, achievements and knowledge. When respondents did talk about the revolt, pro-black empowerment and Antilleanization, they mostly reproduced the negative hegemonic narratives that trivialized and even scorned these events and achievements: the revolt and the pro-black emphasis of Antilleanization were depicted by some as harmful to society. The overall valuation of blackness that arose from these interviews was decidedly negative compared to whiteness. This again signals the persistence of white supremacy, perpetuated through the mechanizations of multiculturalism.

Respectability politics play a central role in this deflection: articulating critique is labeled as disreputable, and disreputableness can amount to repercussions that diminish one's social upward mobility. This pertains both to the way people perceive pro-black reform, which as we saw in hegemonic narratives is presented as an act of disobedience and antagonism rather than as empowerment, and to the individual's responses to the racism they encounter in every day life.

However, to only see these silences in response to every day life confrontations with racism as hegemonic would be a mistake. Various respondents talked about the coping mechanisms they developed to deal with racism. Their accounts illustrate that they do not easily contest the racism directed at them. Many remain silent, or ignore it 
and shrug it off. They perceive it as unpleasant but normal. As said, it is the norm of Curaçao's respectability politics to not direct explicit critique at anyone, and especially not through legal instruments, nor is it the norm to adhere to pro-black emancipatory reform. Some respondents indicate that they are afraid of repercussions, and that they fear the intensity of their own emotions, once they allow them to surface. As discussed in chapter 2 , here too it becomes apparent that these silences are in part hegemonic, but also deliberate actions to navigate the dangers of racial discrimination (see also Sheriff 2001). The silence keeps people safe, as it secure one's social standing and possibilities for improvement. In part it's a complicit silence (Bourdieu 1977), but it is also full of agency.

A last core element of multiculturalism that becomes visible in this deep reading of the stories is the prevalence of a discourse of racelessness. Throughout this dissertation we saw that racelessness engenders numerous deflections, of black empowerment and reform, subaltern critique, white exploitation, and the causal relation between past transgressions against Afrocuraçaoans and their contemporary marginalization (see Goldberg 2002). All of these deflections, though not actively addressed by the respondents, surfaced throughout these twenty-nine stories. They undercut true black reform and safeguard the persistence of racism (Bonilla-Silva 2010; Goldberg 2002; Hale 2002, 2005; Greene 2007; Rahier 2012).

This final chapter showed that the unifying part of the Yu'i Kòrsou ideology of national identity is very pervasive and well known by all respondents, but it does not have a strong enough impact to genuinely invisibilize the impact of Curaçao's deeply rooted racial inequality. Curaçaoans clearly witness and experience the impacts of this 
racial inequality—in fact, they always have. But this is a quintessential part of hegemony: it does not necessarily render oppression invisible. People may in fact be acutely aware of it. It however naturalizes and normalizes oppression to the extent that people do not seek to overthrow it: it informs the natural order of things. This, the chapter illustrates, is what the Yu'i Kòrsou ideology indeed does. For while the Yu'i Kòrsou ideology may not succeed in fully convincing the population that unity and interracial equality are real, through the largely invisible mechanizations of multiculturalism it is still successful in disguising the various ways in which racial marginalization, exclusion, deflection and trivialization are implemented, repelling counter-hegemonic critique and contestation, and thus in safeguarding and perpetuating white supremacy.

On a closing note, this third case study focused on ideology and what parts of it people internalize and perpetuate, and considerably less on the myriad of ways in which people have been resisting to it for centuries, and continue to challenge it successfully today. In the introduction I warned the reader for the one-sidedness of my approach. This chapter was not designed to unveil the "super powers" of the Yu'i Kòrsou ideology of national identity, and to forecast ever-lasting subjugation of Curaçaoans of African descent. Instead, the chapter's ultimate objective is making visible at least some parts of the way hegemonic ideology works, which hopefully contributes to the breaking of at least some of its silences, as to enhance social change. 


\author{
Conclusion: The Sound of Silence \\ The Intricacies of Race and National Ideology in Curaçao
}

Mundu yama Sinta Mira.

The name of the world is Sit and See. ${ }^{121}$

-Curaçaoan proverb

This dissertation is titled The Sound of Silence, Ideology of National Identity and Racial

Inequality in Contemporary Curaçao. Throughout its chapters I have sought to unveil

that contemporary racism in Curaçao is a partially hidden constituent of the Yu'i Kòrsou

ideology of national identity, which advocates unity and equality through

multiculturalism. The main objective of this research was to show how race and racism

have been entangled with Curaçao's hegemonic ideology of national identity, and to

demonstrate that racism has not become obsolete, as many Curaçaoans today often claim.

Via three different case studies I have sought to critically analyze and theorize how this

121 This proverb is also the title of a collection of poems and scholarly articles on womanhood in Curaçao. In the introduction of the collection, editor Joceline Clemencia explains what the proverb means and how she uses it to challenge the long standing silencing of Afrocuraçaoan and especially Afrocuraçaoan women's voices (Clemencia 1992:ix). She writes:

In Curaçao it means that reality is complex and dynamic, and that when you take time to study it, you will be able to discern this complexity. Mundu yama sinta mira speaks of survival based on strength and the wisdom of timing. Only the shrewd ones, who can perceive the difference between a noisy and apparently strong opponent and their own presumable silence and weakness know that in the end they will win, because today's things can change into their opposite tomorrow (Clemencia 1992:ix).

The proverb's meaning, as explained by Clemencia, is an important testament of the empowering dimension of silence. As we saw throughout this thesis, and especially in Dorothy's story, silence is not only about obedience and subjection, but also about resistance and empowerment: about healing and waiting until the time is right to make a move. Clemencia states that "the women of Curaçao were not silent, they awaited the right moment to speak out in the past, and continue to do so now" (Clemencia 1992:x). 
ideology of national identity facilitates the perpetuation of racial inequality, through hegemonic representations, deflections, and silences.

In Chapter 1, I examined how an ideology of white supremacy has over the course of 380 years become deeply embedded in the societal make-up of the island. It informs its racial/spatial order, and legitimizes, safeguards and perpetuates the dominance of the ruling class (Bonilla-Silva 2010). During the colonial era racial hierarchy became increasingly implanted in legislation, education, politics, demography, language, religion, culture production, and intimacy, thus structurally segregating white and black through a myriad of gatekeeping mechanisms (see Bonilla-Silva 2010).

Although the appearance of the ideology of white supremacy changed over time, this dissertation showed that its tenets fundamentally remained the same. After manumission, industrialization brought ample change to the island. A new ideology of national identity, which emulated hybridity and creoleness, grouped the old black and white populations of the island together under the label of the Yu'i Kòrsou, the child of Curaçao. It professed a more inclusive stand towards the Afrocuraçaoan masses, which had been marginalized for so long. But this ideology mostly served the elites. Afrocuraçaoan culture became a figurehead of Curaçao's cultural uniqueness, which strengthened the elites in their claims for autonomy from the Netherlands. It also-at least temporarily—excluded the large stream of immigrants from true participation in the nation. This alleged unity and equality did however not decrease the marginalized position of the Afrodescendant population. Instead, gatekeeping practices remained in effect and white supremacy persisted. 
The 1969 revolt brought about another clear shift in the Yu'i Kòrsou ideology of national identity, by adopting multiculturalism and racelessness, which celebrated diversity and intercultural equality (Hale 2002, 2005). Even though for many Afrocuraçaoans this multicultural reform was initially seen as a victory that would finally diminish —if not end — racism, following scholars like Goldberg (2002), Hale (2002,2005), Greene (2007) and Rahier (2012) I explained this shift as an elite strategy to deflect Afrocuraçaoan demands for additional reforms. Part of this deflection was intensification in the appreciation of Afrocuraçaoan culture: Afrocuraçaoan people and culture were now perceived as the core of Curaçao's national identity. The government initiated legal reform, and through numerous initiatives from both the government and civil society people of color got much more opportunities in education and on the job market. But still, numerous gatekeeping mechanisms, tied to the institutions that had their roots in colonial society, remained intact.

A discussion of how multiculturalism developed on the island, in chapter 1, showed that in spite of its unifying and egalitarian message, the multicultural rendition of the Yu'i Kòrsou ideology of national identity still facilitates the perpetuation of racial inequality and white supremacy. Racelessness plays an essential role in this. Because of the alleged unity and equality "race no longer matters," the narrative goes. Consequently, the structural and institutionalized ways in which the racial hierarchy continues to shape the nation remain in effect (Goldberg 2002; see also Bonilla-Silva 2010).

In the second chapter I explored how the ideology of white supremacy impacts the most intimate dimensions of one's life. Following Ann Stoler I analyzed how racial dominance shaped the lives of three generations of transnational Caribbean women: my 
mother, my grandmother and myself. I explored how Dutch imperial racial ordering of people and places affected our perceptions of self, of our bodies, our intimate relationships, family patterns, behaviors, the way we kept our hair and the dress we chose, the moral codes of respectability that informed our decisions, and so on. Colorism, and whitening though miscegenation as a means of upward social mobility is another theme. This chapter illustrates the concrete impacts that hegemonic ideologies of national identity can have on our lives. Racial ideology seeps into everything: into our thoughts, our feelings, our bodies, our psyches, into the dreams we dare to dream, the choices we make. And because it is naturalized it is pervasive, illusive, and ungraspable. Also, the chapter revealed that hegemony entails an intricate tangle of silences, some of which serve hegemonic indoctrination, while others are instrumental in counter hegemony, resistance, and our agency.

Chapter 3 zoomed in on the impact of multiculturalism on the Curaçaoan population. It reverts back to the mechanizations of multiculturalism, as described in both the theory and the historical analysis in chapter 1 . There we saw that multiculturalism is yet another ideology of white supremacy, which promulgates diversity, intercultural equality, and state-recognized inclusion of subaltern people, particularly through tools, such as legal reform, which allow marginalized peoples to increase their upward social mobility (Hale 2002, 2005; Greene 2007). However, in reality this reform and inclusiveness is just a mirage: it deflects subaltern claims on increased power (Goldberg 2002).

The ethnography conducted in chapter 3 generates more insight in how racism persists, and especially to what extend people seem to be aware of its existence. 
Interviews conducted among 29 respondents from different racial and socio-economic backgrounds examined how Curaçaoans experience and respond to both the unity that the Yu'i Kòrsou ideology proclaim exists, and the impact of racial inequality in people's everyday lives. What initially became clear was that there is a strong discord between the ideology of unity and equality that is promulgated by the Yu'i Kòrsou ideology of national identity, and Afrodescendant people's lived experiences with racism. Also the gatekeeping mechanisms regarding education, language, the job market, and rules regarding propriety resurfaced: they continue to restrict social upward mobility of Afrocuraçaoans. In contemporary society this marginalization remains visible in the distribution of race by class. Today the upper classes are still predominantly white, the middle classes are mixed, and the lower classes are mainly dark skinned.

In the second part of the chapter, I provided a deeper analysis of the twenty-nine stories in order to decipher in particular the hegemonic narratives that people reproduce unknowingly, and how these instruct people in the naturalized and uncontested racial order that is dictated by white supremacy. This analysis centered on racelessness as a key component of multiculturalism (Goldberg 2002). It revealed that in these hegemonic narratives of the nation Afrocuraçaoan reform, resistance, and achievement is consistently trivialized, colonial exploitation as the root case for contemporary racial inequality is whitewashed and obfuscated, white achievement and history is glorified, and critique on white supremacy is deflected. Blackness is presented as the core of the nation, but white norms prevail. The findings in this chapter show the persistent silence that keeps race out of every day conversation, as well as academia and national policy. 
This thesis has attempted to make visible the multiple layers of discourse in Curaçao’s ideology of national identity. Under the discourses of hybridity and multiculturality, which advocate unity, equality and the praise of diversity, white supremacist ideology prevails. Especially in the ways in which people talk about whiteness and blackness the contradictory nature of this ideology becomes evident. And in spite of the censure surrounding race and racism, people know that the myth of racial equality simply doesn't hold up. Over time people have contested racist ideology, among others through the discourses of pro-black empowerment and Antillianization, which every now and then flare up, but wane again. Antillianization and pro-black reform engenders mostly an ideological shift, but it had less impact on the institutional dimension of society. I argue that this is because both the racializedness of Curaçao's institutions, and its gatekeeping mechanisms, are relatively invisible. This does not mean that racism is actually invisible, but that it is difficult to get a good idea of how extensive the structural part of racism is, and what its precise mechanizations are. This thesis shows that this relative invisibility causes an omission of a deliberate address of racism, and thus preserves white supremacy.

Chapter 1 explored how over the course of 380 years an ideology of national identity developed in Curaçao, premised on white supremacy, which persists today. Chapter 2 showed how this hegemonic ideology permeates our lives in such intricate and unseen, normalized manners. This makes it so hard to identify this ideology, and contest it. Chapter 3 further elaborated on the relatively unseen influence of this ideology, which I argued, is much more extensive than the parts that we do see. This is so by design. My analysis of the tenets of multiculturalism in the stories told by twenty-nine respondents 
demonstrated this deep reach of hegemonic ideology. Turning back to the theoretical frame and the data presented in chapter 1, which made visible the goals of Curaçao's multiculturalism (perpetuation of white supremacy), and its means (racelessness, deflection, invisibilization and naturalization of oppression and of supremacy), in chapter 3 I show its ideological mechanizations.

The stories I presented elucidate that Curaçao's silence is never empty space, and never still. The many voices that fill it form a complicated concoction that produces a harmony, though a dissonant and uncomfortable one. The ideology of national identity is a system that reproduces itself, and that protects its objectives, in spite of constant subaltern challenges. The subjugated, the counter hegemonic, the ruling classes all convene here, filling silence's space with their own purposes, wants, needs, fears and cross-sectional allegiances (Gramsci 1971). Oppression, invisibility, deflection, protection, trauma, resistance, empowerment - it all belongs here. But not until we make the full scope of oppression visible, and see what we are really up against, not until we breach the silence, can we make a veritable change. My work seeks to contribute to that. It is a drop in the ocean. But every bit helps.

\section{Recommendations for Research and Policy Innovation}

For decades the address of racism has been silenced by the official narration of the nation, and as a consequence been left largely unaddressed in academia, policymaking, and mainstream media. Because of the way hegemonic ideology reasons away the effects of race and racial discrimination, people are largely unaware of how precisely they operate, and these topics are perceived as "taboo" (see also UN 2015). Remedying racial 
inequality and discrimination will require the identification and breaking of hegemonic silences. Since hegemony is so pervasive, I strongly believe that the address of hegemony should be approached from a great many different angles.

\section{Increase of Funding}

My first recommendation is directed at the government, to make available an adequate budget for the thorough address of racial inequality and discrimination, to fund projects from GO's, NGO's, and civil society. When discussing current initiatives regarding reform, at the end of chapter 1, I pointed out that one of the current obstructions to antidiscrimination reform is the dire lack of available funding. Many of the organizations that are invested in knowledge production and pro-black reform struggle to make ends meat, which impedes the work they seek to do. This shortage in funds is not surprising given the disinterest and lack of active involvement of the government regarding race and racism. It is therefore adamant that the government will acknowledge that people of African descent, which comprise the vast majority of Curaçao's population, are structurally disadvantaged in comparison to the rest of the population, and that as a consequence racism is a genuine threat to the well being of the nation.

The UN Decade for People of African Descent (UNDPAD) however appears to have changed the game, and broken an important hegemonic silence. The Bill for the Curaçaoan Fulfillment of the United Nations Decade for People of African Descent (2015), created by a multidisciplinary working group initiated by the Directorate of Foreign Relations, has been accepted by the Council of Ministers. Nonetheless, currently there is no government funding available yet for the UNDPAD. Therefore I recommend 
that the government takes an actively interested stance, and makes available at least part of the funding needed within a reasonable period of time. This will include reaching out to the Netherlands for additional funding to fight racism. For funding will be an essential baseline for the many recommendations made by the UN Working Group of Experts on People of African Descent (2015), and by the Bill for the Curaçaoan Fulfillment of the United Nations Decade for People of African Descent (2015), and by myself and many others. I advise that NGO's and civil society monitor closely if this funding is indeed allocated.

\section{Knowledge Production}

My second recommendation regarding the breaking of hegemonic silence is to drastically increase knowledge production on the many dimensions of racial inequality and discrimination, and on the culture, history and achievements of Afrodescendants. We cannot hope to make effective policies without thoroughly corroborated qualitative and quantitative knowledge. In fact, I strongly warn against creating policies and projects that are not founded on in-depth inquiries in which race, racism, and racial discrimination are well researched, and validated by the population segments and communities they will apply to.

The first research project that I believe to be crucial to successfully target racial inequality is generating reliable statistical data on race. Currently race is not part of the census. This has contributed greatly to the invisibilization of the impact of race on multiple dimensions of society. I therefore strongly recommend to collect statistical data using a population sample, and through operationalizing race through the use of a well- 
researched and tested lexicon that concurs with people's self-identification. This data will provide us with essential insights in how race interrelates with socioeconomic class, education, work, language, poverty, education, crime, residence, and so on. Based on these data we can work towards the development of effective, targeted policies.

But overall there is very little qualitative and quantitative information available on race, racism, racial inequality, and racial discrimination: a dangerous silence. In appendix X I proposed a rather lengthy though preliminary list of research topics that to my opinion deserve considerable attention. The interrelatedness of race and socioeconomic class, in my opinion, is a crucial topic: how does racism negatively affect individuals, and what are the specific vulnerabilities per class layer that aggravate the impact of race, such as poverty. What kinds of racial discrimination do people experience? How do such vulnerabilities impact people's access to and/or performance in for example health care, education, housing, and finding work? And how do such vulnerabilities make people more susceptible to delinquency and/or becoming the victim of crime and police violence? Race intersects with many other variables, such as gender, age, sexual orientation, and migration status or country of origin: these may increase or diminish these vulnerabilities. I believe that it is crucial to map all this out in order to successfully tackle racial discrimination and institutionalized inequality.

Another important area of inquiry is race and the economic sector. What is the current racial and class composition of the economic sector, regarding business ownership, management and overall employment? What are the obstructions that people of color might experience in the economic sector as entrepreneurs and employees, and that contribute to the perpetuation of the island's current racial/spatial order? 
Furthermore, I mentioned throughout the dissertation that it deserves recommendation to thoroughly document the past and present of Antillianization and problack empowerment, and the key players. I consider this to be especially important in the formulation of a strong counter-hegemonic discourse. I believe that it is of key importance to consider gender in such a study: currently the heroes of the nation are virtually all men. I also recommend the documentation and analysis of representation of race in the Curaçaoan arts in past and present—in popular culture, traditional culture, folklore, and the arts at large, including but not limited to representations of racial oppression and exploitation, resistance, and black empowerment. I belief that the study of contemporary Curaçaoan African Diasporic identity formation in relation to broader, transnational diasporic contexts that the island and its populations partake in through flows of people, commodities, capital, information, through popular culture and expressive culture would also be of great value.

Then, I belief that additional in-depth ethnographic work be done on past and present Afrocuraçaoan dimensions of resistance to white supremacy, in both hidden and overt form. Important historical work has already been done by scholars such as Rose Mary Allen and René Rosalia, but in my opinion especially contemporary forms of resistance and agency deserve more attention. In the light of acknowledging the atrocities of the colonial past, I advice to make visible the intricacies of interracial relations, including but not limited to sexual violence, and to break the stereotypical romantization of such interactions, as well as the classic gender dyad of white male and black female to also include relations between same sex individuals, and black men and white women. And in order to further problematize the glorification of white colonial heritage I propose 
to analyze race and contemporary representations of national identity, and particularly the prevalence of multiculturalism. This I argue should include but not be limited to race and policies of heritage preservation and monumentalization, urban symbolism, urban planning, and demography, the representation of race in mainstream media, the reproduction of narratives on race and national history in school materials of past and present and in tourism. It is evident that this list of recommendations for future research cannot in any way be exhaustive, but it presents the urgent hiatuses that I came across in my current thesis.

I would recommend that institutions such as the University of Curaçao (UoC) and the Foundation National Archeological and Anthropological Memory Management (NAAM), but also the numerous research platforms in the Netherlands, direct part of their attention to such research, and that funding is specifically made available for this. Furthermore, as a former colony, Curaçao's struggle with race did not develop in a vacuum: the island is part of the African Diaspora. Solutions should therefore not be sought in the vacuum of our national borders, but in dialogue with this intra-national, transatlantic space that formed and informed our past and present. I advise that relations with universities in the region and the larger international arena are augmented, with the aim to increase the flow of knowledge and people engaged with race and racism, and to encourage exchange.

I however wish to emphasize that knowledge production should never be a unidirectional process that is directed from a governmental, academic or other kind of "state" institution to civil society. It is this one-sidedness, in which one platform of knowledge making is labeled "official" and esteemed over other platforms, that makes 
hegemony both successful and detrimental to the masses. Instead, I encourage that knowledge be produced in a close dialogue between the state and its inhabitants, so the perspectives and needs of the ruling elites do not trump those of the masses, but instead the perspectives and needs of the wide variety of inhabitants inform the state. It is high time that the masses are duly respected as knowledgeable and active agents.

\section{Human Rights Institute}

In tandem with my emphasis on knowledge production I recommend, as do the UN Working Group and the working group of the Directorate of Foreign Affairs, the origination of a Human Rights Institute. I suggest that such an institution should be intimately linked to the University of Curaçao (UoC), which is currently the prime institution for knowledge production on the island. Human Rights Institutes commonly generate information for - and in collaboration with —a broad range of institutions and organizations in civil society and the government, regarding the awareness of human rights, and the strengthening of marginalized population segments, among others. Therefore I belief that such an institute requires a multidisciplinary environment that has a long standing and broad infrastructure for the production of dependable knowledge and for community outreach and service. Such an institute could work closely with the UoC's Departments of Law, Social Sciences and Economics, Social and Behavioral Sciences, Engineering, and the General Faculty, and the newly developed trajectory of Cultural Studies, as well as with a myriad of organizations from civil society and the government, as to become a booming center of activism, community service, policy making and academic accomplishment. 


\section{Ideological Decolonization}

In this light, I belief that a successful address of racism should include a reformulation of the ideology of national identity, and the excavation of the relatively unseen element of white supremacy that is so pervasive. I refer to this process as "ideological decolonization," and identify four phases, which may overlap ${ }^{122}$. Firstly, it will require a nation-wide dissemination of knowledge that makes visible and officially acknowledges the extent of historical and contemporary oppression and marginalization of people of African descent, the mechanizations through which this oppression and marginalization is executed, and the values of white supremacy that have been communicated consistently. It also involves reinstating Afrocuraçaoan beliefs, stories, practices and traditions that have been shamed, stigmatized, invisibilized, and even outlawed, as well as new beliefs, stories, practices and traditions that augment a positive representation of people of African descent. This relates directly to the abovementioned knowledge production.

This phase really started after the revolt of 1969. During this time it was carried mostly by NGO's and initiatives of civil society, and at some points by political parties such as MAN and Pueblo Soberano, and their leaders. However, as discussed in chapter 1 , these processes of coming to awareness and of an increased acknowledgement of Afrocuraçaoans and Afrodescendants at large as full participants in the nation were hindered by for example a lack of funding and media attention, and especially by the widespread perpetuation of white supremacist values in many dimensions of society. In

\footnotetext{
${ }^{122}$ I base this recommendation regarding decolonization, and my discussion of the decolonization process, on the research presented in my Master's thesis Aboriginality and Indianuity: Decolonization in the Urban Native Community of Vancouver (Roe, 2003).
} 
order to diminish the influence of multiculturalism I recommend that NGO's and civil society in particular keep a close watch on how this reform develops.

Secondly, decolonization equals healing. Once people reach a thorough awareness that their marginalization was not caused by their own "inadequacies," as hegemonic narrations of the nation propose, but by a deliberately constructed and institutionalized ideology that has been kept active for centuries, people are likely to experience a range of emotions, such as anger, sadness, frustration, and distrust. These emotions will have to be addressed through a variety of projects and events that are aimed at a constructive and emotionally safe exchange ${ }^{123}$ of people's experiences and ideas, and based in or relevant to Afrocuraçaoan or Afrodescendant knowledge and tradition. Healing entails the sifting out of harmful societal norms, values and practices and all their manifestations, both in our communities and other settings, and in our own minds. Decolonization in this sense is both a communal and an intimate and ever-ongoing project: we have to create a new, positive and empowering "internal voice" that informs our sense of self in a beneficial and kind manner, and that will overlay the inner voice of subjugation, through which we oppress ourselves, often unknowingly but ever so harshly (see Fanon 1952/1967).

This process of identifying the oppressive elements of the national ideology in our own minds and in society at large, and deliberately replacing them with positive ones will ultimately result in a new, "cleaned up" discourse. Initially this will be shared by some, but in order to dissolve white supremacy as a hegemonic force, ultimately this new

\footnotetext{
${ }^{123}$ The documentary Sombra di Koló ("The Shadow of Color"), which I made in 2014, together with filmmakers Selwyn de Wind and Hester Jonkhout, is an example of a tool that raises awareness. The documentary addresses race and racial inequality in contemporary Curaçao. It has been shown over 70 times on the island and in the Netherlands, always followed by a lengthy discussion with the audience. During these exchanges, which were always emotional but safe and constructive, people exchanged their stories and let off steam.
} 
narration has to become spread nation-wide, which happens in the third stage, and become implemented in the nation's institutions, which is the fourth stage.

\section{Anti-Discrimination Legislation}

It is crucial in the fight against racism and the breaking of hegemonic silences that people report cases of racism and racial discrimination, and that this results in adequate sanctioning. As appendix II shows, Curaçao has an elaborate body of legal instruments, existing of articles in the Constitution and Criminal Code, and several international treaties, which is designed to combat racism and other kinds of discrimination. Currently these instruments are severely underused: the national population is insufficiently unaware of their existence, and of how precisely they can make use of these instruments, and people are afraid that their complains will result in negative repercussions and retaliations. Therefore, like the UN Working Group and the working group of the Directorate of Foreign Affairs, I call for the initiation of an Anti-Discrimination Agency, which operates in collaboration with the Court of Justice, the police, lawyers, the Ombudsman, but also with organizations and agents from civil society, such as neighborhood centers, youth organizations, social workers, and churches. It is important that the various institutions that partake in the judicial process are well geared to one another, so the reporting of discrimination and the subsequent judicial process are easily accessible, transparent, and safe for victims.

Such an institution would take inventory of people's problems with racial discrimination, provide information and help as to how to respond, and the steps to take 
to file a formal complaint. This institution would thus also gather valuable data that further adds insight in how racism impacts individuals and communities.

In order to make the national population aware of this agency and their rights, I recommend the development of a national awareness campaign, to be presented in the mainstream media. This campaign should inform people of what racism is exactly, what people's rights are, best practices in responding to discrimination, how to report such cases to the authorities, and why this is important. 


\section{REFERENCES}

Alexander, J. C. 2004. Towards a Theory of Cultural Trauma. In: J. C. Alexander, N. J. Smelser, P. Sztompka, R. Eyerman and B. Giesen (Eds). Cultural Trauma and Collective Identity. 1-30. Berkely CA, University of California Press.

Allahar, Anton. 2001. "Race" and Class in the Making of Caribbean Political Culture. In: Transforming Anthropology 10(2). 13-29.

Alexander, Karl, Doris R. Entwisle and Carrie S. Horsey. 1997. From First Grade Forward: Early Foundations of High School Dropout. In: Sociology of Education, 70(2). 87-107.

Alofs, Luc. 1999. Revolte en Afscheiding: Dertig Mei en Aruba. In: Oostindie, Gert (Ed). 1999b. Dromen en Littekens; Dertig Jaar na de Curaçaose Revolte, 30 Mei 1969. 163-176. Amsterdam, Amsterdam University Press.

Allen, Rose Mary. 1992. Katholicisme en Volkscultuur: een Dialectische Relatie. Een Aanzet tot de Studie van het Beschavingswerk van de R.K.-Kerk. In: Barbara Boudewijnse, Henk Middelbrink en Chris van de Woestijne (Eds). Kerkwandel en Lekenhandel: De Rooms-Katholieke Kerk op Curaçao. 15-32. Amsterdam: Het Spinhuis.

1996. In Search for Identity: An Analysis of the Commemoration of the Slave-revolt of 17th of August 1795 in Curaçao. Paper presented at the Conference of Culture. Jamaica.

. 2006. Cultural Identity in a Curaçaoan Mirror: A Critical View on René Römer's Contribution. In: R. M. Allen (Ed). René Römer als Inspirator: Actualiseringen van zijn Gedachtengoed. 17-29. Willemstad, Curaçao, University of the Netherlands Antilles.

. 2007. Di Ki Manera? A Social History of Afro-Curaçaoans, 18631917. Amsterdam: SWP Publishers.

. 2009a. The Culturalization of Citizenship: The Netherlands in Comparative Perspective. Paper presented at The Culturalization of Citizenship: The Netherlands in Comparative Perspective. Opening Conference of the ASSR/NWO Cultural Dynamics programme with Forum and OxfamNovib. Amsterdam.

. 2009b. Migrants versus the Yu di Korsou: Race, Class and identity in Curaçaoan Society. In: Hope, Elizabeth. Freedom and Constraint in Caribbean Migration and Diaspora. Miami, Kingston: Ian Randle. 3-19. 
2010. The Complexity of National Identity Construction in Curaçao,

Dutch Caribbean. In: The European Review of Latin American and Caribbean

Studies 89. 117-125.

. 2012a. The Anancy plot in the search of the Curaçaoan identity of the

Yu di Korsou. Paper presented at the seminar Migration, Citizenship and

Belonging: African, Caribbean and European Perspectives, September 11-12

2012, Kwabena Nketia Conference Hall, Institute of African Studies, Legon,

Ghana.

. 2012b. What is Curaçaoan Culture? Reflecting Upon Small-Island

Complexity and Sustainability Through the Lens of Cultural Policies in Curaçao.

Conference Proceedings of the Caribbean Small Island Developing States (SIDS)

Conference March 7-9, 2012, University of Curaçao.

2014. From Bondage to National Belonging in a Dutch Caribbean

Context: Addressing the Yu Di Kòrsou in Post Emancipation Curaçao, 1863-

1915. In: Nicholas Faraclas, Ronald Severing, Christa Weijer, Elisabeth Echteld

and Wim Rutgers (Eds). Transgressing Neocolonial Boundaries in the

Languages, Literatures and Cultures on the ABC Islands and the Rest of the

Dutch Caribbean. 39-56. Curaçao/Puerto Rico Fundashon: Planifikashon di Idioma, University of Curaçao and University de Puerto Rico.

. 2015. Toward Reconstituting Caribbean Identity Discourse from within the Dutch Caribbean Island of Curaçao. In: Brian Meeks and Jermaine McCalpin (Eds). Caribbean Reasonings: Gordon K. Lewis: 94-110. Kingston: Ian Randle.

Andermann, Jens. 2007. The Optic of the State: Visuality and Power in Argentina and Brazil. Pittsburgh: University of Pittsburgh Press.

Anderson, Benedict. 1983/1991. Imagined Communities: Reflections on the Origin and Spread of Nationalism. New York: Verso Books.

Anderson, Leon. 2006. Analytic Autoethnography. In: Journal of Contemporary Ethnography 35(4). 373-395.

Anderson, William and Russell Dynes. 1975. Social Movements, Violence and Change: May Movement in Curaçao. Columbus: Ohio State University Press.

Angelou, Maya. 1967. I Know Why the Caged Bird Sings. New York, Bantam Books.

Ansano, Richenel. 2011. Between Love and Terror: Having a Sense of Belonging is no Joke. In: Iguana's Newfound Voices: Continuity, Divergence and Convergence in 
Language, Culture and Society on the ABC-Islands. Curaçao, Fundashon pa Planifikashon di Idioma and University of Curaçao.

. 2012. To Question Identity: Public Discourse and Transpersonal Ethics in Curaçao. In: Nicholas Faraclas, Ronald Severing, Christa Weijer, Elisabeth Echteld and Wim Rutgers (Eds). Multiplex Cultures and Citizenships : Multiple Perspectives on Language, Literature, Education and Society in the ABC-Islands and Beyond. 55-67. Curaçao/Puerto Rico Fundashon: Planifikashon di Idioma, University of Curaçao and University de Puerto Rico.

2014. Malungo, Praise Names and Places: How Dead can a Language Really be? In: Nicholas Faraclas, Ronald Severing, Christa Weijer, Elisabeth Echteld and Wim Rutgers (Eds). Creole Connections: Transgressing Neocolonial Boundaries in the Languages, Literatures and Cultures of the ABC Islands and the Rest of the Dutch Caribbean. 23-37. Curaçao/Puerto Rico Fundashon: Planifikashon di Idioma, University of Curaçao and University de Puerto Rico.

2015. Enacting Deep Identity in the Midst of Denials of Historic Memory in Curaçao. Paper presented at the Panel on "The Similarities and Transformations of the African Caribbean Cultural Heritage from Music and Dance Perspectives", Caribbean Association 40th Annual Conference, Hilton Riverside Hotel, New Orleans, U.S. A, May 2015.

Antonius, Roland. 2003. Beeldvorming en Taal. Emancipatie and Acceptatie: Curaçao en Curaçaoenaars. In: R. M. Allen, C. Heijes and V. Marcha (Eds). Beeldvorming en Identiteit Honderdveertig Jaar na de Slavernij. 128-139. Amsterdam, Uitgeverij SWP.

Appelbaum, Nancy et al. 2003. Race and Nation in Modern Latin America. Chapel Hill / London, University of North Carolina Press.

Aronsson, Peter and Gabriella Elgenius. 2011. Making national museums in Europe-a comparative approach. Building National Museums in Europe 1750-2010: Conference Proceedings from EuNaMus, European National Museums: Identity Politics, the Uses of the Past and the European Citizen, Bologna 28-30 April 2011. Linköping University Electronic Press.

Bailey, Marlon. 2013. New Terms of Resistance: A Response to Zenzele Isoke. In: Souls: A Critical Journal of Black Politics, Culture, and Society 15(4). 316-337.

Banks, Taunya. 2000. Colorism: A Darker Shade of Pale. In: UCLA Law Review, 47: $1705-1745$. 
Bauman, Richard. 1992. Folklore. In: Richard Bauman (ed.). Folklore, Cultural Performances, and Popular Entertainments: A Communications-Centered Handbook. 29-40. New York, Oxford: Oxford University Press.

Behar, Ruth. 1996. The Vulnerable Observer: Anthropology that Breaks your Heart. Boston: Beacon Press.

Beck, Scott and Kenneth Mijeski. 2000. The Electoral Performance of Ecuador's Patchakutik's Political Movement, 1996-1998. Unpublished Manuscript.

Besson, Jean. 1993. Reputation \& Respectability Reconsidered: A New Perspective on Afro-Caribbean Peasant Women. In: Janet Momsen (ed). Women and Change in the Caribbean: a pan-Caribbean Perspective. 15-37. Kingston: Ian Randle, 1993.

Bijl, Paul. 2012. Colonial Memory and Forgetting in the Netherlands and Indonesia. In: Journal of Genocide Research 14(3/4). 441-461.

Bonilla-Silva, Eduardo. 2000. "This is a White Country": The Racial Ideology of the Western Nations of the World-System. In: Sociological Inquiry 70(2). 188-214. 2010. Racism without Racists: Color-blind Racism and the Persistence of Racial Inequality in the United States. New York / Toronto: Rowman and Littlefield Publishers.

. 2012. The Invisible Weight of Whiteness: the racial grammar of everyday life in contemporary America. Ethnic and Racial Studies, 35(2). 173194.

Bourdieu, Pierre. 1977. On a Theory of Practice. Cambridge: Cambridge University Press.

Broek, Aart. 1992. Een Katholiek Beschavingsoffensief. Papiamentstalige Feuilletons en het Moderne Leven op Curaçao 1918-1938. In: H. Kleijer, A. Knotter en F. van Vree (Eds). Tekens en Teksten; Cultuur, Communicatie en Maatschappelijjke Veranderingen vanaf de Late Middeleeuwen. 119 - 130. Amsterdam: Amsterdam University Press.

1994. Onenigheid is een Genoegen: Omtrent Identiteit Beneden de Wind. Willemstad: Uitgeverij Amigoe. 2006. De Kleur van Mijn Eiland: Aruba, Bonaire, Curaçao. Ideologie en Schrijven in het Papiamentu sinds 1863. Leiden, KITLV Uitgeverij. 
Brondo, Keri. 2010. When Mestizo Becomes (Like) Indio or is it Garífuna?: Multicultural Rights and "Making Place" on Honduras' North Coast. In: The Journal of Latin American and Caribbean Anthropology, 15(1). 170-194.

Brooms, Derrick. 2011. Lest We Forget: Exhibiting (and Remembering) Slavery in African-American Museums. In: Journal of African American Studies 15(4). 508-523.

Burton, Linda, Eduardo Bonilla-Silva, Victor Ray, Rose Buckelew, Elizabeth Hordge Freeman. 2010. Critical Race Theories, Colorism, and the Decade's Research on Families of Color. In: Journal of Marriage and Family, 72(3). 440-459

Butler, David. 2001. Whitewashing Plantations: the Commodification of a Slave-Free Antebellum South. In: International Journal of Hospitality and Tourism Administration 2(3-4). 163-175.

Buzinde, Christine and Carla Santos. 2008. Representations of Slavery. In: Annals of Tourism Research 35(2). 469-488. 36(3). 439-458.

Carr, Leslie. 1997. Color-Blind Racism. Thousand Oaks, CA / London / New Delhi: Sage Publications.

Clemencia, Jocelyn. 1992. Introduction. In: Richenel Ansano, Joceline Clemencia, Jeanette Cook, Eithel Martis (eds). Mundu Yama Sinta Mira: Womanhood in Curaçao. ix-xii. Willemstad: Fundashon Publikashon Curaçao.

Committee 30 May (Committee 30 Mei). 1970. 30 Mei 1969: Rapport van de Commissie tot Onderzoek van de Achtergronden en Oorzaken van de Onlusten welke op 30 Mei 1969 op Curaçao Hebben Plaatsgehad. Oranjestad Aruba: De Wit

Connerton, Paul. 1989. How Societies Remember. Cambrigde / New York: Cambridge University Press.

Croese, Koen. 1999. De Militaire Bijstand. In: Oostindie, Gert (Ed). 1999b. Dromen en Littekens; Dertig Jaar na de Curaçaose Revolte, 30 Mei 1969. 163-176. Amsterdam, Amsterdam University Press.

Cummins, Alissandra. 2004. Caribbean Museums and National Identity. In: History Workshop Journal, 58(1). 224-245. 
Dalhuisen, Leo, Ronald Donk, Rosemarijn Hoefte and Frans Steegh. 1997. Geschiedenis van de Antillen: Aruba, Bonaire, Curaçao, Saba, Sint Eustatius, Sint Maarten. Zutphen: Walburg Pers.

Dávila, Jerry. 2003. Diploma of Whiteness: Race and Social Policy in Brazil, 1917-1945. Durham: Duke University Press.

Debrot, Nicolas. 1935/1955. Mijn Zuster de Negerin. Amsterdam: J.M. Meulenhoff.

Debrot, Nicolas and Gerard Knuvelder. 1945. Arts et Vita: Uiteenzetting van Wederzijdse Standpunten. Helmond: Helmond.

De Haseth, Carel. 1988/2012. Slave and Master (Katibu di Shon). A Dual-Language Edition Oxford: Peter Lang.

Directorate of Foreign Relations. 2015. Nota voor Curaçaose invulling van United Nations Decade for People of African Descent. 30 November 2015.

Do Rego, Charles and Janga, Lionel. 2009. Slavery and Resistance in Curaçao: the Rebellion of 1795. Curaçao: Fundashon Parke Nashonal.

Droogers, André. 2001. Cultuur Als Repertoire: Schema's Maken en Breken. In: E. Bartels, A. van Harskamp and H. Wels. (Eds). Cultuur Maken en Cultuur Breken. 129-142. Delft: Eburon.

Du Bois. William E. B. 1903/1999. The Souls of Black Folk. Cambridge: University Press John Wilson and Son, Cambridge.

Eckkrammer, Eva. 2003. On the Perception of 'Creole' Language and Identity in the Netherlands Antilles. In: G. Collier and U. Fleischmann (Eds). A Pepper-Pot of Cultures: Aspects of Creolization. 85-108. Amsterdam / New York: Editions Rodopi BV.

2007. Papiamentu, Cultural Resistance, and Socio-Cutural Challenges: The ABC Islands in a Nutshell. In: Journal of Caribbean Literature 5(1). 73-93.

Eichstedt, Jennifer and Stephen Small 2002. Representation of Slavery: Race and Ideology in Southern Plantation Museums. Washington / London: Smithso-nian Institution Press.

Essed, Philomena. 1987. Academic Racism: Common Sense in Social Sciences. Amsterdam: University of Amsterdam, Centre for Race and Ethnic Studies. 
1990. Everyday Racism: Reports from Women of Two Cultures. Alameda, CA: Hunter House Publishers.

. 1991. Understanding Everyday Racism: An Interdisciplinary Theory. Newbury Park, CA: Sage Publications.

Essed, Philomena and Isabel Hoving. 2014. Dutch Racism. Amsterdam: Rodolphi B.V.

Eyerman, Ron. 2001. Cultural Trauma: Slavery and the Formation of African American Identity. Cambridge / New York: Cambridge University Press.

. 2013. Social Theory and Trauma. In: Acta Sociologica 56(1). 41-53.

Fanon, Frantz. 1952/1967. Black Skin, White Masks. New York: Grove Press.

Farkas, George. 2008. How Educational Inequality Develops. In: Lin, Ann Chih and David Harris (Eds). The Colors of Poverty: Why Racial and Ethnic Disparities Persist. 261-291. New York: Russell Sage Foundation.

Feagin, Joe. 2006. Systemic Racism: A Theory of Oppression. New York, Routledge.

Firth, Raymond.1975. An Appraisal of Modern Social Anthropology. In: Annual Review of Anthropology, 4. 1-25.

Foucault, Michel. 1977. Discipline and Punish - The Birth of the Prison. Beacon.

Fouse, Gary. 2002. The Story of Papiamentu: a Study in Slavery and Language. Lanham/New York / Oxford: University Press of America.

Freyre, Gilberto. 1933/1970. The Masters and the Slaves: A Study in the Development of Brazilian Civlization. Alfred A. Knopf.

Geertz, Clifford. 1988. Works and Lives: The Anthropologist as Author. Cambridge: Polity.

Gilroy, Paul. 1993. The Black Atlantic: Modernity and Double Consciousness. Cambridge: Harvard University Press.

Goffman, Erving. 1967. Interaction Ritual; Essays on Face-to-Face Behaviour. New York: Doubleday.

Goldberg, David Theo. 1993. Racist Culture: Philosophy and the Politics of Meaning. Oxford: Blackwell Publishers.

. 2002. The Racial State. Malden, MA / Oxford: Blackwell Publishers. 
Goslinga, Cornelis. 1956. Emancipatie en Emancipator. Assen: Van Gorcum.

Gould, Jeffrey. 1998. To Die in this Way: Nicaraguan Indians and the Myth of Mestizaje, 1880-1965. Durham: Duke University Press.

Gramsci, Antonio. 1971. Selections From the Prison Notebooks. New York: International publishers.

Greene, Shane. 2007. Introduction: On Race, Roots/Routes, and Sovereignty in Latin America's Afro-Indigenous Multiculturalisms. In: Journal of Latin American and Caribbean Anthropology, 12(2). 329-355.

Grosfoguel, Ramon and Eric Mielants. 2006. Minorities, Racism and Cultures of Scholarship. In: Journal of Comparative Sociology 47 (3-4). 179-189.

Hale, Charles. 1996. Introduction. In: Journal of Latin American Anthropology 2(1). 2-3. 2002. Does Multiculturalism Menace? Governance, Cultural Rights and the Politics of Identity in Guatemala. In: Journal of Latin American Studies, 34(3). 485-524

2005. Neoliberal Multiculturalism: The Remaking of Cultural Rights and Racial Dominance in Central America. In: Political and Legal Anthropology Review, 28(1). 10-28.

Hall, Stuart. 1986. Culture, Media, language: Working Papers in Cultural Studies 197279. London: Hutchinson.

1997. Representation: Cultural Representations and Signifying

Practices. London / Thousand Oaks: Sage.

. 1999. Whose Heritage? Un-settling "The Heritage", Re-imagining the Post- Nation. In: Whose Heritage? The Impact of Cultural Diversity on Britain's Living Heritage. Manchester, UK: Third Text. 3-13.

2002. Race, the Floating Signifier. Stuart Hall in Lecture. Northampton: Media Education Foundation.

Hamelberg, Johannes. 1901. De Nederlanders op de West-Indische Eilanden. Amsterdam: De Bussy.

Harris, Angela. 2008. From Color Line to Color Chart: Racism and Colorism in the New Century. In: Berkeley Journal of African-American Law \& Policy 10(1). 52-69. 
Hartog, Johannes. 1961/1967a. Curaçao: van Kolonie tot Autonomie. Deel I. Oranjestad, Aruba, De Wit.

. 1961/1967b. Curaçao: van Kolonie tot Autonomie. Deel II. Oranjestad, Aruba, De Wit.

Helman, Albert. 1977. Facetten van de Surinaamse Samenleving. Zutphen: Walburg Pers.

Helsloot, J. I. A. 2012. Zwarte Piet and Cultural Aphasia in the Netherlands. Journal for the Study of Everyday Life 3. 1-20.

Hintzen, Percy. 2002. Race and Creole ethnicity in the Caribbean. In: V. A. Shepherd and G. L. Richards. Questioning Creole: Creolisation Discourses in Caribbean Culture. 92-110. Kingston / London, Ian Randle and James Currey.

Hintzen, Percy and Jean Rahier. 2003. Introduction: From Structural Politics to the Politics of Deconstruction. Self-Ethnographies Problematizing Blackness. In: Problematizing Blackness: Self-Ethnographies by Black Immigrants to the United States. Percy C. Hintzen and Jean Muteba Rahier, eds. New York: Routledge. 120.

Hobbs, Allyson. 2014. A Chosen Exile. Cambridge: Harvard University Press.

Hobsbawm, Eric and Terence Ranger. 1983. The Invention of Tradition. Cambridge: Cambridge University Press.

Hoetink, Harry. 1958. Het Patroon van de Oude Curaçaose Samenleving: een Sociologische Studie. Assen, Van Gorcum.

. 1962. De Gespleten Samenleving in het Caribisch Gebied: Bijdrage tot de Sociologie der Rasrelaties in Gesegmenteerde Maatschappijen. Assen: van Gorcum.

. 1967. The Two Variants of Caribbean Race Relations. London / New York / Tokyo: Oxford University Press.

. 1973. Slavery and Race Relations in the Americas. New York / Evanston / San Francisco / London: Harper Torchbooks.

Hooker, Juliet. 2005. Indigenous Inclusion/Black Exclusion: Race, Ethnicity and Multicultural Citizenship in Latin America. In: Journal of Latin American Studies, 37. 285-310. 
Htun, Mala. 2004. Is Gender like Ethnicity? The Political Representation of Identity Groups. In: Perspectives on Politics, 2(3). 439-458.

Hulst, Hans van. 1997. Morgen Bloeit het Diabaas. Amsterdam: Spinhuis.

Huijgers, D. and L. Ezechiels. 1992. Landhuizen van Curaçao en Bonaire. Amsterdam: Persimmons.

Hunter, Margareth. 2007. The Persistent Problem of Colorism: Skin Tone, Status, and Inequality. In: Sociology Compass, 1(1). 237-254.

Jacobson, David. 1991. Reading Ethnography. Albany NY: Suny Press.

Jenkins, Richard. 1997. Rethinking Ethnicity: Arguments and Explorations. London / Thousand Oaks: Sage.

Jones, Guno. 2012. De Slavernij is Onze Geschiedenis (Niet). Over de Discursieve Strijd om de Betekenis van de NTR-Televisieserie De Slavernij. In: BMGN-Low Countries Historical Review, 127(4). 56-82.

Kempadoo, Kamala. 1996. Prostitution, Marginality and Empowerment: Caribbean Women in the Sex Trade. Beyond Law, 5(14). 69-84.

Kenepa-Römer, Nolda. 1992. Curaçaose Vrouwen in de Slavenmaatschappij. In: Richenel Ansano, Joceline Clemencia, Jeanette Cook, Eithel Martis (eds). Mundu Yama Sinta Mira: Womanhood in Curaçao. 21-42. Willemstad: Fundashon Publikashon Curaçao.

Klooster, Wim. 1994. Subordinate but Proud : Curaçao's Free Blacks and Mulattoes in the Eighteenth Century. In: New West Indian Guide, 68(3/4). 283-300.

Koenigsberg, R. A. 2009. Nations have the Right to Kill: Hitler, the Holocaust, and War. New York, Library of Social Science.

Kroeger, Brooke. 2003. Passing: When People Can't Be Who They Are. New York: Public Affairs.

Kymlicka, Will. 1995. Multicultural citizenship: A liberal theory of minority rights. Oxford, Clarendon Press.

Lauffer, Pierre. 1964/1996. Leyenda di Buchi Fil. In: Kantika pa Bientu. Willemstad: Fundashon Pierre Lauffer.

Lee, Erika. 2004. American Gate keeping: Race and Immigration Law in the Twentieth Century. In: Not Just Black and White: Immigration, Race, and Ethnicity, Then to 
Now. N. Foner and G. M. Frederickson (Eds). 119-144. New York, Russell Sage Foundation.

Lemm. Robert. 2007. Geschiedenis van Spanje. Soesterberg: Aspekt.

Lin, Ann Chih and David Harris (Eds). 2008. Why is American Poverty Still Colored in the Twenty-First Century? In: Lin, Ann Chih and David Harris (Eds). The Colors of Poverty: Why Racial and Ethnic Disparities Persist. 1-18. New York: Russell Sage Foundation.

Loveman, Mara. 2009. Whiteness in Latin America: Measurement and Meaning in National Census 1850-1950. Journal de la Société des Américanistes, 95. 207234.

Loveman, Mara and Jeronimo Muniz. 2007. How Puerto Rico Became White: Boundary Dynamics and Intercensus Racial Reclassification. In: American Sociological Review, 72(6). 915-939.

Massey, Douglas. 1990. American Apartheid: Segregation and the Making of the Underclass. In: American Journal of Sociology, 96(2). 329-357.

Martínez-Echazábal, Lourdes. 1998. Mestizaje and the discourse of national/cultural identity in Latin America, 1845-1959. In: Latin American Perspectives, 25(3). 2142 .

Martinus, Frank. 1997. The Kiss of a Slave. Curaçao: De Curaçaose Courant. . 2003. Nuttige Eilanden. De Hardnekkigheid van een Cliché. In: R. M. Allen, C. Heijes and V. Marcha (Eds). Emancipatie and Acceptatie: Curaçao en Curaçaoënaars. Beeldvorming en Identiteit Honderdveertig Jaar na de Slavernij. 163-175. Amsterdam: Uitgeverij SWP.

Memmi, Albert. 2000. Racism. Minnesota / London, University of Minnesota Press.

Mintz, Sidney. 1985. Sweetness and Power. Viking New York.

Moen, Harry. 2010. Tempu di Chinchirinchi: Bida i Muzik den Otrobanda 1900-1920. Willemstad: Curaçaose Courant.

Nagel, Joan. 1994. Constructing Ethnicity: Creating and Recreating Ethnic Identity and Culture." In: Social Problems, 41. 152-179. . 2003. Race, Ethnicity, and Sexuality. Intimate Intersections, Forbidden Frontiers. New Yok / Oxford, Oxford University Prss. 
Narain, Goretti. 1995. Taaltalent in Ontwikkeling. Tilburg: Tilburg University Press.

Nita, Amador. 1952. De Sociale Wensdromen van Het Landskind in de Gelijke Delen van het Nieuwe Koninkrijk. Willemstad: Casa Editorial "Emile."

"Emile."

. 1954. Pueblo Te Unda Bo ta Bai? Willemstad: Casa Editorial

. 1958. De Likwidatie van de Nederlandse Antillen Deel I. Oranjestad: Amigu di Aruba NV.

Oostindie, Gert. 1999a. Curaçao, 30 Mei 1969: Verhalen over de Revolte. Amsterdam, Amsterdam University Press.

2002. Het Paradijs Overzee: de 'Nederlandse' Caraïben en

Nederland. Leiden: KITLV Press.

. 2008. Dutch Colonialism, Migration and Cultural Heritage. Leiden:

KITLV Press.

Oostindie, Gert (Ed). 1999b. Dromen en Littekens; Dertig Jaar na de Curaçaose Revolte, $30 \mathrm{Mei}$ 1969. Amsterdam: Amsterdam University Press.

Oers, van, Johannes. 1993. De Maatschappelijke Context van het Schoolwezen in de Kolonie Curaçao 1816-1837 Met Inbegrip van de Onderhorige Eilanden Aruba en Bonaire. Proefschrift. Tilburg: Katholieke Universiteit Brabandt.

Owensby, Brian. 2005. Toward a History of Brazil's "Cordial Racism": Race Beyond Liberalism. In: Comparative Studies in Society and History, 47(2). 318-347.

Paula, Alejandro. 1967. From Objective to Subjective Social Barriers: A Historicophilosophical Analysis of Certain Negative Attitudes Among the Negroid Population of Curaçao. Curaçao, Salas.

. 1989. Hoofdmomenten in de Staatskundige Ontwikkeling van de Nederlandse Antillen 1865-1986. In: Lanternu, 9. 1-96.

Ponzanesi, Sandra. 2005. Beyond the Black Venus: Colonial Sexual Politics and Contemporary Visual Practices. In: J. Andall and D. Duncan (Eds). Italian Colonialism: Legacy and Memory.165-189. Bern: Peter Lang.

Poria, Yaniv and Gregory Ashworth 2009. Heritage Tourism-Current Resource for Conflict. In: Annals of Tourism Research, 36(3). 522-525. 
Price, Richard and Sally Price. 1997. Shadowboxing in the Mangrove. In: Cultural Anthropology,12(1). 3-36.

Rahier, Jean. 2003a. The Ghost of Leopold II: The Belgian Royal Museum of Central Africa and its Dusty Colonialist Exhibition. In: Research in African Literatures, 34(1). 58-84.

. 2003b. Mestizaje, Mulataje, Mestiçagem In Latin American Ideologies of National Identities. In: Journal of Latin American Anthropology, 8(1). 40-50.

. 2008. Soccer and the (Tri-) Color of the Ecuadorian Nation: Visual and Ideological (Dis-) Continuities of Black Otherness from Monocultural Mestizaje to Multiculturalism. In: Visual Anthropology Review, 24(2). 148-182.

. 2010. The Microphysics of Colonial Power: Violence, Intimacy, and Sexuality In Belgian Colonial Literature. In: La Présence Africaine en Europe et au-delà (African Presence in Europe and Beyond). K. Gyssels and B. Ledent (Eds). Paris, l'Harmattan: 41-64.

. 2012. Introduction. Black Social Movements in Latin America: From Monocultural Mestizaje and "Invisibility" to Multiculturalism and State Corporatism/Co-optation. In: Jean Rahier (Ed). Black Social Movements in Latin America: From Monocultural Mestizaje to Multiculturalism. 1-12. London / New York: Palgrave MacMillan.

Reinders, Alex. 1993. Politieke geschiedenis van de Nederlandse Antillen en Aruba 1950-1993. Zutphen: Walburg Pers.

Reiter, Bernd. 2013. Multiculturalism and Racialization in Latin America and the Caribbean. In: MEMORIAS Revista digital de Historia y Arqueología desde el Caribe colombiano Año, 10(19). 30-45

Roe, Angela. 2003. Aboriginality and Indianuity: Decolonization in the Urban Native Community of Vancouver. Master's thesis.

Römer, Louis-Philip. 2016. Speaking Like a Sovereign Public on Talk Radio: Respectability, Refusal, and the Politics of Conditionality in Curaçao. $\mathrm{PhD}$ Dissertation. New York: New York University.

Römer, René. 1974. Het 'Wij' van de Curaçaoënaar. In: Kristof, 1(2). 49-62. . 1977. Cultureel Mozaïek van de Nederlandse Antillen. Zutphen: Walburg Pers. 
Walburg Pers.

.1979/1981. Een Volk Op Weg / Un Pueblo na Kaminda. Zutphen:

. 1981 Samenleven op een Caribisch Eiland: Een Sociologische

Verkenning. Curaçao: Van Dorp Eddine.

. 1998. Ethnicity and Social Change in Curaçao. In: H. Johnson and

K. Watson. The White Minority in the Caribbean. 159-167.Kingston, Princeton.

. 1995. De Yaya. Schijnbaar Nederig, Maakte zij Dikwijls de Dienst

Uit. Curaçao: Curaçaose Courant N.V.

. 2003. Beeldvorming en Politiek: Een Diachronische Analyse. In:

Emancipatie and Acceptatie: Curaçao en Curaçaö̈naars. In: R. M. Allen, C.

Heijes and V. Marcha (Eds). Beeldvorming en Identiteit Honderdveertig Jaar na de Slavernij. 18-34. Amsterdam: Uitgeverij SWP.

Römer-Kenepa, Nolda. 1992. Onderwijs als Veiligheidsklep: De Rooms-Katholieke Kerk en het Volksonderwijs op de Nederlandse Antillen 1824-1863. In: Barbara Boudewijnse, Henk Middelbrink en Chris van de Woestijne (Eds). Kerkwandel en Lekenhandel: De Rooms-Katholieke Kerk op Curaçao. 33-54. Amsterdam: Spinhuis.

Rosalia, René. 1997. Tambú: De Legale en Kerkelijke Repressie van Afro-Curaçaose Volksuitingen. Zutphen, Walburg Pers.

Ruiz-Junco, Natalia and Salvador Vidal Ortiz. 2011. Autoethnography: The Sociological through the Personal. In: Ieva Zake and Michael DeCesare (Eds). New Directions in Sociology: Essays on Theory and Methodology in the 21st Century. 193-211. Jefferson, NC: McFarland Publishers.

Rupert, Linda. 2012. Creolization and contraband. Curaçao in the Early Modern Atlantic World. Athens / London, University of Georgia Press.

Rutgers, Wim. 2012. Literary Texts on Slavery in the Past and Future. Tula: from Rebel to National Hero. In: Nicholas Faraclas, Ronald Severing, Christa Weijer and Elisabeth Echteld (Eds). Multiplex Cultures and Citizenships: Multiple Perspectives on Language, Literature, Education and Society in the ABC-Islands and Beyond. 145-166. Curaçao: Fundashon pa Planifikashon di Idioma / University of the Netherlands Antilles. San Juan: Universidad de Puerto Rico.

Said, Edward. 1978. Orientalism. New York, Pantheon.

Schmith, Jennifer. 1996. Monumenten en Standbeelden van de Nederlandse Antillen. Curaçao: Personal Publication. 
Schrils, James. 2003. Emancipatie en Onze Politieke Cultuur. In: Rose Mary Allen, Coen Heijes and Valdemar Marcha. Emancipatie and Acceptatie: Curaçao en Curaçaoenaars. Beeldvorming en Identiteit Honderdveertig Jaar na de Slavernij. 117-127. Amsterdam (Eds.) Uitgeverij SWP.

Scott, James. 1987. Weapons of the Weak: Everyday Forms Of Peasant Resistance. New Haven, CT, Yale University Press.

Seth, Suman. 2009. Putting Knowledge in its Place: Science, Colonialism, and the Postcolonial. In: Postcolonial Studies, 12(4). 373-388.

Sheriff, Robin. 2000. Exposing Silence as Cultural Censorship: a Brazilian Case. In: American Anthropologist, 102. 114-132. . 2001. Dreaming Equality: Color, Race, and Racism in Urban Brazil. New Brunswik / New Jersey / London, Rutgers University Press.

Skidmore, Thomas. 2002. Raízes de Gilberto Freyre. In: Journal of Latin American Studies, 34(1).1-20.

Smith, Felipe. 2010. The African Diaspora as Imagined Community. In: Jean Rahier, Percy Hintzen and Felipe Smith (Eds). Global Circuits of Blackness:

Interrogating the African Diaspora. 3-28. Chicago / Springfield / Champaign, University of Illinois Press.

Spivak, Gayatri Chakravort. 2010. Can the Subaltern Speak?: Reflections on the History of an Idea. New York, Columbia University Press.

Stepan, Nancy. 1991. The Hour of Eugenics: Race, Gender, and Nation in Latin America. Ithaca, NJ, Cornell University Press.

Stoler, Ann. 2002. Carnal Knowledge and Imperial Power: Race and The Intimate in Colonial Rule. Berkeley, University of California Press.

Stutzman, Ronald. 1981. El Mestizaje: an All-inclusive Ideology of Exclusion. In: Cultural transformations and ethnicity in modern Ecuador. Norman Whitten (Ed). Urbana, IL, University of Illinois Press: 45-94.

Tannen, Deborah. 1985. Silence: Anything But. Perspectives on Silence. Norwood, NJ, Ablex. 93-111.

Telles, Edward and René Flores. 2013. Not Just Color: Whiteness, Nation and Status in Latin America. In: Hispanic American Historical Review, 93. 411-449. 
Timothy, Dallen and Stephen Boyd. 2006. Heritage Tourism in the 21st Century: Valued Traditions and New Perspectives. In: Journal of Heritage Tourism, 1(1). 1-16.

Thomas, Deborah. 2004. Modern Blackness. Nationalism, Globalization, and the Politics of Culture in Jamaica. Durham, London: Duke University Press.

Trepagnier, Barbara. 2010. Silent Racism: How Well-Meaning White People Perpetuate the Racial Divide. Boulder, CO: Paradigm.

Trouillot, Michel-Rolph. 1995. Silencing the Past: Power and the Production of History. Boston, MA: Beacon Press.

United Nations. 2014. Programme of activities for the implementation of the International Decade for People of African Descent. 18 November 2014. A/RES/69/16. . 2015. Report of the Working Group of Experts on People of African Descent on its sixteenth session. Mission to the Netherlands. 20 July 2015. A/HRC/30/56/Add.1.

Van Cott, Donna Lee. 2000. The Friendly Liquidation of the Past: the Politics of Diversity in Latin America. Pittsburgh: University of Pittsburgh Press.

Vasconcelos, José. 1997. The Cosmic Race. Baltimore, MD and London: Johns Hopkins University Press.

Verton, Peter. 1977. Politieke Dynamiek en Dekolonisatie: De Nederlandse Antillen tussen Autonomie en Onafhankelijkheid. Alphen a/d Rijn: Samson.

Weiner, Melissa. 2014. The Ideologically Colonized Metropole: Dutch Racism and Racist Denial. In: Sociology Compass, 8(6). 731-744.

Wekker, Gloria. 2016. White Innocence: Paradoxes of Colonialism and Race. Durham / London: Duke University Press.

Wheelock, Darren and Christopher Uggen. 2008. Punishment, Crime and Poverty. In: Lin, Ann Chih and David Harris (Eds). The Colors of Poverty: Why Racial and Ethnic Disparities Persist. 261-291. New York: Russell Sage Foundation.

White, E. Francis. (2010). Dark continent of our bodies: Black feminism \& politics of respectability. Temple University Press.

Williams, Eric. 1944. Capitalism and Slavery. Chapel Hill / London, University of North Carolina Press. 
Wilson, Peter. 1969. Reputation and Respectability: A Suggestion for Caribbean Ethnology. In: Man, 4(1). 70-84.

Witteveen, Ieteke. 2006. René Römer over Cultureel erfgoed en de Restauratie van Geheugen. In: René Römer als Inspirator: Actualiseringen van zijn Gedachtengoed. R. M. Allen (Ed). Willemstad, University of the Netherlands Antilles. 30-42.

Wolf, Eric. 1982. Europe and the People Without History. Berkeley, Los Angeles, London: University of California Press. 


\section{APPENDICES}

\section{Appendix I Categories in Curaçao's Color Hierarchy}

\begin{tabular}{|c|c|c|}
\hline $\begin{array}{l}\text { Papiamentu } \\
\text { name }\end{array}$ & English translation & Contemporary use \\
\hline Makamba & $\begin{array}{l}\text { No exact translation. The original } \\
\text { word "Makamba" refers to a } \\
\text { specific tribe in Africa, from } \\
\text { which a fairly large group of } \\
\text { slaves was brought to Curaçao } \\
\text { (Hoetink 1958). Over time the } \\
\text { name began to signify "stranger" } \\
\text { or "outsider." }\end{array}$ & $\begin{array}{l}\text { This label refers to white Dutch people. } \\
\text { "Makamba" commonly refers to the outsider } \\
\text { status of a white Dutch person living on or dealing } \\
\text { with Curaçao. Said person does not integrate } \\
\text { (sufficiently) in Curaçao's culture and society, and } \\
\text { instead shows a strong allegiance to the } \\
\text { Netherlands and to Dutch culture and identity. } \\
\text { Although commonly signifying a white person, } \\
\text { Makamba can be used to denote a person of any } \\
\text { phenotype, as long as they strongly adhere to } \\
\text { Dutch culture. Speaking Dutch fluently is a key } \\
\text { part of this category. } \\
\text { Makamba can be used as a matter of fact } \\
\text { descriptor of a white Dutch person, or jokingly or } \\
\text { critically, to indicate that a Dutch person has not } \\
\text { integrated enough in Curaçaoan culture. In this } \\
\text { sense it can also signify a Curaçaoan of color who } \\
\text { has integrated too much into Dutch culture. } \\
\text { The label also has a very strong negative and } \\
\text { derogatory meaning when it is used to express the } \\
\text { resentment Curaçaoans feel regarding white Dutch } \\
\text { superiority today, especially with regards to the } \\
\text { island. } \\
\text { White Dutch people often use the label in a } \\
\text { neutral or positive way. }\end{array}$ \\
\hline Blanku & $\begin{array}{l}\text { "White." Derived from the Dutch } \\
\text { word "blank" which literally } \\
\text { translates as "colorless," "clear," } \\
\text { "clean," and "immaculate." In } \\
\text { Dutch blank is commonly used to } \\
\text { refer to white people. }\end{array}$ & $\begin{array}{l}\text { The label refers to white people in general, or a } \\
\text { very light skinned person of racially mixed origins } \\
\text { whose skin is white or nearly white, and who has } \\
\text { predominantly white features. } \\
\text { This label does not indicate an outsider status in } \\
\text { the way that Makamba does. The person can be a } \\
\text { Yu'i Kòrsou and thus have a full or partial insider } \\
\text { status. In Curaçao "blanku" is not a negative } \\
\text { term }{ }^{124} \text {, as it literally translates as the color white. } \\
\text { Hair texture is a centrally important marker of this } \\
\text { label. It cannot be afro-textured but it has to be } \\
\text { curly, wavy or sleek. }\end{array}$ \\
\hline
\end{tabular}

${ }^{124}$ In the Netherlands the racial label "blank" however is getting more and more critique over its significance of purity. It is slowly becoming replaced by "wit" (white). 


\begin{tabular}{|c|c|c|}
\hline Koló kla & "Clear color" or "light color." & $\begin{array}{l}\text { A person who has an overall white (what in the } \\
\text { US is referred to as Caucasian) phenotype but } \\
\text { who has a slightly darker complexion, like people } \\
\text { in the Mediterranean area. Or a person with a } \\
\text { white skin tone but with some black facial } \\
\text { features or hair texture. The person may be of } \\
\text { racially mixed origin, but this is not necessarily, } \\
\text { nor does he or she have to be Afrodescendant. } \\
\text { People with a fully white phenotype may still be } \\
\text { referred to as kolo kla as a way to express that } \\
\text { they are considered to have insider status. } \\
\text { This is the case when one is locally oriented, } \\
\text { immersed in Curaçaoan culture, and particularly } \\
\text { in the nuances of every day life, norms and values, } \\
\text { street culture and humor. This includes speaking } \\
\text { fluent and accent-free Papiamentu. One must } \\
\text { furthermore have a strong knowledge of and } \\
\text { allegiance to Curaçao's Afrocuraçaoan heritage as } \\
\text { being the center of national culture, and not only } \\
\text { participate in the island's white elite culture, be it } \\
\text { of the Dutch-born or the Curaçaoan-born white } \\
\text { population. This is especially important for those } \\
\text { people that were not born on Curaçao but that } \\
\text { integrated later on. }\end{array}$ \\
\hline Koló habrí & "Open color" & $\begin{array}{l}\text { This label refers to light-skinned black people. } \\
\text { This category is similar to koló kla though here } \\
\text { one's black features - body and behavior - tend to } \\
\text { be more pronounced. The hair is commonly afro- } \\
\text { textured or a smaller curl. } \\
\text { The label's fluid boundaries allow both white } \\
\text { people who are not Afrodescendant as well as } \\
\text { darker skinned black people to fall into the } \\
\text { category. People that look largely white may still } \\
\text { be labeled koló habrí if they are very locally } \\
\text { oriented and knowledgeable - and preferably } \\
\text { participants in - Afrocuraçaoan culture. This does } \\
\text { not mean that they may not at the same time also } \\
\text { belong to white elite circles, and spend the vast } \\
\text { majority of his or her time there. The main } \\
\text { characteristic is that the person is fully proficient } \\
\text { in, and appreciative of, Afrocuraçaoan culture. } \\
\text { On the other hand, darker skinned people who are } \\
\text { labeled as or self identify as koló habrí are } \\
\text { considered to have a more elite and/or white } \\
\text { allegiance, be this to the Netherlands, the local } \\
\text { elites, or another white culture. They may also be } \\
\text { seen as of a higher socioeconomic status. }\end{array}$ \\
\hline
\end{tabular}




\begin{tabular}{|c|c|c|}
\hline Korá & "Red" & $\begin{array}{l}\text { This category refers to people with red hair, or to } \\
\text { light skinned black people with blond or light } \\
\text { brown hair as opposed to dark hair. The skin tone } \\
\text { can be white or a light brown, possibly with } \\
\text { freckles, a skin that burns in the sun, or that has a } \\
\text { reddish brown hue. } \\
\text { This category refers to an insider status. This can } \\
\text { be through being born on the island, or for } \\
\text { foreign-born people through black allegiance, } \\
\text { and/or proficiency with Curaçaoan culture. }\end{array}$ \\
\hline Mispel & $\begin{array}{l}\text { "Sapodilla," the shade of brown } \\
\text { of the fruit's peel }\end{array}$ & $\begin{array}{l}\text { This label is only used for women. This is a } \\
\text { medium light brown skin tone. The person has } \\
\text { undeniably black physical features, most often } \\
\text { including afro-textured hair or strongly curled } \\
\text { hair. Mispel refers to the beauty ideal of the } \\
\text { lighter skin tone, which in Curaçao is more } \\
\text { imperative for women then for men. } \\
\text { Again the label is fluid, and is also used for darker } \\
\text { skinned women if they have very pretty features, } \\
\text { or when they have a higher socio-economic status. } \\
\text { It is also used when women have features that are } \\
\text { associated with white bodies, such as curly or } \\
\text { sleek hair, or non-curvy physiques. }\end{array}$ \\
\hline Koló Bruin & "Brown" & $\begin{array}{l}\text { This label covers a range of skin tones, including } \\
\text { mispel, but it is commonly perceived as slightly } \\
\text { darker than mispel. This skin tone is also } \\
\text { perceived as the most common skin tone for } \\
\text { Curaçaoans, or as "the norm," and is therefore not } \\
\text { necessarily mentioned as a descriptor: it is the } \\
\text { default. Those who deviate from this color, be it } \\
\text { darker or lighter, are described in the above and } \\
\text { below mentioned color terms. } \\
\text { Again allegiance and cultural immergence play a } \\
\text { significant role. People with a somewhat lighter } \\
\text { brown skin tone can self-identify as brown, while } \\
\text { they could also choose to identify with a lighter } \\
\text { skin tone. } \\
\text { It can also be used to signify darker-skinned } \\
\text { people who are of a higher socio-economic class } \\
\text { and/or who are strongly immersed in or allegiant } \\
\text { to white culture. }\end{array}$ \\
\hline
\end{tabular}




\begin{tabular}{|c|c|c|}
\hline $\begin{array}{l}\text { Koló bruin skur / } \\
\text { koló skur }\end{array}$ & "Dark brown" / "Dark color" & $\begin{array}{l}\text { This label refers to people with a dark brown skin } \\
\text { tone and clear black features. } \\
\text { Allegiance still matters, as people with this skin } \\
\text { tone may still be perceived as lighter brown when } \\
\text { they are thought to have less immergence in black } \\
\text { Curaçaoan culture, or have a strong allegiance to } \\
\text { white culture. }\end{array}$ \\
\hline Pretu & "Black" & $\begin{array}{l}\text { This label refers to people with a very dark brown } \\
\text { skin tone. It is also the umbrella notion for all } \\
\text { Afrodescendant people. } \\
\text { Here allegiance matters less: people with this } \\
\text { phenotype can be called koló bruin skur or koló } \\
\text { bruin, but their explicitly black features imply } \\
\text { their allegiance. }\end{array}$ \\
\hline Pretu sera & "Closed black" & $\begin{array}{l}\text { This is the darkest shade of brown skin tone. This } \\
\text { is a rare shade and a rarely used label. }\end{array}$ \\
\hline
\end{tabular}




\section{Appendix II Anti-discrimination Legislation in Curaçao}

\begin{tabular}{|l|l|}
\hline $\begin{array}{l}\text { Constitution } \\
\text { Article } 3\end{array}$ \\
\hline $\begin{array}{l}\text { In } 1865, \text { two years after abolition, the anti discrimination clause became part of the } \\
\text { Government Regulations (Regeringsreglement) of the Dutch colonies (van Rijn } \\
1999: 138) . \text { This clause became article 3 in the Constitution of the Netherlands } \\
\text { Antilles, which was accepted in 1955. In 2010 Curaçao issued its own Constitution } \\
\text { when it reached autonomous status in the Kingdom of the Netherlands. Article 3, now } \\
\text { much more specified with regards to race and all other forms of discrimination, } \\
\text { remains in effect. }\end{array}$ \\
$\begin{array}{l}\text { Criminal Code of Curaçao } \\
\text { Article 1:221 read together with the articles 2:60, 2:61, 2:62, 2:63 en 3:12 }\end{array}$ \\
$\begin{array}{l}\text { In the pre 10-10-2010 version of the Criminal Code of Curaçao these articles, } \\
\text { which were then articles 143a, 143b and 143c, were signed on Christmas Day, } \\
\text { December 25, 1971, and became operational retroactively as of December 9, } 1971 . \\
\text { Two weeks later, on 9-1-1972 the CERD treaty was signed by the Kingdom of the } \\
\text { Netherlands. The two events appear related. }\end{array}$ \\
\hline
\end{tabular}

International Treaties against Racial Discrimination

\begin{tabular}{|l|l|}
\hline & Convention for the Protection of Human Rights and Fundamental Freedoms \\
\hline Nov 4, 1950 & Adopted and opened for signature and ratification \\
\hline Aug 31, 1954 & Signed by the Kingdom of the Netherlands and ratified by the Netherlands \\
\hline Dec 31, 1955 & Ratified by the Netherlands Antilles \\
\hline & $\begin{array}{l}\text { International Convention on the Elimination of All Forms of Racial } \\
\text { Discrimination (CERD) }\end{array}$ \\
\hline Dec 21, 1965 & $\begin{array}{l}\text { Adopted and opened for signature and ratification by General Assembly resolution } \\
2106 \text { (XX) }\end{array}$ \\
\hline Jan 9, 1972 & $\begin{array}{l}\text { Signed by the Kingdom of the Netherlands and ratified by the Netherlands and the } \\
\text { Netherlands Antilles }\end{array}$ \\
\hline
\end{tabular}

\footnotetext{
${ }^{125}$ The Charter of the Kingdom of the Netherlands (Statuut van het Koninkrijk der Nederlanden) pertains to all constituents of the Kingdom, which since 10-10-2010 include the Netherlands, Aruba, Curaçao and St. Martin. Bonaire, Statia and Saba are since then municipalities of the Netherlands. Since 1955 the Netherlands Antilles, then comprised of Aruba, Bonaire, Curaçao, Statia, Saba and St. Martin, had their own Constitution, which was called "Staatsregeling," in which the islands specified a number of laws as one country. Since 2010 Curaçao has become an autonomous constituent of the Dutch Kingdom and thus specified its own Staatsregeling.
} 


\begin{tabular}{|l|l|}
\hline & International Covenant on Civil and Political Rights (IVBPR) \\
\hline Dec 16,1966 & Adopted and opened for signature and ratification \\
\hline March 11,1979 & $\begin{array}{l}\text { Signed by the Kingdom of the Netherlands and ratified by the Netherlands and the } \\
\text { Netherlands Antilles }\end{array}$ \\
\hline & International Covenant on Economic, Social and Cultural Rights (IVESCR) \\
\hline & Adopted and opened for signature and ratification \\
\hline Dec 16,1966 11,1979 & $\begin{array}{l}\text { Signed by the Kingdom of the Netherlands and ratified by the Netherlands and the } \\
\text { Netherlands Antilles }\end{array}$ \\
\hline & Convention against Discrimination in Education \\
\hline & Adopted and opened for signature and ratification \\
\hline Dec 14,1960 & Signed by the Kingdom of the Netherlands \\
\hline June 25,1966 25,1966 & Ratified by the Netherlands and the Netherlands Antilles \\
\hline & \\
\hline & Convention on the Elimination of All Forms of Discrimination against Women \\
\hline Dec 18,1979 & Adopted and opened for signature and ratification \\
\hline July 17, 1980 & Signed by the Kingdom of the Netherlands \\
\hline Aug 22,1991 & Ratified by the Netherlands and the Netherlands Antilles \\
\hline
\end{tabular}

This list of treaties is not exhaustive. However, in 2015 the United Nations Report of the Working Group of Experts on People of African Descent on its sixteenth session: Mission to the Netherlands (2015), the Working Group makes a specific recommendation to the Kingdom of the Netherlands to include the International Convention on the Protection of the Rights of All Migrant Workers and Members of Their Families, so it can better protect the rights and needs of all Afrodescendants (UN 2015:19). In the case of Curaçao this would be an important measure to address ethnic discrimination of Afrodescendant immigrants, as well as vulnerabilities that immigrants experience when they are undocumented or have temporary visas. The Report writes:

While the Netherlands has ratified most of the core human rights instruments and its national legal framework covers a broad range of offences related to racial discrimination, the protection offered by the law is not always sufficient to overcome persistent and structural disparities specifically affecting people of African descent. The Netherlands should consider ratifying the International Convention on the Protection of the Rights of All Migrant Workers and Members of Their Families, and adopting legislation to address the specific needs of people of African descent (UN 2015:19). 


\section{Appendix III Overview of Interviewees and Interview Protocol for the Case Study on Curaçao's Color Hierarchy}

These data were obtained through semi-structured interviews I conducted with a group of 12 respondents. I asked them the following two questions:

1. Name the different classifications of skin color and phenotype in Curaçao.

2. Describe the different classifications of skin color and phenotype in Curaçao.

3. Give examples of local or international people that fit these categories.

I used the below stratified probability sample to recruit my respondents. It is diverse for the variables skin color or phenotype, age, gender and socioeconomic background, see the sample design shown in the table. The variable for phenotype is a fluid range, not a binary.

Variables of the respondents

\begin{tabular}{|c|c|c|c|c|c|c|c|c|c|}
\hline Age & \multicolumn{3}{|c|}{$18-29$} & \multicolumn{3}{|c|}{$30-55$} & \multicolumn{3}{|l|}{$56+$} \\
\hline Gender & \multicolumn{2}{|l|}{$\mathrm{M}$} & $\mathrm{F}$ & $\mathrm{M}$ & \multicolumn{2}{|c|}{$\mathrm{F}$} & $\mathrm{M}$ & \multicolumn{2}{|c|}{$\mathrm{F}$} \\
\hline $\begin{array}{l}\text { Phenotype } \\
\text { (scale) }\end{array}$ & \multicolumn{3}{|c|}{ Black - - - white } & \multicolumn{3}{|c|}{ Black - - - White } & \multicolumn{3}{|c|}{ Black - - - White } \\
\hline Education & High & Med & Low & High & Med & Low & High & Med & Low \\
\hline Income level & High & Med & Low & High & Med & Low & High & Med & Low \\
\hline Occupation & \multicolumn{3}{|c|}{ Various } & \multicolumn{3}{|c|}{ Various } & \multicolumn{3}{|c|}{ Various } \\
\hline $\begin{array}{l}\text { Social } \\
\text { network }\end{array}$ & \multicolumn{3}{|c|}{ Various } & \multicolumn{3}{|c|}{ Various } & \multicolumn{3}{|c|}{ Various } \\
\hline
\end{tabular}




\section{Appendix IV Curaçao's Museums}

\begin{tabular}{|c|c|c|c|c|}
\hline & Open & Collection & Era & Building / site \\
\hline \multicolumn{5}{|l|}{ General Society } \\
\hline $\begin{array}{l}\text { Money Museum Yotín } \\
\text { Kortá }\end{array}$ & 1993 & $\begin{array}{l}\text { The development of Curaçao's } \\
\text { national currency past to present. }\end{array}$ & $16^{\text {th }}-21^{\text {st }} \mathrm{c}$ & Colonial mansion \\
\hline Postal Stamp Museum & 1985 & $\begin{array}{l}\text { Collection of Curaçao's stamps } \\
\text { past to present }\end{array}$ & $17^{\text {th }}-21^{\text {st }} \mathrm{c}$ & $\begin{array}{l}\text { Oldest house in } \\
\text { Punda } 1693\end{array}$ \\
\hline Carnival Museum & 2010 & Collection of costumes & $20^{\text {th }}-21^{\text {st }} \mathrm{c}$ & Colonial mansion \\
\hline $\begin{array}{l}\text { Children's Museum } \\
\text { Curaçao }\end{array}$ & 2015 & Children in Curaçao's Society & & Modern building \\
\hline \multicolumn{5}{|l|}{ European Elite Heritage } \\
\hline Curaçao Museum & 1948 & $\begin{array}{l}\text { Furniture and artifacts of Dutch } \\
\text { colonial elite } 17,18,19^{\text {th }} \text { century, } \\
\text { Dutch and regional art. }\end{array}$ & $17^{\text {th }}-21^{\text {st }} \mathrm{c}$. & $\begin{array}{l}\text { Military hospital, } \\
1853\end{array}$ \\
\hline Maritime Museum & 1998 & $\begin{array}{l}\text { Maritime developments and } \\
\text { achievements of the Dutch, the } \\
\text { Dutch West India Company, and } \\
\text { the harbor of Willemstad. }\end{array}$ & $15^{\text {th }}-21^{\text {st }} \mathrm{c}$ & $\begin{array}{l}\text { Colonial mansion } \\
1729\end{array}$ \\
\hline $\begin{array}{l}\text { Fort Church \& Protestant } \\
\text { Historical Cultural } \\
\text { Museum }\end{array}$ & 1992 & $\begin{array}{l}\text { Religious artifacts of prominent } \\
\text { Dutch Protestant families. }\end{array}$ & $17^{\text {th }}-21^{\text {st }} \mathrm{c}$. & $\begin{array}{l}\text { Colonial era church } \\
1769\end{array}$ \\
\hline Rif Fort Museum & 2014 & $\begin{array}{l}\text { History of the Dutch military fort } \\
\text { during colonial rule. }\end{array}$ & $19^{\text {th }}-21^{\text {st }} \mathrm{c}$. & Military Fort \\
\hline Jewish Museum & 1970 & $\begin{array}{l}\text { Religious artifacts of prominent } \\
\text { Portuguese Jewish families. }\end{array}$ & $15^{\text {th }}-21^{\text {st }} \mathrm{c}$ & $\begin{array}{l}\text { Part of the } \\
\text { synagogue complex }\end{array}$ \\
\hline Octagon & 1980 & $\begin{array}{l}\text { Life of Venezuelan freedom } \\
\text { fighter and general Simon Bolivar, } \\
\text { and his years of exile in Curaçao. }\end{array}$ & $19^{\text {th }} \mathrm{c}$. & Colonial building \\
\hline Mongui Maduro Library & 2010 & $\begin{array}{l}\text { Furniture, artifacts and archives of } \\
\text { Jewish community in Curaçao. }\end{array}$ & $19^{\text {th }}-20^{\text {th }} \mathrm{c}$ & $\begin{array}{l}\text { Plantation house } \\
\text { Rooi Catootje }\end{array}$ \\
\hline The Liqueur Factory & 1896 & $\begin{array}{l}\text { Traditional and contemporary } \\
\text { artifacts for liqueur production }\end{array}$ & $19^{\text {th }}-21^{\text {st }} \mathrm{c}$ & $\begin{array}{l}\text { Plantation house } \\
\text { Chobolobo }\end{array}$ \\
\hline Plantation Savonet & 2010 & $\begin{array}{l}\text { The history of plantation Savonet } \\
\text { and nature / island in general. }\end{array}$ & $\begin{array}{l}4000 \text { years, focus } \\
\text { on } 17^{\text {th }}-21^{\text {st }} \mathrm{c} .\end{array}$ & $\begin{array}{l}\text { Plantation house } \\
\text { from } 1662\end{array}$ \\
\hline \multicolumn{5}{|l|}{ Afrocuraçaoan Heritage } \\
\hline Museo Tula & 2006 & $\begin{array}{l}\text { Traditional Afro-Curaçaoan } \\
\text { lifestyles and slavery }\end{array}$ & $18^{\text {th }}-20^{\text {th }} \mathrm{c}$ & $\begin{array}{l}\text { Plantation house } \\
\text { Knip }\end{array}$ \\
\hline Kas di Pal'i Maishi & 2000 & $\begin{array}{l}19^{\text {th }} \text { century traditional Afro- } \\
\text { Curaçaoan lifestyle and lore }\end{array}$ & 17 th $-20^{\text {th }} \mathrm{c}$. & Slave house, 1880 \\
\hline $\begin{array}{l}\text { Den Paradera Herbal } \\
\text { Garden }\end{array}$ & 1981 & $\begin{array}{l}\text { Traditional Afro-Curaçaoan } \\
\text { herbal garden }\end{array}$ & $19^{\text {th }}-20^{\text {th }} \quad$ c. & \\
\hline $\begin{array}{l}\text { Museo di Tambú Shon } \\
\text { Cola }\end{array}$ & 2015 & $\begin{array}{l}\text { Historical development of Afro- } \\
\text { Curaçaoan drumming tradition } \\
\text { and accompanying cultural } \\
\text { practices. }\end{array}$ & $17^{\text {th }}-21^{\text {st }} \mathrm{c}$. & Colonial mansion \\
\hline \multicolumn{5}{|l|}{ Slavery } \\
\hline Kura Hulanda Museum & 2003 & $\begin{array}{l}\text { Cultures of the peoples of the } \\
\text { Caribbean basin, including slavery }\end{array}$ & $\begin{array}{l}4000 \text { years, focus } \\
\text { on } 17^{\text {th }}-21^{\text {st }} \mathrm{c} \text {. }\end{array}$ & $\begin{array}{l}\text { Mansion and slave } \\
\text { market courtyard }\end{array}$ \\
\hline
\end{tabular}




\section{Appendix V Statistical Distribution of Religion in Curaçao}

Table Population by religion and sex

\begin{tabular}{|c|c|c|c|c|}
\hline \multirow{2}{*}{ Religion } & \multicolumn{4}{|c|}{ Total } \\
\hline & Male & Female & Total & $\%$ \\
\hline Christianity & & & & \\
\hline Roman Catholic & 50346 & 59192 & 109538 & 72.7 \\
\hline Methodist & 285 & 460 & 745 & 0.5 \\
\hline Protestant & 2301 & 2590 & 4891 & 3.2 \\
\hline Pentecostal & 3866 & 6104 & 9970 & 6.6 \\
\hline Adventist & 1905 & 2549 & 4454 & 3.0 \\
\hline Hinduism & 1152 & 1906 & 3058 & 2.0 \\
\hline Anglican & 118 & 218 & 336 & 0.2 \\
\hline Evangelical & 1155 & 1644 & 2799 & 1.9 \\
\hline Mormonism & 28 & 58 & 86 & 0.1 \\
\hline Baptism & 18 & 5 & 23 & $* *$ \\
\hline Christian* & 547 & 833 & 1380 & 0.9 \\
\hline Subtotal & 61721 & 75559 & 137280 & 91.0 \\
\hline Jehova's Witness & 658 & 564 & 1222 & 0.8 \\
\hline Islam & 426 & 325 & 751 & 0.5 \\
\hline Judaism & 141 & 155 & 296 & 0.2 \\
\hline Other religion & 553 & 632 & 1185 & 0.8 \\
\hline No religion & 4894 & 4083 & 8977 & 6.0 \\
\hline Not reported & 455 & 397 & 852 & 0.6 \\
\hline Total & 68848 & 81715 & 150563 & \\
\hline
\end{tabular}

Census 2011, Central Bureau Statistics

*This group consist of persons which answered the question about belonging to a Christin-based religion, without further specification.

** The number is too small.

The column with percentages was added by me.

Original table: Table D-5. Population by religion, age group and sex, Census 2011. www.cbs.cw, visited April $4^{\text {th }} 2016$. 
Appendix VI Overview of Respondents in the Bario Case Study

\begin{tabular}{|c|c|c|c|c|c|}
\hline $\begin{array}{l}\text { Respond } \\
\text { ent }\end{array}$ & Age & $\mathrm{F} / \mathrm{M}$ & Skin color & $\begin{array}{l}\text { Level of Education } \\
\left.\text { (Dutch system }^{* *}\right)\end{array}$ & Occupation \\
\hline \multicolumn{6}{|c|}{ Respondents Barber } \\
\hline 1. & 18 & $\mathrm{~F}$ & Dark brown & Pre-University Ed. & Student \\
\hline 2. & 24 & $\mathrm{M}$ & Dark brown & Vocational Training & Mechanic \\
\hline 3. & 30 & $\mathrm{~F}$ & Dark brown & Higher Professional Ed. & Elementary school teacher \\
\hline 4. & 55 & $\mathrm{M}$ & Dark brown & $\begin{array}{l}\text { Senior Secondary } \\
\text { Vocational Ed. }\end{array}$ & Mechanic, planter \\
\hline 5. & 80 & $\mathrm{~F}$ & Dark Brown & Primary Ed. & Retired cleaning lady \\
\hline 6. & 69 & M & Dark brown & Higher Professional Ed. & Retired social cultural worker \\
\hline \multicolumn{6}{|c|}{ Respondents Seru Fortuna Bieuw / Seru Papaya } \\
\hline 7. & 21 & $\mathrm{~F}$ & Brown & $\begin{array}{l}\text { Pre-Vocational } \\
\text { Secondary Ed. }\end{array}$ & Cook, waitress \\
\hline 8. & 19 & $\mathrm{M}$ & Dark brown & $\begin{array}{l}\text { Pre-Vocational } \\
\text { Secondary Ed. }\end{array}$ & Student \\
\hline 9. & 39 & $\mathrm{~F}$ & Mispel & $\begin{array}{l}\text { Senior Secondary } \\
\text { Vocational Ed. }\end{array}$ & Cook \\
\hline 10. & 35 & $\mathrm{M}$ & Brown & Lower Secondary Ed. & Baggage handler airport \\
\hline 11. & 55 & $\mathrm{~F}$ & Dark brown & Lower Secondary Ed. & Seamstress \\
\hline 12. & 65 & $\mathrm{M}$ & Dark brown & Lower Secondary Ed. & Roadside worker \\
\hline \multicolumn{6}{|c|}{ Respondents Otrobanda } \\
\hline 13. & 18 & $\mathrm{~F}$ & Brown & $\begin{array}{l}\text { Pre-Vocational } \\
\text { Secondary Ed. }\end{array}$ & Student \\
\hline 14. & 18 & M & Brown & $\begin{array}{l}\text { Pre-Vocational } \\
\text { Secondary Ed. }\end{array}$ & Student \\
\hline 15. & $40 \mathrm{~s}$ & $\mathrm{~V}$ & Brown & $\begin{array}{l}\text { Senior Secondary } \\
\text { Vocational Ed. }\end{array}$ & Bookkeeper \\
\hline 16. & 33 & $\mathrm{M}$ & Dark brown & $\begin{array}{l}\text { Senior General } \\
\text { Secondary Ed }\end{array}$ & Painter, construction worker \\
\hline 17. & $70 \mathrm{~s}$ & $\mathrm{~F}$ & Light brown & Higher Professional Ed. & $\begin{array}{l}\text { Retired elementary school } \\
\text { teacher }\end{array}$ \\
\hline & $70 \mathrm{~s}$ & $\mathrm{~F}$ & Dark brown & Primary Education & $\begin{array}{l}\text { Road sweeper for waste } \\
\text { management company }\end{array}$ \\
\hline
\end{tabular}




\begin{tabular}{|c|c|c|c|c|c|}
\hline 18. & $70 \mathrm{~s}$ & $\mathrm{M}$ & $\begin{array}{l}\text { Very light- } \\
\text { skinned }\end{array}$ & Higher Professional Ed & Retired P.E. Teacher \\
\hline \multicolumn{6}{|c|}{ Respondents Janwé } \\
\hline 19. & 18 & $\mathrm{~F}$ & Light-skinned & Pre-University Ed. & School \\
\hline 20. & 26 & $\mathrm{M}$ & Light brown & University & Pilot \\
\hline 21. & 36 & $\mathrm{~F}$ & Brown & University & Bank manager \\
\hline 22. & 36 & $\mathrm{M}$ & Brown & Higher Professional Ed. & $\begin{array}{l}\text { Entrepreneur and sales } \\
\text { representative }\end{array}$ \\
\hline 23. & $80 \mathrm{~s}$ & $\mathrm{~F}$ & Light brown & Lower Secondary Ed. & Shop assistant \\
\hline 24. & 56 & $\mathrm{M}$ & Dark brown & University & Bank manager \\
\hline \multicolumn{6}{|c|}{ Respondents Jan Sofat } \\
\hline 25. & 18 & $\mathrm{~F}$ & Light skinned & University & Student \\
\hline 26. & 26 & $\mathrm{M}$ & $\begin{array}{l}\text { Very light- } \\
\text { skinned }\end{array}$ & University & Student \\
\hline 27. & 45 & $\mathrm{~V}$ & White & University & Director of a Foundation \\
\hline $\begin{array}{l}\text { 28. non- } \\
\text { response }\end{array}$ & $\mathrm{x}$ & $\mathrm{M}$ & $\mathrm{x}$ & $\mathrm{x}$ & $\mathrm{x}$ \\
\hline 29. & 75 & $\mathrm{~F}$ & White, Dutch & Higher Professional Ed. & $\begin{array}{l}\text { Retired teacher, spiritual } \\
\text { worker }\end{array}$ \\
\hline 30. & $70 \mathrm{~s}$ & $\mathrm{M}$ & White, Dutch & $\begin{array}{l}\text { University / Higher } \\
\text { Professional Ed. }\end{array}$ & Civil engineer \\
\hline
\end{tabular}


** Overview of the Dutch educational system, which also pertains to Curaçao and other parts of the Dutch Kingdom.
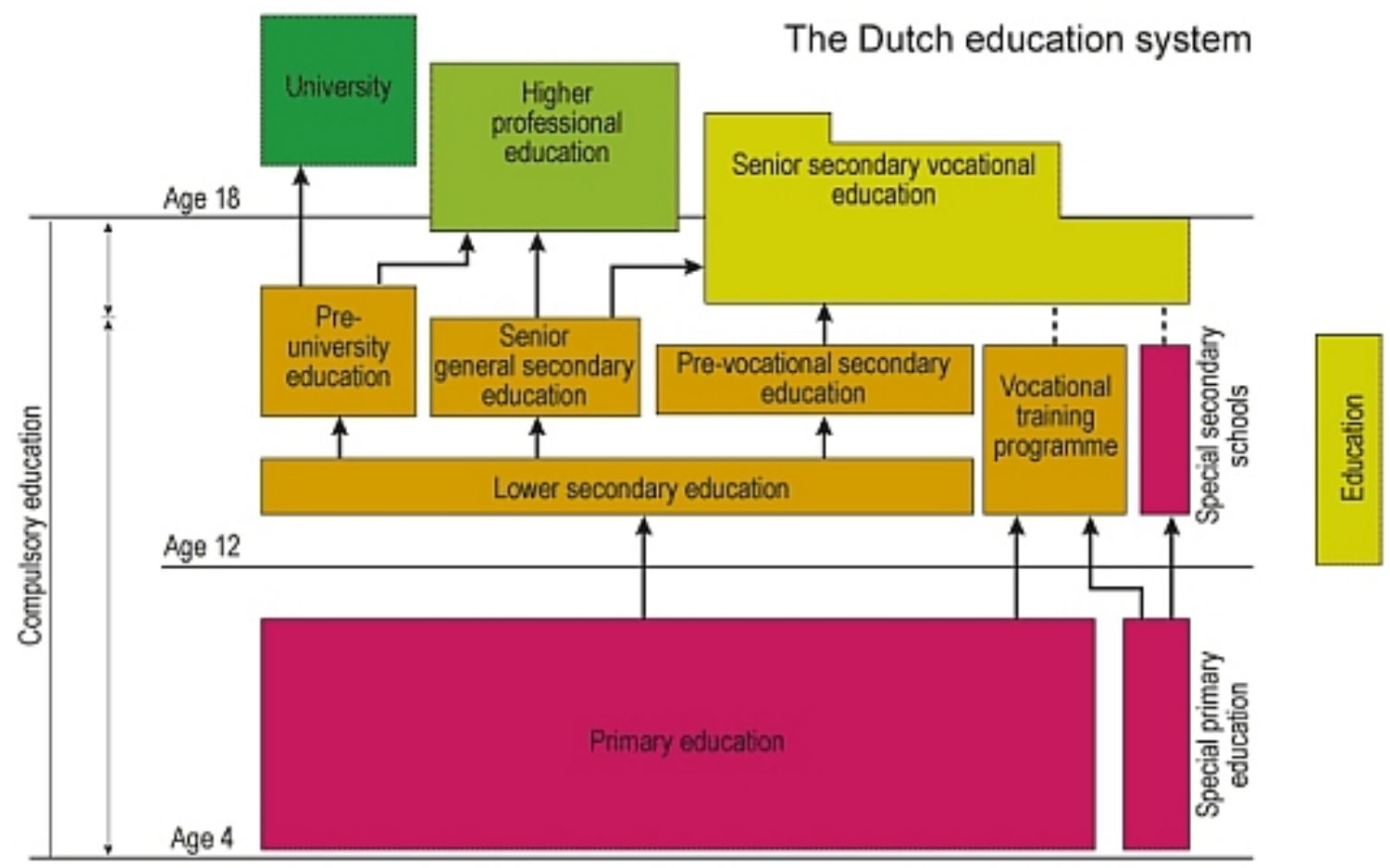

Source: Du Bois-Reymond (2009)

Du Bois-Reymond, Manuela (2009) The Integration of Formal and Non-Formal Education: The Dutch "brede school." In: Social Work and Society International Online Journal, Vol 7(2).

http://www.socwork.net/sws/article/view/72/331, site visited April $12^{\text {th }} 2016$. 


\section{Appendix VII Interview Protocol Bario Case Study}

1. Tell me something about race or color / Kontami algu over di rasa of koló.

This question would lead to a number of follow-up questions that were specific to the topics the respondent introduced. I made an effort to not lead, but at the same time to be critical of the narratives they presented. I would let people tell their stories, and afterwards dig deeper into the contradictions in their stories.

2. How do you describe your own color? Kiko ta bo koló?

3. What is your age? / Kuantu anjo bo tin?

4. What was the last school you attended / what is your level of education? Kual ta e delaster skol b'a bai / Ki ta bo nivel di edukashon?

5. Who did you come home with, partner-wise? / Ken b'a bin kas kun'e komo partner? 
Appendix VIII Victims of Crime in 1 Year (1981- 2008), in Percentages

\begin{tabular}{|l|r|r|r|r|r|}
\hline & $\mathbf{1 9 8 0 / 8 1}$ & $\mathbf{1 9 9 1 / 9 2}$ & $\mathbf{1 9 9 4 / 9 5}$ & $\mathbf{2 0 0 7 / 0 8}$ & $\mathbf{2 0 1 3} / \mathbf{1 4}$ \\
\hline car theft & 1,2 & 1,4 & 1,2 & 1,5 & 0,9 \\
theft from car & 9,1 & 8,0 & 9,0 & 7,1 & 7,9 \\
car vandalism & & & 3,9 & 3,7 & 3,8 \\
burglary (break-in) & 7,3 & 9,0 & 8,9 & 5.7 & 5.2 \\
intent of burglary (break-in) & & & 5,4 & 4,0 & 2,8 \\
theft from yard, garden, porch & & 8,8 & 10,0 & 6,7 & 5,5 \\
robbery/theft of personal properties & 4,4 & 2,6 & 4,4 & 3,4 & 2,1 \\
vandalism & 3,1 & 3,4 & 2,6 & 2,4 & 1,8 \\
assault/threat & & & 3,3 & 1,9 & 1,8 \\
hit and run & 0,8 & 1,0 & 1,9 & 1,6 & 1,9 \\
other crime & 2,1 & 0,6 & 0.4 & 0,9 & 0,6 \\
total & 18,8 & 27,5 & 39,0 & 26,3 & 21,7 \\
\hline CBS: Victim Survey & & \\
\hline
\end{tabular}




\section{Appendix IX Interview Results per Bario}

\begin{tabular}{|c|c|c|c|c|c|c|c|c|}
\hline & & $\begin{array}{l}\text { Barber } \\
(n=6)\end{array}$ & $\begin{array}{l}\text { SeruF } \\
(n=6)\end{array}$ & $\begin{array}{l}\text { OtroB } \\
(n=6)\end{array}$ & $\begin{array}{l}\text { Janwé } \\
(n=6)\end{array}$ & $\begin{array}{l}\text { SpW } \\
(n=5)\end{array}$ & Tot & $\%$ \\
\hline & Phenotype respondents & dark & dark & varies & varies & white & & \\
\hline 1 & I don't see color & 2 & 1 & 0 & 3 & 4 & 10 & 36 \\
\hline 2 & $\begin{array}{l}\text { I'm not discriminated against / } \\
\text { Discrimination is passé }\end{array}$ & 1 & 2 & 3 & 3 & 2 & 11 & 38 \\
\hline 3 & There is unity & 1 & 1 & 3 & 2 & 4 & 11 & 38 \\
\hline 4 & There is discrimination & 6 & 6 & 6 & 6 & 5 & 29 & 100 \\
\hline 5 & Black is negative & 5 & 4 & 4 & 6 & 3 & 22 & 76 \\
\hline 6 & Black is positive & 1 & 1 & 2 & 2 & 3 & 9 & 31 \\
\hline 7 & White is negative & 2 & 2 & 3 & 2 & 1 & 10 & 36 \\
\hline 8 & White is positive & 3 & 1 & 2 & 1 & 1 & 9 & 31 \\
\hline 9 & White is better than black & 5 & 5 & 3 & 4 & 4 & 21 & 72 \\
\hline 10 & White and black are equal & 5 & 4 & 4 & 4 & 5 & 22 & 76 \\
\hline 11 & Black is better than white & 0 & 0 & 0 & 0 & 0 & 0 & $\mathbf{0}$ \\
\hline 12 & Tula & 0 & 1 & 1 & 0 & 1 & 3 & 10 \\
\hline 13 & $\begin{array}{l}\text { Emancipation and Afrocuraçaoan } \\
\text { empowerment }\end{array}$ & 1 & 1 & 4 & 1 & 2 & 9 & 31 \\
\hline 14 & Slavery & 3 & 1 & 4 & 1 & 3 & 12 & 41 \\
\hline 15 & Black to black discrimination & 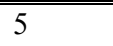 & 2 & $\overline{22}$ & 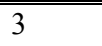 & 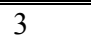 & 17 & $\overline{52}$ \\
\hline 16 & Teasing / bullying with black features & 3 & 2 & 1 & 1 & 0 & 7 & 24 \\
\hline 17 & Color hierarchy & 2 & 0 & 0 & 0 & 0 & 1 & 7 \\
\hline 18 & "Drecha rasa" or "fixing the race" & 0 & 1 & 1 & 1 & 0 & 3 & 10 \\
\hline 19 & "Work & 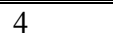 & 4 & 4 & 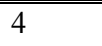 & 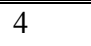 & 20 & 69 \\
\hline 20 & School & 4 & 4 & 4 & 2 & 2 & 16 & 55 \\
\hline 21 & Poverty & 1 & 3 & 1 & 1 & 3 & 9 & 31 \\
\hline 22 & Crime & 0 & 5 & 2 & 0 & 1 & 8 & 30 \\
\hline 23 & Response to racist behavior & 3 & 2 & 3 & 2 & 2 & 12 & 41 \\
\hline 24 & Respondent mentions Yu'i Kòrsou & 0 & 0 & 0 & 0 & 4 & 4 & 14 \\
\hline
\end{tabular}




\section{Appendix X Recommendations for Future Research}

Throughout this dissertation I have often remarked on topics that are not included in this thesis but that are in much need of thorough address. I here list some of the research that I consider to be the most urgent.

1. Interrelatedness of race and socioeconomic class: how does racism negatively affect individuals, and what are the specific vulnerabilities per class layer that aggravate the impact of race, such as poverty. What kinds of racial discrimination do people experience? How do such vulnerabilities impact people's access to and performance in for example health care, education, housing, finding work? And how do such vulnerabilities make people more susceptible to delinquency and/or becoming the victim of crime and police violence? Race intersects with many other variables, such as gender, age, sexual orientation, and migration status or country of origin: these may increase or diminish these vulnerabilities. This must all be mapped out.

a. The interrelatedness between race and poverty.

b. The interrelatedness between race, poverty, crime, delinquency and violence (including but not limited to domestic violence), and the juridical elements of criminal punishment.

c. The interrelatedness between race and health.

d. The racial dimensions of education, including but not limited to the selection procedures of the educational system, on the gate keeping mechanisms regarding language politics and funding of schools, and on the racialized content of class materials.

e. Race and the housing market, including but not limited to race based policies of the social housing projects and urban planning.

f. Race and gender: in what ways does race impact males and females differently, and how does this play out per socioeconomic class section.

g. Race and sexual orientation: in what ways does race impact LBGTQ people differently compared to heterosexuals, and how does this play out per socioeconomic class section.

h. Race and age: how does race impact people of different age categories (child, adolescent, adult, elderly).

i. Race and migration status or country of origin: how does race impact immigrants? What role do the various ethnic backgrounds play, as well as whether people are documented or not? 
2. Race and the economic sector.

a. The racial and class composition of the economic sector, regarding business ownership, management and employees

b. Benefits of and challenges to black entrepreneurship, compared to white and other non-white entrepreneurship

c. Racism in bank, loan and insurance policies.

d. Racism in HRM selection procedures and diversity management.

e. How does race in these abovementioned topics intersect with socioeconomic class, gender, sexual orientation, ethnic background and immigrant status?

3. Historical exploration and documentation.

a. Documentation of the past and present of the development of Antillianization and pro-black empowerment, and their key players.

b. Past and present Afrocuraçaoan dimensions of resistance to white supremacy, hidden and overt.

c. The intricacies of interracial relations, including but not limited to sexual violence.

d. Representation of race in the Curaçaoan arts in past and present. Documentation of representations of race in popular culture, traditional culture, folklore, and the arts at large, including but not limited to representations of racial oppression and exploitation, resistance, black empowerment.

4. Race and contemporary representations of national identity: prevalence of multiculturalism.

a. Race and policies of heritage preservation and monumentalization.

b. Race and urban symbolism, urban planning, and demography.

c. Representation of race in mainstream media.

d. Reproduction of narratives on race and national history in school materials of past and present, including but not limited to slavery, resistance, and empowerment.

e. Race and tourism, including an exploration of the possibilities of pro-poor tourism.

f. Contemporary Curaçaoan African Diasporic identity formation in relation to broader, transnational diasporic contexts that the island and its populations 
partake in through flows of people, commodities, capital, information, through popular culture and expressive culture. 
Appendix XI Bill for the Curaçaoan Fulfillment of the United Nations Decade for People of African Descent

Published by the Directorate of Foreign Relations of the Ministry of General Affairs, on 30 November 2015. The original title is Nota voor Curaçaose invulling van United Nations Decade for People of African Descent.

I. Recognizing that the position of people of African descent is oftentimes disadvantaged compared to that of the rest of society, and that discrimination on the basis of race/skin color is therefore a problem in Curaçao's society.

II. For the duration of the decennium the government will dedicate itself to improve the societal, social and economic position of people of African descent.

III. Making a choice of one of three proposed definitions of 'people of African descent.'

IV. Agreeing to the coordination of the International Decade for People of African Descent (UNDPAD) by the Foundation National Archaeological - Anthropological Memory Management (NAAM).

V. Launching a governmental website regarding the UNDPAD and human rights.

VI. Initiation of a Human Rights Institute by the Ombudsman.

VII. Initiating an Anti Discrimination Agency.

VIII. Adapting educational curriculums to the history as experienced by people of African descent, and dissemination of information regarding discrimination, respect, equality and (self)acceptance.

IX. Deciding upon immigration policy and the laws that illegal immigrants have, and upholding these.

X. Directorate of Foreign Relations and NGO's are to inform ministries on human rights and racial discrimination as to generate awareness within the government on this, and on the UNDPAD.

XI. NGO's that organize activities within the context of the UNDPAD can apply for additional reimbursement/subsidy.

XII. The multidisciplinary group (MDG) that has dedicated itself to the fulfillment of the UNDPAD will launch the UNDPAD on the international day of human rights, 10 December 2015, for involved organizations and citizens. An extensive launch for the national population will take place at a later time.

XIII. Appointment of one or more ambassadors that will raise attention for racial discrimination and breaking the taboo within the context of the UNDPAD.

(Directorate of Foreign Relations 2015:2,3) 
Appendix XII Lyrics

Nelson Mandela - Dongo (2014)

Niun koño,

Djis un badge ku un tiki power!

Bo ke bati nos den grupo,

Pa sirbi i proteha,

Pero hopi ta korupto.

Hopi partí wanta,

Grita mí den mi kara,

Wak mi kar'i sanka,

Min por hasi nada!

Mal uso di poder,

Paso pòrnada bo ke dal mí,

Bo kièr sa ku mi tin miedu,

Ta más rabia bo ta n'ami!

Paso mi ta pretu?

Bo ta kla pa kue mi sera?

Voorbeeld grandi mi por nabu, Nelson Mandela!

Ba drenta den mi kas,

Ba haña kos eiden?

Bo konfiská un kilo,

B'a entrega 800.

Kiko pasa ku e sobra anto?

Dikon bo no deklará un kilo?

Bo mama no a siñabu?

P'a kue kos ku no ta di bo?

Free mi nigga Gino,

Free mi nigga Sandy,

M'a bisa nan "trankilo",

Nan lo tei un 'beki!

Korda hasi bo trabou bon,

Rònt mundu mi ta papia.

Min ta papia di Kòrsou so,

Paso rònt mundu e ko'i ta pasa.

Bo ta klap mi den mi lomba,

Si mi sali kore,

Si mi ta keda para tambe,

Tantu sla m'a kome.

Bo ke baha grita,

Ni kuminda mi promé,

Bisa mi keda rustig,

Bo por lag'e hode!

Kla pa boei mí, kla pa stot mí,

Kibra repchi, mandá mi poli,
[You're] fucking nothing,

Just a badge with a bit of power!

You want to beat us in groups,

To serve and protect,

But many are corrupt.

Many beat you,

Yell in my face,

Look down on me,

I can't do anything!

Abuse of power,

Because you want to beat me for no reason,

You think I am scared,

But you only piss me off more!

Because I am black?

You want to throw me in jail?

I can give you a grand example,

Nelson Mandela!

You entered my house,

You found something there?

You confiscated a kilo,

But handed in 800 .

What happened with the rest, eh?

Why did you not hand in a kilo?

Did your mama not teach you?

You can't take things that are not yours?

Free my nigga Gino,

Free my nigga Sandy,

I told them to "take it easy,"

They will be out in a bit!

Remember, do your job well,

I am talking about around the world.

I'm not talking just about Curaçao,

Cuz this happens around the world...

You shoot me in my back,

If I run away,

If I stay put,

I also get beaten up.

You start yelling as you get out of the car,

Without greeting me first,

Tell me to keep my cool,

Fuck you!

Ready to cuff me, ready to beat me,

Break my ribs, send me to the ER, 
6 luna riba krùk.

M'a pèrdè kaso, si mi bai dilanti,

Si mi hasi algu tambe, bo ke arestá mí?

$\mathrm{Pa}$ tantu tempu,

Nan ke karsela mí,

Bo ke menasá mí,

Pa bo n'ami miedu,

Bo ta dal mi wanta sin m'a hasi fresku,

Si mi no hasi nada, sua laga mi ketu!

Hasi bo trabou p'abo por bai laga mí,

Bisa mi kon Kòrsou por bai dilanti,

Bin ku prueba mustra tantu mati,

$\mathrm{Ku}$ a pèrdè bida na Hulanda akí!

Niun koño,

Djis un badge ku un tiki power!

Bo ke bati'e nos den grupo,

Pa sirbi i proteha,

Pero hopi ta korupto.

Hopi partí wanta,

Grita mí den mi kara,

Wak mi kar'i sanka,

Min por hasi nada!

Mal uso di poder,

Paso pòrnada bo ke dal mí,

Bo kièr sa ku mi tin miedu,

Ta más rabia bo ta n'ami!

Paso mi ta pretu?

Bo ta kla pa kue mi sera?

Voorbeeld grandi mi por nabu

Nelson Mandela!
6 months on crutches.

I already lost if I take it to court, If I move on you, you gonna arrest me? This has been going on for so long, They want to incarcerate me

You want to threaten me,

So you can scare me,

You beat me without a reason,

When I don't do anything, man, fuck off!

Do what you gotta do and leave me alone, Tell me how can Curaçao get ahead, I got proof that so many of my friends, Have died here in the Netherlands!

[You're] fucking nothing, Just a badge with a bit of power!

You want to beat us in groups,

To serve and protect,

But many are corrupt.

Many beat you,

Yell in my face,

Look down on me,

I can't do anything!

Abuse of power,

Because you want to beat me for no reason, You think I am scared,

But you only piss me off more!

Because I am black?

You want to throw me in jail?

I can give you a grand example,

Nelson Mandela!

https://soundcloud.com/shaiconq/dongo-nelson-mandela 


\section{Koi Makambanan / This is for the Dutch - Mosta Man (2009}

Bob Marley di "emancipate yourself

From mental slavery,"

Michael Jackson a hasi su mes blanku,

Ba wak si.

Nos no por sigui asinaki.

Ai esaki ta pa e Makambanan,

No mi lubida riba mi pasado naw, naw, naw

1795 Tula e katibu a disidi di libera su tribu, E tabata tin rabia riba e Makamba,

Pero ku su motibu.

La reina mes,

Ta riba nos rasanan ta riku,

Su rasa a dal Mandela,

Binti piku anja kastigu,

Mi no sa presis, pero mas ku 25.

El a sali bira presidente,

Tur hende blanku ke ta amigo.

Ai esaki ta koi Makambanan,

No mi lubida riba mi pasado naw naw naw,

Ai esaki ta koi Makambanan,

No mi lubida riba Afrika naw naw naw,

Hiba mi for di Afrika,

i hiba mi Amerika

Batimi hasimi slaaf,

Kier sa mi tin ku keda braaf

Ai ai, bo kemen esei tin mag

Try to push mi down mi rasa elke dag

Kon mi por hasi feest Koninginnedag

Beatrice duna bling bling na su paleis

Na Den Haag,

Ik op de straat met mn lege maag,

E progreso, e koi a bin muchu traag.

Ai esaki ta e Makambanan,

Ai no mi lubida riba mi pasado,

Ai esaki e Makambanan,

Ai no mi lubida riba Afrika naw naw naw,

Ai Afrika, su naturalesa,

Su bellesa, su rikesa,

Bosnan ta ladron, bosnan ta maton,

Bosnan a separami foi mi nashon,
Bob Marley said "emancipate yourself

From mental slavery,"

Michael Jackson made himself white,

You saw it.

We can't go on like this.

This is for the Dutch,

Don't let me forget my past, no, no, no,

1795 Tula the slave decided to free his tribe, He was mad at the Dutch,

But for a reason.

The queen herself,

Became rich from exploiting our race,

Her race punished Mandela,

For more than 20 years,

I don't know precisely but more than 25 .

He came out of jail became president,

All white people wanted to be his friend.

This is for the Dutch,

Don't let me forget my past, no, no, no,

This is for the Dutch,

Don't let me forget Africa, no no no,

Took me from Africa, brought me to America, Beat me, enslaved me They thought I had to be obedient. Ai ai, you mean that was allowed, Try to push me down, my race, every day, How can I celebrate Queensday

Beatrix puts on the bling bling in her palace in the Hague,

Me in the street with my stomach empty,

Progess, that came too slow.

This is for the Dutch,

Don't let me forget my past, no, no, no,

This is for the Dutch,

Don't let me forget Africa, no no no,

Africa's nature,

Her beauty, her abundance,

You are thieves, you are killers,

You separated me from my nation, 
Bo kemen,

Mi no tin mag di bula den KLM,

Pesei Afrika mi a bin represent.

E stem, Goddamn,

Bosnan kier sa ku nos ta kens?

Ai esaki ta e Makambanan

Ai no mi lubida, riba Afrika naw naw naw

Ai esaki ta e Makambanan

No mi lubida, riba mi pasado naw naw naw

Tula e katibu libera su tribu,

Rasista ku su motibu,

Nigger for real, man,

E Makambanan kier sa ku nos ta bobo,

Nan kier sa ku nos ta mahoso,

Paso nos tin kabei duru,

Nanishi grandi, lip diki,

Pero nos ta hendenan bunita,

Hendenan fuerte,

Afrikano nos ta, ketubai!

Wanta nos abou,

Awor nan ta kita nos paspoort,

Nos no tin mag di bai Ulanda.

Danki Dios nan a mata Pim Fortuyn,

For real nigger!

Mi'n tin miedu di niun hende, no,

E berdat, mi ta bisanan den nan kara brother,

For real...

Ai esaki ta pa e Makambanan,

Pa mi lubida, riba mi pasado naw naw naw,

Ai esaki ta pa e Makambanan,

Pa mi lubida, riba Afrika naw naw naw,

Gobierdo di Korsou ta chupa chupa Makamba, Nan ta skop bosnan despues den bosnan atras...
You mean,

I am not allowed to fly with KLM,

That's why I came to represent Africa.

The voice, Goddamn,

You think we are stupid?

This is for the Dutch,

Don't let me forget Africa, no no no, This is for the Dutch,

Don’t let me forget my past, no, no, no,

Tula liberated his tribe,

He was racist for a reason,

Nigger for real, man.

The Dutch think we're stupid,

They think we are ugly,

Because we have frizzy hair,

Big noses, thick lips,

But we are beautiful people,

Strong people,

Africans we are, still!

Beat us down,

Now they take our passports,

We are not allowed to go to the Netherlands.

Thank God they killed Pim Fortuyn

For real nigger!

I ain't afraid of anyone, no,

The truth, I tell it to their face brother,

For real...

This is for the Dutch,

Don't let me forget my past, no, no, no,

This is for the Dutch,

Don't let me forget Africa, no no no,

The Curaçaoan government sucks up to the Dutch,

And then they kick you in the ass....

https://www.youtube.com/watch?v=XYlwkJJXUD8 
VITA

\author{
ANGELA E. ROE \\ Born, Amsterdam, Netherlands \\ B.A., Cultural Anthropology \\ University of Amsterdam \\ Amsterdam, the Netherlands \\ M.A., Cultural Anthropology \\ Free University of Amsterdam \\ Amsterdam, the Netherlands
}

1994-1996

1997-2003

2007-2009

M.A., Global \& Sociocultural Studies

Florida International University

Miami, Florida

Teaching Assistant

Florida International University

Miami, Florida

2009-2016

Doctoral Candidate

Florida International University

Miami, Florida

\title{
PUBLICATIONS AND PRESENTATIONS
}

Roe, A. E. (May, 2016). “Curaçao Seen Through the Lens of Race.” Lecture presented at the General Faculty of the University of Curaçao lecture cycle in preparation of the Bachelor degree in Culture Studies.

Roe, A. E. (September, 2015). Sombra di Koló / The Shadow of Color: Race Relations in Curaçao Today. Screening presented at the Royal University of Leiden, Netherlands, at the Royal Netherlands Institute of Southeast Asian and Caribbean Studies.

Roe, A. E. (May, 2015) Sombra di Koló / The Shadow of Color: Race Relations in Curaçao Today. Screening presented at the Annual Conference of the Caribbean Studies Association, New Orleans, USA.

Roe, A. E. (March, 2015). Sombra di Koló / The Shadow of Color: Race Relations in Curaçao Today. Screening presented at Bridgewater State University.

Roe, A. E. (March, 2015.) "Colorism and Pigmentocracy in the Dutch Caribbean." Lecture presented at the English Department ENGL 318 at Bridgewater State University. 
Roe, A. E. (January, 2015). "Curaçao's Slave Codes and their Contemporary Legacy." Lecture presented at the Annual Program in Comparative and International Law in Curaçao, co-sponsored by the University of Baltimore School of Law and the Maurice A. Deane School of Law at Hofstra University, offered in cooperation with the Erasmus University Rotterdam Faculty of Law, and hosted by the University of Curaçao.

Roe, A. E. (October, 2014). "Contemporary Race Relations in Curaçao and their Roots in Colonial Slave Codes." Lecture presented at the School of Law at the University of Curaçao.

Roe, A. E. Sombra di Koló / The Shadow of Color: Race Relations in Curaçao Today. Documentary Film. 2014. 71 min. Willemstad, Curaçao: Warwarú Productions.

Roe, A. E. (June, 2013). "Racism and Racial Representation in Curaçao Today." Lecture presented at the interdisciplinary lecture series "150 Years of Abolition of Slavery" of the University of Curaçao.

Roe, A. E. (November, 2014) Sombra di Koló / The Shadow of Color: Race Relations in Curaçao Today. Screening presented at the Caribbean Regional Conference of Psychology, hosted by the Caribbean Alliance of National Psychological Associations (CANPA), Paramaribo, Surinam.

Roe, A. E. (November, 2010). "In the Belly of the Tambú: Curaçao's African Heritage and the Re-Imagination of a Nation." Paper presented at the Annual Conference of the American Anthropological Association, New Orleans.

Roe, A. E. (May, 2010) "No Tur Sinku Dede Ta Pareu" ("Not All Five Fingers Are The Same"): Inclusion, Exclusion and the Imagining of Nationhood in Curaçao." Paper presented at the Annual Conference of the Caribbean Studies Association, Barbados.

Roe, A. E. (December, 2009). "Disjunction Between National Identity Formation and the Lived Experience of Racism in the Postcolonial Dutch Caribbean." Paper presented at the Annual Conference of the American Anthropological Association, Philadelphia.

Roe, A. E. (June, 2009). "Curaçao's Myth of Racial Democracy.” Paper presented at the Annual Conference of the Caribbean Studies Association, Kingston, Jamaica.

Roe, A. E. (May, 2008).“The Sound of Silence: A Personal Narrative about Three Generations of Dutch-Caribbean Women." Paper presented at the Annual Conference of the Caribbean Studies Association, San Andres Island, Colombia.

Roe, A. E. "Review of "The Politics of Passion: Women's Sexual Culture in the AfroSurinamese Diaspora." The Journal of Latin American and Caribbean Anthropology, 12(1), February 2007: 285-287. 